\title{
Acquired Torsade de Pointes arrhythmias : role of early afterdepolarizations and dispersion of repolarization
}

Citation for published version (APA):

Verduyn, S. C. (1996). Acquired Torsade de Pointes arrhythmias : role of early afterdepolarizations and dispersion of repolarization. [Doctoral Thesis, Maastricht University]. Datawyse / Universitaire Pers Maastricht. https://doi.org/10.26481/dis.19960614sv

Document status and date:

Published: 01/01/1996

DOI:

10.26481/dis.19960614sv

Document Version:

Publisher's PDF, also known as Version of record

\section{Please check the document version of this publication:}

- A submitted manuscript is the version of the article upon submission and before peer-review. There can be important differences between the submitted version and the official published version of record.

People interested in the research are advised to contact the author for the final version of the publication, or visit the DOI to the publisher's website.

- The final author version and the galley proof are versions of the publication after peer review.

- The final published version features the final layout of the paper including the volume, issue and page numbers.

Link to publication

\footnotetext{
General rights rights.

- You may freely distribute the URL identifying the publication in the public portal. please follow below link for the End User Agreement:

www.umlib.nl/taverne-license

Take down policy

If you believe that this document breaches copyright please contact us at:

repository@maastrichtuniversity.nl

providing details and we will investigate your claim.
}

Copyright and moral rights for the publications made accessible in the public portal are retained by the authors and/or other copyright owners and it is a condition of accessing publications that users recognise and abide by the legal requirements associated with these

- Users may download and print one copy of any publication from the public portal for the purpose of private study or research.

- You may not further distribute the material or use it for any profit-making activity or commercial gain

If the publication is distributed under the terms of Article $25 \mathrm{fa}$ of the Dutch Copyright Act, indicated by the "Taverne" license above, 


\section{Acquired Torsade de Pointes arrhythmias role of early afterdepolarizations and dispersion of repolarization}


ISBN nummer 90-9009490-3

(1) S.C. Verduyn, Maastricht 1996

Omslag: Torsade de Pointes: a Cardiac Ballet, Ilse Verduyn - v.d. Dool

Lay-out en druk: Datawyse | Universitaire Pers Maastricht 


\section{Acquired Torsade de Pointes arrhythmias role of early afterdepolarizations and dispersion of repolarization}

\section{PROEFSCHRIIFT}

ter verkrijging van de graad van docror aan de Rijksuniversiteit Limburg te Maastricht, op gezag van de Rector Magnificus, Prof. mr. M.J. Cohen, volgens het besluit van her College van Dekanen, in het openbaar te verdedigen op vrijdag 14 juni 1996 om 14.00 uur

door

\section{S.C. Verduyn}

geboren te Zevenhuizen

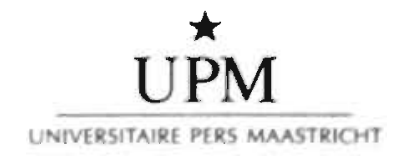




\section{Promotor:}

Prof dr H.J.J. Wellens

Copromotor:

Dr M.A. Vos

\section{Beoordelings commissie:}

Prof dr M.A. Allessie (voorzitter)

Dr C. Antzelevitch (Masonic Medical Research Laboratory, Utica, USA)

Dr H.J.G.M. Crijns (Rijksuniversiteit Groningen)

Prof dr R.S. Reneman

Prof dr J.F.M. Smits

Financial support by the Netherlands Heart Foundation and Stichting Rescar for the publication of this thesis are gratefully acknowledged. 


\section{Contents}

List of abbreviations $\quad 7$

Preface 8

Chapter 1

Review of the literature $\quad 11$

\section{Chapter 2}

Reproducible induction of early afterdepolarizations and Torsade de Pointes arrhythmias by $d$-sotalol and pacing in the dog with chronic atrioventricular block 27

\section{Chapter 3}

Role of interventricular dispersion of repolarization for the induction of acquired early afterdepolarization dependent Torsade de Pointes arrhythmias: reversal by magnesium $\quad 47$

\section{Chapter 4}

Further observations to confirm the importance of dispersion of repolarization and early afterdepolarizations in the genesis of acquired Torsade de Pointes arrhythmias: A comparison between almokalant and $d$-sotalol using the dog as its own control 67

\section{Chapter 5}

An essential contribution of early afterdepolarizations to dispersion of repolarization in the mechanism of acquired. Torsade de Pointes Arrhythmias 85 


\section{Chapter 6}

The effect of flunarizine and ryanodine on acquired Torsade de Pointes arrhythmias in the intact canine heart 103

\section{Chapter 7}

Electrophysiologic adaptations induced by chronic complete atrioventricular block predispose the canine heart for the induction of acquired Torsade de Pointes arrhythmias 123

\section{Chapter 8}

General Discussion 143

Summary 157

Samenvatting $\quad 161$

Nawoord 165

Publications $\quad 167$

Curriculum Vitae $\quad 171$ 


\section{List of Abbreviations}

$\begin{array}{ll}\triangle A P D & \text { : Dispersion of action potential duration } \\ \text { APD } & \text { : Action potential duration } \\ \text { AV } & \text { : Atrioventricular } \\ \text { AT } & \text { : Activation time } \\ \text { CL-IVR } & \text { : Cycle length of the idioventricular rhythm } \\ \text { EAD }(s) & \text { : Early afterdepolarization(s) } \\ \text { EB(s) } & \text { : Ectopic beat(s) } \\ \text { LV } & \text { : Left ventricle } \\ \text { MAP } & \text { : Monophasic action potential } \\ \text { PES } & \text { : Programmed electrical stimulation } \\ \text { PF } & \text { : Purkinje fibers } \\ \text { RV } & \text { : Right ventricle } \\ \text { SEM } & \text { : Standard error of mean } \\ \text { SR } & \text { : Sinus rhythm } \\ \text { SD } & \text { : Standard deviation } \\ \text { SLS } & \text { : Short long short sequence } \\ \text { TdP } & \text { : Torsade de Pointes arrhythmia(s) } \\ \text { VT } & \text { : Ventricular tachycardia }\end{array}$




\section{Preface}

Every human being experiences cardiac arrhythmias during his or her life. The severity may vary from innocent occasional ectopic beats to life threatening arrhythmias. Treatment of cardiac arrhythmias should preferably be based on knowledge about the different responsible mechanisms. Several mechanisms are known, of which reentry is studied best, but there is also abnormal automaticity and triggered activity. The relevance of these different mechanisms for every clinically occurring arrhythmia is not clear. The studies described in this thesis are focussing on the phenomenon of the appearance of a new and different arrhythmia occurring after treatment with drugs aimed to prevent and/or suppress heart rhythm disturbances. This is called a proarrhythmic effect of antiarrhythmic drugs.

The name of the particular arrhythmia, which is the focus of this dissertation, is Torsade de Pointes (TdP). In the past several other names have been used to describe this arrhythmia because of its typical configuration. It is known for a long time that $\mathrm{TdP}$ arrhythmias occur in the presence of prolonged ventricular repolarization which can be recognized on the electrocardiogram as a prolonged QT interval. They are more common during bradycardia and are characterized by a specific twisting of the QRS complexes like a corkscrew around the baseline of ECG. The arrhythmia often terminates spontaneously but may deteriorate in to ventricular fibrillation and thereby lead to the death of the patient.

Although investigations have been performed to study the circumstances leading to this arrhythmia and how ro prevent it, no clinical relevant animal model existed in the early nineties in which the mechanism of TdP could be reproducibly studied.

The aim of the research reported in this thesis was to evaluate the value of an animal model of acquired TdP arrhyrhmias in which the mechanism of initiation, continuation and termination of the arrhythmia could be studied. Moreover such a model could allow the comparison of potential of different (new) antiarrhythmic drugs to induce TdP under well controlled and reproducible circumstances.

This thesis consists of 8 chapters. In chapter 1 a review is given of the literature on different models and the mechanism(s) of acquired Torsade de Pointes arrhythmias that appeared until 1992. (the start of this PhD thesis). The dog model developed in Maastricht to study acquired TdP is described in chapter 2. The role of early afterdepolarizations (EADs) and interventricular dispersion of repolarization ( $\triangle A P D)$ in the generation of $\mathrm{TdP}$ is discussed in chapters 3 and 4 . Using a group comparison (inducible versus non inducible dogs) the role of these parameters was determined. In chapter 3 the suppressive effect of magnesium is also reported. In chapter 4 , two drugs ( $d$-sotalol and almokalant) were administered in two separate experiments in the same dog to 
evaluate the relevance of EADs and interventricular $\triangle A P D$ for the induction of TdP. The contribution of EADs to interventricular $\triangle A P D$ is the subject of chapter 5 . This was done by studying the dynamic changes in berween reproducible induced $\mathrm{TdP}$ episodes. Chapter 6 relates to the treatment of TdP by two drugs that are known to influence intracellular calcium, flunarizine and ryanodine. The influence of the electrophysiologic changes induced by chronic complete AV block on Torsade de Pointes incidence is discussed in chapter 7 , by studying the dog at two different time points ( 0 and 5 weeks) after AV block. Chapter 8 contains a general discussion using the data presented in this thesis and the most recent literature. This is followed by a summary in English and Dutch. 



\section{Chapter 1}

\section{Review of the literature}

\subsection{Introduction}

Torsade de Pointes arrhythmias (TdP) are defined as polymorphic rachycardias showing a specific rotating pattern of the QRS complexes around the baseline in the presence of a prolonged repolarization (figure 1). TdP was first used by Dessertenne to describe a polymorphic tachycardia in a patient with acute third degree AV block (1). Since that time the name TdP has been used, although initially other names were also given like cardiac ballet, aspecific polymorphous tachycardia, atypical tachycardia, and transienı or self terminating ventricular fibrillation $(2,3)$.

$\mathrm{TdP}$ can be found in two different patient populations: 1) patients with a congenital and therefore genetically determined cause of prolonged repolarization and 2) patients with an acquired form of prolonged repolarization (4).

The congenital long QT syndrome can be either familial or idioparhic (4). The familial type consist of two subgroups: 1) the Jervell-Lange Nielsen syndrome which is associated with deafness and 2) the Romano Ward syndrome with normal hearing (5). These syndromes are found in a small part of the population. Recently there has been a marked progress concerning their generic basis (6-8).

Acquired or drug induced $\mathrm{TdP}$ is a less rare phenomenon. Its occurrence is higher when synergistic circumstances as bradycardia, hypokalemia and/or hypomagnesemia are present (9). This in contrast to congenital TdP, in which bradycardia does not have to be an essential component (4).

This review will deal with the acquired or drug induced form of TdP. First the clinical circumstances and drugs leading to TdP will be discussed (\$1.2). This is followed by a description of several in vitro, in vivo and computer models of $\operatorname{TdP}(\$ 1.3)$, which were published before 1992 and formed the background for the development of our dog model of acquired TdP. Thereafter, the importance of ventricular heterogeneity of repolarization for the generation of $\mathrm{TdP}$ will be discussed $(\$ 1.4)$. Finally the different possible treatments will be summarized ( $\$ 1.5)$. 
The use of antiarrhythmic drugs can be associated with different proarrhythmic side effects (13). As pointed out by Wellens et al. (13) five different proarrhythmic responses may occur after administration of a drug 1) Worsening of an arrhythmia which is already present; 2) The induction of sinoatrial or atrioventricular block or the suppression of escape mechanisms; 3) Uncovering of a hidden arrhythmia mechanism; 4) Induction of a new arrhythmia mechanism; 5) Combination of 1 to 4 . The TdP arrhythmias fall in the fourth caregory.

Depending upon the antiarrhythmic drug used, TdP arrhythmias may occur in about 1 to $10 \%$ of patients (11). In those patients, episodes of TdP are often reperitive till preventive and/or suppressive measures are taken (4). These episodes often end spontancously but can also deteriorate into ventricular fibrillation. (4). In sudden arrhythmic death documented by a Holter recording, a TdP arrhythmia was found in 12\% of cases as the initiation of the arrhythmia which led to the dearh of the patient (12).

Apart from the specific undulating pattern of the QRS complexes, TdP often shows a typical initiation sequence, the so-called short long short sequence (see figure 1) that is present in more than $95 \%$ of patients (13-15). It has been suggested to put more emphasis on this mode of initiation, when defining TdP arrhythmias (16).

Another feature which may be observed in the TdP parient is the change in the TU wave morphology. Not only a prolongation of the QT time is seen, but this is often associated with the appearance of a prominent $U$ wave (4, figure 1). On the electrocardiogram, the $U$ wave is the wave that directly follows the $T$ wave, and has under normal circumstances the same direction as the $T$ wave. Abnormalities in repolarization may lead to $U$ waves which are directed opposite to the $T$ wave or a fusion between the $T$ and $U$ wave. The exact origin of the $\mathrm{U}$ wave is still not known.

Understanding the mechanism(s) involved in TdP can help to determine the risk of an individual patient and to develop drugs which are devoid of this proarrhythmic effect. The most frequent cause of $\mathrm{TdP}$ arrhythmias is the administration of class Ia and class III antiarrhythmic drugs, but also other drugs which prolong repolarization may lead to TdP (see table 1). The antiarrhythmic effect of class la and III drugs (table 2) is at least partly based on the prolongation of repolarization. Because no alternative antiarrhythmic drugs are presently available to replace these drugs, prevention of TdP induction by removing these drugs from the market is not a realistic possibility.

In contrast to earlier suggestions (17) more specific $\mathrm{K}^{+}$channel antagonists do not seem to have a lower incidence of $\mathrm{TdP}$ (11, table 2). Channel specificity can be defined as one channel e.g. $\mathrm{Na}^{+}, \mathrm{Ca}^{2+}$ or $\mathrm{K}^{+}$but there is also a subdivision of $\mathrm{K}^{+}$channels. However, a drug like amiodarone which blocks many channels, like $\mathrm{K}^{+}, \mathrm{Ca}^{2+}$ and $\mathrm{Na}^{+}$channels, has a very low incidence of $\mathrm{TdP}$. Despite a similar lengthening in $\mathrm{QT}$, there are even reports in which amiodarone was safely and effectively administered to patients who developed TdP after other antiarrhythmic drugs $(18,19)$. 

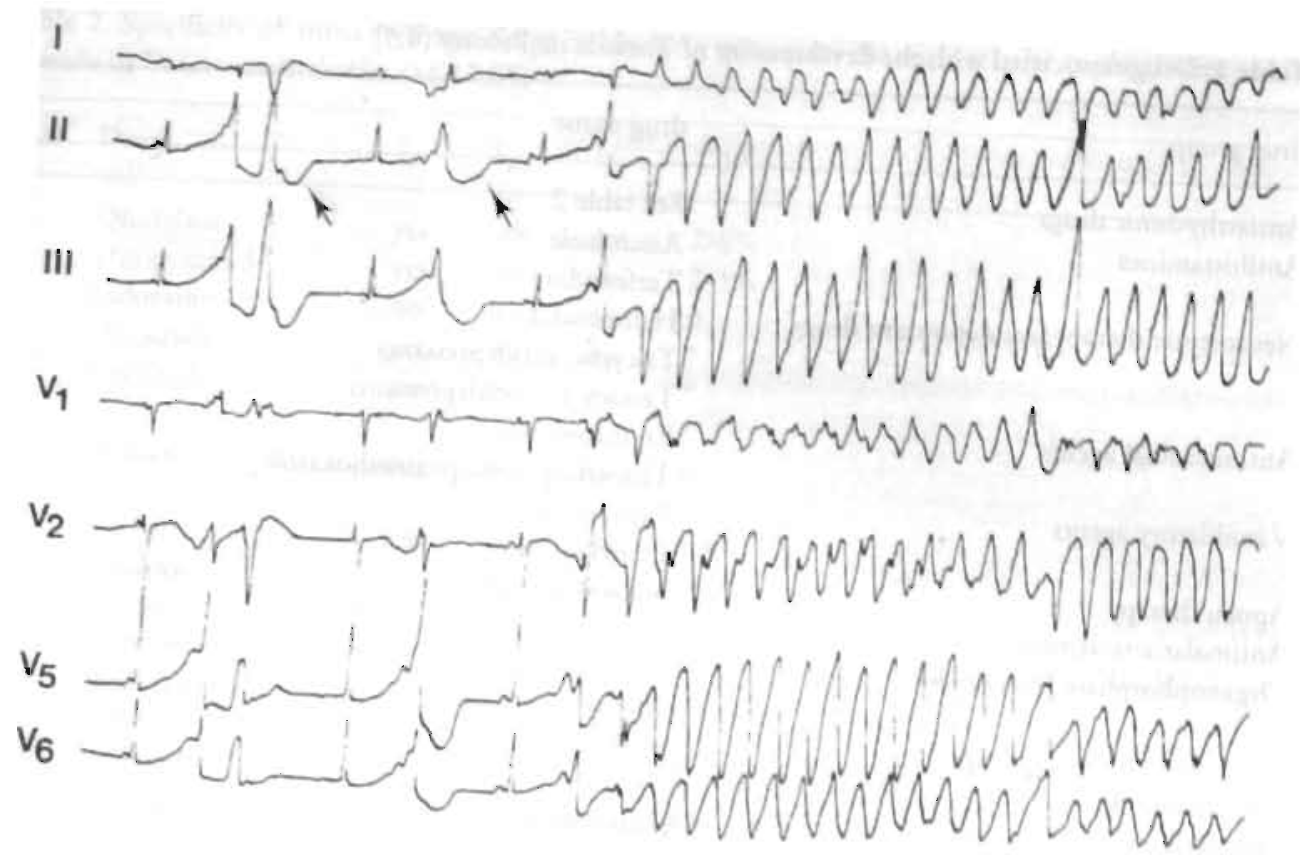

is 1

Figure 1. Episode of acquired TdP.

The ECG shows in seven simultancously recorded leads a typical example of a Torsade Pointes arrhythmia
after quinidine. Note the QT protong after quinidine. Note the QT prolongation, the pronounced U waves (arrows) and the short long shor
sequence which precedes the TdP.

So although TdP is per definition linked to a prolonged QT duration, (QT values above $600 \mathrm{~ms}(20)$ or a QT time above $440 \mathrm{~ms}$ (15). have been described as a definite risk for development of TdP), no definite QT time can be established that has sufficient specificity and sensitivity to predict TdP.

The development and the use of monophasic action potentials (MAP) catheters, which are able to reliably record the configuration and duration of the action potential (APD) of the heart in specific regions (21-23), offered new opportunities to investigate the electrophysiological mechanism(s) involved in TdP" generation. In patients with congenital long QT, the MAP recordings $(24,25)$ showed a "distinct hump" in the repolarization phase. Careful examination of the MAP recordings also showed regional differences in right ventricular APD (24,25), leading to intraventricular dispersion. Similar findings were observed in case reports of patients with acquired $\operatorname{TdP}(26,27,28)$, These distinct humps were described as early afterdepolarizations (EADs), and have been 
Table 1. Drugs associated with the development of Torsade de Pointes $(4,5)$

\begin{tabular}{ll}
\hline drug group & drug name \\
\hline Antiarrhythmic drugs & See table 2 \\
Antihistamines & Astemizole \\
& Terfenadine \\
Neuroleptic therapy/antidepressant drugs & Haloperidol \\
& Tricyclic antidepressants \\
& Tetracyclic antidepressants \\
Antimicrobial agents & Erythromycin \\
& Trimethoprimsulphamethoxazole \\
Vasodilatory agents & Papaverine \\
& Prenylamine \\
Apneu therapy & Suxamethonium \\
Antimalaria treatment & Halofantine \\
Organophosphate Insecticides & Dimethoate \\
& Methylparathion \\
Cholesterol lowering drugs & Probucol \\
Prostaglandine & Furosemide \\
Diuretics & Kectoconazole \\
Antifungal agents & Itraconazole \\
Serotonine antagonist & Tropisetron \\
& Ketanserin \\
\hline
\end{tabular}

defined as a depolarizing potential that begins prior to the completion of repolarization and causes interruption or retardation of repolarization (29). Some studies showed a link between the U wave on the ECG and the EADs on the MAP (26). In one patient. with procainamide induced $\mathrm{TdP}$ there was a clear difference between the right and left ventricular APD, so called interventricular dispersion (27). In most cases EADs were only seen on the longest APD (responsible for the ventricular dispersion) (27).

\subsection{Models of TdP}

The mechanism of TdP has been studied in several models. Those studies can be divided in three subgroups: 1) QRS morphology studies using computer models and in vivo data aimed at mimicking the specific TdP configuration, 2) EAD based models by applying toxins and high dosages of drugs in vivo and in vitro, and 3) animal models which try to reproduce the clinical circumstances such as bradycardia and the administration of TdP producing drugs in therapeutic dosages (pharmacological models). 
Table 2. Specificity of antiarrhythmic drugs in blocking potassium channels, relative to development of Torsade de Pointes arrhythmias $(11,17,85)$

\begin{tabular}{|c|c|c|c|c|c|}
\hline Class & Drug & $\mathrm{I}_{\mathrm{K}}$ & $\mathrm{I}_{\mathrm{K} 1}$ & $I_{\text {to }}$ & $\mathrm{TdP}$ \\
\hline \multirow[t]{2}{*}{ la } & Quinidine & yes. & yes & yes & $2-8 \%$ \\
\hline & Disopyramide & yes & yes & yes & $2-3 \%$ \\
\hline lb & Lidocaine & no & no & no & 0 \\
\hline \multirow[t]{2}{*}{ Ic } & Flecainide & yes & no & no & $\cdot$ \\
\hline & Encainide & yes & no & no & • \\
\hline II & $\beta$ blocker & no & no & no & 0 \\
\hline \multirow[t]{8}{*}{ III } & Sotalol & yes & yes & yes & $1.5 \%$ \\
\hline & $d$-sotalol & yes & yes & yes & $1-2 \%$ \\
\hline & Amiodarone & yes & yes & no & $<1 \%$ \\
\hline & Clofilium & yes & yes & no & $10 \%$ \\
\hline & Almokalant & yes & no & no & $6 \%$ \\
\hline & E 4031 & yes & no & no & $\cdot$ \\
\hline & Doferilide & yes & no & no & $\cdot$ \\
\hline & Ibutilide & $?$ & $?$ & $?$ & $8 \%$ \\
\hline IV & Bepridil & & & & - \\
\hline
\end{tabular}

$\because$ exact incidence not yet known.

\subsubsection{QRS Morphology studies}

In the early description of Dessertenne it was suggested that two competing foci were responsible for the twisting morphology of TdP (1). This hypothesis has been tested in a porcine Langendorff heart (30) and in a dog heart (31) in situ. In both cases pacing from a left and right ventricular site at similar cycle length but slighrly out of phase resulted in a TdP like configuration $(30,31)$. In a dog with "normal" quinidine concentrations and prolonged APD, application of acotinine on two sites of the heart, leading to two triggering foci, also led to TdP (32). Other studies have stressed the importance of alterations in ventricular activation site rather than two competing foci (33). Thirdly, the TdP morphology can be explained by a reentrant mechanism caused by dispersion caused by differences in duration of repolarization at different sites (34-35). As far as the QRS morphology is concerned, all these theories (the two competing foci, changing activation patterns of one focus or a reentrant circuit) can be possible. 


\subsubsection{EAD based models}

The registration of EADs in patients with TdP by MAP catheters $(24,25)$ led to investigations as to the presence and causal mechanisms of these humps. In vitro models using canine Purkinje fibers superfused with cesium (36,37), barium (38), quinidine $(13,37-40)$ or procainamide (41) were the first tested models. These studies also allowed evaluation of the frequency dependence of EADs, that demonstrating a clear bradycardia dependence. Many studies are only capable of showing EADs at a cycle length exceeding $2000 \mathrm{~ms}(36,42)$. The APD of Purkinje fibers is longer than that of myocardial cells (figure 2). Therefore Purkinje fibers seem to be more sensitive for the generation of EADs and have been most extensively used in vitro.

In vitro studies provide the ideal circumstances to test the ionic background of the EAD. It was demonstrated (table 3 ) that EADs can be generated under several circumstances, ranging from drugs that block potassium channels, drugs that delay $\mathrm{Na}^{+}$-channel inactivation (43) to drugs that open $\mathrm{Ca}^{2+}$ channels (44). Each induced EAD seems to have a rather specific way to be suppressed, although in all cases shortening of the APD by acceleration of the rate is effective (table 3 ). A drug like isoprenaline can be used to induce (45), facilitate (46) or inhibit EADs (46), depending whether its dominating effect was an increase in repolarization or an increase in rate.

EADs have been suggested to occur at different membrane potentials: low membrane potentials: phase 2 , in the plateau phase with a take off potential about $-30 \mathrm{mV}$ and at higher membrane potentials: phase 3 EADs $(-60 \mathrm{mV})$. After cesium both kinds of EADs (figure 3) have been observed in vitro (36) and in vivo (47). The phase 2 EADs can also be evoked by the $\mathrm{Ca}^{2+}$ agonist Bay $\mathrm{K} 6844$ (44), and are logically suppressed by $\mathrm{Ca}^{2+}$ antagonists like nitrendipine (48). With ryanodine and the $\mathrm{Ca}^{2+}$ chelator BAPTA the phase 2 EAD seem not suppressible (48). These findings suggest that the $\mathrm{Ca}^{2+}$ window current is a likely mechanism for the phase 2 EADs (44).

Phase 3 EADs are not only induced by cesium but also occur after treatment with isoprenaline (45). In contrast to phase 2 EADs the phase 3 EADs are responsive to treatment with ryanodine (45). This observation indicates that different channel(s) and/or mechanisms are involved as suggested by Szabo and co workers. They have put emphasis on the $\mathrm{Na}^{+} / \mathrm{Ca}^{2+}$ exchange (49).

Suppression of EADs is also accomplished with magnesium (37), and substances which are not directly related to ion channels such as prostaglandines (50) and/ or $\alpha$ adrenergic blockade (51). The effects of $\alpha$ adrenergic blockade could point to the involvement of an altered intracellular $\mathrm{Ca}^{2+}$ handling in the cell.

Most drugs which induce EADs in vitro were also used in the intact dog to investigate whether their application would lead to $\mathrm{TdP}$ in vivo. Cesium has been the most often 


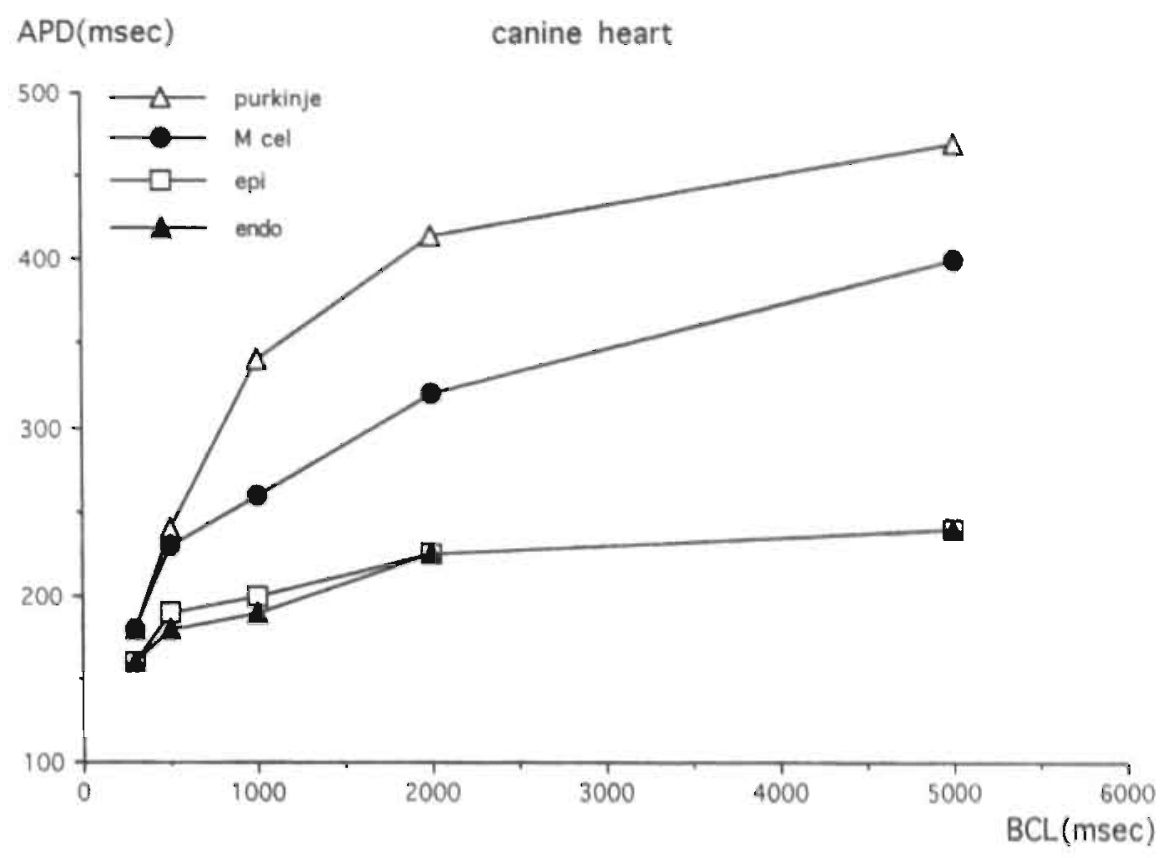

Figure 2. Frequency dependent behaviot of actionpotential from the different cells types.

The actionpotential duration (APD) of the four different cell types of the canine heart is depicted at cycle lengths ranging from 300 to $5000 \mathrm{~ms}$. With an increase in cycle length the transmural difference increases, because the APD of the Purkinje and to a lesser extent of the M cell prolong relatively more in response to a prolongation of the cycle length. Data modified from references 76 and 84 .

used drug (47,50,52-58), but other drugs like anthopleurine A (59) or toxic dosages of quinidine were also administered $(33,60)$.

Because rate is an important factor in clinical TdP, several interventions were made to slow heart rate, like vagal stimulation (58), crushing the sinus node, or the creation of complete AV block $(32,47,52)$. Some drugs like cesium have the advantage of not only prolonging the cycle length but also to create long pauses because of induction of AV block (55) which may act as a trigger for TdP. The limitations of cesium induced polymorphic VT are described in the article of Nayebpour et al. (61).

\subsubsection{Models using drugs that are clinically used}

Originally, administration of clinically used drugs only lead to the appearance of TdP like morphologies when toxic dosages were used or when they were combined with ischemia (31), or after the application of aconitine (32, see table 4). In the sixties, Roberts 
Table 3 . In vitro studies reporting on the croking of carly afterdepolarizarions

\begin{tabular}{|c|c|c|c|c|c|c|c|}
\hline drug/condition & $\begin{array}{l}\text { channel } \\
\text { affected }\end{array}$ & $\begin{array}{l}\text { phase } 2 \\
\text { EADs }\end{array}$ & $\begin{array}{l}\text { phase } 3 \\
\text { FADs }\end{array}$ & cells & antegonis & $\begin{array}{l}\text { nor affected } \\
\text { by }\end{array}$ & $\begin{array}{l}\text { entancesd } \\
\text { by }\end{array}$ \\
\hline 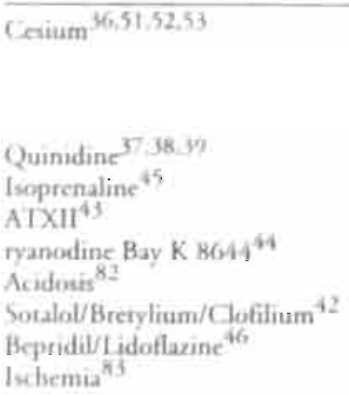 & $\begin{array}{l}\mathrm{Na}^{*} \cdot \mathrm{K}^{*} \\
? \\
\mathrm{Na}^{*} \\
\mathrm{C} \mathrm{L} \\
\mathrm{K}^{*} \\
\mathrm{C} \mathrm{L}_{\mathrm{L}} \mathrm{N} \mathrm{Na}^{*}\end{array}$ & + & $\begin{array}{l}+ \\
+\end{array}$ & $\begin{array}{l}\text { PF } \\
\text { myocytes } \\
\text { PF } \\
\text { PF } \\
\text { PF } \\
\text { PF } \\
\text { PF } \\
\text { PF }\end{array}$ & 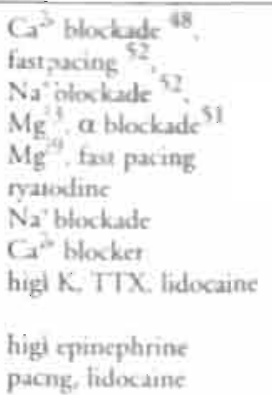 & $\begin{array}{l}\mathrm{Ca}^{2}+\text { blockade ryanodine } \\
\text { verapumil manganese } \\
\text { ryanodine }\end{array}$ & $\begin{array}{l}\text { low } \mathrm{K}^{2} \text {, fow } \mathrm{Ca}^{2} \text {. } \\
\text { ischemia } \\
\text { low epincphrinc, long } \mathrm{Cl} \text {. } \\
\text { quinidine, long } \mathrm{Cl} \text {. }\end{array}$ \\
\hline
\end{tabular}

Abbreviations: PF: Purkinje fibers, Cl: cycle length

Table 4. Review of in vivo studies. TaP using dog models

\begin{tabular}{|c|c|c|c|c|c|c|c|}
\hline drug & ancithesia & diuretics & hear rate & stimularion & MAP & & suppression. \\
\hline cesium $37.6 t$ & : & no & SR & decrease of rate by vapal stim & - & MVT, PVT, IdP rare & $\begin{array}{l}\beta \text { blockade } \\
\text { quindine } \\
\text { lidocaine }\end{array}$ \\
\hline quinidine 33 & + & no & SR & PES & - & PVT & \\
\hline $\operatorname{ccsium}^{52}$ & , & no & SR/AV block & & - & PVT & TTX, rapid pacing \\
\hline quinidine ${ }^{3 !}$ & . & no & SR & PES, ischemia & - & PVT & \\
\hline cesium ${ }^{47}$ & , & nes & AV block & stellate ganglion stim & EAD: & VT/PVT & \\
\hline anthopleurine 59 & . & no & SR $(480-2400 \mathrm{~ms})$ & & EAI s cndo/cpi & & lidecaine, rapid pacing \\
\hline cesumm? & : & no & SR & & EADs & VT & magnesium \\
\hline Acotinind/quinidine 3 ? & , & no & SR/AV block & & - & $\begin{array}{l}\text { QT }=\text { fong } \rightarrow \text { Tdl } \\
\text { QT }=\text { short } \rightarrow \text { PVT }\end{array}$ & \\
\hline cesium 56 & , & ne & & & EADs & PVT & pacing \\
\hline $\operatorname{cesiam}_{54}^{5 x}$ & , & no & SR & vagal stim & $\mathrm{EAD} / \mathrm{DAD}$ & VT & \\
\hline $\begin{array}{l}\text { crsium }^{54} \\
\text { sotalal/quinidine } 63,64\end{array}$ & twake & $\begin{array}{l}\text { no } \\
\text { yes/no }\end{array}$ & $\begin{array}{l}800 \mathrm{~ms} \text { atrial pacing } \\
\text { AV block }\end{array}$ & left and right ansea stioclavia stim & $E A D=L V>E A D=R V$ & $\begin{array}{l}\text { VT } \\
\text { TdP }\end{array}$ & \\
\hline
\end{tabular}

Abbreviations: SR: sinus rate, AV: complete arrioventricular. PES: programmed electrical aimulation. MAP: monophasic action potential, EADs: carly afterdepolarizations;

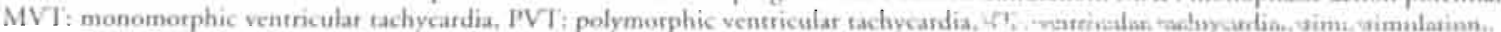



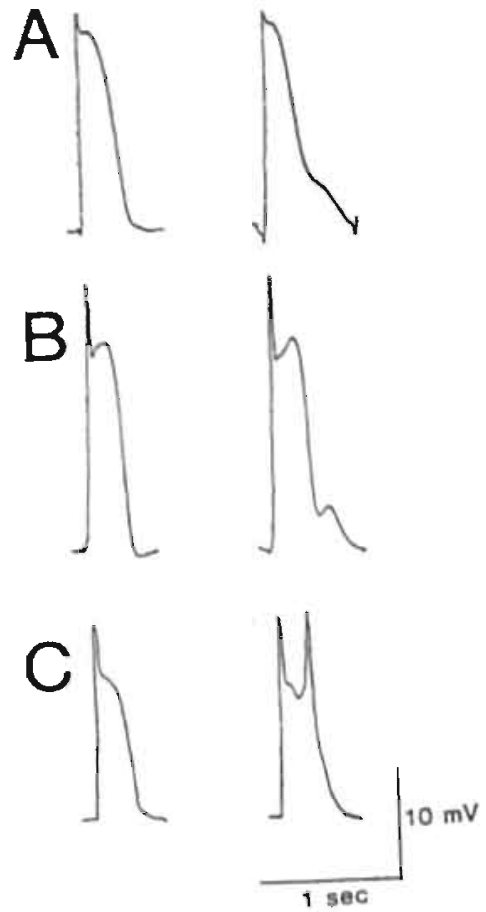

Figure 3. Occurrence of early afterdepolarizations after cesium administration in a dog. On the left side a smooth monophasic action potential signal is shown during the control state. After cesium a high membrane potential early afterdepolarization is shown in panel $A$ and $B$ and a low membrane potential early afterdepolarization in panel C (47). Figure reproduced with permission from the American Heart Association and the authors.

et al. reported that in awake dogs with complete AV block quinidine administration led to ectopic activity, short runs of ventricular tachycardia, and to periods of syncope (62). It took another 30 years before two models were published in which clinically used drugs led to TdP. These models were developed independently from our own model, one is an awake dog model while the other uses rabbits (63-65).

In hypokalemic awake dogs with chronic AV block, administration of quinidine only leads to TdP after prolonged infusion or after a further deceleration in ventricular rate using $\beta$ blockade (63). Similarly it was also shown that administration of $\mathrm{dl}$-sotalol leads. ro spontaneous TdP (64). 
In the other model, rabbits are pretreated with the $\alpha$ agonist methoxamine, followed by the infusion of several class III agents (65). Spontaneous episodes of TdP evolve following ectopic beats despite the fast heart rate of the rabbits. Omittance of the $\alpha$ agonist requires a ten to hundred fold increase of the class III dose leading to TdP (65).

From all these model studies, consensus was reached about the necessity of EADs for the occurrence of ectopic beats preceding TdP. The mechanism of continuation and termination remained to be elucidated.

\subsection{Ventricular heterogeneity in repolarization}

The clinical observation of a difference in duration of repolarization between different ventricular regions (27) in patients with $\mathrm{TdP}$ has been neglected in the experimental studies during the period between 1980 and 1990. Dispersion in repolarization is a common phenomena which has been shown to be present during baseline situation in parients $(24,66,67-69)$, see table 5 . It is thought to represent a measure of non homogeneous recovery of excitability which can include differences in APD, differences in refractory period, and/or differences in activation times. Finally it can be present as transmural, interventricular as well as intraventricular dispersion.

It was hypothesized that differences in repolarization duration could initiate reexcitation, because cells with a prolonged APD caused by local EADs were capable to reexcite the neighboring cells (70). Other groups disapproved of this mechanism and suggested that triggering EADs were also responsibie for the continuation (29).

Surawicz (71) pointed to the pro's and con's of both EADs and dispersion of repolarization in the mechanism of the TdP. In the in situ experiments, most attention was directed to the development and behavior of EADs. Although in some experimental studies more than one MAP catheter was placed, no attention was given to differences in duration, despite the observation of the preferential increase of LV EAD compared with the RV EAD after stellate ganglion stimulation (54).

A study using MAPs at four different endocardial sites in dogs, did not find an increased difference in repolarization after administration of a total of $18 \mathrm{mg}$ quinidine (72). Although none of the dogs developed EADs and/or TdP, these authors suggested that other factors than the intrinsic APD prolongation after quinidine must be responsible for TdP induction (72).

Dispersion as a mechanism for arrhythmias has been more extensively studied in other fields, e.g. an increase in dispersion of APD by regional cooling and warming of the ventricle facilitates tachycardia induction (73). No specific attention was ever placed to interventricular dispersion. In vitro studies showed that the different antiarrhythmic drugs increase or decrease the difference in APD between the Purkinje and ventricular muscle cells in a cycle length dependent fashion (74). Besides the difference berween 
Table 5. Data on intraventricular dispersion in patients without QT. prolongation

number of subjects/source registration site dispersion technique

$\mathrm{n}=28^{67}$

\begin{tabular}{|c|c|c|c|}
\hline Heart catheterization. & intra RV endocardial & $0-38 \mathrm{~ms}$ & $\begin{array}{l}\text { suction MAP } \\
\text { rate dependent }\end{array}$ \\
\hline
\end{tabular}

Heart carheterization intra RV endocardial $0-40 \mathrm{~ms}$

suction MAP

$\mathrm{n}=7^{68}$

Heart catheterization

intra LV endocardial $43 \pm 18(21-64) \mathrm{ms}$

contact MAP

$5-11$ sites

RV APD $<$ LV APD

$\mathrm{n}=3^{68}$

$\mathrm{CABG}$

intra LV epicardial $59 \pm 11(45-73) \mathrm{ms}$

epi APD < endo APD

$5-10$ sites

inverse relation $\mathrm{AT}$ and $\mathrm{APD}$

$\mathrm{n}=10^{69}$

CABG

intra L.V epicardial

$40 \pm 19(21-89) \mathrm{ms}$

contact MAP inverse

$\mathrm{n}=8^{66}$

10 sites

relation $\mathrm{AT}$ and $\mathrm{APD}$

Electrophysiologic study

intra LV endocardial

$0-40 \mathrm{~ms}$

contact MAP

$2-3$ sites

Abbreviations: APD : action potential duration, AT: activation time, CABG: coronary artery bypass grafting, LV: left ventricle, RV: right ventricle, MAP: monophasic action potential.

ventricular myocytes and Purkinje fibers, recent investigations also showed difference between the different subpopulations of the myocardial cells: epicardial, endocardial and $\mathrm{M}$ cells (75,76). In figure 2 , the frequency dependent changes are summarized, at slower rates the APD prolongation is most pronounced in the Purkinje fibers, followed by the $M$ cell region, which creates an enlarged difference in intramural APD. The $\mathrm{M}$ cells might also provide a possible explanation for the $\mathrm{U}$ wave formation (75). In addition. administration of $\mathrm{K}^{*}$ channel blocking drugs induces EADs more easily in $\mathrm{M}$ cells than in endocardial and epicardial myocytes (75).

\subsection{Treatment of TdP}

Treatment of acquired TdP in patients consists of withdrawal of the offending drug. For direct suppression, every measure that shortens the cycle length is capable of suppressing episodes of TdP (4). This can be achieved by isoprenaline infusion and ventricular pacing. The most often used medicament is magnesium (20) which is a very 
effective suppressor of TdP. In addition, the calcium antagonist verapamil and lidocaine have administered to prevent TdP (77). In vitro (see also table 3), all interactions that shorten action potential duration are effective in prevention of the EADs. Most used is the $\mathrm{Na}^{+}$channel blocker tetrodotoxin (TTX), but also several $\mathrm{Ca}^{2+}$ antagonists have proven their efficacy $(44,48,52,53)$.

In 1990 we started to develop our TdP model in dogs with chronic AV block. This AV block dog was used because in Maastricht much experience had been obtained using this model to study different mechanisms of ventricular arrhythmias under awake and anesthetized circumstances (78-81).

\section{REFERENCES}

1. Dessertenne F. La Tachycardie ventriculaire a deux foyers opposes variables. Arch Mal Couer 1966; 59: 263-272.

2. Krikler DM, Curry PVL. Torsade de Pointes, an atypical ventricular tachycardia. Br Heart / 1976; 38 : $117-120$.

3. Wellens HJj, Vermeulen A, Durrer D. Ventricular fibrillation occurring from arousal from sleep by auditory stimuli. Circulation 1972; 46: 661-665.

4. Jackman WM. Friday KJ. Anderson JL, Aliot EM, Clark M, Lazzara R. The Long QT syndromes: a critical review, new clinical observations and a unifying hypothesis. Prog Cardiovase Dis 1988; 31: 118-172.

5. Schwartz PJ. Periti M, Malliani A. The long QT syndrome. Am Heart J 1975; 89: 378-390.

6. Roden DM, George Al. Bennet PB. Recent advantages in understanding the molecular mechanisms of the long QT syndrome. J Cardiovasc Electrophysiol 1995; 6: 1023-1031.

7. Rosen MR. Long QT syndrome patients with gene mutations. Circulation 1995: 92: 3373-3375.

8. Grace AA, Chien KR. Congenital Long QT syndromes. Toward molecular dissection of arrhythmias substrates. Circulation 1995; 92: 2786-2789.

9. Stratmann HG, Kennedy HL. Torsade de Pointes associated with drugs and toxins recognition and management. Am Heart / 1987; 113: 1470-1482.

10. Wellens HJJ, Smeets JLM, Vos MA. Gorgels APM. Antiarrhythmic drug treatment: need for continuous vigilance. Br. Heart f 1992: 67: 25-33.

11. Singh BN, Saram JSM, Zhang ZH, Takanaka C. Controlling cardiac arrhythmias by lengthening repolarization: rationale from experimental findings and clinical considerations. In: QT prolongation and ventricular arrhythmias Annals of the New York academy of sciences edited by Hashiba K, Moss AJ. Schwarz PJ. 1992; 644: 187-209.

12. Bayes De Luna A. Coumel P. Leclereq JF. Ambulatory sudden cardiac death: mechanisms of production of fatal arrhythmia on the basis of data from 187 cases. Am Heart f 1989; 117: 181-189.

13. Roden DM, Thompson KA. Hoffman BF, Woosley RL. Clinical features and basic mechanisms of quinidine induced arrhythmias. I Am Coll Cardiol 1986; 8; 73A-78 A.

14. Kay GN, Plumb VJ, Arciniegas JG, Henthorn RW, Waldo AL. Torsade de Pointes: the long short initiating sequence and other clinical features: observations in 32 patients. J Am Coll Cardiol 1983; 2: 806-817.

15. Bauman JL, Bauernfeind RA. Hoff JV. Strasberg B. Swiryn S. Rosen KM. Torsade de Pointes due to quinidine: Observations in 31 patients. Am Heart J 1984: 107: 425-430. 
16. Cranefield PF. Aronson RS. Torsade de Pointes and other pause induced ventricular tachycardias: the short long short sequence and early afterdepolarizations. PACE 1988; 11: 670-678.

17. Colatsky T], Follmer CH, Starmer CF. Channel specificity in antiarthythmic drug action. Mechanism of potassium channel block and its role in suppressing and aggravating cardiac arrhythmias. Circularion $1990 ; 82: 2235-2242$.

18. Nguyen TP. Scheinman MM, Seger J. Polymorphous ventricular tachycardia: clinical characterization, therapy and QT interval. Circulation 1986; 74: 340-351.

19. Mattioni TA. Zhetrin TA, Sermiento JJ. Parker M, Lesch M, Kehou RF. Amiodarone in patients with previous drug mediated torsade de pointes. Long term efficacy. Ann Internal Med 1989; 111:574-580.

20. Keren A, Tzivoni D, Gavish D, Levi J. Gottlicb S, Benhrin J, Stern S. Etiology, warning signs and therapy of Torsade de Pointes. A study of 10 patients. Circulation 1981; 64: 1167-1174.

21. Olsson B, Varnauskas E, Korsgren M. Further improved method for measuring monophasic action potentials of the intact human heart. J Electrocardiol 1971; 4: 19-23.

22. Franz MR. Method and theory of monophasic action potential recording. Progress Candiovase Dis 1991; 33: $347-368$

23. Zipes DP. Monophasic actionpotentialts in the diagnosis of triggered arrhythmias. Progress Cardiovase Dis 1991; 33: 385-396.

24. Bonatti V. Rolli A, Botti G. Monophasic action potential studies in human subjects with prolonged ventricular repolarization and long. QT syndromes. Eur Heart / 1985; 6: 131-143 (suppl).

25. Gavrilescu S, Luca C. Right ventricular monophasic actionpotentials in parients with long QT syndrome. Br Heart J 1978; 40: 1014-1018.

26. El-Sherif N, Bekheit SS, Henkin R. Quinidine induced long QT interval and Torsade de Pointes: role of bradycardia dependent early afterdepolarizations. J Am Coll Cardiol 1989; 14: 252-257.

27. Habbab MA, El-Sherif N. Drug induced Torsade de pointes: Role of early afterdepolarizations and dispersion of repolarization. Am / Medicine 1990; 89:241-246.

28. Shimizu W, Tanaka K, Suenga K, Wakamoto A. Bradycardia dependent carly afterdepolarizarions in a patient with QTU prolongation and torsade de pointes in association with marked bradycardia and hypokaiemia. PACE 1991; 14: 1105-1111.

29. Cranefield PF. Aronson RS. Cardiac arrhythmias: the role of triggered activity and other mechanisms. 1988 Futura Publishing Mnt Kisco New York.

30. Naumann d'Alnoncourt C, Zierhut W, Lüderizz B. Torsade de Pointes tachycardia, reenury or focal activity. Br Heart J 1982; 48: 213-216.

31. Bardy GH, Ungerleider RM, Smith WM, Ideker RE. A mechanism of Torsades de Pointes in a canine model. Circulation 1983; 67: 52-59.

32. Leichter D. Danilo P. Boyden P. Rosen IS, Rosen MR. A canine model of Torsades de Pointes. PACE $1988 ; 11: 2235-2245$.

33. Inoue H, Murakawa Y. Toda I, Nozaki A, Marsuo H. Mashima S, Sugimoto I. Epicardial activation patterns of torsade de pointes in canine hearts with quinidine-induced long QT inierval but without myocardial infarction. Am Heart / 1986; 111: 1080-1087.

34. Abildskov JA, Lux RL. The mechanism of simulated Torsade de Pointes in a computer model of propagated excitation. / Cardiovasc Electrophysiol 1991; 2: 224-237.

35. Zetelaki Z, Allessie MA. Can Torsade de Pointes be based on a reentrant mechanism. New trends in arrhythmias 1991; 7:97-101.

36. Damiano BP, Rosen MR. Effects of pacing on triggered activity induced by early afterdepolarizations. Circulation 1984; 69: 1013-1025.

37. Kaseda S, Gilmour RF, Zipes DP. Depressant effect of magnesium on early afterdepolarizations and triggered activity induced by cesium, quinidine and 4-aminopyridine in canine cardiac Purkinje fibers. Am Heart / 1989: 118: 458-466. 
38. Takanaka C, Singh BN. Barium-induced nondriven action potentials as a model of triggered potentials from early after depolarizations: significance of slow channel activity and differing effects of quinidine and amiodarone. J Am Coll Cardiol 1990; 18: 213-221.

39. Davidenko JM, Cohen L, Goodrow R, Antzelevitch C. Quinidine induced action potential prolongation, early after depolarizarions and triggered activity in canine purkinje fibers: effects of stimulation rate, potassium and magnesium. Circulation 1989; 79: 674-686.

40. Nattel S, Quantz MA. Pharmacological response of quinidine induced early afterdepolarizations in. canine purkinje fibers: insights into underlying ionic mechanisms. Cardiovasc Res 1988; 22: 808-817.

41. Dangman $\mathrm{KH}, \mathrm{BF}$ Hoffman. In vivo and in vitro antiarrhythmic effects of $\mathrm{N}$-acetyl Procainamide. J Pharmacol Exp Ther 1981; 217:851-862.

42. Gough WB. El-Sherif N. The differential response of normal and ischaemic Purkinje fibers to clofilium. d-sotalol and bretylium. Cardiovase Res 1989; 26:554-559.

43. Bourjdir M. El-Sherif N. Pharmocolocigal evaluation of carly afterdepolarisations induced by sea anemone toxin (ATXII) in dog heart. Cardiovase Res 1991; 25: 818-819.

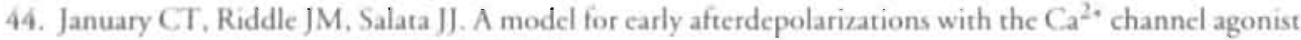
Bay K 8644. Circ Res 1988; 62:563-571.

45. Priori SG, Corr PB. Mechanism underlying carly and delayed afterdepolarizations induced by cathecholamines. Am f Physiol 1990; 258: H1796-H1805.

46. Campbell RM. Woosley RL, lansmith DHS, Roden DM. Lack of triggered automaticity despite repolarizarion abnormalities due to bepridil and lidoflazine. PACE 1990; 13: 30-36.

47. Hanich RF, Levine JH. Spear JF. Moore EN. Autonomic modulation of ventricular arrhythmia in cesium chloride induced long QT syndrome. Circulation 1988: 77: 1181-1161.

48. Marhan E. Robinson SW, Wier GW. Mechanism of arrhythmogenic delayed and early afterdepolarizations in ferret ventricular muscle. / Clin Inest 1978; 78: $1185-1192$.

49. Szabo B, Sweidan R. Patterson A, Scherlag Bj, Lazzara R. Increased intracellular $\mathrm{Ca}^{2+}$ may be important also for early afterdepolarizations. / Am Coll Cardiol 1987; 9:210A (abstract).

50. Miyazaki T, Pride HP. Zipes. DP. Prostaglandin modulation of early after depolarizations and ventricular tachyarthythmias induced by cesium chloride combined with efferent cardiac stimulation in dogs. J Am Coll Cardiol 1990; 1287-1295.

51. Kaseda S. Zipes DP. Effects of alpha adrenergic stimulation and blockade on early afterdepolarization induced by cesium in canine cardiac purkinje fibers. / Cardiovase Electrophysiol 1990; 1: 31-40.

52. Brachmann J. Scherlag BJ, Rosenshtraukh LV. Lazzara R. Bradycardia dependent triggered activity: Relevance to drug induced multiform, ventricular tachycardia. Circulation 1983; 68: 846-856.

53. Bailie DS, Inoue H. Kaseda S. Ben David J. Zipes DP. Magnesium suppression of early afterdepolarizations and ventricular tachyarrhythmias induced by cesium in dogs. Circulation 1988; 77: 1395-1402.

54. Ben-David J. Zipes DP. Differential response to right and left ansae subclavia stimulation of early afterdepolarizations and ventricular tachycardia induced by cesium in dogs. Circulation 1988; 78: $1241-1250$.

55. Graham B, Gilmour RF, Stanton MS, Zipes DP. OPC-88117 suppresses early and delayed afterdepolarizations and arrhythmias induced by cesium, 4-aminopyridine and digitalis in canine Purkinje fibers and in the canine heart in situ. Am Heart ] 1989; 118; 708-716.

56. Levine JH, Spear JF, Guarnieri T. Weisfeldt ML, de Langen CDJ, Becker LC. Moore EN. Cesium chloride-induced long QT syndrome: Demonstration of afterdepolarizations and triggered activity in vivo. Cinculation 1985: 72: 1092-1103.

57. Nayebpour M, Nattel S. Pharmacologic response of cesium induced ventricular tachyarrhythmias in anestherized dogs. / Candionuse Pharmacol 1990; 18:552-561.

58. Patterson E, Szabo B, Scherlag B], Lazzara R. Early and delayed afterdepolarizations associated with cesium chloride-induced arrhychmias in the dog. Cardiovase Res 1990; 18: 323-331. 
59. El-Sherif N, Zeiler RH, Craelius W. Gough WB, Henkin R. QTU prolongation and polymorphic ventricular tachyarrhythmias due to bradycardia dependent afterdepolarizations. Afterdepolarizations and ventricular arrhythmias. Circ Res 1988: 63: 286-305.

60. Inoue H. Matsuo H, Mashima S, Murao S. Effects of atrial pacing, isoprenaline and lignocaine on experimental polymorphous ventricular tachycardia. Cardiovase Res 1984; 18: 538-547.

61. Nayebpour M, Solymoss BC, Nattel S. Cardiovascular and metabolie effects of caesium chloride injection in dogs, limitations as model for the long QT syndrome. Candiovesc Res 1989; 23: 756-766.

62. Roberts J. Stadter RP. Cairoli V. Modell W. Relarionship berween adrenergic activity and cardiac actions of quinidine. Circ Res 1962: 11: 758-7764.

63. Weissenburger J. Chezalviel F. Davy JM, Lainee P. Guhennec C. Pennin E, Engel F. Cynober L. Motte G. Cheymol G. Methods and limitations of an experimental model of long QT syndrome. / Pharmacol Meth 1991: 26: 23-42.

64. Weissenburger J, Davy JM, Chezalviel F. ErtzbischoffO, Poirier JM, Engel F, Lainee P., Penin E, Motte G. Cheymol G. Arrhythmogenic activities of anti arrhythmic drugs in conscious hypokalemic dogs with atrioventricular block: comparison between quinidine, lidocaine, flecainide, propranolol and sotalol. J Pharmocol Exp Ther 1991: 259:871-883.

65. Carlsson L. Almgren O, Duker G. QTU-prolongation and Torsades de Pointes induced by putative class $\mathrm{II}$ antiarrhythmic agents in the rabbit: Eriology and interventions. / Cardiouvese Pharmaco/ 1990; 16: $276-285$.

66. Shimizu W, Ohe T, Kurita T, Takaki H, Aihara N, Kmakurka S, Matsuhisa M, Shimomura K. Early afterdepolarizations induced by isoproterenol in patients with congenital long QT syndrome. Circulation 1991; 84: 1918-1923.

67. Olsson SB. Right ventricular monophasic action potentials during regular rhythm. A heart catheterization study in man. Acra Med Scand 1972: 191: 145-187.

68. Franz MR, Bargheer K. Raffenbeul W, Haverich A, Lichten PR. Monophasic action potential mapping in human subjects with normal electrocardiograms: direct evidence for the genesis of the $T$ wave. Circulation 1987: 75: 379-386.

69. Cowan CJ, Hilton CJ. Griffiths CJ. Tansuphaswadikul S. Bourke JP. Murray A. Campbell RWE. Sequence of epicardial repolarisation and configuration of the T wave. Br Heart / 1988: 60: 424-433.

70. Brugada P, Wellens HJJ. Early afterdepolarizations: Role in conduction block, "prolonged repolarization-dependent reexcitation," and tachyarrhythmias in the human heart. PACE 1985; 8: 889-896.

71. Surawicz B. Electrophysiological substrate of Torsade de Pointes: Dispersion of repolarization or early afterdepolarizations. J Am Coll Cardiol 1989; 14: 172-182.

72. Brugada J, Sassine A, Escande D, Masse C, Puech P. Effects of quinidine on ventricular repolarization. Eur Heart / 1987; 8: 1340-1345.

73. Kuo CS, Munakata K. Reddy P. Surawice B. Characteristics and possible mechanism of ventricular arrhythmia dependent on the dispersion of action potentials. Circulation 1983:67: 1356-1367.

74. Varro A, Nakaya Y. Elharrar V. Surawice B. Effect of antiarrhythmic drugs on the cycle length dependent action potential duration in dog purkinje and ventricular muscle fibers. / Cardiovase Pharmacol 1986: 8: 178-185.

75. Antzelevitch C, Sicouri S, Litovsky SH, Lukas A, Krishnan SC, Di Diego JM, Gintant GA, Liu DW. Heterogeneity within the ventricular wall. Electrophysiology and pharmacology of epicardial, endocardial and M cells. Circ Res 1991; 69: 1427-1451.

76. Sicouri S, Antzelevitch C. A subpopulation of cells with unique electrophysiological properties in the deep subepicardium of the canine ventricle. The M cell. Circ Res 1991: 68: 1729-1741.

77. Jackman WM. Szabo B, Friday KJ. Margolis PD, Moulton K. Wang X, Patterson E. Lazzara R. Ventricular tachyrhythmias related to early afterdepolarizations and triggered firing: relationship to QT interval prolongation and potential therapeutic role for calcium blocking agents. I Cardiovase Electrophysiol 1990; 1: 170-195. 
78. Gorgels APM, Leunissen HDM, Brugada P, Dassen WRM, Richards D, Wellens HJJ. Extrastimulus related shortening of the first post pacing interval in digitalis induced ventricular arrhythmias. $/ \mathrm{Am}$ Coll Cardiol 1983; 1840-857.

79. Vos MA, Gorgels APM, Leunissen JDM, Brugada P, Wellens HJJ. The effect of an entrainment protocol on ouabain-induced ventricular tachycardia. PACE 1989; 12: 1485-1493.

80. Vos MA, Gorgels APM, Leunissen JDM, Wellens HJJ. Flunarizine allows differentiation between mechanisms of arrhychmias in the intact heart. Circularion 1990; 81: 343-351.

81. Vos MA, Van Deursen RTAM, Gorgels APM, Leunissen JDM, Wellens HJJ. Significance of the number of stimuli to initiate ouabain-induced arrhythmias in the intact heart. Circulation Research 1991: 68: 38-44.

82. Corabocuf E, Deroubaix E, Coulombe A. Acidosis induced abnormal repolarization and reperitive activity in isolated dog Purkinje fibers. If Physiol 1980; 76: 97-106.

83. Rozanski GJ. Witt RC. Early afterdepolarizations and triggered activity in rabbit purkinje fibers recovering from ischemic like conditions. Role of acidosis. Circulation 199 I; 83: I252-1260.

84. Elharrar V, Surawicz B. Cycle length effect on the restitution of action potential duration in dog cardiac fibers. Am f Physiol 1983; 244: H782-H792.

85. Hohnloser SH, Singh BN. Proarrhythmia with class III antiarrhythmic drugs:definition, electrophysiologic mechanisms, incidence, predisposing factors, and clinical implications. / Cardiovasc Electrophysiol 1995: 6: 920-936. 
Chapter 2

Reproducible induction of early afterdepolarizations and Torsade de Pointes arrhythmias by $d$-sotalol and pacing in the dog with chronic atrioventricular block

Marc A. Vos

S. Cora Verduyn

Anton P.M. Gorgels

Gyorgyi C. Lipcsei

Hein J.J. Wellens 


\section{ABSTRACT}

Background: It has been well established that (antiarrhythmic) drugs can also have proarrhythmic effects such as Torsade de Pointes arrhythmias (TdP). It was the purpose of this study to create an animal model with a high incidence of reproducible TdP that occur under clinically relevant circumstances.

Methods: Experiments were performed in anesthetized dogs that had been in chronic atrioventricular (AV) block for $9 \pm 6$ weeks. Inducibility of TdP was attempted using different pacing modes before and after the administration of $2 \mathrm{mg} / \mathrm{kg} d$-sotalol (dS). In some experiments, endocardial monophasic action potentials (MAP) were recorded. Results: dS increased the cycle length of the idioventricular rhychm (CL-IVR: $1475 \pm$ 460 to $1730 \pm 570 \mathrm{~ms}, \mathrm{P}<0.01)$ and the QT time $(390 \pm 65$ to $480 \pm 85 \mathrm{~ms}, \mathrm{P}<0.01)$. In 10\% of the experiments "spontaneous" TdP occurred after dS. The incidence of "pacing dependent" TdP was 52\% ( $<<0.01)$. In the inducible group CL-IVR and QT time were significantly longer despite equal percentual increases in these parameters after $\mathrm{dS}$ in both groups. The pacing modes consisting of more than one frequency change had a higher induction rate of TdP $(P<0.05)$. Reproducibility of induction of TdP $(\geq 3$ times using the same pacing train) remained present for about 60 minutes after $\mathrm{dS}$ and was $>90 \%$ within the same animal over weeks. Induction of TdP was related to the presence of early afterdepolarizations (EADs) on the MAP recordings: $5 / 6$ in the inducible group vs. $2 / 6$ in the non responders. Inducibility could be further increased to $89 \%$ when a second bolus of $\mathrm{dS}$ was administered to non inducible dogs. On the other hand, decreasing QT time by faster basic pacing, isoprenaline or $\mathrm{MgSO}_{4}$ prevented induction of TdP. This effect of $\mathrm{MgSO}_{4}$ coincided with disappearance of EADs.

Conclusions: Our animal model shows a high incidence of reproducible acquired TdP arrhythmias allowing study of mechanism and treatment of TdP. Induction of TdP was related to the combination of 1 ) a slow ventricular rate, 2) prolongation of QT time, 3) a sudden induced rate change which often requires $\geq 2$ cycle length changes, and 4 ) the presence of EADs.

\section{INTRODUCTION}

Torsade de Pointes arrhythmias (TdP) can be congenital or acquired (1). The latter often occur in the presence of drugs which prolong ventricular repolarization, such as class la and III drugs. By definition, one of the characteristics of the drug induced TdP is the prolongation of the QT(U) duration. Prolongation of the refractory period of cardiac muscle is at the same time the desired antiarrhythmic goal to prevent reentrant tachycardias.

Several canine models exist (2-10), which enable the study of the morphological or mechanistic characteristics of TdP arrhythmias. Initiation of TdP is often associated 
with early afterdepolarizations (EADs) (2-5). Still, we had the impression that the addition of a model that mimicks the clinical circumstances of TdP is of importance for a) the comparison of the proarrhythmic potential of drugs to initiate TdP, and b) to study mechanisms and treatment of TdP. The clinical conditions known to favor acquired TdP are 1) bradycardia, 2) therapeutic dosages of drugs that prolong QT duration, 3) sequences of short long short intervals and 4) hypokalemia and/or hypomagnesemia (1).

In the dog we developed a highly reproducible TdP model by mimicking the first three circumstances by 1) chronic AV block, 2) administration of $2 \mathrm{mg} / \mathrm{kg} d$-sotalol, and 3) specific pacing modes. To investigate the model further, we increased basic heart rate by pacing, we administered $\mathrm{MgSO}_{4}$ and isoprenaline and we recorded monophasic action potentials (MAP) to demonstrate involvement of EADs. Finally, different pacing modes were used to clarify the relevance of the number of cycle length changes (e.g. the short long short sequence) needed to initiate TdP.

\section{METHODS}

The study protocol was approved by the Committee for Experiments on Animals of the University of Limburg, Maastricht, The Netherlands and conducted in accordance with the guidelines of the American Physiological Society.

The experiments were performed on 18 adult mongrel dogs of either sex having a body weight between $20-35 \mathrm{~kg}(26 \pm 5)$. In a. preliminary surgery, a right thoracotomy was performed to induce a. permanent complete AV block by injecting $37 \%$ formaldehyde into the AV junction. (11). During the same session, pacing electrodes (Bakken Research Center, Medtronic, Maastricht, The Netherlands) were inserted epicardially into the basal portion of the right ventricle and the apex of the left ventricle. The wires were exteriorized through the back of the neck.

Six surface electrocardiographic leads and one local electrocardiogram were continuously registered and stored on optical disk. All drugs were administered through a canula in a cephalic vein.

Anaesthesia was induced by 1) premedication i.m. (1 ml/5 kg: $10 \mathrm{mg}$ oxycodon, $1 \mathrm{mg}$ acepromazine, and $0.5 \mathrm{mg}$ atropine) and 2) sodium pentobarbital ( $20 \mathrm{mg} / \mathrm{kg}$ i.v.). The dogs were artificially ventilated through a cuffed endotracheal tube using a mixture of oxygen, nitrous oxide and halothane (vapor concentration $0.5 \%$ ) by a respirator. Ventilation was controlled by continuous reading of the carbon dioxide concentration in the expired air. A thermal mattress was used to maintain adequate body temperature, Proper care was taken postoperatively, including antibiotics (1000 mg ampicilin) and analgetics ( $0.3 \mathrm{mg}$ i.m. buprenorfine). 


\section{Pacing modes}

Stimulation was done preferably from the right ventricular lead with a programmable stimulator having a synchronizing circuir (12). Unipolar stimuli were given using a pulse width of $2 \mathrm{~ms}$ and a stimulus strength of twice the diastolic threshold. As indifferent electrode, we used a needle placed through the skin.

Pacing consisted of four different pacing modes, which represent respectively one, two and three cycle length changes. The pacing modes for the one cycle length change consisted of 1) 3 stimuli (NVS=3), and 2) continuous pacing for 30 seconds (CP). Both were performed with equal interstimulus intervals and shortened from 1200 to $400 \mathrm{~ms}$ in steps of $100 \mathrm{~ms}$ for NVS=3, while CP was started just below the cycle length of the idioventricular rhythm (CL-IVR) and reduced to 1200, 900, 600 and $400 \mathrm{~ms}$. The pacing modes with more than one frequency change were: 3 ) a basic train of 8 stimuli followed by an extrastimulus $(8+1)$, and 4 ) a short long short sequence (SLS). The extrastimulus was shortened from $350 \mathrm{~ms}$ down in steps of $10 \mathrm{~ms}$ until the effective refractory period (VERP) was reached. VERP was defined as the longest stimulus interval which was not followed by a ventricular complex. VERP was determined during IVR and at paced rates similar to the CP protocol. SLS consisted of a) 4-8 paced beats with an interval of $600 \mathrm{~ms}$ followed by a beat with an interval of $1200 \mathrm{~ms}$ and finally an extrastimulus (4-8x600/1200/extra), b) $400 / 800 /$ extra, and/or c) $2 \times 300 / 900 /$ extra. The pacing protocol needed 30-40 minures for completion, while the different pacing modes were applied in a random manner.

Incidence of TdP was related to a specific pacing train and mode. Moreover, because $\mathrm{TdP}$ frequently started before the pacing train was completed, induction was also classified to the specific change in cycle length that seemed to be responsible for the initiation of TdP. When TdP was induced during the first 8 paced beats of either CP or $8+1$, it was classified as being induced after one frequency change. A dog was considered inducible when a $\mathrm{TdP}$ arrhychmia could be reproducibly induced by the same pacing train for at least 3 times.

\section{Definition TdP}

A Torsade de Pointes arrhythmia was defined as a polymorphic ventricular tachycardia (VT) consisting of $\geq 5$ beats twisting around the baseline having a rate of more than 200 bears/min which occur in the setring of a prolonged QT(U) duration (1). These VTs either stop spontaneously or degenerate into ventricular fibrillation. The VT was terminated using cardioversion (60-70 Joule) when it lasted longer than $10 \mathrm{sec}$. Defibrillation was performed maximally 6 times per experiment. TdP was differentiated from VF using the following characteristics: 1) twisting QRS behaviour using all 6 ECG-leads, 2) the (change in) amplitude of the QRS complex in a single ECG lead, and 3) the frequency of the arrhythmia. 


\section{Experiments}

At least two weeks after the creation of complete AV block, the dogs were anaesthetized (see above). A blood sample was taken 1) to measure plasma levels of the electrolytes: calcium, sodium, potassium and magnesium, and 2) to establish their kidney function by measuring ureum and kreatinine. Two defibrillation patches, which were connected to a defibrillator, were attached at both sides of the chest. Most dogs were tested at different weeks to investigate reproducibility of their response.

After the baseline pacing protocol, a bolus $d$-sotalol ( $2 \mathrm{mg} / \mathrm{kg} / 5 \mathrm{~min}$ ) was administered. Thereafter, 5 minutes elapsed before pacing was resumed. The experiments were divided in two groups: inducible (I) and non inducible (NI). In group I, we distinguished between TdP which occurred spontaneously after $d$-sotalol ("spontaneous" TdP) and TdP which was pacing dependent ("pacing dependent" TdP). Because the number of cardioversions per experiment was limited, it was often not possible to repeat the complete pacing protocol in group 1 .

In the majority of the experiments belonging to the group NI, we added another bolus $d$-sotalol ( $2 \mathrm{mg} / \mathrm{kg} / 5 \mathrm{~min})$ and repeated the pacing protocol.

When TdP was inducible, we performed three procedures. First, the inducibility and reproducibility of $\mathrm{T} \mathrm{dP}$ arrhythmias was tested further using different pacing modes. Also the length of the period ( $\mathrm{min}$ ) was derermined during which a single bolus of $d$-sotalol in combination with pacing was able to induce TdP. Second, the basic ventricular rate was accelerated by: 1) pacing, or 2) administration of isoprenaline i.v. (10 $\mu \mathrm{g} / 5 \mathrm{~min})$. Thereafter, the specific pacing train responsible for $\mathrm{TdP}$ induction was repeated. Third, $\mathrm{MgSO}_{4}(100 \mathrm{mg} / \mathrm{kg} / 2 \mathrm{~min})$ was administered to assess its suppressive effect against "spontaneous" TdP and to study its preventive effect against "pacing dependent" TdP.

\section{Monophasic Action Potentials}

A single endocardial MAP recording was made before and after $d$-sotalol to detect EADs in 12 experiments. Either through the jugularis vein $(n=11)$ or the carotid artery $(n=1)$, the MAP catheters (Franz combination catheter, EPT \# 1650) were placed randomly under fluoroscopy (13). The MAP was amplified by a DC-coupled differential amplifier, which is provided with a $20 \mathrm{mV}$ calibration pulse. The MAP signals were sampled at a rate of $1 \mathrm{KHz}$. The recording sites were chosen based on stability, quality of the signal and an amplitude which had to exceed $15 \mathrm{mV}$ (13). The presence of an EAD on the MAP recording was defined as a retardation in repolarization (2-5). 
The following parameters were measured in each experiment by two independent observers: CL-IVR, QRS duration, and QT(U) duration. QT(U)c duration was calculated according to Bazett's formula (14).

\section{Statistics}

For determination of statistical difference $(P<0.05)$, we used analysis of variance (ANOVA) for comparisons between more than two groups, followed by Bonferroni's $t$-test when the F-value permitted. Paired Student's $t$-test was applied to compare data between two groups and $\chi^{2}$ testing was used when the data were presented as percentages. All data are presented as mean \pm standard deviation (SD), or when indicated as mean \pm standard error of the mean (SEM).

\section{RESULTS}

In 18 dogs, we performed 42 experiments $(2.5 \pm 1.2)$. The mean time interval between the first experiment and AV block was $9 \pm 6$ weeks, whereas the time in between experiments was $14 \pm 9$ days. All dogs had normal electrolytes except for a slightly decreased potassium level of $3.4 \mathrm{mmol} / \mathrm{l}$ in one dog receiving diuretics because of heart failure.

\section{Pacing under control conditions}

We were not able to induce TdP by pacing under baseline conditions. However in 3 dogs, we noticed transient episodes of repolarization abnormalities (occurrence of U-waves) in the first spontaneous beats directly following pacing.

\section{Electrophysiologic effects of d-sotalol}

Administration of $d$-sotalol resulted in a marked increase in the CL-IVR from $1475 \pm$ 460 to $1730 \pm 570 \mathrm{~ms}(\mathrm{P}<0.01)$ and QT duration from $390 \pm 65$ to $480 \pm 85 \mathrm{~ms}$ (P<0.01), often occurring in the presence of $U$ waves.

In a subset of dogs $(n=8)$, we investigated the duration of these electrophysiologic changes (figure 1). The increases in CL-IVR and QT duration diminished in time, but remained present during the investigational period of $50 \mathrm{~min}$. Also, $\mathrm{QT}_{c}$ showed a similar behaviour. No changes were observed in QRS duration. 

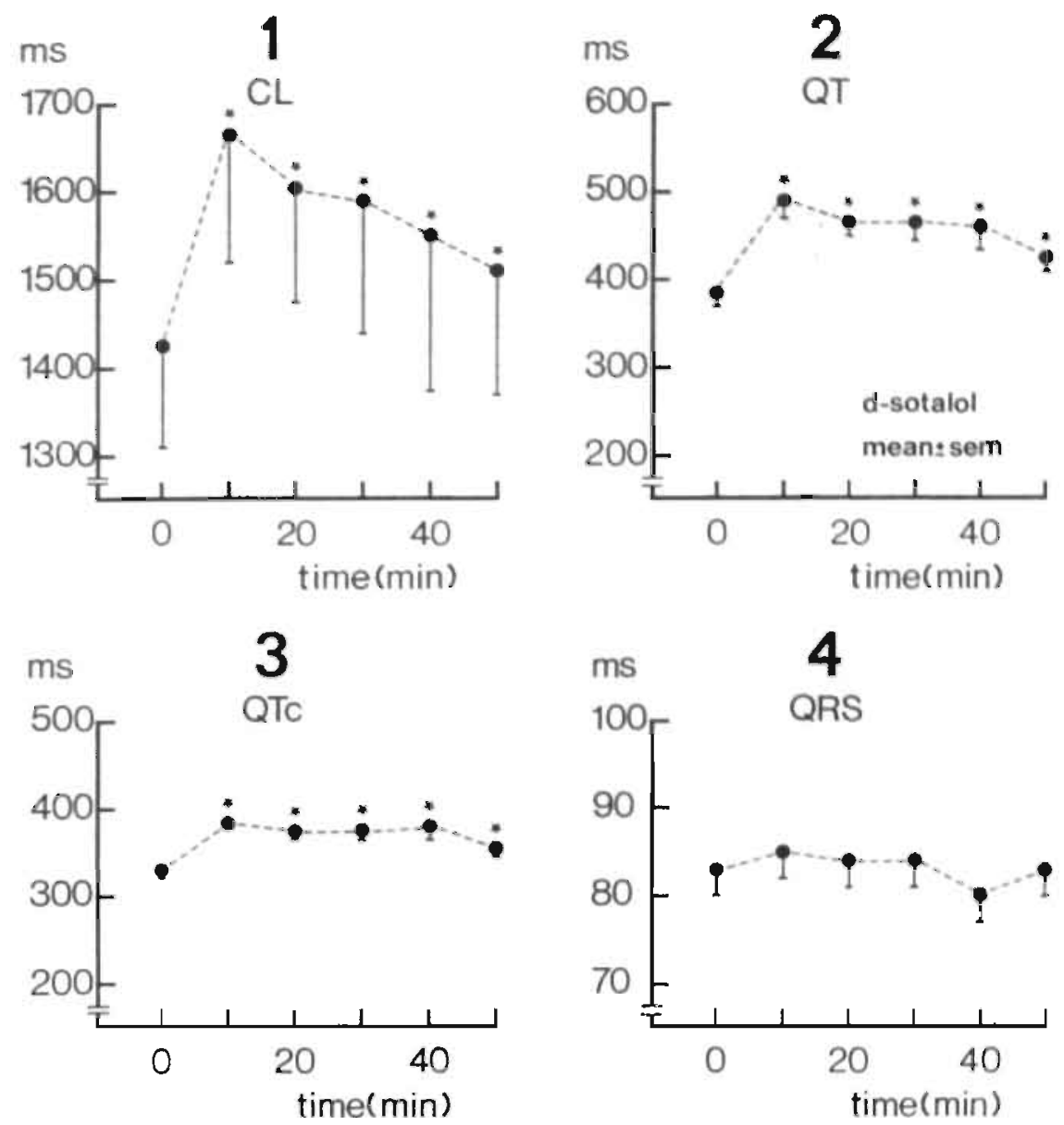

Figure 1. Time dependent electrophysiologic effects of one bolus of $d$-sotalol ( $2 \mathrm{mg} / \mathrm{kg}$ ).

The time dependent electrophysiological effects of $d$-sotalol are described for CL-IVR, QT, QT, and QRS duration (panels $1-4$ respectively). The time after $d$-soralol is presented on the $x$-axis for $0-50$ minutes. CL-IVR, QT duration and QT time were all maximally increased 10 minutes afier $d$-sotalol (panels 1-3). From that period on, the effect diminished, but remained statistically significant for 40 minutes, i.e. 50 minutes after the start of $d$-sotalol. Reproducible induction of TdP arrhythmias was possible for a similar time period. Finally, QRS duration did not change after $d$-sotalol (panel 4).

VERP during spontaneous IVR increased from $265 \pm 60$ to $325 \pm 65 \mathrm{~ms}(\mathrm{P}<0.05)$. The effect of $d$-sotalol on VERP was reverse-use dependent: the relative increase of VERP was greater at slower heart rates $(+23 \%)$ than at faster ones $(+2 \%, \mathrm{P}<0.01)$. 


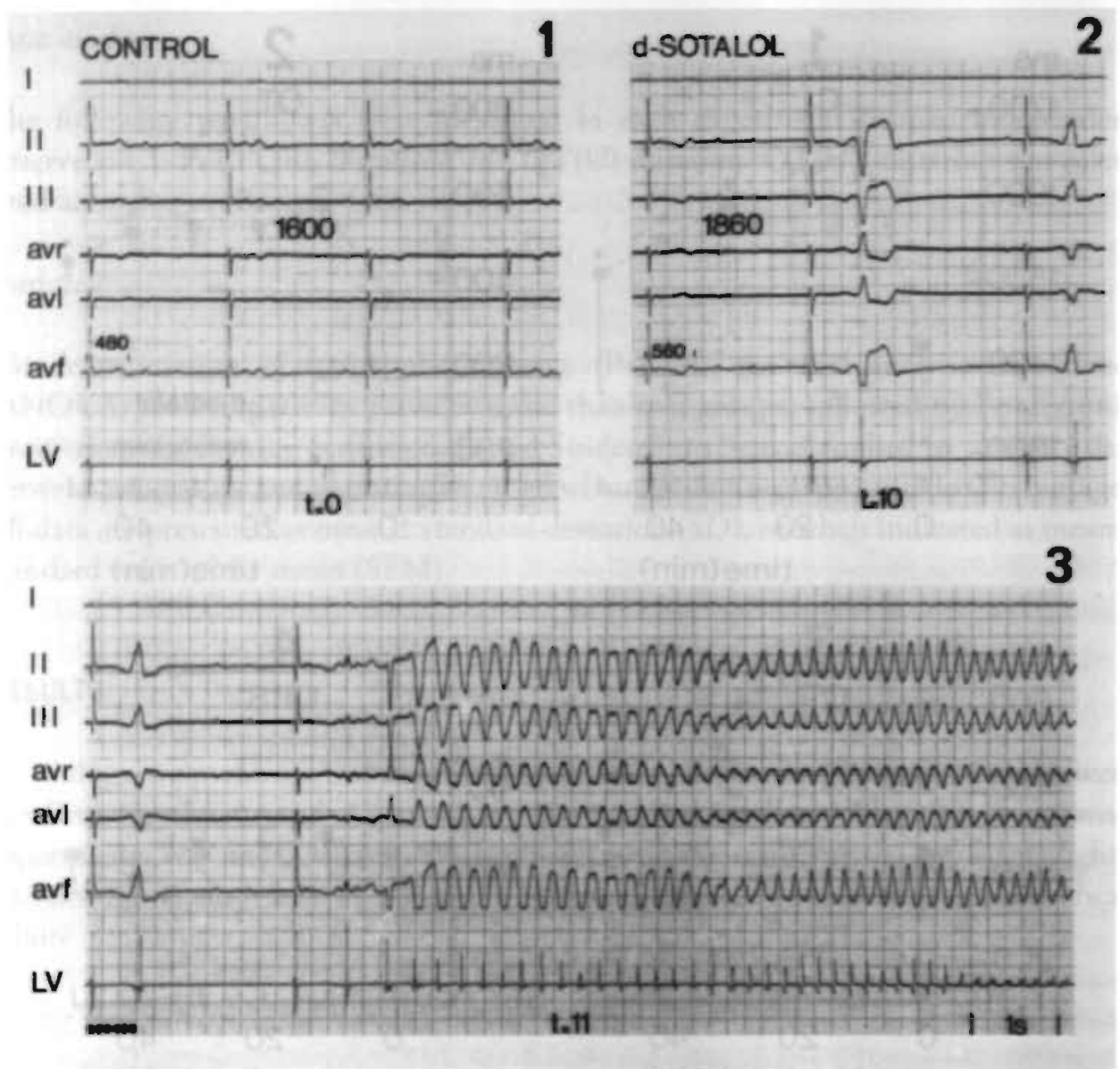

Figure 2. "Spontaneous" TdP arrhythmia after $d$-sotalol.

Six surface electrocardiographic leads and a local electrogram from the left ventricular (LV) apex are recorded simultancously in an anaesthetized dog with chronic AV block. Paper speed is $25 \mathrm{~mm} / \mathrm{sec}$. Panel 1: spontaneous idioventricular rhythm. Panel 2: 10 minutes after $d$-sotalol CL-IVR and QT time are increased and ectopic beats with different QRS configurations occur at the end of the TU wave. Panel 3: spontancous induction of a TdP arrhythmia. Note the "typical" short long short sequence which precedes the polymorphic VT.

\section{Spontaneous TdP arrhythmias after d-sotalol}

Following $d$-sotalol administration, we noticed four "spontaneous" appearances of a TdP arrhythmia: $4 / 42=10 \%$ (figure 2, panel 3). These episodes were repetitive and often needed interventions, such as cardioversion and back-up pacing at faster rates to suppress the arrhythmia. More frequently $(50 \%)$, ectopic beats with different configurations often arising from the end of the TU wave were observed (figure 2, panel 2). 


\section{Inducibility of TdP arrhythmias after d-sotalol}

After the first bolus of $d$-sotalol, pacing resulted in reproducible TdP in 22/42 experiments $(52 \%, \mathrm{P}<0.01$ vs "spontaneous"), which appeared in 12 of the $18 \mathrm{dogs}$. An example is presented in figure 3 . In all dogs with "spontaneous" TdP, pacing also resulted in the induction of TdP. Inducibility remained present using similar pacing modes for at least 60 minutes in the 3 dogs, in which this was tested.

Inducibility was related to CL-IVR and QT(U) duration (table 1). In the NI group $(\mathrm{n}=20), C L-I V R$ and QT time were significantly shorter, although the relative increase induced by $d$-sotalol was comparable for both parameters in both groups. Correction for QRS duration (JT interval) revealed no differences in the quantification of the parameter of repolarization.

Only in two dogs, the (in)ability to induce TdP was not reproducible in subsequent experiments: one inducible and one non inducible dog that reversed their response. Therefore, the reproducibility is quite high $(38 / 42=90 \%)$.

\section{Registration of EADs by MAP recordings}

EADs were registered in 7/12 experiments (figures 4-6). In half of the MAP experiments, $\mathrm{TdP}$ could be induced. The occurrence of ectopic beats was related to the presence of EADs in 4/5 experiments (figure 4). EADs were seen in 5/6 inducible and in 2/6 non inducible experiments. In figure 5 , an example is presented of a $\mathrm{TdP}$ induction by "pacing" which is initiated by EAD-dependent triggered beats. Often, pronunciation of $\mathrm{EAD}$ amplitude was seen during the pacing train.

\section{Effect of the pacing mode on inducibility of TdP arrhythmias}

In a subgroup of subsequent, inducible experiments $(n=11)$, we analyzed the induction of 55 episodes of $\mathrm{TdP}$ in relation to the pacing mode. Defibrillation was performed in 21 cases, while spontaneous termination occurred in $34 \mathrm{TdP}$. Induction either occurred during the pacing train or directly thereafter (figures 3 and 5). In case of $\mathrm{CP}$, induction was always seen in the beginning of the pacing train. The incidence of $\mathrm{TdP}$ in relation to pacing mode is presented in the left part of table 2. It is shown that the modes $8+1$ and SLS are equally effecrive and possess a greater ability to induce TdP than the other two modes $(P<0.05)$, while NVS $=3$ is more successful than $C P(P<0.05)$.

Induction was related to the number of cycle length changes: Half of the inductions occurred after one change in cycle length, i.e. starting during or directly after protocols 1 or 2, or during the first frequency change of protocols 3 and 4 (right part of table 2, presented as first change). However, inducibility was only possible in the other half of the experiments by at least 2 frequency changes, as illustrated in figures 3 and 5 . 
Table 1. Electrophysiologic changes of $d$-sotalol $(2 \mathrm{mg} / \mathrm{kg})$

\begin{tabular}{llll}
\hline Inducible experiments $(\mathrm{N}=22)$ & Control & D-SOT $\left(10^{\circ}\right)$ & $\%$ \\
\hline CL-IVR (ms) & $1745 \pm 465$ & $2055 \pm 580^{\circ}$ & +18 \\
QT(U) & $420 \pm 60$ & $535 \pm 80^{\circ}$ & +27 \\
QT. & $325 \pm 45$ & $380 \pm 60^{\circ}$ & +17 \\
& & & \\
\hline Non inducible experiments $(\mathrm{N}=20)$ & Control & D-SOT $\left(10^{\prime}\right)$ & $\%$ \\
\hline CL-IVR (ms) & $1175 \pm 190^{\circ}$ & $1370 \pm 255^{\circ}$ & +17 \\
QT (U) & $350 \pm 45^{*}$ & $425 \pm 50^{\circ}$ & +21 \\
QT. & $325 \pm 45$ & $365 \pm 40^{\circ}$ & +12 \\
\hline
\end{tabular}

"P<0.001 vs control: " $P<0.001$ vs inducible, mean \pm SD

\section{d-SOTALOL}

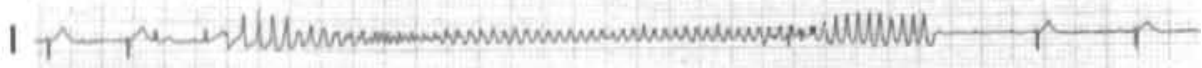

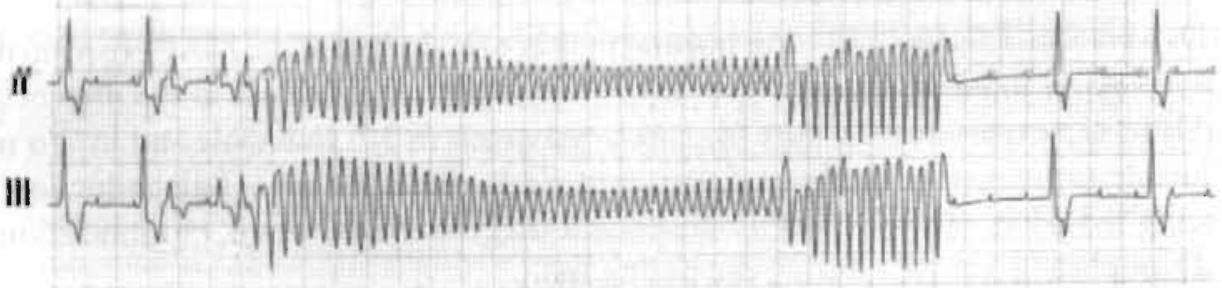

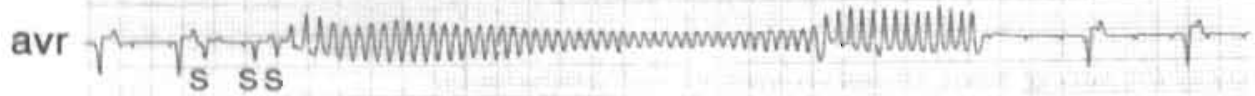

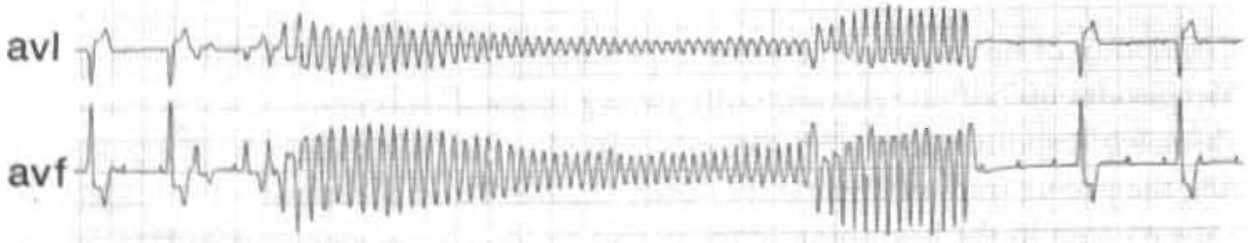

$400800 /$ extra

910387

Figure 3. Induction of a TdP arrhythmia directy after pacing in the presence of d-sotalol.

Six simultancously recorded ECG-leads are shown at a paper speed of $10 \mathrm{~mm} / \mathrm{sec}$. After $d$-sotalol. the idioventricular rhythm is interrupted by a short long short sequence $(400 / 800 /$ extra). Directly following this pacing protocol, a self terminating TdP occurs. We have dassified this sequence as a TdP induced by three cycle length changes. 


\section{CONTROL}
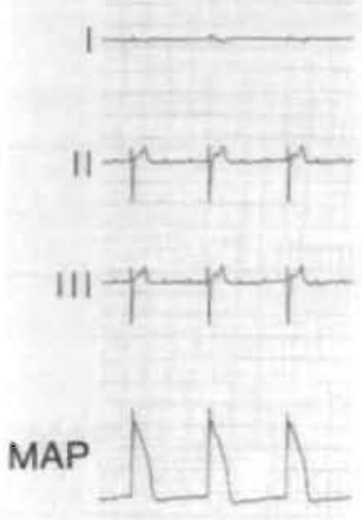

sacas
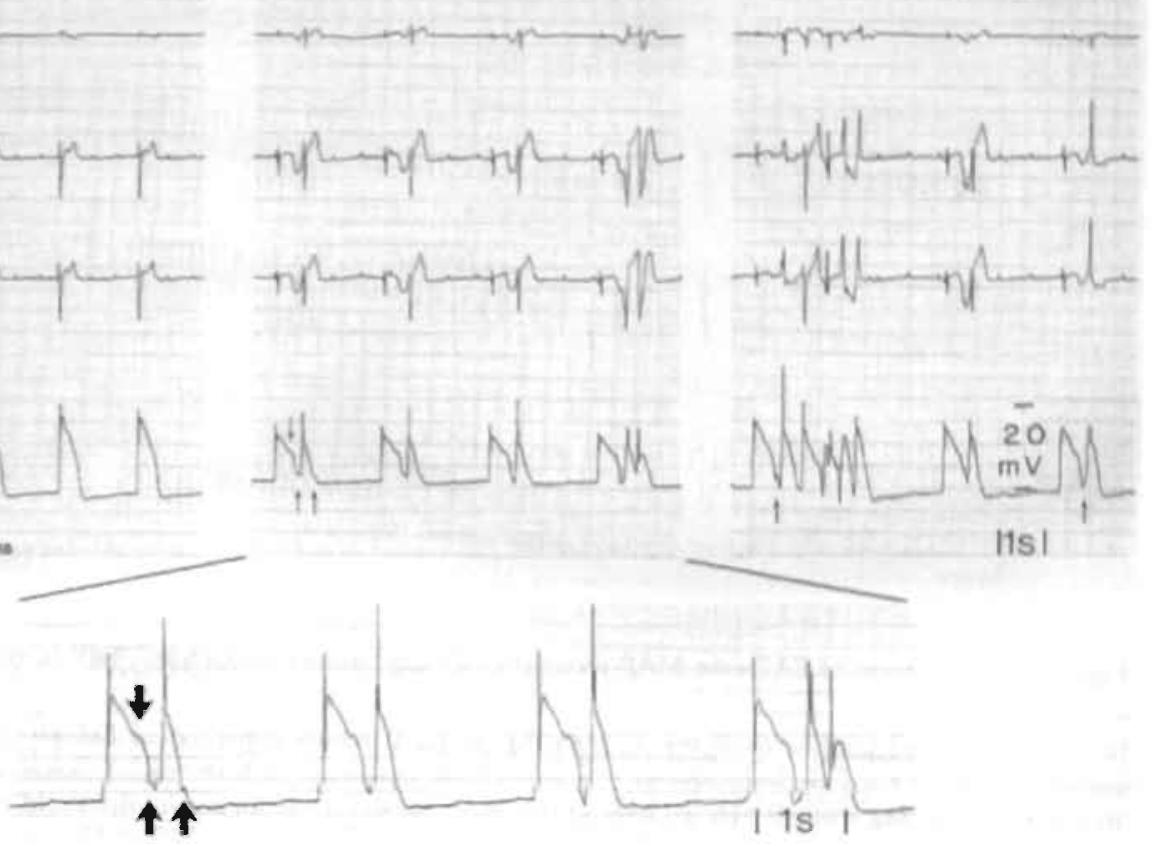

$|1 s|$

Figure 4. Registration of EADs on MAP recordings during spontancous ectopic activity after d-sotalol.

Three surface ECG-leads and an endocardial MAP registration from the apex of the left ventricle are simultaneously seen at a paper speed of $10 \mathrm{~mm} / \mathrm{sec}$. After $d$-sotalol (middle and right panel), spontaneous ectopic beats from different origin occur during the idioventricular rhythm. In the enlarged MAP recording of the middle panel, phase 2 subthreshold EADs ( $\downarrow$ ) can be clearly seer. Also phase 3 EADs $(\uparrow$ ) can be seen which trigger and induce (an) ectopic beat(s).

\section{Inducibility in the non inducible group after a second bolus of d-sotalol}

After administration of a second bolus of $d$-sotalol in 14 of the 20 non inducible experiments, inducibility increased to a total of $32 / 36(89 \%, P<0.01$ vs first bolus $d$-sotalol). This was accompanied by increases in CL-IVR from $1340 \pm 190$ to $1690 \pm$ $500 \mathrm{~ms}, \mathrm{p} \leq 0.05$ and $\mathrm{QT}(\mathrm{U})$ duration from $450 \pm 60$ to $490 \pm 55 \mathrm{~ms}, \mathrm{p} \leq 0.05$. 


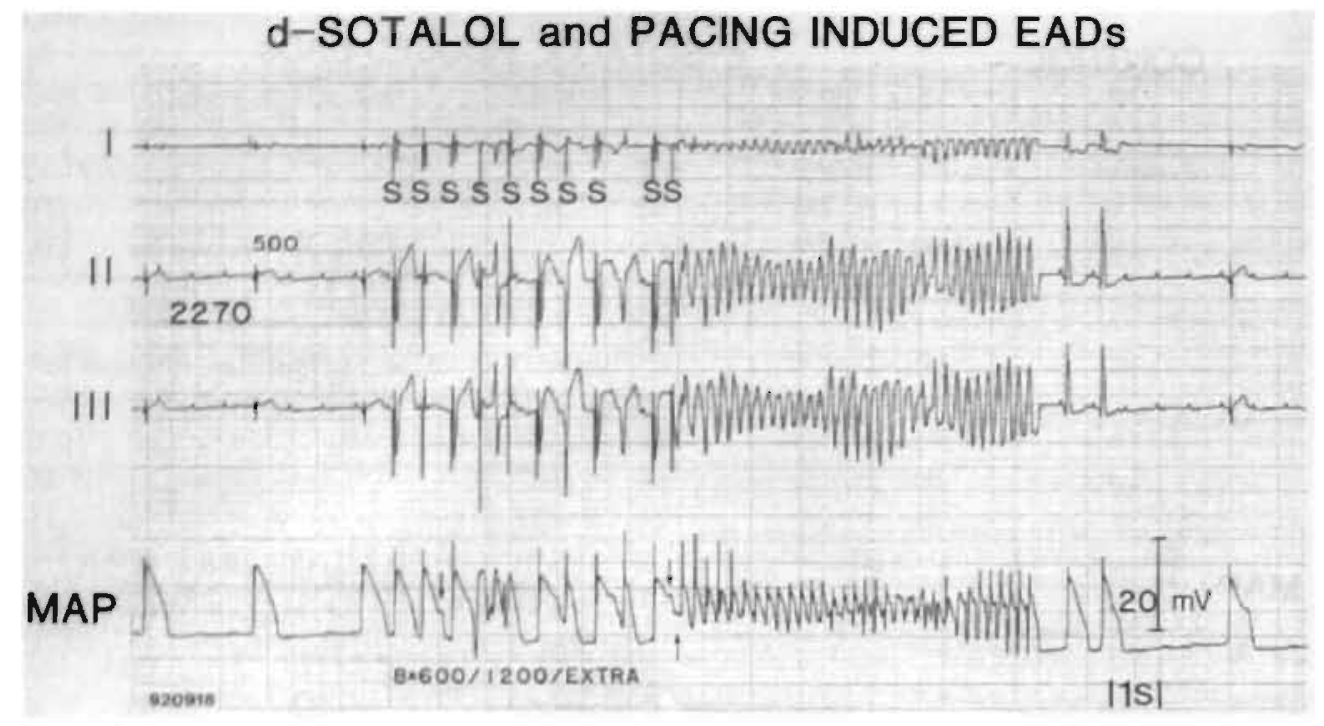

Figure 5. Registration of EADs on MAP recordings during "pacing dependent" TdP in the presence of d-sotalol.

In the same experiment as in figure 4, a pacing protocol which consisted of $8 \times 600 / 1200 /$ extra was performed. Paced beats are indicated by S. Ectopic beats interfered with the paced complexes. Resulting in a self terminating TdP. When we look at the MAP signal, again we see subthreshold phase 2 EADs (second "paced" beat) and triggering phase 3 EADs (last part of the pacing train) that are responsible for the initiation of ectopic beats and eventually TdP. This inducrion of TdP was classified to have started after rwo cycle length changes.

Table 2. The relevance of the pacing mode for the inducibility of TdP arrhythmias in a subgroup of inducible animals

\begin{tabular}{lccccc}
\hline & incidence & lst change & 2nd change & 3rd change & total \\
\hline SLS & $90 \% "$ & 9 & 7 & 9 & 25 \\
$8+1$ & $100 \%{ }^{\circ}$ & 6 & 11 & - & 17 \\
NVS $=3$ & $63 \%^{*}$ & 10 & - & - & 10 \\
CP & $20 \%$ & 3 & - & - & 3 \\
total $(\%)$ & & $50 \%$ & $30 \%$ & $20 \%$ & 55 \\
\hline
\end{tabular}

CP: continuous pacing for 30 seconds, $8+1: 8$ stimuli + 1 extra, NVS=3: three stimuli, SLS: short long: short. "p<0.05 vs CP: "p<0.05 vs NVS=3 and CP 


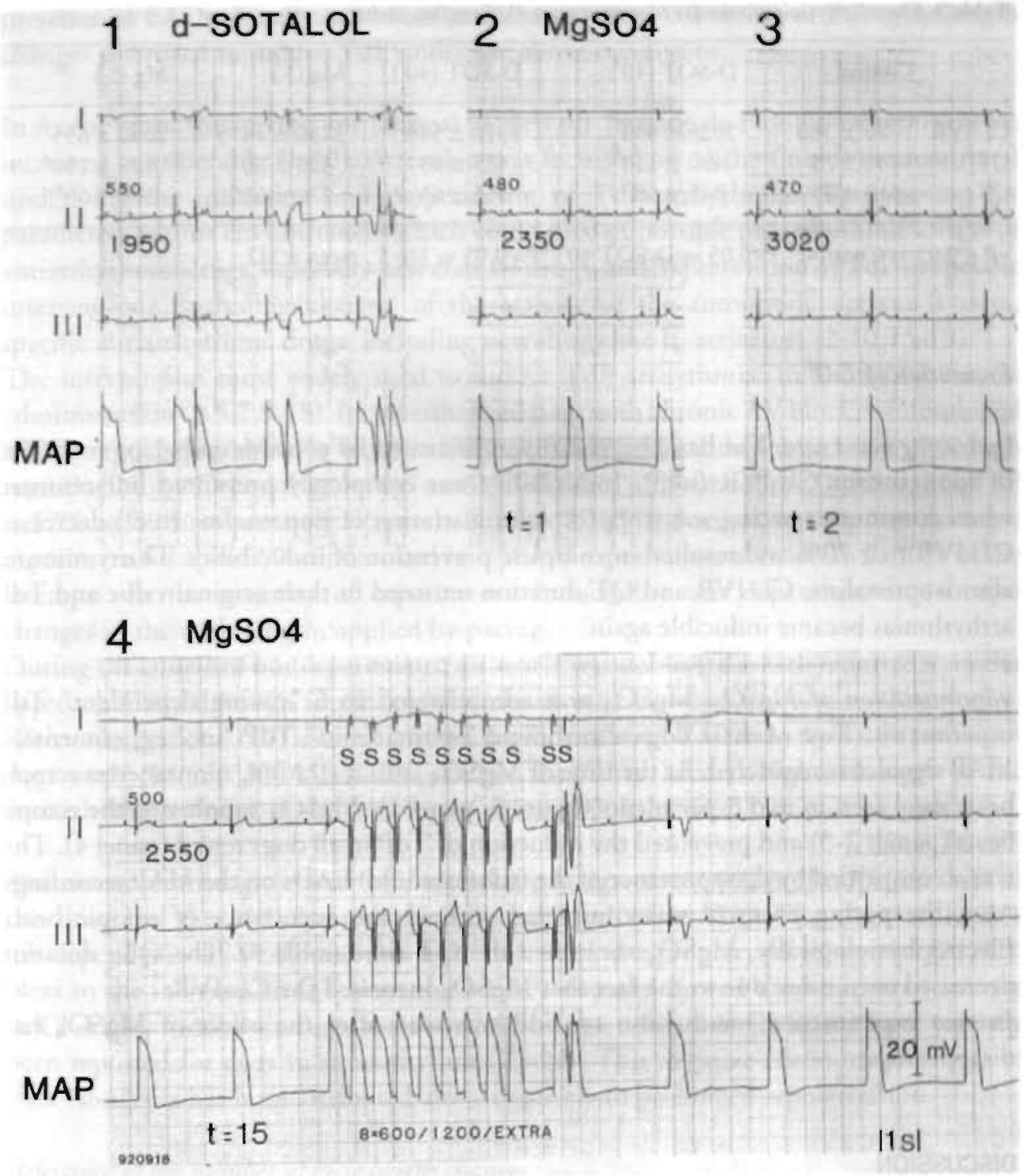

Figure 6. Administration of $\mathrm{MgSO}_{4}$.

This is the same experiment as in figures 4-5. At the time of $\mathrm{MgSO}_{4}$ administration, ectopic beats are still present (panel, 1). Also, subthreshold and triggered EADs can be seen on the MAP registration. Following $\mathrm{MgSO}_{4}$, the QT duration shortens to $470 \mathrm{~ms}$, while the cycle length increases. The ectopic beats completely disappear and the repolarization phase of the action potential becomes smooth (panels 2-3). Pacing is no longer able to induce ectopic beats, EADs, or a TdP arrhythmia (panel 4). Note the repolarization abnormality (negative $\mathrm{T}$ wave) in the first spontaneous beat postpacing. 
Table 3. Electrophysiologic results of magnesium ( $100 \mathrm{mg} / \mathrm{kg}$ * $\mathrm{n}=6)$ )

\begin{tabular}{lccccc}
\hline \multicolumn{1}{c}{ Control } & D-SOT $\left(10^{*}\right)$ & D-SOT $\left(40^{\prime}\right)$ & $\mathrm{Mg}\left(3^{\prime}\right)$ & $\mathrm{Mg}\left(5^{\prime}\right)$ \\
\hline CL-IVR & $1710 \pm 390$ & $2025 \pm 490^{\circ}$ & $1910 \pm 540$ & $2730 \pm 1475$ & $2030 \pm 655$ \\
QT(U) & $405 \pm 75$ & $490 \pm 110^{\circ}$ & $485 \pm 95$ & $420 \pm 80^{*}$ & $435 \pm 110^{*}$ \\
QTc & $310 \pm 35$ & $345 \pm 60^{\circ}$ & $355 \pm 65$ & $270 \pm 65^{*}$ & $300 \pm 60^{* *}$ \\
\hline
\end{tabular}

P $\mathrm{P}<0.05$ vs Control; " $\mathrm{P}<0.05$ vs D-SOT 40 ; " $\mathrm{P}<0.05$ vs Mg 3', mean $\pm \mathrm{SD}$

\section{Prevention of TdP}

increasing heart rate: The basic heart rate was increased by continuous pacing to $\pm 65 \%$ of spontaneous CL-IVR ( $\mathrm{n}=3$ ). Inducibility was completely prevented but returned when continuous pacing was stopped. Administration of isoprenaline $(n=2)$ decreased CL-IVR to $\pm 70 \%$ and resulted in complete prevention of inducibility. Thirty minutes after isoprenaline, CL-IVR and QT duration returned to their original value and TdP arrhythmias became inducible again.

administration of $\mathrm{MgSO}_{4}: \mathrm{MgSO}_{4}$ was administered to 6 "pacing dependent" TdP experiments. Two of these dogs also showed "spontaneous" TdP. In 2 experiments, a MAP signal was registered. At the time of $\mathrm{MgSO}_{4}$ administration, spontaneous ectopic beats were seen in two experiments (figure 6, panel 1). $\mathrm{MgSO}_{4}$ suppressed the ectopic beats (panels 2-3) and prevented the induction of TdP in all dogs tested (panel 4). This was accompanied by disappearance of the (subthreshold) EADs on the MAP recordings. Also, the pacing protocol was completed without the occurrence of ectopic beats. Electrophysiologically, $\mathrm{MgSO}_{4}$ shortened the QT time (table 3). The QT duration decreased even more due to the fact that $\mathrm{MgSO}_{4}$ increased the CL-IVR.

In two experiments, reinduction of $\mathrm{TdP}$ was seen after the effect of $\mathrm{MgSO}_{4}$ had. disappeared.

\section{DISCUSSION}

When we summarize the results in this animal model, it becomes obvious that to reproducibly induce TdP arrhythmias, the CL-IVR and the QT time have to be sufficiently long at the start of the experiment. Shortening of the QT duration by either an increase in the heart rate by pacing, administration of isoprenaline or $\mathrm{MgSO}_{4}$ will prevent induction, whereas a second bolus of $d$-sotalol, which further lengthens QT time and CL-IVR, will tend to make the non susceptible animals inducible. Both the "spontaneous" TdP as the "pacing dependent" TdP rely for their induction on the 
presence of EADs. Finally, a sudden rate change often consisting of $\geq 2$ cycle length changes is needed to induce TdP under the above conditions.

In recent years, the interest for (animal models of) Torsade de Pointes-arrhythmias has increased considerably (1-10). Attention was focussed on 1) the (ionic) mechanism(s) underlying the induction and perpetuation of TdP arrhythmias, 2) screening for parameters and/or circumstances which could predict possible proarrhythmic effects of antiarrhythmic drugs, especially new class III drugs, and 3) prevention of TdP by specific interventions, including changes of the activity of the autonomic nervous system. specific antiarrhythmic drugs, including new drugs like $\mathrm{I}_{\mathrm{k}}$-activators (2-10,15-19).

The intervention most widely used to induce TdP arrhythmias in animals is cesium administration $(3,5,7,9,18)$. In anaesthetized dogs with chronic AV block, we developed a TdP model that shows a high incidence of TdP inducibility together with a high reproducibility. Depending on the number of doses of $d$-sotalol the incidence of TdP is $52 \%$ or $89 \%$ respectively. Reproducibility of TdP induction was present during a experiment for about 60 minutes and in repeated experiments over weeks in $90 \%$ of the attempts. In the majority of experiments, inducibility was dependent on (abrupe) changes in the cycle length, applied by pacing.

During the course of our experiments, an article was published which reported a similar approach (10), although important differences exist between the two methodologies. W. ejssenburger et al. (10), studied oponsanenus inducrion. of. TdP arrbythmias in conscions dogs with chronic AV block. To achieve that, they needed higher dosages of the antiarrhythmic drugs, in the presence of either hypokalemia, $\beta$ blockade or both.

The electrophysiologic effects of $d$-sotalol are in agreement with a therapeutic dose of this drug and they do represent clinically achieved values (20). The observed reverse use-dependency of VERP has also been described as a property of $(d)$-sotalol $(21,22)$. Next to the increases in QT time and VERP, $d$-sotalol slowed the heart rate (increase in CL-IVR). Similar findings for $d$-sotalol but also other class III agents have recently been reported for dogs in sinus rhythm (23-24). This negative chronotropic effect of class III-agents has been attributed almost entirely to prolonged repolarization.

\section{Relevance of the number of cycle length changes}

Spontaneous, drug induced TdP arrhythmias often show a specific initiating sequence that is related to the occurrence of spontaneous ectopic beats: short long short intervals which represent 3 abrupt cycle length changes in a short period of time $(1,6,10,15,19)$. Using a similar pacing mode, we tried to imitate this sequence. Because there is controversy in the literature about the specificity of this sequence $(1,25-27)$, we also used orher pacing modes to study their (possible) relevance. Two pacing modes were clearly superior in initiating TdP arrhythmias in our model: SLS and 8+1. Especially, 
the equal incidence of the $8+1$ pacing mode is of interest, because this is worldwide the most often used pacing mode during electrophysiologic studies.

Using the MAP catheter, we saw the occurrence of (triggered) EADs directly after the start of pacing (figure 5) when the rate was relatively fast and the APD relatively short in comparison to the idioventricular rhythm. This observation indicates that (inadequate) adaptation of the duration of the action potential to abrupt changes in cycle length are of importance for the induction of TdP. This has also been suggested by others (28). Support for this line of thinking comes from the results of the two pacing modes with fixed interstimulus intervals but differences in duration (NVS=3 vs CP). The higher inducibility of NVS $=3$ underscores the importance of (an) abrupt frequency change(s) rather than the duration of pacing. Additional confirmation comes from 1) the observation that, in case of CP, TdP always started within the first 10 beats, and 2) that one cycle length change already induced $\mathrm{TdP}$ in half of the experiments. When however a second or a third interval change is added, inducibility is doubled.

The fact that prolonged pacing is often used to prevent induction of spontaneous drug induced $\mathrm{TdP}$ is another argument to stress the importance of the abruptness of the cycle length change.

Interpretation of these data should however be done with some caution. Because we allowed ourselves only a small number of cardioversions per experiment, we could not always study all pacing modes in the same experiment. We tried to correct this by using the other pacing modes in a subsequent experiment of the same animal. Still, we cannot answer questions concerning cycle length dependence (interstimulus interval) and/or possible interference of different pacing modes on inducibility of TdP.

The most effective treatment for clinical acquired $T d P$ are rapid ventricular pacing, isoproterenol or magnesium administration (1). They were all tested and considered effective in preventing $\mathrm{TdP}$ arrhythmias.

\section{EAD dependent TdP}

Several studies have addressed the involvement of triggered activity resulting from EADs in the initiation of $\operatorname{TdP}(2-5,15,18,19)$. And although the contribution of EADs is still not completely resolved, evidence is becoming more convincing that EADs play an important role in the inducrion of acquired TdP. As seen in this study, the presence of EADs seems to be related to as well "spontaneous" as "pacing dependent" TdP. It is however difficult to demonstrate the causal relation between the presence of EADs, triggered beats elicited by EADs, and the actual TdP. The continuous shift in site of origin of EADs and the elicited beats together with the speed of the arrhythmias complicate the MAP registrations. This technique itself has also some technical difficulties, like stability and the possibility of registering artefacts. We relied on some good fortune to be at the site of origin of the EAD (figures 4-6). Still, we are convinced that 
these recordings in a few experiments are representative for the model. We also believe that the experiments with $\mathrm{MgSO}_{4}$ demonstrate that the EADs are no artefacts. Therefore, we think that initiation of TdP is EAD dependent. Whether the same mechanism is also responsible for the perpetuation of the arrhythmia has to be established.

\section{The relevance of this animal model}

A relatively low incidence of "spontaneous" TdP arrhythmias occurring after $d$-sotalol administration was observed in these experiments. We defined TdP as $\geq 5$ beats. More frequently ( $\pm 50 \%$ ), ectopic beats occurred arising from the TU-wave that seem to be dependent on EADs. These beats occurred as singles, doubles or triplets. Reproducible initiation of $\mathrm{TdP}$ arrhythmias required cycle length changes which were induced by pacing. Still, we believe that this "pacing dependent" TdP can be used to study mechanism and treatment of "spontaneous" acquired TdP because 1) in dogs showing "spontaneous" TdP, pacing was also able to induce TdP reproducibly, 2) both forms of TdP seem to be dependent for their initiation on the presence of EADs (figures 4 and 5), 3) "pacing dependent" TdP" showed the same specific ECG characteristics as "spontaneous" TdP and often terminated spontaneously, and 4) both forms of TdP could be suppressed by $\mathrm{MgSO}_{4}$ (figure 6), levcromakalim (17), flunarizine (29) and by increasing the heart rate.

In this model, we have rested the dogs at a relatively long period after application of AV block ( $9 \pm 6$ weeks). The bradycardia related volume overload and subsequent biventricular hypertrophy (personal observations) could be of importance for the inducibility of TdP. Currently, we are documenting these changes over time, both echocardiographically and electrophysiologically and we are testing the relevance of these changes for the inducibility of TdP. The observation by Strauss et al. (21) that application of acute AV block together with a similar dose of $d$-sotalol did not result in TdP arrhythmias, indicates that additional changes have to be present.

At this moment, we are also testing other drugs that prolong action potential duration. Our results indicate that this animal model can be used to compare the proarrhythmic potential of different drugs. Whether this model is suitable to predict the occurrence of $\mathrm{TdP}$ in patients treated with these drugs has to be determined.

In conclusion, this animal model shows a high incidence of reproducible, acquired Torsade de Pointes arrhythmias, that allows study of mechanism and treatment of these triggered tachycardias. 


\section{Acknowledgements}

The technical assistance of Mrs. H.D.M. Leunissen and Mrs. J. van der Zande in performing the experiments and B. van der Steld, MS for the development of the hardand software allowing data collection and analysis is greatly appreciated. Also the authors would like to acknowledge the help of the Bakken Research Institute (Medtronic), Maastricht, The Netherlands in providing the electrodes.

This study was supported by a grant from the Netherlands Heart Foundation (\#91,104).

\section{REFERENCES}

1. Jackman WM, Friday KJ. Anderson JL, Aliot EM, Clark M, Lazzara R. The long QT-syndromes: a critical revicw, new clinical observations and a unifying hypothesis. Prog Cardiovasc Dis 1988; 31: $115-172$

2. El-Sherif N, Zciler RH. Graclius W. Gough WB. Henkin R. QTU prolongation and polymorphic ventricular tachyarrhythmias due to bradycardia dependent early after-depolarizations. Cinc Res 1988; 63: $286-305$.

3. Ben David J, Zipes DP. Differential response to right and left ansae subclaviae stimulation of early afterdepolarizations and ventricular tachycardia induced by cesium in dogs. Circulation 1988: 78: $1241-1250$

4. Patterson E, Szabo B, Scherlag BJ, Lazzara R. Early and delayed afterdepolarizations associated with cesium chloride induced arrhythmias in the dog. / Cardiouasc Pharmacol 1990; 15: 323-331.

5. Hanich RF: Levine JH. Spear JF, Moore EN. Autonomic modulation of ventricular arrhythmia in cesium chloride induced long QT syndrome. Circularion 1988; 77: 1149-1161.

6. Brachmann J, Scherlag B], Rosenshtraukh LV, Lazzara R. Bradycardia-dependent triggered activity: relevance io drug-induced multiform ventricular tachycardia. Circulation 1983; 68: 846-856.

7. Nayebpour M, Solymoss BC, Nattel S. Cardiovascular and metabolic effects of caesium chloride injection in dogs - L imitations as a model for the long QT syndrome. Cardiovase Res 1989: 23: 756-766.

8. Bardy SH, Ungerleider RM. Smith WM. Ideker RE. A mechanism of Torsades de Pointes in a canine model. Circulation 1983:67:52-59

9. Leichter D. Danilo P Jr. Boyden P. Rosen TS. Rosen MR. A canine model of Torsades de Pointes: PACE, 1988; 11:2235-2245.

10. Weissenburger ), Chezalviel F, Davy JM, Lainẹe P, Guhennnec C, Penin E. Engel F, Cynober L, Motte G. Cheymol G. Merhods and limitations of an experimental model of long QT syndrome. J Pharmacol Meth 1991: 26; 23-42.

11. Steiner CH, Kovalik ATHW. A simple technique for production of chronic complete heart block in dogs. / App/ Physiol 1968: 25: 631-632.

12. Steld A v.d., Dassen W. Gorgels APM. Beekman HDM. Wellens HJJ. Flexible multiprocessor system to support electrophysiological investigation in animals. Computers in Cardial 1984; 11:525-528.

13. Franz MR, Chin MC. Sharkey HR, Griffin JC, Scheinmann MM. A new single catheter technique for simultaneous measurement of action potential duration and refractory period in vivo. I Am Coll Cardiol $1990 ; 16: 878-886$.

14. Bazetr HC. An analysis of the rime relations of electrocardiograms. Heart 1920: 7: 353-368. 
15. Carlsson L, Abrahamsson C. Drews L. Duker G. Anti-arthythmic effects of potassium channel openers in rhychm abnormalities related to delayed repolarization. Circularion 1992; 85: 1491-1500.

16. Fish FA, Prahesh C. Roden DM. Suppression of repolarization-related arrhythmias in vitro and in vivo by low dose potassium channd activators. Cinvalation 1990: 82: 1362-1369.

17. Vos MA, Gorgels APM, Lipseci GE, de Groot SHM, Leunissen HDM, Wellens H77. Mechanism specific anti-arrhythmic effects of the polassium channel activator Levcromalialim against repolarization dependent tachycardias J Candiovasc Electrop/ysiol 1994: 5: 731-742.

18. Bardy DS, Inoue H, Kaseda S, Ben-David J. Zipes DP. Magnesium suppression of early afterdepolarizations and ventricular tachyarrhythmias induced by cesium in dogs. Circulation 1988; 77; 1395-1402.

19. Buchanan LV, Kabell G, Brunden MN, Gibson JK. Comparative assessment of ibutilide, d-sotalol, cofilium, E-4031 and UK-68.798 in a rabbit model of pro-arrhythmia. J Cardionase Pharmacol 1993; 220: 540-549.

20. Antonaccio MJ, Gomoll AW. Sotalol. Pharmacological and anti-arrhythmic effects, Candionasc Drug Revieus 1988; 6:239-263.

21. Strauss HC, Bigger JT. Hoffman BE. Electrophysiological and beta receptor blocking effects of MJ 1999 on dog and rabbit cardiac tissuc. Circ Res 1970; 24: 661-671.

22. Hondeghem LM. Snijders DJ. Class III antiarrhythmic agents have a lot of potential but a long way to go. Cinculation 1990; 81: 686-690.

23. Duker G. Almgren O, Carlsson L. Electrophysiologic and hemodynamic effects of H234/09) (almokalant), quinidine and d-sotalol in the anaesthetized dogs. / Candiovase Pharmacol 1992; 20: 458-465.

24. Mortensen E, Yang T, Refsum H. Class III anti-arrhyrhmic action and inotropy: effects of doferilide in acute ischemic heart failure in dogs. / Cardorase Pharmacol 1992; 19; 216-221.

25. Kay GN, Plumb VJ. Arcinicgas JG. Henthorn RW, Waldo AL. Torsade de Pointes: The long-short initiating sequence and other dinical features. / Am Coll Cardiol 1983; 2: 806-817.

26. Evans ER, Curry PVL, Fitchett DH, Krikler DM. Torsade de Pointes initiated by electrical ventricular stimulation. J Electrocardiology 1976; 9: 255-258.

27. Horowitz L. Greenspan AM. Spielman SR, Josephson ME. Torsade de Pointes: Electrophysiologic studies in parients without transient pharmacologic or metabolic abnormalitics. (ircularion 1981; 63: $1120-1128$.

28. Arwell D, Lee JA. A cellular basis for the primary long QT syndromes, Lances 1988: 1:1136-1139.

29. Vos MA, Verduyn SC, Lipesei GE, van der Zande J. Leunissen HDM. Gorgels APM. Induction of acquired bradycardia dependent Torsade de Pointes arrhythmias is prevented by Flunarizine: A comparison with $\mathrm{MgSO}_{4}$ (abstract), Circulation 1992: 86: 1-560. 

Chapter 3

Role of interventricular dispersion of repolarization for the induction of acquired early afterdepolarization dependent Torsade de Pointes arrhythmias: reversal by magnesium

\section{S. Cora Verduyn}

Marc A. Vos

Jolanda van der Zande

Bert J. van de Steld

Hein J.J. Wellens

Article accepted by Circulation.

Abstract presented at the American Heart Association. Congress 1994:

Circulation 1994; 90: 1-412. 


\section{ABSTRACT}

Background: The mechanism of acquired Torsade de Pointes arrhythmias (TdP) is not clear. To study the importance of 1) triggered activity by early afterdepolarizations (EADs) and 2) interventricular dispersion in duration of repolarization ( $\triangle A P D)$ for the initiation of TdP, both parameters were recorded in our recently described animal model of acquired TdP. In half of the anestherized dogs with chronic complete AV block, the combination of $d$-sotalol and pacing leads to reproducible induction of TdP ( $\geq 3$ times TdP using the same pacing mode).

Methods: Eleven inducible (I) and nine non inducible dogs (NI) after $d$-sotalol were compared. From at least two sites, endocardial monophasic action potentials (MAPs) were registered to record EADs and to measure regional differences in action potential duration (APD). The rate dependent behavior of the interventricular $\triangle A P D$ (APD of left minus right ventricle) was studied in seven dogs in which no EADs were visible. $\mathrm{MgSO}_{4}(100 \mathrm{mg} / \mathrm{kg}$ ) was administered to $7 d$-sotalol treated dogs (4 I and $3 \mathrm{NI}$ dogs). Results: In the absence of EADs, we demonstrated that interventricular $\triangle \mathrm{APD}$ is bradycardia dependent (greater at longer paced cycle lengths (PCL)). d-Sotalol prolonged the spontaneous cycle length of the idioventricular rhythm (CL-IVR), QT time and the APD of both ventricles, but did not increase interventricular $\triangle A P D$ when the PCL was kept constant. After $d$-sotalol the I dogs demonstrated a longer CL-IVR: $2115 \pm 320$ vs $1615 \pm 265 \mathrm{~ms}$, $(P<0.05)$, increased QT time ( $540 \pm 80$ vs $450 \pm 70 \mathrm{~ms}$. $\mathrm{P}<0.05)$, a higher incidence of EADs (14/22 MAPs vs 5/18 MAPs, $\mathrm{P}<0.05)$, an equal number of triggered ectopic beats induced by EADs (8/11 vs $4 / 9)$ and an increased interventricular $\triangle A P D(135 \pm 55$ vs $60 \pm 40 \mathrm{~ms}, \mathrm{p}<0.05)$. Interventricular $\triangle A P D$ was always larger than the simultaneously recorded APD differences within one ventricle. Although CL.-IVR increased after $\mathrm{MgSO}_{4}(1885 \pm 320$ to $2400 \pm 755 \mathrm{~ms}, \mathrm{P}<0.05$ ), this drug prevented induction of TdP (4/4) by suppressing EADs, decreasing APD and the interventricular $\triangle A P D$ from $110 \pm 45$ to $55 \pm 60 \mathrm{~ms}(\mathrm{P}<0.05)$.

Conclusions: 1) In the absence of EADs, $\triangle \mathrm{APD}$ demonstrates frequency dependence 2) Increased interventricular $\triangle A P D$ in the presence of local EADs is an important factor in the initiation of TdP and 3) $\mathrm{MgSO}_{4}$ diminishes both interventricular $\triangle \mathrm{APD}$ and presence of EADs.

\section{INTRODUCTION}

Prolongation of QT duration with (antiarrhythmic) drugs has been associated with cardiac arrhythmias, like Torsade de Pointes (1,2). Because repolarization parameters will lengthen when heart rate slows, the incidence of acquired TdP will increase under bradycardic circumstances. In recent years, evidence has accumulated that early afterdepolarizations (EADs) play a decisive role in the genesis of ectopic beats and the $\mathrm{U}$ 
wave changes that often precede the spontaneous occurring TdP (3-8). It has been demonstrated in vitro and in vivo that EADs are bradycardia dependent and originate preferably in cells with prolonged action potential duration (APD) (8-12). No evidence was provided that the EAD dependent triggered activity also led to TdP (13).

In patients with congenital TdP, intraventricular dispersion of APD has been observed $(14,15)$. Also, these studies provided evidence that EADs occurred site specifically, thereby explaining (in part) the observed intraventricular dispersion (14-16). More recently, interventricular dispersion was seen in combination with EADs in a patient with acquired TdP (17).

In our animal model of pacing induced TdP (18), our main objective was to investigate the contribution of two parameters i.e. EADs and interventricular dispersion of APD for the initiation of TdP. For this purpose, we compared inducible vs non inducible experiments after $d$-sotalol and we administered $\mathrm{MgSO}_{4}$ because of its antiarrhythmic effect on TdP (18-21). Our additional goals were to determine the frequency dependence of the interventricular dispersion in the absence of EADs and, secondly to differentiate between inter- and intraventricular dispersion in APD. For the latter goal, multiple (simultaneous) endocardial MAP recordings were made in some dogs.

\section{METHODS}

All experiments were performed according to the principies of the American Physiological Society and approved by the Committee for Experiments on Animals of the University of Limburg, Maastricht, the Netherlands.

\section{General}

The experiments were performed on 20 anestherized adult dogs with chronic AV block ( $5 \pm 3$ weeks) of either sex with a body weight between 18 and $34 \mathrm{~kg}$. Each dog had one epicardial electrode (Bakken Research Center, Medtronic, Maastricht, The Netherlands) implanted at the apex of the left ventricle, when a right sided thoracotomy was performed to produce a complete AV block by injection of formaldehyde $(0.37 \%)$ in the AV groove (18). Between AV block and the experiment a minimum of two weeks elapsed.

Pacing was done with a programmable stimulator capable of pacing synchronously to the QRS complexes. Unipolar stimuli were given using a pulse width of $2 \mathrm{~ms}$ and a stimulus strength of twice the diastolic threshold. As indifferent electrode a needle was placed through the skin. Six surface electrocardiographic leads and $\geq 2$ endocardial MAP signals were simultaneously registered and stored on hard disc. All drugs were administered through a canula in the cephalic vein. 
Anaesthesia was induced by 1) premedication i.m. ( $1 \mathrm{ml} / 5 \mathrm{~kg}: 10 \mathrm{mg}$ oxycodon, $1 \mathrm{mg}$ acepromazine and $0.5 \mathrm{mg}$ atropine $)$ and 2 ) sodium pentobarbital $(20 \mathrm{mg} / \mathrm{kg}$ i.v.). The dogs were artificially ventilated through a cuffed endotracheal tube using a mixture of oxygen, nitrous oxide and halothane (vapor concentration $0.5 \%-1 \%$ ) by a respirator. Ventilation was controlled by continuous reading of the carbon dioxide concentration in the expired air. A thermal mattress was used to maintain adequate body temperature. Proper care was taken after the experiments, including administration of antibiotics ( $1000 \mathrm{mg}$ ampicillin) and analgesics $(0.3 \mathrm{mg}$ i.m. buprenorfine). A temporary pacemaker (with a maximum of 24 hours) was given after the AV block operation and also after the experiments, because the animals are tested repeatedly.

\section{Induction of Torsade de Pointes arrhythmias}

A detailed description of the Torsade de Pointes protocol is described elsewhere (18). In short, anesthetized animals received two defibrillation parches that were artached to both sides of the chest and connected with a defibrillator. Half an hour after the onset of anaesthesia, pacing was done from the epicardial electrode and consisted of two different pacing modes: 1) short long short sequence and 2) 8 basic stimuli followed by an extra stimulus. The interstimulus interval was 400,600 or $1200 \mathrm{~ms}$, the extrastimulus was shortened from $500 \mathrm{~ms}$ with steps of $50 \mathrm{~ms}$ till $300 \mathrm{~ms}$. After completing the pacing protocol, a bolus of $d$-sotalol $(2 \mathrm{mg} / \mathrm{kg} / 5 \mathrm{~min})$ was administered. Pacing was resumed 10 minutes after the start of the bolus. A Torsade de Pointes arrhythmia was defined as a polymorphic ventricular tachycardia consisting of $\geq 5$ beats, which twisted around its baseline in the presence of a prolonged $\mathrm{QT}(\mathrm{U})$ duration. When TdP did not stop spontancously in 10 seconds or when it deteriorated into ventricular fibrillation, cardioversion (60-70 J) was performed.

This animal model of "pacing induced" TdP results in reproducible TdP arrhythmias in half of the animals (18). In 20 consecutive experiments in which stable MAP recordings could be made, we induced TdP in eleven animals (inducible group). Inducibility was defined as the initiation of TdP for at least 3 times using the same pacing mode.

\section{$\mathrm{MgSO}_{4}$ administration}

$\mathrm{MgSO}_{4}(100 \mathrm{mg} / \mathrm{kg} / 2 \mathrm{~min})$ was administered within 45 minutes after $d$-sotalol to $7 / 20$ animals, 4 inducible and 3 non inducible dogs. We have demonstrated that one bolus of $d$-sotalol is capable of reproducible induction of TdP for at least 60 minutes (18). At 5 minutes after the start of the injection of $\mathrm{MgSO}_{4}$, the pacing modes which. led to $\mathrm{TdP}$ induction were repeated. 
Endocardial monophasic action potentials were recorded simultaneously to observe the occurrence of EADs and to measure the (differences in) the duration of the action potential (APD). A quadripolar contact electrode (Franz combination catheter, EPT \# 1650), that provides both pacing and MAP recording (22) capabilities was placed endocardially in the left and in the right ventricle. Placement was based on quality of the signal. Therefore a carotid and/or femoral artery and an external jugular vein were dissected free and the 7 French MAP catheter was introduced under fluoroscopy. After the experiment the carotid artery and the external jugular vein were sewed-up. The MAP signals were amplified with an isolated DC coupled differential amplifier with calibrated gains of 10,20, 50,100, 200 and 500 (custom made, University of Limburg). The offset of the amplifier is variable and can be adjusted to the recorded signal. All amplifiers are provided with a $20 \mathrm{mV}$ calibration pulse. Data acquisition of the MAP signals is achieved by an 8 bits Analog to Digital Converter resulting in a $0.39 \%$ resolution of full scale. The MAP signals are sampled at a rate of $1 \mathrm{kHz}$ per signal. MAP phases were defined according to the definitions used for transmembrane potentials (9). Amplitude was defined between phase 4 and 2 of the signal. Besides a minimal amplitude of $15 \mathrm{mV}$, the MAP had to have a constant configuration and a smooth shape during control circumstances. After placement of the MAP catheter, 5 paced beats were given using the MAP electrode to register the ECG (QRS morphology). This morphology was used to determine the site at which the MAP catheter was placed and also used for correct repositioning, when amplitude decreased and adjustment was necessary. EADs were defined as an interruption of the smooth contour of phase 2 or 3 of the action potential $(4,9)$. The presence of EADs was examined in all MAPs.

\section{Inter- and intraventricular difference in $A P D$}

In all experiments, two MAP catheters were placed randomly to measure the APD in the left and in the right ventricle. After the first 10 minutes of $d$-sotalol, we replaced these catheters to several sites (23) to measure intraventricular differences in APD in seven experiments. To more carefully asses LV intraventricular differences especially in regard to EADs. We placed an additional LV MAP catheter, while the first MAP catheter remained at a stable site in 4 experiments.

\section{Frequency related changes of $A P D$ and interventricular $\triangle A P D$ after d-sotalol}

In 7 experiments a paced ventricular rhythm (on the epicardial electrode) with a paced cycle length (PCL) of 1000 and $500 \mathrm{~ms}$ was used to investigate the rate related changes of the APD and the interventricular $\triangle \mathrm{APD}$. At steady state (>2 minutes pacing) the 
APD was determined as the average of 5 beats. After administration of $d$-sotalol the APD measurements were repeated, and we could include a PCL of $1500 \mathrm{~ms}$.

\section{Data analysis}

All data were analyzed using a custom made computer program with a resolution of 2 $\mathrm{ms}$ and adjustable gain and time scale. Using lead II, electrophysiological measurements of cycle length of the idioventricular rhythm (CL-IVR) and QT(U) time were performed before and after the administration of $d$-sotalol and $\mathrm{MgSO}_{4}$. The $\mathrm{QT}_{\mathrm{c}}$ time was calculated using the formula of Bazett $\left(\mathrm{QT}_{c}=\mathrm{QT} / \mathrm{CL}-\mathrm{IVR}, 24\right)$, to correct for rate differences. The action potential duration was measured after total repolarization $\left(=\mathrm{APD}_{100}\right)$ and was determined for both ventricles at the same time points as the other parameters. Interventricular dispersion was calculated as the difference between the APD of the left and right ventricle ( $\triangle A P D$ ). Each value represents the mean of 5 consecutive beats. Additionally the incidence of spontaneous beats was scored which occurred during the first 10 minutes of $d$-sotalol.

\section{Statistics}

Paired Student's $t$-test was applied to compare data under the different conditions (drugs). To compare differences berween inducible and non inducible dogs an unpaired $t$-test was used. P values $\leq 0.05$ were considered significant. All data are presented as mean \pm standard deviation (SD).

\section{RESULTS}

\section{Electrophysiological effects of $d$-sotalol}

In the twenty dogs tested, $d$-sotalol significantly prolonged QT time from $405 \pm 75$ to $500 \pm 90 \mathrm{~ms}$ and the Cl-IVR from $1585 \pm 335$ to $1890 \pm 385 \mathrm{~ms}$ (both $\mathrm{P}<0.001$ ), while the QRS duration was not affected. All these measurements were performed at the start of $d$-sotalol (control) and at the end of the observation period of 10 minutes. The APD of the LV ( $390 \pm 65$ to $495 \pm 90 \mathrm{~ms}, \mathrm{P}<0.01$ ) prolonged more (both absolutely and relatively) than the RV ( $330 \pm 40$ to $395 \pm 55 \mathrm{~ms}$ ) leading to a larger interventricular $\triangle A P D$ after $d$-sotalol (from $60 \pm 30$ to $100 \pm 65 \mathrm{~ms}, \mathrm{P}<0.01$ ).

Only once we saw EADs under control conditions (1/20, see further). Within the 10 minutes observation period after $d$-sotalol spontaneous ectopic beats occurred in 12/20 dogs. The responsible EADs occurred in 14/20 dogs, and were present more predominantly in the LV $(12 / 20)$ than in the RV $(7 / 20)$. 
Under baseline conditions, the LV APD of these 20 dogs showed a linear relation with QT time $(r=0.81, P<0.01)$ and with CL-IVR $(r=0.8, P<0.01)$.

The APD of both ventricles increased when the PCL was lengthened from 500 to 1000 $\mathrm{ms}$ (figure 1). In addition, a clear frequency dependence was seen for the interventricular $\triangle A P D(P<0.05)$, because the LV APD prolonged more than the RV APD when the $\mathrm{PCL}$ increased. In the absence of EADs, similar observations were obtained after $d$-sotalol. The more pronounced increase of the LV APD at the different PCL resulted again in bradycardic lengthening of the interventricular $\triangle A P D$. However, $d$-sotalol did not increase the interventricular $\triangle \mathrm{APD}$ at these specific paced frequencies (figure 1). In the 7 dogs presented in table 1 ( $4 \mathrm{I}$ and $3 \mathrm{NI}$ ), the APD was measured at several intraventricular sites after $d$-sotalol. The mean interventricular $\triangle A P D$ at randomly chosen sites was $105 \pm 65 \mathrm{~ms}$. The mean intraventricular difference in APD of the left and right ventricle only amounted to maximal $30 \pm 25 \mathrm{~ms}$ and $20 \pm 20 \mathrm{~ms}$ respectively. Furthermore the intraventricular differences did not differ between inducible and non inducible dogs.

Table 1. Inter and intraventricular differences in action potential duration after $d$-sotalol

\begin{tabular}{|c|c|c|c|c|c|c|c|c|c|}
\hline dog & CL-IVR & LV APD & RV APD & $\triangle \mathrm{APD}$ & LV APD* & RV APD* & LV-LV* & RV'-RV* & $\triangle A I D R A N G E$ \\
\hline $1^{\#}$ & 2215 & 425 & 390 & 35 & 435 & 385 & 10 & 5 & $35-50$ \\
\hline 2 & 1335 & 460 & 375 & 85 & 460 & 390 & 0 & 15 & $70-85$ \\
\hline $3^{\pi}$ & 2295 & 590 & 505 & 85 & 640 & 480 & 50 & 25 & $85-160$ \\
\hline $4^{2}$ & 1830 & 540 & 305 & 235 & 485 & 320 & 55 & 15 & $165-235$ \\
\hline $5^{*}$ & 2600 & 590 & 445 & 145 & $555-590$ & 495 & $0-35$ & 50 & $60-145$ \\
\hline 6 & 1350 & 395 & 320 & 75 & $355-425$ & 325 & $30-70$ & 5 & $30-\mathrm{j} 05$ \\
\hline 7 & 1660 & 455 & 385 & 70 & 485 & 385 & 30 & 0 & $70-100$ \\
\hline MEAN & ง 1900 & 495 & 390 & 105 & & & 30 & 20 & 100 \\
\hline $\pm S \mathrm{SD}$ & \pm 490 & \pm 80 & \pm 70 & \pm 65 & & & \pm 25 & \pm 20 & \pm 55 \\
\hline
\end{tabular}

All values are expressed in milliseconds, CL-IVR: cycle length of the idioventricular rhythm, LV APD: action potential duration of the left ventricle, RV APD: action potential duration of the righe ventricle, $\triangle A P D:$ LV APD - RV APD (interventricular difference as found when only 2 MAPs would have been placed). LV APD", RV APD", APD of the left and right ventricle at other sites. LV-LV", RV-RV': range of intraventricular differences found, $\triangle A P D$ RANGE, the range of interventricular differences, " inducible animals. 


\section{Pacing without EADs}

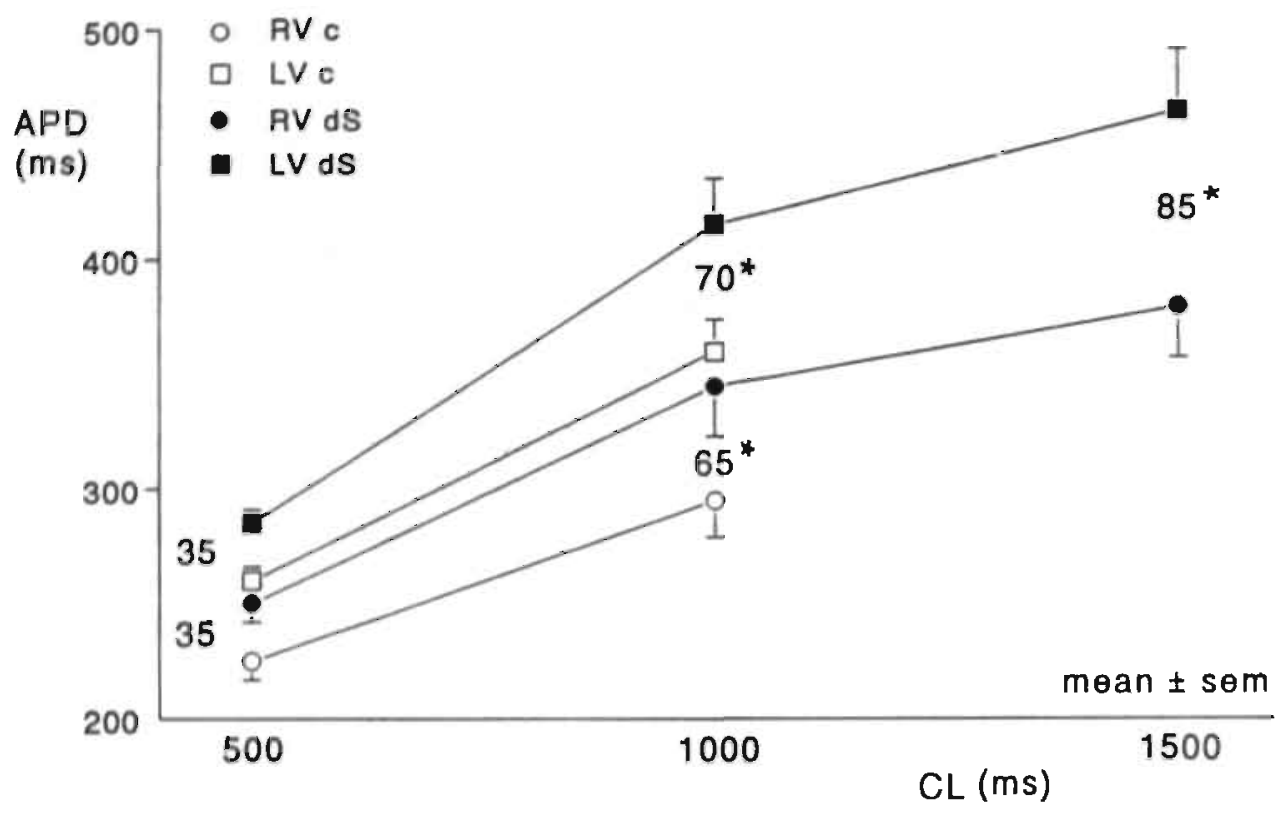

Figure 1. Frequency dependent behavior of action potential duration (APD) and interventricular difference in APD ( $\triangle \mathrm{APD})$ before and after $d$-sotalol.

In this graph the frequency dependent behavior of the APD and the interventricular $\triangle A P D$ is shown. On the $y$ axis the APD is depicted of the left (LV) and the right ventricle (RV). The dogs $(n=7)$ are paced at steady state through the lefi epicardial clectrode. The $\mathrm{x}$ axis represents the paced cycle length (PCL). At $500 \mathrm{~ms}$ the interventricular $\triangle A P D$ amounts $35 \mathrm{~ms}$ during baseline. With an increase in cycle length to $1000 \mathrm{~ms}$ the APD of both ventricles prolong significantly. The LV APD increases relatively more, leading to a significantly higher interventricular $\triangle A P D$ at rhe longer cycle length $(P<0,05)$. $d$-Sotalol (dS) increases the absolute value of both APDs. Interventricular $\triangle A P D$ displays bradycardia dependence although the amount of interventricular $\triangle A P D$ is not increased at a specific PCL in the absence of EADs.

\section{Torsade de Pointes arrhythmias}

When we divided the dogs in two groups (inducible and non inducible), we found that under baseline conditions the electrophysiological values (CL-IVR and QT) of the susceptible dogs were longer than those of the non inducible dogs (reference 18 and table 2). This was also the case for the LV, RV APD and interventricular $\triangle A P D$ (75 \pm 30 vs $40 \pm 30$ ms, $\mathrm{p} \leq 0.01$ ), while the $\mathrm{QT}_{\mathrm{c}}$ was similar.

$d$-Sotalol further enhanced the length of the repolarization, as illustrated in figure 2 . With the exception of interventricular $\triangle A P D$ in the non inducible group, all parameters 
Table 2. Electrophysiological changes after $d$-sotalol $(2 \mathrm{mg} / \mathrm{kg})$

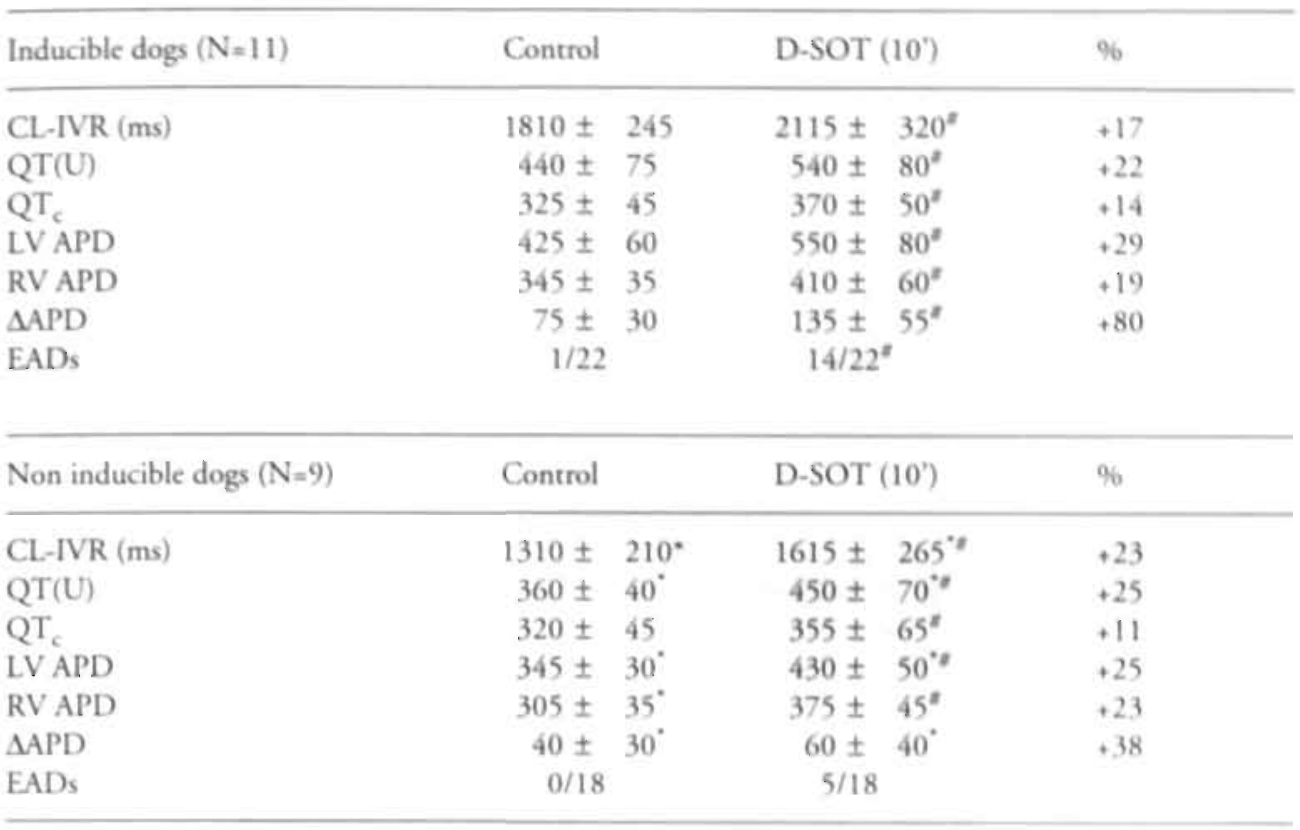

- $\mathrm{P}<0.05$ vs inducible, "P<0.05 vs control, D-SOT (10"): 10 minutes $d$-sotalol, CL.IVR: cycle length idioventricular rhythm, QT ; corrected QT time according to Bazett, LV APD: action potential duration of the left ventricle, RV APD: action potential duration of the right ventricle, $\triangle A P D:$ LV APD - RV APD. EADs: early afterdepolarizations observed on the MAP in both the right and left ventricle i.e. in total $20 * 2=40$ MAP recordings.

demonstrated a significant increase (table 2), resulting in a large difference in interventricular $\triangle A P D(135 \pm 55 \mathrm{~ms}$ vs $60 \pm 40 \mathrm{~ms}, \mathrm{p}<0.01)$ berween the inducible and non inducible group.

The development of EADs after $d$-sotalol was noticed in almost all inducible (10/11, figure 2) as well as in half of the non inducible dogs (4/9). The ectopic beats did not differ in both groups $(8 / 11$ vs $4 / 9)$.

With the exception of one dog (see below) pacing under control conditions did not lead to TdP (figure 2, panel 1). Following $d$-sotalol, induction of TdP occurred often during the pacing train, because pacing exaggerated the occurrence of EADs and spontaneous beats (figure 2, panel 2).

One of the susceptible dogs showed already prominent $U$ waves when the dog was tested consciously prior to the experiment. When anesthetized, this dog possessed EADs and a large interventricular dispersion under baseline conditions (figure 3, panel 1) and pacing led to $\mathrm{TdP}$. After treatment with $\mathrm{MgSO}_{4}$ the ECG normalized and the induction 


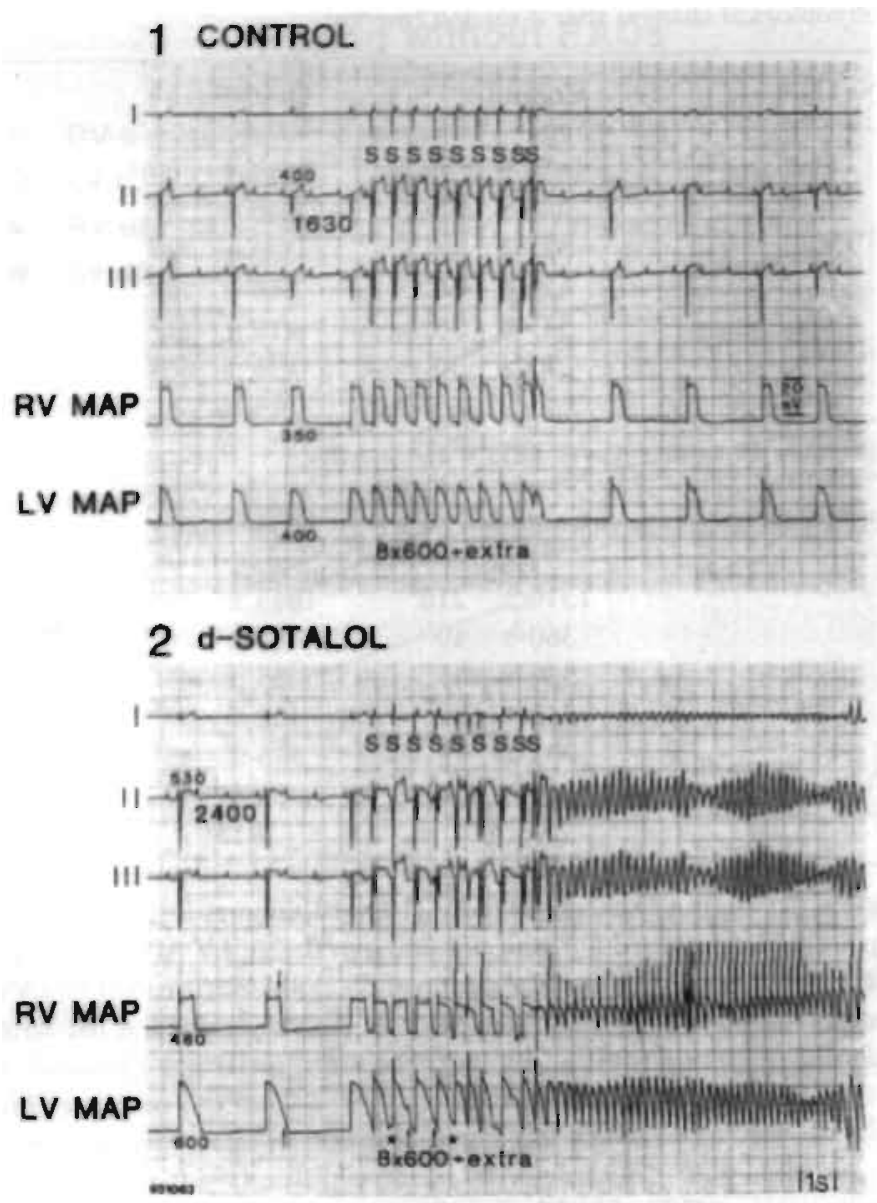

Figure 2. Initiation of a "pacing induced" Torsade de Pointes arrhythmị afiet $d$-sotalot.

A three lead ECG and rwo monophasic action potential (MAP) signals recorded endocardially in the right (RV) and left ventricle (LV) are shown at a paper speed of $10 \mathrm{~mm} / \mathrm{s}$. A pacing train of $8^{*} 600 \mathrm{~ms}$ followed by an extrastimulus during control conditions does not induce any arrhythmic event (panel 1). Stimulation is shown by a S. Interventricular $\triangle A P D$ amounts to $50 \mathrm{~ms}$. In panel 2 , administration of $d$-sotalol leads to an increase in cycle length of the idioventricular rhythm, the QT time, and both the RV MAP ( 350 to $460 \mathrm{~ms}$ ) and the LV MAP ( 400 to $600 \mathrm{~ms}$ ). Because the increase in LV APD is more pronounced, the interventricular AAPD is increased to $140 \mathrm{~ms}$. Note the occurrence of EADs on both MAPs (see arrows). Repetition of the pacing train results in a. TdP. The arrhythmia starts already during the pacing train by beats that are triggered by EADs (marked by an asterisk). Also subthreshold EADs can be clearly seen, especially in LV MAP (arrows). 
1 pre d-SOT

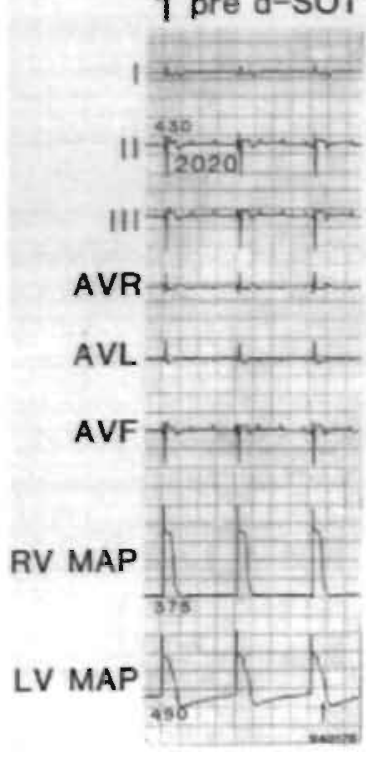

\section{2 d-SOTALOL}

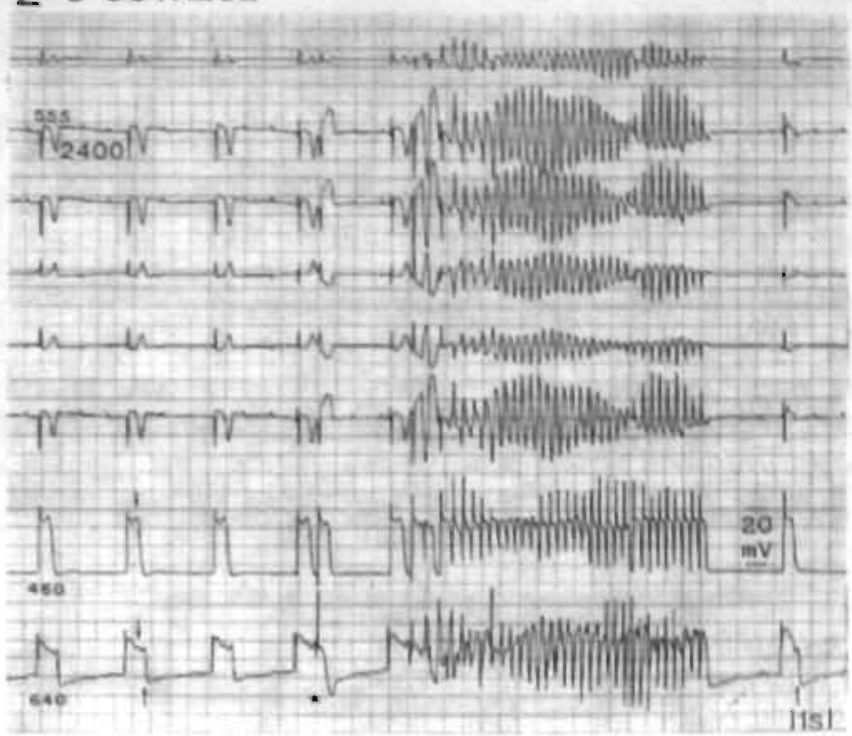

Figure 3. Spontancous TdP after $d$-sotalol.

In this figure a six lead ECG is shown together with MAP recordings in the right (RV MAP) and in the left ventricle (LV MAP) recorded at a paper speed of $10 \mathrm{~mm} / \mathrm{s}$. Already under control conditions this dog had a pronounced interventricular dispersion of APD ( $\triangle A P D$ ) of $115 \mathrm{~ms}$ and EADs can be seen on the LV MAP (arrow, panel I). Administration of $d$-sotalol (panel 2) increases the CL-IVR, QT time, RV APD to $460 \mathrm{~ms}$ and LV APD to $640 \mathrm{~ms}$ resulting in a dispersion of $180 \mathrm{~ms}$. Also negarive T waves develop and. the EADs became more pronounced (see arrows), leading to ectopic beats (asterisk) and spontaneous TdP. This self terminating TdP starts in the classical way of a short long short sequence triggered by the EADs occurring on the LV MAP.

of TdP by pacing was prevented. Thirryfive minutes afrer $\mathrm{MgSO}_{4}, d$-sotalol induced spontaneously triggered beats resulting several times in episodes, of spontaneous $\mathrm{TdP}$ (figure 3, panel 2). For a second rime $\mathrm{MgSO}_{4}$ was administered to this dog, to abolish the effect of $d$-sotalol (figure 4).

\section{Effects of $\mathrm{MgSO}_{4}$}

$\mathrm{MgSO}_{4}$ was administered at $35 \pm 8$ minutes after $d$-sotalol to 7 animals ( 41 and $3 \mathrm{NI}$ ). Because the electrophysiological effects of $d$-sotalol decrease in time (18), the value "d-sotalol 35" " was introduced representing the electrophysiologic measurements at the start of $\mathrm{MgSO}_{4}$ administration. No significant differences were found between $d$-sotalol 10 ' and "d-sotalol 35'". In 6/7 animals EADs (both inducible and non inducible for 

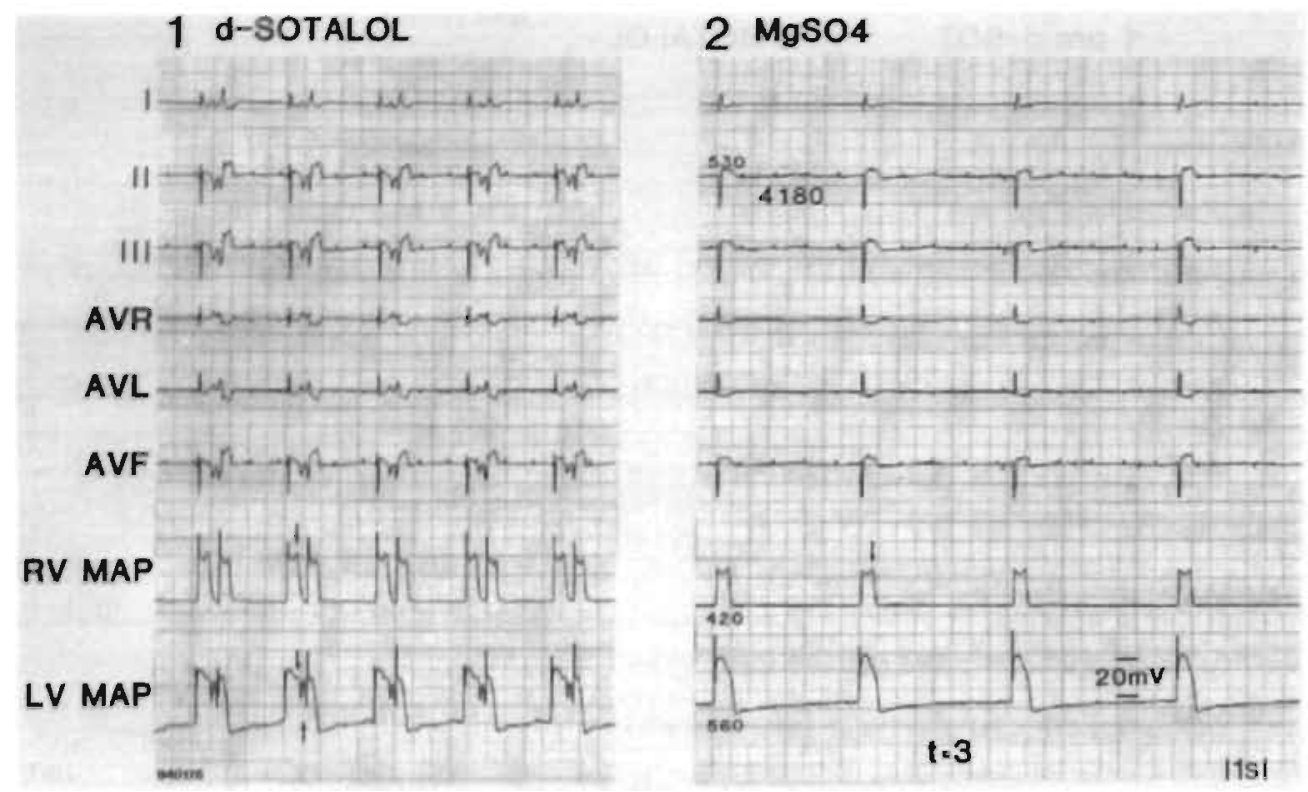

Figure 4. Effect of $\mathrm{MgSO}_{4}$.

Same dog and composition as figure 3. At the start of $\mathrm{MgSO}_{4}$ (20 minutes after $d$-sotalol) a bigemic rhythm exist. The L.V MAP is markedly prolonged compared with the RV APD and has very pronounced EADs, that trigger ectopic beats (panel 1). Three minutes after start of $\mathrm{MgSO}_{4}$ the repolarization process has changed (disappearance of the negative U waves), the ecropic beats are suppressed and the QT time, RV APD and the LV APD markedly shortened resulting in less dispersion. All this takes place while the CI-IVR increases (!) to $4180 \mathrm{~ms}$. The EADs of LV MAP have disappeared completely, while the EADs in RV MAP remained present but appear with less amplitude.

$\mathrm{TdP}$ ) and in $2 / 7$ animals ectopic beats were present at the moment of $\mathrm{MgSO}_{4}$. adminstration. The effect of $\mathrm{MgSO}_{4}$ was most pronounced at 3 minutes after the start of the injection. Although the CL-IVR increased, $\mathrm{MgSO}_{4} 1$ ) diminished QT rime (table 3). 2) suppressed ectopic beats (2/2) (figure 4, panels 1-2), and 3) either suppressed (3/6) or diminished the amplitude of EADs (3/6, eg figure 4, panel 2), and 4) shortened RV and LV APD. Because of the more overt decrease of the LV APD, the interventricular $\triangle \mathrm{APD}(55 \pm 60 \mathrm{~ms}$ ) was significantly decreased to values comparable with baseline ( 60 $\pm 35 \mathrm{~ms}$, table 3). $\mathrm{MgSO}_{4}$ prevented $\mathrm{TdP}$ induction (4/4). The magnitude of the electrophysiological effects of $\mathrm{MgSO}_{4}$ was more pronounced for the CL-IVR, LV APD and RV APD in the inducible dogs, while interventricular $\triangle A P D$ was halved in both groups. 
Table 3. Electrophysiologic effects of $\mathrm{MgSO}_{4}(100 \mathrm{mg} / \mathrm{kg})$ in $7 \mathrm{dogs}$ ( 4 inducible and 3 non inducible)

\begin{tabular}{lccc}
\hline & CONTROL & D-SOT $\left(35^{\prime}\right)$ & $\mathrm{MgSO}_{4}\left(3^{\prime}\right)$ \\
\hline CL-IVR (ms) & $1625 \pm 320$ & $1885 \pm 320^{\circ}$ & $2400 \pm 755^{\circ}$ \\
QT(U) & $410 \pm 50$ & $530 \pm 85^{\circ}$ & $470 \pm 65^{\circ}$ \\
QT & $325 \pm 50$ & $390 \pm 70^{\circ}$ & $310 \pm 60^{\circ}$ \\
LVAPD & $390 \pm 70$ & $510 \pm 100^{\circ}$ & $435 \pm 85^{\circ}$ \\
RV APD & $330 \pm 40$ & $400 \pm 60^{\circ}$ & $380 \pm 40^{\circ}$ \\
DAPD & $60 \pm 35$ & $110 \pm 45^{\circ}$ & $55 \pm 60^{*}$ \\
\hline
\end{tabular}

MEAN $\pm S D ;{ }^{*} \mathrm{P}<0.05$ vs control, ${ }^{\prime} \mathrm{P}<0.05$ vs D-SOT (35'); D-SOT (35'): 35 minutes $d$-sotalol, $\mathrm{MgSO}_{4}$ (3'): 3 minutes $\mathrm{MgSO}_{4}, \mathrm{CL}-\mathrm{IVR}$ : cycle length idioventricular thythm, QT corrected QT time, LV APD: action potential duration of the left ventricle, RV APD: action potential duration of the right ventricle, $\triangle A P D$; interventricular dispersion of APD calculated as LV APD - RV APD.

\section{DISCUSSION}

In our opinion, this study presents new information regarding the relevance of interventricular $\triangle A P D$ for the initiation of acquired $T d P$ arrhythmias in our animal model. Although this has been suggested by others $(13.17)$ we have made the following important observations: 1) In the absence of EADs, interventricular $\triangle A P D$ demonstrates bradycardia dependence: there is an increase in interventricular $\triangle A P D$ when the heart rate slows; 2) After $d$-sotalol, interventricular $\triangle A P D$ is increased because of slowing of the IVR and site specific occurrence of EADs; 3) endocardially measured interventricular $\triangle A P D$ is always greater than intraventricular differences in APD; 4) Both the presence of EADs and interventricular $\triangle A P D$ are greater in the inducible dogs, while the incidence of ectopic beats does not differ; and 5) suppression or prevention of TdP by $\mathrm{MgSO}_{4}$ is related to disappearance of EADs and diminishment of interventricular $\triangle \mathrm{APD}$.

Interventricular dispersion in APD

Since the description of TdP arrbythmias more than 25 years ago (25), several mechanisms have been proposed to explain irs occurrence, like EAD dependent triggered activity (ectopic bears) and reentry based on dispersion. In the intact heart, both parameters can be measured by the use of MAP catherers, which provide information on regional repolarization $(22,26)$. In patient studies, both intra- and interventricular differences in APD have been indicated to be reiated to TdP (14-17). When EADs originate at specific sites, APD will prolong regionally and by definition dispersion will increase. Recent studies have also indicated an increased dispersion of repolarization in acquired TdP by measuring QT intervals in multiple ECG leads (27-29). 
Rate dependent behavior of repolarization parameters and EADs is widely acknowledged (see e.g. 1,4,9,10). Data concerning the frequency dependence of APD dispersion are scarce. Still, there is some evidence that differences in APD are smaller at faster rates $(30,31)$. In the present study $\geq 2 \mathrm{MAPs}$ were recorded simultaneously. For the first time, we present evidence that the sensitivity of the APD to prolong when the heart frequency decreases is different for the LV than the RV, resulting in an increase in interventricular $\triangle A P D$ (bradycardia dependence). These observations are obtained in the absence of EADs on the registered MAPs so that the increase cannot be explained by the contribution of EADs to interventricular $\triangle A P D$. Similar information can be obtained from table 2 , but now in the presence of EADs. Comparing the different cycle lengths in the groups with and without $d$-sotalol, a clear lengthening of the interventricular $\triangle A P D$ is seen as the CL-IVR between groups increases. To what extent EADs exactly contribute to this interventricular $\triangle \mathrm{APD}$ is not known, but a contribution will exist when EADs are induced at selected sites as is the case with $d$-sotalol for the LV.

A possible explanation for the higher sensitivity of the LV to prolong after a frequency change might be the presence of M cells (32). The canine myocardium is said to exist of circa $40 \%$ of M cells. Under baseline conditions the M cells of the LV show more prolongation at slower cycle lengths than the RV M cells, leading to an interventricular $\triangle A P D$ of approximately $100 \mathrm{msec}$ at $2000 \mathrm{msec}$ (figure 4 of reference 12). Regional development of EADs by class III drugs will attribute to the dispersion and it is known that $M$ cells are also more sensitive than endo- and epicardial cells to develop EADs after drugs such as quinidine, $d l$-sotalol, and Bay K 8644 (12).

Although $d$-sotalol will not increase interventricular $\triangle A P D$ at steady state $\mathrm{CL}$ in the absence of EADs (figure 1), administration of the drug will influence interventricular $\triangle A P D$ in several ways: 1) increase in CL-IVR, and 2) occurrence of (sire-specific) EADs. A second indication that EADs and interventricular $\triangle A P D$ are two independent phenomena is indicated by the effects of $\mathrm{MgSO}_{4}$. The induced increase in CL-IVR would normally be associated with an increase in APD and interventricular $\triangle A P D$. When extrapolation of the APD to a CL of $2400 \mathrm{~ms}$ is allowed (using table 2, baseline values, no EADs), the calculated LV APD would be approximately $510 \mathrm{~ms}$, while the $\mathrm{RV}$ has a length around $380 \mathrm{~ms}$. The mean values that were observed after $\mathrm{MgSO}_{4}$ are however much less: LV APD of $435 \mathrm{~ms}$ and RV APD of $380 \mathrm{~ms}$, resulting in a interventricular $\triangle A P D$ of $55 \mathrm{~ms}$ similar to baseline (table 3). The shorter LV APD is partially caused by the disappearance of the EAD but to a larger extent to homogenization of repolarization by a more pronounced shortening of the LV APD.

Whether the pronounced interventricular $\triangle A P D$ is related to the presence of chronic complete AV block seems indicated by rhe results of a recent study (33).

To determine the exact coneribution of EADs to interventricular $\triangle A P D$ further studies need to be performed. 
Based on our data, we cannot assess the exact contribution of EADs for interventricular $\triangle A P D$. But we do believe that we provide evidence that both EADs and interventricular $\triangle A P D$, as suggested by others $(1,13,17)$, have to be present in a certain magnitude to induce TdP. Inducible dogs have a higher incidence of EADs, a similar incidence of ectopic beats as non inducible dogs but possess a more pronounced interventricular $\triangle A P D$. Because EADs and ectopic beats are also present in the non inducible group, their appearance alone seems not sufficient to induce TdP. The fact that the presence of ectopic beats does not lead to spontaneous TdP nor seems related to pacing induced $\mathrm{TdP}$ could be explained by 1) the differences in coupling interval, 2) the number of beats in the pacing train, 3) to the lack of interventricular $\triangle \mathrm{APD}$, or 4) combination of these factors.

Secondly, prevention of $\mathrm{TdP}$ by $\mathrm{MgSO}_{4}$ is achieved through a more pronounced reduction of repolarization leading to less interventricular $\triangle A P D$. Similar data that we obtained in a different study confirm this observation: in the same dog the higher occurrence of (spontaneous) TdP after almokalant was associated with more EADs and a higher interventricular $\triangle A P D$ compared with $d$-sotalol (34).

This study again emphasizes the role for bradycardia in the genesis of TdP. EADs. APD and interventricular $\triangle \mathrm{APD}$ all show bradycardia dependence. Acceleration of the rate either by isoprenaline or ventricular pacing prevents the occurrence of TdP (18). And a further slowing of the rate by a second bolus of $d$-sotalol in the non inducible dogs, increases inducibility to $70-80 \%$ (18).

\section{Intraventricular differences in APD}

Next to interventricular $\triangle A P D$, intraventricular differences in APD could also contribute to dispersion of repolarization. Although only in part of the dogs the APD was measured at multiple sites in the same ventricle, these data show that in our animals (table 1) the observed intraventricular differences are much less than interventricular $\triangle A P D$. So it seems that the ventricles themselves behave more uniformly, although potentially large intraventricular differences can never be excluded, because of the regional information provided by the MAP catheter which was placed randomly.

\section{Possible consequences of dispersion for the mechanism of TdP}

A non uniform repolarization of the heart (dispersion) has already for a long time been acknowledged as a substrate for lethal ventricular arrhythmias (35). Differences in repolarization will favor reentry which could perperuate the ectopic impulse formation after the first triggered beat $(s)$ and so initiate TdP. One of the possibilities is spiral wave reentry which causes polymorphic patterns in epicardial sheets. The spiral wave reentry 
is due to a gradient in dispersion or conduction velocity (36). Another possibility is intramural reentry caused by transmural dispersion due to the M cells (12).

However a role of reentry in the mechanism of continuation of TdP has never been proven. Recent research using three dimensional mapping suggested the presence of different foci $(37,38)$, originating from the endocardium as the perpetuation substrate of the arrhythmia. The present study is not able to discriminate between triggered activity or reentry for the mechanism of continuation of TdP.

\section{Limitations}

Our data point to the involvement of interventricular $\triangle A P D$ and EADs in the initiation of TdP. However neither the presence of EADs nor an absolute amount of interventricular $\triangle \mathrm{APD}$ can predict the occurrence of $\mathrm{TdP}$, because a small overlap in the values of the interventricular $\triangle \mathrm{APD}$ between inducible and non inducible dogs is present.

It may be important to note that all rate dependent effects of the differences in APD are reported during steady state paced cycle lengths or during a relatively stable CL-IVR $(30,31)$. A sudden rate change after $d$-sotalol i.e. by programmed electrical stimulation or by triggered beats may increase interventricular $\triangle \mathrm{APD}$, due to a (temporal) accentuation in EADs (see e.g. figure 2). This can provide the trigger for the initiation of TdP, either due to the triggering of the accentuated EADs or due to the prolonged interventricular $\triangle \mathrm{APD}$. The dynamic behavior of EADs and interventricular $\triangle \mathrm{APD}$ in relation to frequency needs therefore further investigation.

During spontaneous IVR the activation rimes will differ depending on the origin of the focus. This may influence differences in APD when we consider a relation between the time of acrivation and AP duration (39,40). There are numerical places for impulse formarion in our dogs. Therefore, we do not believe that specific activation site will markedly influence dispersion in APD.

\section{Conclusions}

Like EADs, interventricular $\triangle A P D$ independently demonstrates frequency dependence during steady state rhythms. An increased interventricular $\triangle A P D$ with or without the contribution of local EADs is an important factor in the initiation of TdP.

\section{Acknowledgements}

We thank the Bakken Research Institute (Medtronic) Maastricht, the Netherlands for providing the epicardial electrodes. This study was supported by a grant from the Netherlands Heart Foundation (\#91:104), 


\section{REFERENCES}

1. Jackman WM, Friday KJ, Anderson, JL, Alior EM, Clark M, Lazzara R. The Long QT syndromes: a critical review, new clinical observations and a unifying hypothesis. Prog Candiovvesc Dis 1988; 31: $115-172$.

2. Nguyen TP, Scheinman MM, Seger J. Polymorphous ventricular tachycardia: dinical characterization, therapy and QT interval. Circularion 1986; 74: 340-349.

3. El-Sherif N, Zeiler. RH, Craelius W, Gough WB, Henkin R. QTU prolongation and polymorphic ventricular tachyarthythmias due to bradycardia dependent afterdepolarizations. Afterdepolarizations and ventricular arrhythmias. Circ Res 1988; 63: 286-305.

4. Levine JH, Spear JF, Guarnieri T, Weisfeldr. ML, de Langen CDJ, Becker LC, Moore EN. Cesium chloride-induced long QT syndrome: Demonstration of after-depolarizations and triggered activity in vivo. Circulation 1985; 72: 1092-1103.

5. Patterson E, Szabo B. Scherlag BJ, Lazzara R. Early afterdepolarizations associated with cesium chloride-induced arrhythmias in the dog. / Cardiovasc Res 1990; 15: 323-3.

6. Ben-David J, DP Zipes, GM Ayers, Pride HP. Canine left ventricular hypertrophy predisposes to ventricular tachycardia induction by phase 2 early afterdepolarizations after administration of Bay K 8644. J Am Coll Cardiol 1992; 20: 1576-1584.

7. Davidenko JM, Cohen L, Goodrow R, Antzelevitch. C. Quinidine induced action potential prolongation, early after depolarizations and triggered activity in canine purkinje fibers: effects of stimulation rate, potassium and magnesium. Circulation 1989; 79; 674-686.

8. Roden DM, KA Thompson, BF Hoffman. RL Woosley. Clinical features and basic mechanisms of quinidine induced arrhythmias. $/ \mathrm{Am}$ Coll Cardiol 1986;8; 73A-78 A.

9. Damiano BP. MR Rosen. Effects of pacing on triggered acrivity induced by carly afterdepolarizations. Circulation 1984; 69: 1013-1025.

10. Hanich RF, Levine JH, Spear JF, Moore EN. Autonomic modulation of ventricular arrhythmia in cesium chloride induced long QT syndrome. Circulation 1988; 77: 1149-1161.

11. Li Z-Y, C Maldonado, C Zee-Cheng. S. Hiromasa, I Kupersmith. Purkinje fibre-papillary muscle interaction in the genesis of triggered activity in a guinea pig model. Cardiovasc Res 1992:26: 543-548.

12. Antzelevitch C, Sicouri S. Clinical relevance of cardiac arrhythmias generated by afterdepolarizations. Role of $\mathrm{M}$ cells in the generation of $\mathrm{U}$ waves, triggered activity and Torsade de Pointes. / Am Coll Cardiol 1994; 23: 259-277.

13. Surawicz B. Electrophysiological substrate of Torsade de Pointes: Dispersion of repolarization or early afterdepolarizations. J Am Coll Cardiol 1989; 14: 172-182.

14. Bonatti V, Rolli A, Botti G. Monophasic action potential studies in human subjects with prolonged ventricular repolarization and long QT syndromes. Eur Heart ] 1985; 6: 131-143 (suppl).

15. Gavrilescu S, Luca C. Right ventricular monophasic actionpotentials in patients with long QT syndrome. Br Heart J 1978; 40: 1014-1018.

16. Shimizu W, Ohe T, Kurita T, Takaki H, Aihara N, Kmakurka S, Matsuhisa M, Shimomura K. Early afterdepolarizations induced by isoproterenol in patients with congenital long QT syndrome. Circularion 1991: 84: 1915-1923.

17. Habbab MA, EI-Sherif N. Drug induced Torsade de pointes: Role of early afterdepolarizations and dispersion of repolarization. Am / Medicine 1990; 89: 241-246.

18. Vos MA, Verduyn SC. Gorgels APM, Lipscei GC, Wellens HJJ. Reproducible induction of early afterdepolarizations and torsade de pointes arrhythmias by $\mathrm{d}$-sotalol and pacing in the dog with chronic atrioventricular block. Circulation 1995; 91: 864-872.

19. Banai S, Tzivoni D. Drug therapy for Torsade de Pointes. J Cardiovasc Electrophysiol 1993; 4: 206-210. 
20. Bailie DS, Inoue H, Kaseda S, Ben David J, Zipes DP. Magnesium suppression of early afterdepolarizations and ventricular tachyarrhythmias induced by cesium in dogs. Circulation 1988; 77: 1395-1402.

21. Carlsson L. Almgren O. Duker G. QTU-prolongation and Torsades de Pointes induced by putative class III antiarrhythmic agents in the rabbit: Etiology and interventions. J Cardiovasc Pharmacol 1990; 16: $276-285$.

22. Franz MR. Method and theory of monophasic action potential recording. Progress Cardiovase Dis 1991; 33: $347-368$.

23. Josephson ME, Waxman HL, Marchlinski FE, Buxton AE, Doherty JU, Kienzle MG. Electrocardiographic fearures of ectopic impulse formation specificity of ventricular activation patterns. In Tachycardias: mechanisms diagnosis treatment. ed Josephson ME, Wellens HJJ. 1984 Lea and Febiger, USA p363-386.

24. Bazetr HC. An analysis of the time relations of electrocardiograms. Hearr 1920; 7: 353-368.

25. Desertenne F. La Tachycardie ventriculaire a deux foyers opposes variables. Arch Mal Couer 1966:59: 263-272.

26. Olsson SB. Monophasic action potentials from right, atrial muscle recorded during heart catheterization. Acta Med Scand 1971; 190:369-379.

27. Hii JTY, Wyse DG, Gillis AM, Duff HJ, Solylo MA, Mitchell LB. Precordial QT time interval dispersion as a marker of torsade de pointes: disparate effects of class $1 \mathrm{~A}$ antiarrhythmic drugs and amiodarone. Circularion 1992; 86: 1376-1382.

28. Hohnloser SH, Loo van de A, Kalusche D, Arendes W, Quart B. Does Sotalol induced alteration of QT dispersion predict drug effectiveness or proarrhythmic hazard. Circulation 1993; 88: 1-213 (abstract).

29. Carlsson L, Abrahamsson C. Andersson B, Düker G, Schiller-Linhardt G. Proarrhythmic effects of the class III agent almokalant: importance of infusion rate, QT dispersion, and early afterdepolarizations. Cardionass Res 1993: 27:2186-2193.

30. Kuo CS, Munakata K, Reddy P. Surawicz B. Characteristics and possible mechanism of ventricular arrhythmia dependent on the dispersion of action potentials. Circulation 1983:67:1356-1367.

31. Morgan IM. Cunningham D. Rowland E. Dispersion of monophasic action potential duration: demonstrable in humans after premature ventricular extra stimulation but not in steady state. $\int \mathrm{Am}$ Coll Cardiol 1992; 19: 1244-1253.

32. Sicouri S, Antzelevitch C. A subpopulation of cells with unique electrophysiological properties in the deep subepicardium of the canine ventricle. The M cell. Circ Res 1991; 68: 1729-1741.

33. Verduyn SC, Vos MA, J van der Zande, SHMA de Groot, MA Allessie, HJj Wellens. Biventricular hypertrophy facilitates occurience of acquired Torsade de Pointes arrhythmias in dogs. Circulation 1995: 92: 1-504 (abstract).

34. Verduyn SC, Vos MA, Zande van der J, Wellens HJJ. Further observations to confirm the importance of dispersion of repolarization and early afterdepolarizations in the genesis of acquired Torsade de Pointes arrhythmias. A comparison between almokalant and $d$-sotalol using the dog as its own control. Accepted for publication in $/ \mathrm{Am}$ Coll Cardiol

35. Han J, Moe GK. Non uniform recovery of excitability in ventricular muscle. Circ Res 1964: 14: 44-60.

36. Davidenko JM. Pertsov AM, Baxter WT, Cabo C, Jalife J. Gradients in action potential duration and conduction velocity underlic polymorphic tachycardia in isolated cardiac tissue. PACE 1994; 17: 762 (abstract).

37. Stern LD, Schoels W, Senges JC, Freigang KD, Bauer A, Kuebler W, Brachmann J. Activation patterns of canine cesium chloride induced ventricular arrhythmias determined by three dimensional mapping. PACE 1994: 17: 762 (abstract).

38. Katsuki T. Usuda K. Sagakami S, Nakamura Y, Takata S, Kobayashi K. Mechanisms of initiation and maintenance of Torsades de Pointes. PACE 1994: 17: 763 (abstract). 
39. Franz MR, Bargheer K, Rafflenbeul W, Haverich A, Lichten PR. Monophasic action potential mapping in human subjects with normal electrocardiograms: direct evidence for the genesis of the T wave. Circulation 1987; 75: 379-386.

40. Kuo CS, Amlie JP, Munakata K, Reddy CP, Surawicz B. Dispersion of monophasic action potential duration and activation times during atrial pacing, ventricular pacing, and ventricular premature stimulation in canine ventricles. Cardionase Res 1983; 17: 152-161. 

Chapter 4

Further observations to confirm the importance of interventricular dispersion of repolarization and early afterdepolarizations in the genesis of acquired Torsade de Pointes arrhythmias: a comparison between almokalant and $d$-sotalol using the dog as its own control

\section{S. Cora Verduyn}

Marc A. Vos

Jolanda van der Zande

Joep L.R.M. Smeets

Hein J.J. Wellens

Article accepted by J Am Coll Cardiol

Abstract presented at the American College of Cardiology 1995

J Am Coll Cardiol 1995;170A 


\section{ABSTRACT}

Objectives: Further investigation of the initiating mechanism of acquired Torsade de Pointes (TdP) arrhythmias.

Background: Administration of class III agents can be associated with TdP. We have developed a dog model in which after $d$-sotalol TdP can be reproducibly induced by pacing. This model shows reproducible results over weeks.

Methods: In 14 anesthetized dogs with chronic complete AV block, two separate experiments were performed in which $d$-sotalol $(2 \mathrm{mg} / \mathrm{kg})$ or almokalant $(0.12 \mathrm{mg} / \mathrm{kg})$ were administered. Monophasic action potentials were simultaneously recorded from the endocardium of the right and the left ventricle to register early afterdepolarizations (EADs) and to measure the action potential duration (APD). Interventricular dispersion of repolarization ( $\triangle \mathrm{APD}$ ) was defined as the APD of the left ventricle (LV) minus that of the right ventricle (RV). Results: Baseline conditions were identical in the serial performed experiments (cycle length of the idioventricular rhythm (CL-IVR); $1645 \pm$ $325 \mathrm{~ms}$, QT time: $400 \pm 55 \mathrm{~ms}$, LV APD: $375 \pm 45 \mathrm{~ms}$, RV APD: $330 \pm 35 \mathrm{~ms}$, and interventricular $\triangle \mathrm{APD}: 45 \pm 25 \mathrm{~ms}$ (mean $\pm \mathrm{SD}$ ). The CL-IVR and QT time increased with $16 \%$ and $26 \%$ after $d$-sotalol and with $15 \%$ and $31 \%$ after almokalant. Similar to EADs ( $18 / 22$ vs 1 I/24, $P<0.05$ ), single or multiple ectopic beats were more frequently observed after almokalant than after $d$-sotalol. After both drugs the LV APD prolonged more than that of the right ventricle, thereby increasing interventricular $\triangle A P D$. This was more pronounced after almokalant $(110 \pm 60 \mathrm{~ms})$ than for $d$-sotalol $(80 \pm 45 \mathrm{~ms}$, $P<0.05)$. Spontancous $T d P$ was observed in $10 / 14$ dogs after almokalant, and the incidence could be increased to $12 / 14$ after programmed electrical stimulation (PES). After $d$-sotalol, TdP could only be induced by PES $(5 / 14, \mathrm{P}<0.05)$.

Conclusions: In the same dog, almokalant induced more delay in repolarization, more EADs, and more ventricular inhomogeneity in APD than $d$-sotalol. These changes were related to a higher incidence of TdP, and thereby confirm the importance of EADs and interventricular $\triangle \mathrm{APD}$ in the genesis of TdP. The findings also show the possible value of our model to evaluate proarrhythmic potential of different drugs.

\section{INTRODUCTION}

Antiarrhythmic drugs which prolong repolarization without affecting conduction have attracted interest, because of their possible value in prevention and suppression of reentrant tachycardias (1-3). However class III drugs do produce Torsade de Pointes (TdP) arrhythmias in about $1-5 \%$ of patients $(1,2,4-9)$.

Many articles have pointed to the relevance of early afterdepolarizations (EADs) and EAD dependent ectopic beats (EBs) for the initiation of TdP arrhythmias (9-12). Whether they can be solely responsible for the initiation and/or whether other factors 
like ventricular dispersion of repolarization ( $\triangle \mathrm{APD})$ do contribute is still a matter of discussion (13-15). Regional differences in the duration of the action potential (APD) can be present within the ventricular wall (transmural), within one ventricle (intraventricular) and/or between ventricles (interventricular).

Comparing inducible vs non inducible animals in our canine model of $\mathrm{TdP}$, we have demonstrated that the number of EADs is higher and the amount of interventricular $\triangle A P D$ larger, using endocardially placed monophasic action potential (MAP) catheters (16). In anestherized dogs with chronic complete AV block, TdP can be reproducibly initiated using the combination of d-sotalol and pacing in half of the experiments (17). Because the response is maintained over weeks (17), we compared the effect of two antiarrhythmic drugs, $\mathrm{d}$-sotalol and almokalant in their ability to induce TdP arrhythmias in the same dog. In this way we could assess whether differences in the occurrence of EADs, EAD dependent EBs and/or interventricular $\triangle A P D$ could explain initiation of TdP.

\section{METHODS}

The study protocol was approved by the Committee for Experiments on Animals of the University of Limburg, Maastricht, the Netherlands and conducted in accordance with the guidelines of the American Physiological Society.

\section{General}

The experiments were performed on anesthetized adult mongrel dogs of eirher sex with a body weight between 20 and $31 \mathrm{~kg}$. In preliminary surgery, a right thoracotomy was performed to induce a permanent complete AV block by injection of $37 \%$ formaldehyde into the AV junction (18). During the same session, a pacing electrode (Bakken Research Center, Medtronic) was inserted at the apex of the left ventricle. The wire was exteriorized through the back of the neck of the dog. Six surface electrocardiographic leads and 2 endocardial MAP were simultaneously registered and stored on optical disc. All drugs were administered through a canula in the cephalic vein.

Anaesthesia was induced by l) premedication i.m. (1 ml/5 kg: $10 \mathrm{mg}$ oxycodon, $1 \mathrm{mg}$ acepromazine and $0.5 \mathrm{mg}$ atropine) and 2) sodium pentobarbital $(20 \mathrm{mg} / \mathrm{kg}$ i.v. $)$. The dogs were artificially ventilated through a cuffed endotracheal tube using a mixture of oxygen, nitrous oxide and halothane (vapor concentration $0.5 \%-1 \%$ ) by a respirator. Ventilation was controlled by continuous reading of the carbon dioxide concentration in the expired air. A thermal mattress was used to maintain adequate body temperature. Proper care was taken before and after the experiments, including antibiotics $(1000 \mathrm{mg}$ ampicillin) and analgesics $(0.03 \mathrm{mg} / 7 \mathrm{~kg} \mathrm{i.m}$. buprenorfine). A temporary ventricular 
pacemaker (VVI) was sometimes given after the AV block operation and after the experiments. Pacing was switched off after a maximum of 24 hours.

\section{Determination of dose almokalant}

In sinus, rhythm dogs, other investigators have shown that the effect of $0.35 \mathrm{mg} / \mathrm{kg}$ almokalant on electrophysiological parameters as APD was about two times as strong as $3 \mathrm{mg} / \mathrm{kg} d$-sotalol (19). Therefore we chose a dose of $0.12 \mathrm{mg} / \mathrm{kg}$ almokalant, to create similar effects as $2 \mathrm{mg} / \mathrm{kg} d$-sotalol. This is the dose that we have used in the past (16-18) to induce $\mathrm{TdP}$ :

In preliminary experiments two dogs were tested with this dose of almokalant. These dogs showed repetitive episodes of spontaneous TdP. This is in contrast with the low incidence ( $\pm 8 \%$ ) of spontaneous TdP with $d$-sotalol in our model (17). Administration of almokalant also resulted in the death of an animal during the infusion of almokalant $(0.06 \mathrm{mg} / \mathrm{kg})$ : an episode of TdP deteriorated into ventricular fibrillation which could not be cardioverted. Therefore, we started to administer almokalant $(0.12 \mathrm{mg} / \mathrm{kg} / 5 \mathrm{~min})$ first to selected dogs $(n=3)$ in whom no TdP could be induced by $d$-sotalol. In these experiments the arrhythmogenic potential of almokalant was well controlled so that we than administered almokalant to eleven successive dogs. In the 14 dogs tested, $d$-sotalol was given first ( $4 \pm 2.2$ weeks after creation of complete AV block) in eleven dogs, followed by almokalant $3 \pm 2.1$ weeks later. In three dogs the order was reversed; almokalant at $5 \pm 2.6$ weeks and $d$-sotalol at $9 \pm 3.1$ weeks of chronic complete AV block. The time of administration of almokalant was doubled from 5 to 10 minutes in the last 10 animals following a publication on the possible relation between (high) infusion rate and the initiation of TdP by almokalant (11).

\section{Induction of Torsade de Pointes arrhythmias}

A detailed description of the TdP protocol is described elsewhere (17). In short, at least 2 weeks after creation of AV block anestherized animals received two defibrillation patches that were attached to both sides of the chest and connected with a defibrillator. Ar least half an hour after the onset of anaesthesia programmed electrical stimulation (PES) was performed from the epicardial electrode. Stimulation was done with a programmable stimulator capable of pacing synchronously to the QRS complexes. Unipolar stimuli were given using a pulse of $2 \mathrm{~ms}$ and a stimulus strength of twice diastolic threshold. As indifferent electrode a needle was placed through the skin. PES consisted of two different pacing protocols: 1) A short long short sequence (400 $800+$ extrastimulus, or 4*600 1200+ exirastimulus) and 2) 8 basic stimuli followed by an extrastimulus. The interstimulus intervals were 600 or $1200 \mathrm{~ms}$. The extrastimulus interval in both pacing protocols was shortened from $500 \mathrm{~ms}$ using steps of $50 \mathrm{~ms}$ till 
$300 \mathrm{~ms}$. After completing the basic pacing protocol, $d$-sotalol $(2 \mathrm{mg} / \mathrm{kg} / 5 \mathrm{~min})$ or almokalant $(0.12 \mathrm{mg} / \mathrm{kg} / 5$ or $10 \mathrm{~min})$ were administered.

Pacing was resumed 10 minutes after the start of the infusion unless spontancous TdP had occurred during the observation period. When TdP occurred, we tried to perform the pacing protocol at 15 minutes. Pacing was always performed in a random order. A TdP arrhythmia was defined as a polymorphic ventricular tachycardia consisting of 5 beats or more twisting around the baseline in the setting of a prolonged QT(U) duration. TdP was terminated using cardioversion $(60-70 \mathrm{~J})$ when it lasted longer than 10 seconds. A dog was called inducible when TdP was induced 3 times or more using the same pacing mode and/or when spontaneous initiation of TdP occurred ( $\geq 3$ times). In one experiment problems with cardioversion urged us to stop prematurely, so that reproducibility could not be assessed.

\section{Monophasic Action Potentials}

MAPs were recorded to observe the occurrence of EADs and to measure the APD the of the left (LV) and right ventricle (RV), Quadripolar contact electrodes (Franz combination catheter, EPT \# 1650), that provide both pacing and MAP recording capabilities were placed endocardially in the right and in the left ventricle via the external jugular vein and the carotid artery under fluoroscopic guidance. MAP phases were defined according to the definitions used for transmembrane potentials (20). Amplitude was defined between phase 4 and 2 of the signal. Besides a minimal amplitude of $15 \mathrm{mV}$ the MAP had to have a constant configuration and a smooth shape during control circumstances.

The MAP carheters were randomly placed in the ventricle and accepted for analysis if all these conditions were fulfilled. Good quality MAPs in both ventricles were present in $11 / 14$ experiments with almokalant and in 12/14 experiments with $d$-sotalol. EADs were defined as an interruption of the smooth contour of phase 2 and/or 3 of the action potential (10). The presence of EADs was examined in both MAPs.

\section{Data analysis}

With the use of a custom made compurer program with a resolution of $2 \mathrm{~ms}$ and adjustable gain and time scale, the following parameters were measured: cycle length of the idioventricular rhythm (CL-IVR), QT time and APD. All electrophysiological data reported are the mean of 5 consecutive (single) beats, and were checked by an independent blinded observer.

Interventricular $\triangle A P D$ was defined as the difference between the LV APD and RV APD measured after total repolarization $\left(=\mathrm{APD}_{100}\right)$. 


\section{Statistics}

Multiple measurements ANOVA, followed by a Bonferroni t-test was used to compare the data between the two treatments and a $\chi^{2}$ test was used when the data were presented as percentages. $\mathrm{P}$ values $\leq 0.05$ were considered significant. All data are presented as mean \pm standard deviation (SD), unless otherwise specified.

\section{RESIJLTS}

\section{Slow and fast infusion of almokalant}

The change in infusion rate ( 5 vs 10 minutes) of almokalant did not alter the electrophysiological effects nor the (time of) occurrence of EBs and/or incidence of TdP. Therefore, we will present the data as a whole.

\section{Electrophysiological effects}

Baseline conditions were similar in each of the 14 serially tested animals. Values for CL-IVR, QT time, APD of both ventricles and the interventricular $\triangle \mathrm{APD}$ are summarized in table 1. At 10 minutes, $d$-sotalol had significantly prolonged the CL-IVR with $16 \%$, and the QI time with $26 \%$. It aiso signiticantly increased the LV APD and RV APD. Because prolongation of the LV APD was more pronounced ( $27 \%$ vs $21 \%$ ), interventricular $\triangle \mathrm{APD}$ increased significantly (table 1).

Also almokalant significantly increased the CL-IVR and all the repolarization parameters. Again interventricular $\triangle A P D$ increased $(p \leq 0.05)$ due to a more pronounced increase in the LV APD compared to the RV APD ( $45 \%$ vs $29 \%$, table 1).

Table 1. Electrophysiologic effects of $d$-sotalo! and almokalant

\begin{tabular}{|c|c|c|c|c|c|c|}
\hline & \multicolumn{3}{|l|}{$d$-sotalol } & \multicolumn{3}{|l|}{ almokalant } \\
\hline & $0^{\prime}$ & $10^{\prime}$ & $\%$ & $0^{\circ}$ & $10^{\circ}$ & $\%$ \\
\hline CL-IVR & $1620 \pm 300$ & $1880 \pm 370^{\circ}$ & +16 & $1670 \pm 360$ & $1910 \pm 425^{\circ}$ & +15 \\
\hline QT & $390 \pm 50$ & $495 \pm 80^{\circ}$ & +26 & $415 \pm 55$ & $545 \pm 115^{\circ}$ & +31 \\
\hline RV APD & $320 \pm 30$ & $390 \pm 45^{\circ}$ & +21 & $335 \pm 35$ & $440 \pm 60^{\circ}=$ & $+29^{2}$ \\
\hline LV APD & $370 \pm 45$ & $470 \pm 60^{\circ}$ & +27 & $375 \pm 45$ & $535 \pm 110^{\circ}=$ & $+45^{z}$ \\
\hline$\triangle A P D$ & $50 \pm 25$ & $80 \pm 45^{\circ}$ & +75 & $40 \pm 20$ & $110 \pm 60=$ & +330 \\
\hline
\end{tabular}

"P<0.05 $t=10$ vs $t=0, " P<0.05$ almokalant vs $d$-sotalol. CL-IVR: cycle length of the idioventricular rhythm, APD: action potential duration, LV: left ventricle, RV: right ventricle. $\triangle A P D: L V$ APD - RV APD. Data are in milliseconds (mean \pm SD) measured at the start and after 10 minutes of drug administration. 

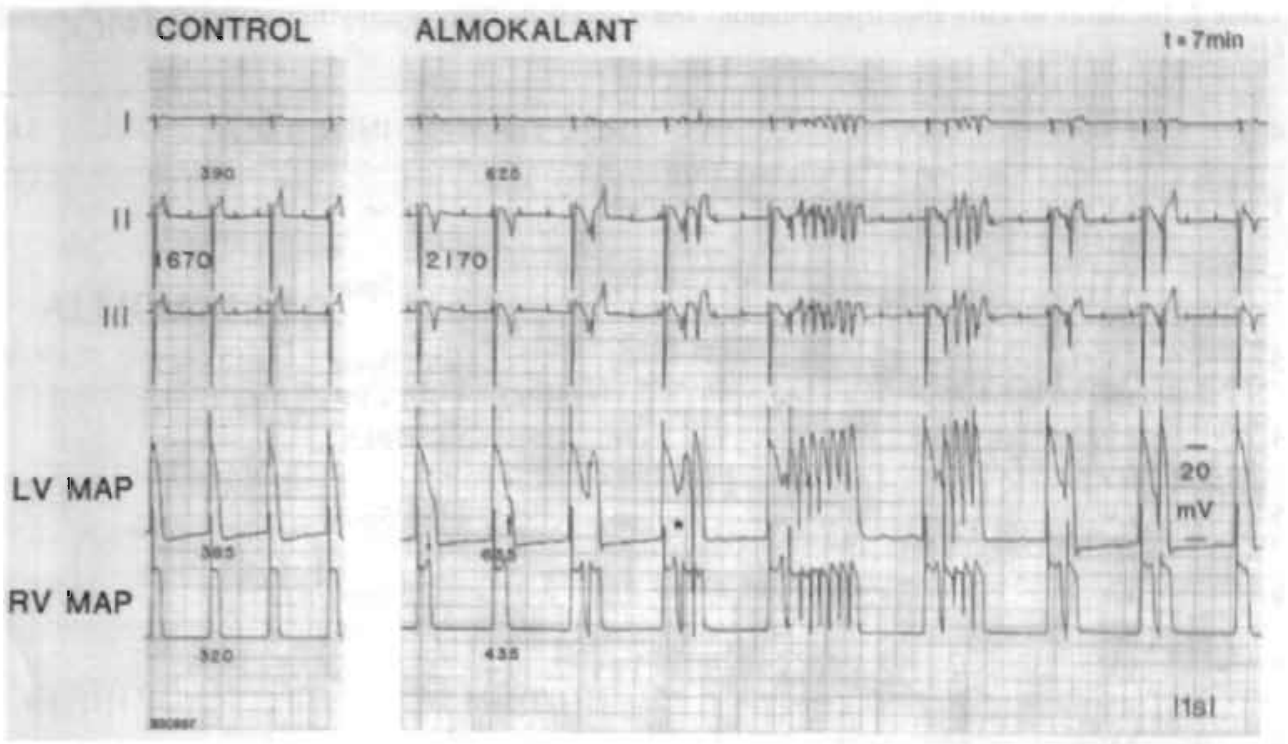

Figure 1. Occurrence of EADs, triggered beats and spontancous TdP-arrhythmia after almokalant in the canine heart.

Three simultancously recorded surface electrocardiographic kads and two endocardial monophasic action potentials (one from the lefr: LV MAP and one from the right ventride: RV MAP) are presented. Paper speed is $10 \mathrm{~mm} / \mathrm{sec}$. Panel 1: Baseline conditions with a spontaneous idioventricular thythm having a cycle length of $1670 \mathrm{~ms}$ (IVR), and a QT time of $390 \mathrm{~ms}$. The difference between the left and the right action potential duration (AAPD) is $65 \mathrm{~ms}$. Pane $2: 7$ minutes after almokalant CL-IVR (2170 ms) and QT-timc (625 ms) have increased and the positive $T$ wave (lead II and III) has changed inro a negative TU wave. Dispersion in repolarization (AAPD) has increased to $200 \mathrm{~ms}$. In both MAPs, early afierdepolarizations (EADs) are present (arrows). Spontaneous ectopic beats occur in the repolarization phase. Some of them clearly seemed to be triggered by an EAD that has reached threshold (asterisk). This is followed by a shon period of TdP.

When comparing d-sotalol with almokalant, no differences were found in the amount of lengthening of the CL-IVR. However the effect on the parameters of repolarization was greater after almokalant (table 1).

Presence of early afterdepolarizations, ectopic beats, and spontaneous initiation of Torsade de Poinies

In the first 10 minutes, administration of the drugs resulted in the occurrence of EADs (figure 1, panel 2) in 18/22 MAPs with almokalant and in 1//24 MAPs after $d$-sotalol (table 2). Wirh $d$-sotalol EADs tended to appear more frequent in the left ventrick $(P<0.1$, table 2), whereas no difference was seen after almokalant. Single EBs developed 
Table 2. Incidence of early afterdepolarizations and Torsade de Pointes arrhythmias (TdP) after $d$-sotalol (dS) and almokalant (A)

\begin{tabular}{|c|c|c|c|c|c|}
\hline $\operatorname{dog}$ & LV/RV & EAD dS & EAD A & INDU TdP dS & INDU TdP A \\
\hline \multirow[t]{2}{*}{1} & LV & + & + & no & no \\
\hline & RV & + & + & & \\
\hline \multirow[t]{2}{*}{2} & LV & + & + & PES & Spon ${ }^{\prime}$ \\
\hline & RV & - & + & & \\
\hline \multirow[t]{2}{*}{3} & LV & + & + & no & Spon \\
\hline & RV & - & + & & + PES \\
\hline \multirow[t]{2}{*}{4} & LV & - & + & PES & PES \\
\hline & RV & - & + & & \\
\hline \multirow[t]{2}{*}{5} & LV & - & + & no & Spon" \\
\hline & RV & - & + & & \\
\hline \multirow[t]{2}{*}{6} & LV & + & + & PES & Spon \\
\hline & RV & + & - & & + PES \\
\hline \multirow[t]{2}{*}{7} & LV & . & + & PES & Spon" \\
\hline & RV & - & + & & \\
\hline \multirow[t]{2}{*}{8} & LV & + & + & no & Spon \\
\hline & RV & - & + & & + PES \\
\hline \multirow[t]{2}{*}{9} & LV & + & - & PES & PES \\
\hline & RV & - & - & & \\
\hline \multirow[t]{2}{*}{10} & LV & , & , & no & Spon \\
\hline & RV & + & - & & + PES \\
\hline \multirow[t]{2}{*}{11} & LV & - & + & no & \\
\hline & RV & - & + & & PES \\
\hline \multirow[t]{2}{*}{12} & LV & - & ND & no & Spon ${ }^{2}$ \\
\hline & RV & - & & & \\
\hline 13 & ND & & ND & no & Spon \\
\hline 14 & ND & & ND & no & no \\
\hline Total & & $11 / 24$ & $18 / 22^{\circ}$ & $5 / 14$ & $12 / 14^{\circ}$ \\
\hline
\end{tabular}

LV: left ventricle, RV: right. ventricle, EADs: carly after depolarizations present in RV or LV, ND: not determined, INDU: inducibility; no: no TdP, PES: induction by programmed electrical stimulation, Spon: spontaneous initiation of TdP. "P<0.05 vs dS. "Due to spontaneous activity no PES could be peformed.

in almost all dogs with almokalant (13/14) and in less than half of the dogs after $d$-sotalol (5/14). Moreover, multiple EBs were observed after almokalant. In some experiments these spontaneous beats could be associated with triggering of EADs recorded with the MAP catheter (figure 1, panel 2).

Despite the occurrence of EBs after $d$-sotalol, none of these dogs developed spontaneous TdP. Almokalant induced spontaneous TdP in 9 dogs (figures 1 and 2), which was 


\section{CONTROL}

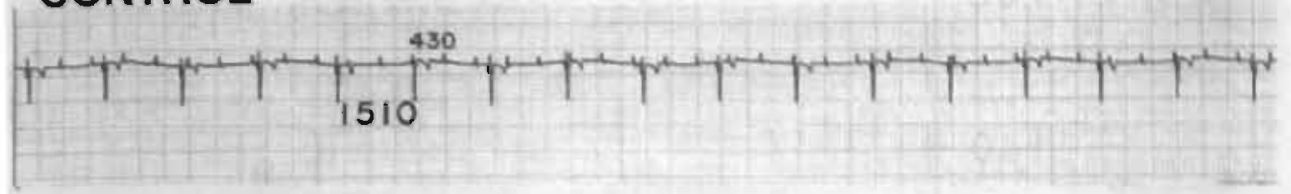

\section{ALMOKALANT}

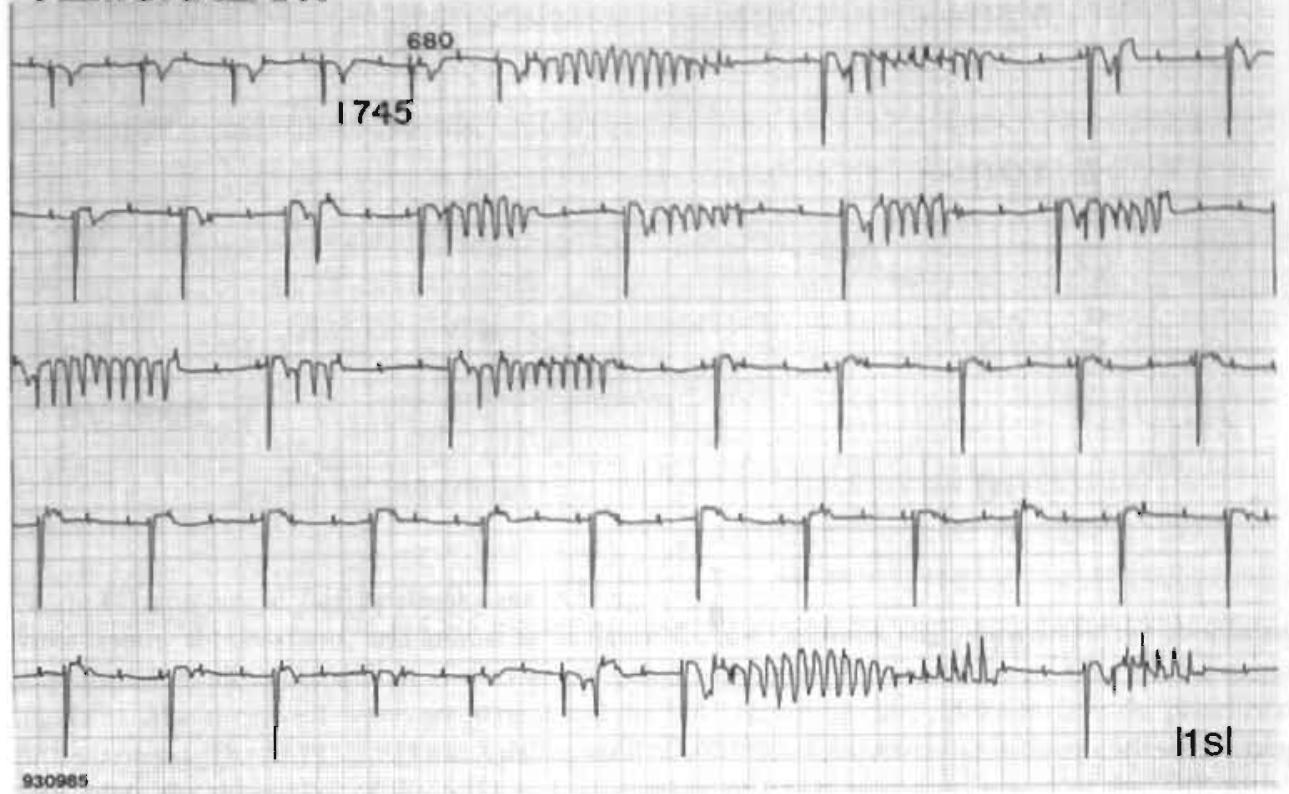

Figure 2. Continuous ectopic activiry and TdP after almokalant.

Recordings are shown at a paper speed of $10 \mathrm{~mm} / \mathrm{s}$. Before the administration of almokalane (CONTROL) a stable cycle length of the idioventricular rhythm (CL-IVR) (1510 mis) with a QT time of $430 \mathrm{~ms}$ is present. Administrarion of almokalant $(0.12 \mathrm{mg} / \mathrm{kg} / 10 \mathrm{~min}) \mathrm{led}$ to the occurrence of ectopic beats at 3 minutes. From that time on to 30 minutes after the start of the infusion, episodes of ectopic beats and 'TdP alternated with the IVR. In this figure a continuous recording of $225 \mathrm{sec}$ starting 5 minutes after start of almokalant is shown. Almokalant has increased the CL-IVR to $1745 \mathrm{~ms}$ and the QT time to $680 \mathrm{~ms}$. Furthermore the $T$ wave has become more negative. At the end of this $T$ wave an ectopic beat starts a period of TdP. After cessation another period of TdP evolves. After a change in the site of origin of the IVR (different QRS configurations) a new episode of TdP starts now after a short long short sequence. 


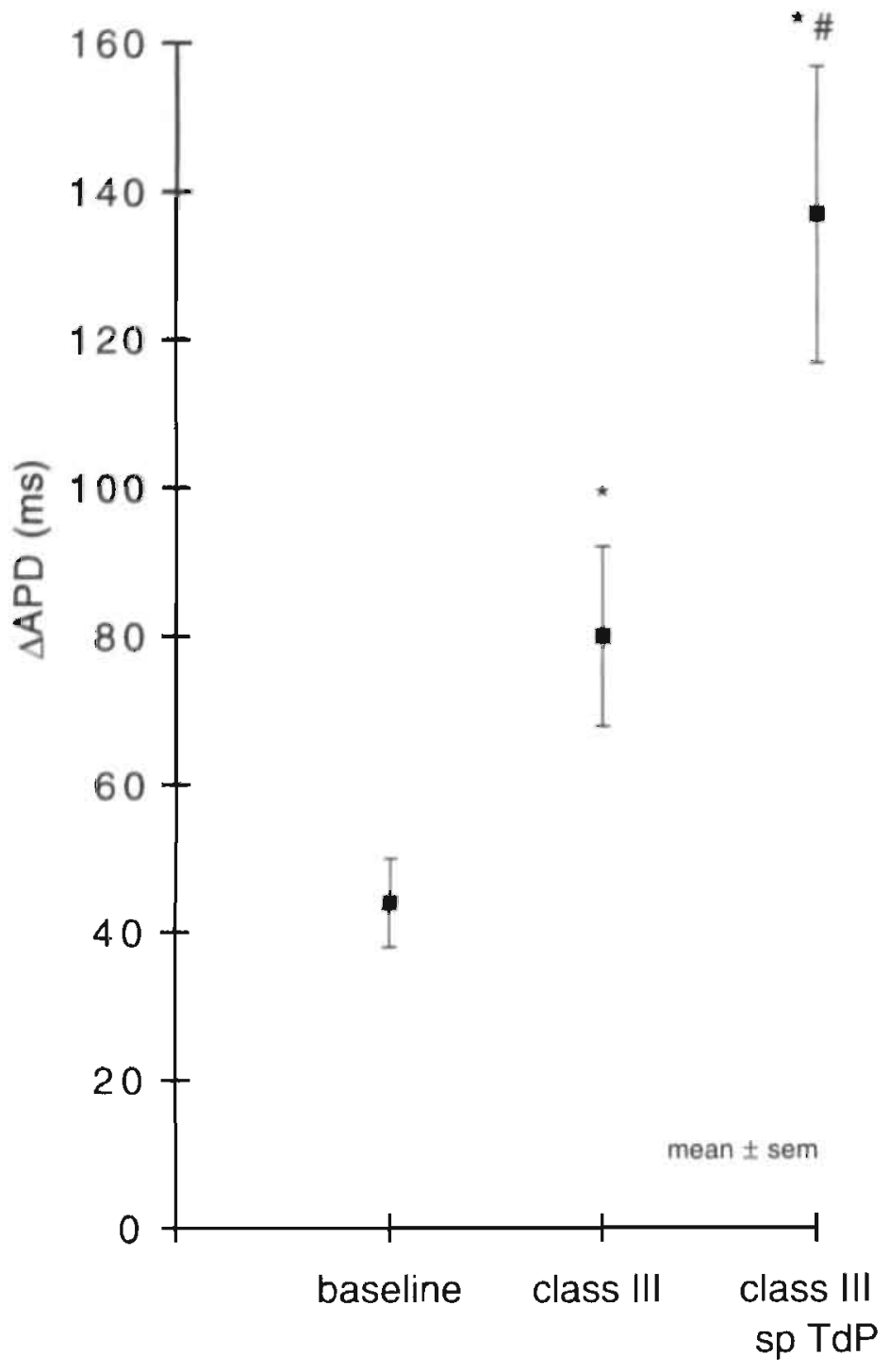

Figure 3. Incidence of spontaneous Torsade de Pointes related to interventriculat dispersion.

This graph shows the mean values ( \pm SEM) of interventricular dispersion in APD ( $\triangle A P D)$ in the animals with MAPs at both experiments. Dispersion has been dividend in rhree groups 1) baseline, 2) after class III without spontaneous TdP (class III. d-sotalol and almokalant: $\mathrm{n}=15$ ), and 3) after class III drugs in those experiments with spontaneous occurrence of TdP (sp TdP, almokalant; $\mathrm{n}=7$ ). The last group has the largest interventricular $\triangle A P D(P<0.05)$ compared with baseline $\left({ }^{*}\right)$ and class III $(*)$. Interventricular $\triangle A P D$ of $95 \mathrm{~ms}$ has a specificity of $73 \%$ and a sensitivity of $85 \%$ to predict TdP 


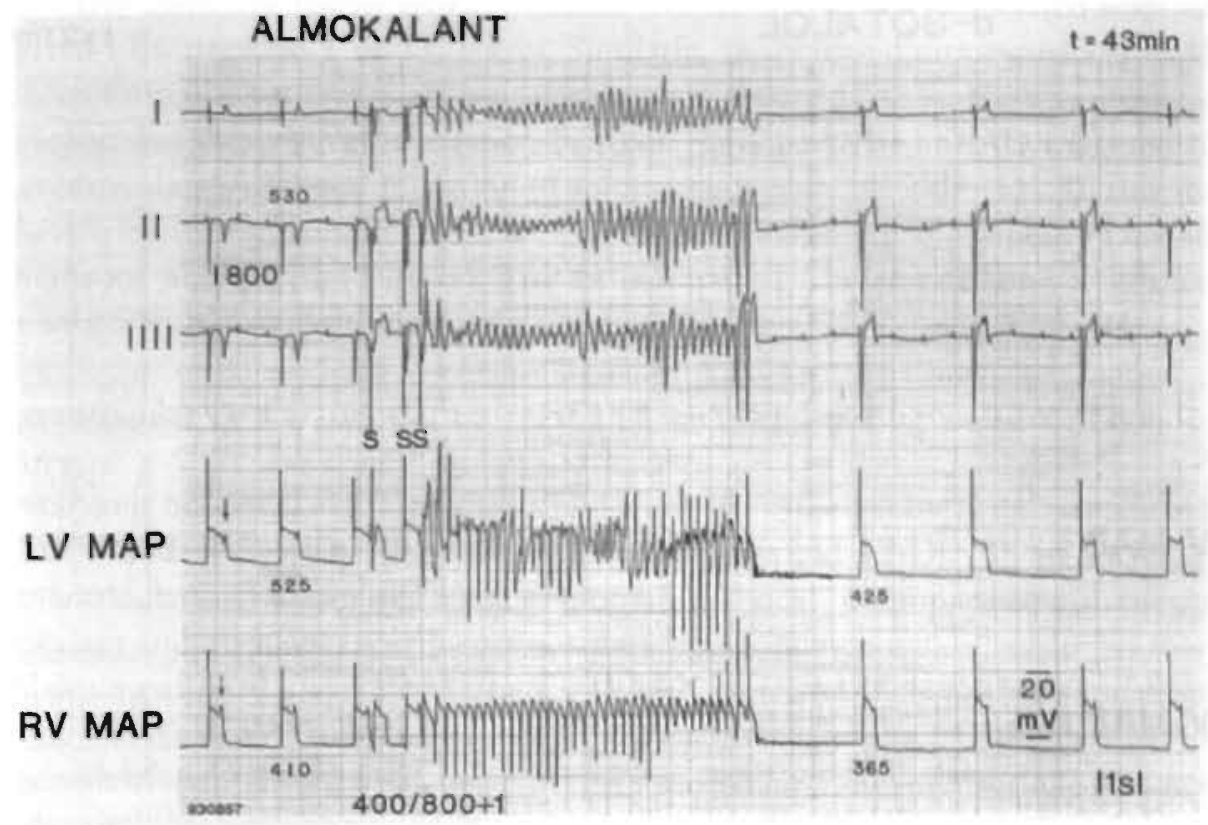

Figure 4. Induction of TdP by almokalant.

Same layout, abbreviations, and animal as in figure 1. Ar 43 minures after the start of the almokalant administration, all values still are shorter as compared with figure 1, but still longer than after $d$-sotalol (figure 5). Also negative $T$ waves are present and the MAP' recording clearly demonstrates the presence of EADs (arrows). The $\triangle A P D$ is $125 \mathrm{~ms}$. A pacing train of $400 / 800+i$ extraspimulus initiates a self terminating TdP. Note the shorrening of the APD and suppression of EADs after termination of the TdP with a diminution of $\triangle A P D$ to $60 \mathrm{~ms}$. Thereafter the EADs reoccur and APD starts to increase.

associated with a significantly larger interventricular dipsersion (figure 3) and a higher incidence and number of the EBs.

\section{Induction of Torsade de Pointes after programmed clectrical stimulation}

After $d$-sotalol, PES resulted in the induction of TdP in 5 dogs.

PES could not be performed in 4/9 spontaneously inducible dogs because ectopic activity and periods of $\mathrm{TdP}$ prohibited this (see example in figure 2). In the orher $5 \mathrm{dogs}$ pacing induced $\mathrm{TdP}$ in 4 animals (table 2 ). In the dogs without spontaneous arrhythmias $(n=5)$, pacing resulted in 3 dogs in TdP. Therefore the total incidence of TdP after almokalant was $12 / 14$ dogs.

An representative illustration of the difference in response to $d$-sotalol and almokalant in the same animal is shown in figures 4 and 5. Comparing d-sotalol with almokalant 


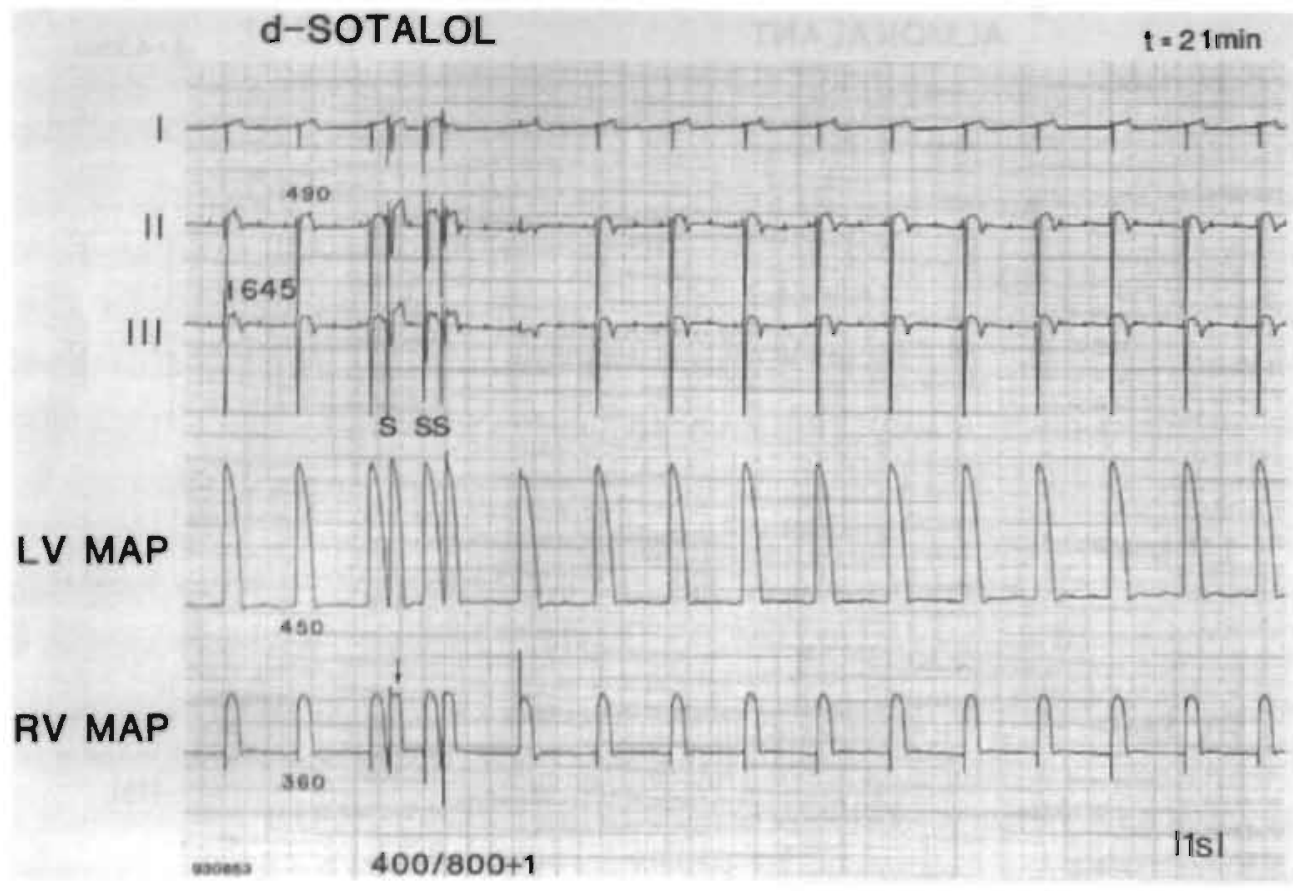

Figure 5. No TdP with pacing after $d$-sotalol.

Same animal as in figures 1 and 4. After $d$-sotalol a slow CL-IVR (1645 ms) is seen accompanied by a prolonged QT time $(490 \mathrm{~ms})$. In both ventricles no EADs are present, and the interventricular $\triangle A P D$ measures 90 ms. Performance of the same pacing train as used with almokalant did not initiate a TdP after d-sotalol, although pacing seemed to evoke an EAD in the RV (arrow).

showed: 1) a higher incidence of TAP by almokalant independent of the order of the experiments, and 2) all inducible dogs with $d$-sotalol were also inducible with almokalant (table 2).

In two dogs, $d$-sotalol was administered in a third experiment. The response was similar to the first experiment thereby confirming reproducibility.

\section{DISCUSSION}

The exact contribution of the different factors leading to initiation of $\mathrm{TdP}$ is still a matter of discussion. Besides the accepted parameters: bradycardia and (class III induced) prolonged QT time, EADs and $\triangle A P D$ have been indicated in the genesis of TdP. By 
using MAP catheters, the in vivo appearance of EADs have been associated with EAD triggered EBs, negative T or TU waves. Similarly, an increased intraventricular $\triangle A P D$ has been found in patients with congenital or acquired TdP (13). However, only one case report has shown a causal relation between the occurrence of EAD triggered EBs, interventricular $\triangle \mathrm{APD}$ and initiation of spontaneous acquired TdP (15). In this study we have tried to confirm the importance of both parameters in the genesis of acquired spontaneous and pacing induced TdP by comparing the proarrhythmic effects of almokalant with $d$-sotalol.

Interventricular $\triangle A P D$ in relation to spontaneous and pacing induced Torsade de Pointes

Spontaneous occurrence of TdP after almokalant was preceded by 1) an increase in the LV APD and RV APD, 2) occurrence of subthreshold EADs, 3) an increase in interventricular $\triangle \mathrm{APD}$ (figure 3), and 4) spontaneous EBs. In comparison with the other almokalant and $d$-sotalol experiments not showing spontaneous TdP, we found that all the above mentioned parameters were significantly increased. This confirms and extends the importance of EADs (and their triggered responses) and interventricular $\triangle A P D$ in the genesis of spontaneous TdP. In a previous study we have shown that these parameters also discriminate berween pacing inducible and non inducible dogs after $d$-sotalol in this model (16). Prevention and/or suppression of $\mathrm{TdP}$ by $\mathrm{MgSO}_{4}$ resulted from disappearance of EADs $(13,17)$ and diminishment of interventricular $\triangle A P D(16)$.

Using PES, we demonstrated that the incidence of TdP could be increased markedly. Also in this study pacing inducible dogs showed a larger interventricular $\triangle \mathrm{APD}$, than the non susceptible ones.

In dogs with chronic complete AV block, we have shown that interventricular $\triangle A P D$ is present under baseline conditions and is bradycardia dependent, with a decrease in heart rate an increase in interventricular $\triangle A P D$ is seen (16). In vitro studies using isolated canine myocytes showed that under baseline conditions the APD of the left endocardial (and epicardial) cells is longer than that of the right ventricle (21). This difference has been described to be even more pronounced for the $M$ cell, located within the myocardium.

Like the Purkinje fiber, the $\mathrm{M}$ cell is much more sensitive for class III agents in its ability to prolong the APD and to develop EADs (21). The increase in interventricular $\triangle A P D$ in our experiments after class III drugs, is primarily due to a larger decrease of the LV APD compared to the RV APD. By decreasing heart rate, class III agents will increase the interventricular differences in APD. Therefore the effect of almokalant (or $d$-sotalol) could be different for the various tissues involved in the heart explaining interventricular $\triangle A P D$. The $M$ cells are not only described in dogs (21), but recent studies also showed the existence of these M cells in normal human myocardium (22). It is not known to 
what extent the M cell contribute to the APD as recorded by the endocardially placed MAP catheter.

Regional appearances of EADs can also explain the increase in interventricular $\triangle A P D$. $d$-Sotalol predominantly induced EADs in the left ventricle, while almokalant produced them in both ventricles. Because administration of almokalant led to a more pronounced increase in interventricular $\triangle A P D$, the relative contribution of the amplitude of the EADs might be important.

\section{Difference between spontaneously occurring and pacing induced TdP}

When spontaneous episodes of TdP occur, pacing will normally also lead to the reproducible induction of these arrhythmias (see e.g. figures 1 and 4 and reference 17). Dogs with spontaneous TdP have more EBs (both single and multiple EBs) than dogs without. For the induction of pacing induced TdP, the presence of single EBs during idioventricular rhythm does not seem to be essential (23), indicating that either the number of EBs and/or their respective coupling interval is not sufficient to start spontaneous TdP. Our pacing modes do consist of several beats with multiple frequency changes (17) and can lead to the occurrence of EADs and triggered EBs within the pacing train. Therefore, application of PES can lead to TdP in those dogs that do not show spontancous TdP. When considering that the respective contributions of the different parameters is equal, pacing can only lead to TdP when interventricular $\triangle A P D$ is or becomes present. Until now we have not been able to determine the dynamic changes within the pacing train.

\section{Almokalant and d-sotalol: proarrhythmic and electrophysiological effects}

The proarrhythmic potential of class III agents is well known (1-9). Prolongation of repolarization is the mechanism of the antiarrhythmic effect of class III drugs, but prolongation is also associated with the risk of TdP development. Measurement of the absolute QT interval does not predict proarrhythmic potential both in clinical conditions (5) as in our animal model (24). Currently QT dispersion (as a parameter of non homogenous repolarization) is frequently mentioned as a possible tool to predict proarrhythmic risk as well as antiarrhythmic efficacy (25). The QT dispersion measured in multiple ECG leads correlates with the dispersion in regional repolarization measured by epicardial MAPs (26). Because QT dispersion shows a large variation, due to different methodologies and different patient characteristics, the question to its use as a general arrhythmic marker has still nor been resolved (27).

This makes it important to screen for the proarrhythmic potential of a new class III agents using an animal model. Most animal TdP models have used non clinically relevant drugs like cesium (10,13,28) or Bay K8644 (29). The only exceptions are an awake AV block dog model with hypokalemia and $\beta$ blockade followed by antiarthythmic drugs 
(30) and a rabbit model (31). In the awake dog it is not possible to measure MAPs and thereby correlate proarrhythmic findings to EADs and APD. In the rabbit, TdP develops at relatively fast heart rates after administration of class III agents and concomitant $\alpha$ adrenergic stimulation. Comparison between different agents in the same animal concomitant with MAP recordings have not been described until this study (30-32).

Because the response of the dog is maintained over weeks, serial comparison for screening of proarrhythmic effects of (antiarrhythmic) drugs is feasible. Although this information cannot be translated into the exact incidence of TdP in the patient population, it allows an estimation of the relative risk of drugs and their risk/benefit ratio.

Almokalant and $d$-sotalol both prolong the APD by blockade of $\mathrm{K}^{+}$currents (33-35). While almokalant is a selective blocker of $\mathrm{I}_{\mathrm{Kr}}(33,35)$, the data from the literature are not consistent for $d$-sotalol. It might also affect other $\mathrm{K}^{+}$channels like $\mathrm{I}_{\mathrm{K} 1}, \mathrm{I}_{\mathrm{Ks}}$ and $\mathrm{I}_{\text {to }}$ (35-37). In addition, $d$-sotalol has some $\beta$ blocking effects, (less than $5 \%$ of $d$-sotalol (6)) whereas almokalant is devoid of $\beta$ blocking activity (34).

The difference in prolongation of the APD and occurrence of EADs after $d$-sotalol compared to almokalant may be explained by 1) differences in dose and/or kinetics, or 2) administration time. In the preparation of this study we calculated that a dose of 0.12 $\mathrm{mg} / \mathrm{kg}$ almokalant should give approximately the same effect on repolarization as 2 $\mathrm{mg} / \mathrm{kg} d$-sotalol (13). The former is comparable with the dose given to patients to treat ventricular tachycardias (38). The effect on CL-IVR and QT was about equal for both drugs (table 1), although it should be mentioned that in the experiments with almokalant, the electrophysiological measurements were often hampered due to recurrent presence of EBs and episodes of TdP. This could have led to an underestimation of the electrophysiological effects of almokalant. The kinetics between the two drugs could also be different, in vitro data show that the effect of $d$-sotalol has a slower onset than almokalant (35).

Doubling the time of administration of almokalant did not alter the response, which is in contrast to the reported effects in patients (38) and rabbits (11).

\section{Limitations and implications}

In this study two MAP catheters were randomly placed, one in the left and the other in the right ventricle. This provides information about the differences in repolarization between the two ventricles (interventricular $\triangle A P D$ ). Possible transmural or intraventricular differences in APD have not been assessed in this study. Placement of multiple MAP catheters with $\mathrm{d}$-sotalol revealed that the intraventricular difference amounted only to $20-30 \%$ of the interventricular $\triangle A P D$ (16). We do not know the type and the amount of cells contributing to the MAP. Similarly, whether the presence of $\mathrm{EAD}$ on the MAP is real or based on differences in transmural repolarization is not 
known. However, interventions specifically directed to EAD formation like pacing and drugs leads to disappearance of these EADs.

Transmural differences have been implicated in the mechanism of TdP (21). Besides their relevance for the occurrence of EADs, differences in APD have been shown to create the substrate for a reentrant tachycardia (39). Whether reentry plays a role in the initiation and continuation of TdP is still unclear. It is conceivable that reentry succeeds triggered activity $(40,41)$, this is certainly the case when TdP progresses into ventricular fibrillation.

Interventricular $\triangle \mathrm{APD}$ is not likely to play a role in reentrant arrhythmias, because spatial dispersion is located to far apart. Still the polymorphic appearance of TdP can be explained by interventricular $\triangle \mathrm{APD}$. Appearance of EBs from single foci can lead to $\mathrm{TdP}$ when this "monomorphic tachycardia" encounters continuously shifting areas of repolarization. Things become more complicated when triggered EBs arise from multiple sites in the ventricles.

\section{Conclusions}

Our study confirms the relevance of interventricular $\triangle A P D$ and EADs for the initiation of (spontancous) acquired TdP.

These findings also show that this canine model of TdP can be used to screen for the proarrhythmic potential of drugs.

\section{Acknowledgements}

We are grateful to Mr H. Wiering and C. Ketelaars, ASTRA Nederland who provided us with almokalant and to Mr J. Verschuuren, Bristol Meyers Squibb for $d$-sotalol. The Bakken Research Institute (Medtronic) Maastricht, the Netherlands gave us the epicardial electrodes. The study was financially supported by a grant from the Netherlands Heart Foundation ( $\# 91.104)$.

\section{REFERENCES}

1. Colatsky TJ. Follmer CH, Starmer CF. Channel specificity in antiarrhythmic drug action. Mechanism of potassium channel block and its role in suppressing and aggravating cardiac arthythmias. Circulation $1990 ; 82: 2235-42$.

2. Hondeghem LM. Snyders DJ. Class III antiarthythmic agents have a lot of porential but a long way to go. Reduced effecriveness and dangers of reverse use dependence. Circulation 1990; 81: 687-90.

3. Singh BN. Wellens HIJ. Hiraoka M. ed. Electropharmocological control of cardiac arrhythmias: to delay conduction or to prolong refractoriness. Mnt Kisco, NY. Futura Publishing, 1994, USA.

4. McNeil DJ. Davies RO. Deitchman D. Clinical safety profile in the treatment of arrhythmias. Am J Cardiol 1993: 72: 44A-50A. 
5. Nguyen TP, Scheinman MM, Seger J. Polymorphous ventricular tachycardia: clinical characterization, therapy and QT interval. Circulation 1986; 74: 340-49.

6. Hohnloser SH. Woosley RL. Sotalol. New England / Med 1994: 331:31-8.

7. Hohnloser SH, Klingenleben T, Singh BN. Amiodarone-associated proarrhythmic effects. A review with special reference to Torsade de Pointes tachycardia. Ann Intern Med 1994; 121: 529-35.

8. Wiesfeld ACP, Crijns HJGM, Bergstrand RH. Almgren O, Hillege HL. Lie KI. Torsade de pointes with almokalant, a new class III antiarrhythmic drug. Am Heart / 1993; 126: 1008-11.

9. Jackman WM, Friday KJ, Anderson JL. Aliot EM, Clark M, Lazzara R. The Long QT syndromes: a critical review, new clinical observations and a unifying hypothesis. Prog Cardiovase Dis 1988; 31: $115-72$.

10. Levine JH, Spear JF, Guarnieri T, Weisfeldr ML, de Langen CDJ, Becker LC, Moore EN. Cesium chloride-induced long QT syndrome: Demonstration of after-depolarizations and rriggered activity in vivo. Circulation 1985: 72: 1092-[103.

11. Carlsson L, Abrahamsson C, Andersson B, Düker G. Schiller-Linhardt G. Proarrhythmic effects of the dass III agent almokalant: importance of infusion rate, QT dispersion, and carly afterdepolarizations. Cardiovase Res 1993: 27:2186-93.

12. Bonatti V, Rolli A, Botti G. Monophasic action potential studies in human subjects with prolonged ventricular repolarization and long QT syndromes. Eur Heart / 1985: 6: 131-43 (suppl).

13. Bailie DS, Inoue H. Kaseda S, Ben David J, Zipes DP. Magnesium suppression of early afterdepolarizations and ventricular tachyarrhythmias induced by cesium in dogs. Circularion 1988; 77: 1395-1402.

14. Surawicz B. Electrophysiological substrate of Torsade de Pointes: Dispersion of repolarization or early afterdepolarizations. J Am Coll Cardiol 1989; 14: 172-182.

15. Habbab MA, El-Sherif N. Drug induced Torsade de pointes: Role of early afterdepolarizations and dispersion of repolarization. Am / Medicine 1990; 89: 241-246.

16. Verduyn SC, Vos MA, Zande vd J, Steld vd BJ. Wellens HJ. Role of interventricular dispersion of repolarization for the induction of acquired carly afterdepolarization dependent Torsade de Pointes arrhychmias: reversal by magnesium. accepted for publication Circulation 1996

17. Vos MA, Verduyn SC. Gorgels APM, Lipscei GC, Wellens HJJ. Reproducible induction of early afterdepolarizations and torsade de pointes arthythmias by $\mathrm{d}$-sotalol and pacing in the dog with chronic atrioventricular block. Circulation 1995; 91: 864-72.

18. Vos MA, Gorgels APM, Lipscei GC, de Groot SHM, Leunissen JDM. Wellens HJJ. Mechanism specific anti-arrhythmic effects of the potassium channel activator leveromakalim against repolarization dependenr tachycardias. J Cardiovase Electrophysiol 1994: 5: 731-42.

19. Duker G, Almgren O, Carlsson L. Electrophysiologic and hemodynamic effects of $\mathrm{H} \mathrm{234/09}$ (Almokalant), Quinidine, and (+)-Sotalol in the anesthetized dog. / Cardiovasc Pharmacol 1992; 20: 458-65.

20. Damiano BP, MR Rosen. Effects of pacing on iriggered activity induced by early afterdepolarizations. Circulation 1984; 69: 1013-25.

21. Antzelevitch C, Sicouri S. Clinical relevance of cardiac arrhythmias generated by afterdepolarizations. Role of M cells in the generation of $U$ waves, triggered activity and Torsade de Pointes. J Am Coll Cardiol 1994; 23: 259-77.

22. Drouin E, Charpentier F, Gauthier C, Laurent K, Le Marec H. Electrophysiological characteristics of cells spanning the left ventricular wall of human heart evidence for the presence of $\mathrm{M}$ cells. / Am Coll Cardiol 1995; 26: 185-192.

23. Verduyn SC, Vos MA, vạn dẹ Zande J. Wellens HJJ. Occurrence of early afterdepolarizations induced triggered beats does nor quarantee initiation of spontaneous Torsade de Pointes. PACE 1995; 18: 1095 (abstract).

24. Verduyn SC, Vos MA, Gorgels APM, Leunissen. JDM, van der Zande J, Wellens HJJ. QT time: predictor of the occurrence of acquired Torsade de Pointes arrhythmias. PACE 1994; 17:826 (abstract). 
25. Hii JTY. Wyse DG, Gillis AM, Duff HJ, Solylo MA, Mitchell LB. Precordial QT time interval dispersion as a marker of torsade de pointes: disparate effects of class $1 \mathrm{~A}$ antiarrhythmic drugs and amiodarone, Circulation 1992; 86: 1376-82.

26. Zabel M, Portnoy S, Franz MR. Electrocardiographic indexes of ventricular repolarization: an isolated. heart validation study. I Am Coll Cardiol 1995; 25: 746-752.

27. Statters DJ, Malik M, Ward DE, Camm A]. QT dispersion: problems of methodology and clinical significance. / Cardiovase Electrophysiol 1994; 5: 672-85.

28. Nayebpour M, S Nattel. Pharmacologic response of cesium induced ventricular tachyarrhythmias in anestherized dogs. / Cardiovase Pharmocol 1990; 15:552-61.

29. Ben-David J. Zipes DP, Ayers GM, Pride HP. Canine left ventricular hypertrophy predisposes to ventricular tachycardia induction by phase 2 carly afterdepolarizations after administration of Bay K 8644. / Am Coll Cardiol 1992; 20: 1576-1584.

30. Weissenburger J, Davy JM. Chezalvie! F, ErtzbischoffO, Poirier JM. Engel F, Lainee P, Penin E, Motte G. Cheymol G. Arrhythmogenic activities of anti arthythmic drugs in conscious hypokalemic dogs with atrioventricular block: comparison between quinidine, lidocainc, flecainide, propranolol and sotalol. J Pharmocal Exper Ther 1991; 259: 871-883.

31. Carlsson L. Almgren O. Duker G. QTU-prolongation and Torsades de Pointes induced by putative class III antiarrhythmic agents in the rabbit: Etiology and interventions. / Cardsovase Pharmacol 1990; 16: $276-85$.

32. Buchanan LV, Kabell G, Brunden MN, Gibson JK. Comparative assessment of ibutilide, d-sotalol, clofilium. E4031, and UK-68.798 in a rabbit model of proarrhythmia. / Cardiovase Pharmacol 1993: 22: $540-549$.

33. Sanguinetti, Jurkiewicz NK. Two components of cardiac delayed rectifier $\mathrm{K}^{*}$ current. Differential. sensitivity to block by class III antiarrhvthmic agents. / Gen Phriol 1990: 96: 195-215

34. Almgren O. Electropharmocological profile and antiarrhythmic potential of almokalant ( $\mathrm{H} 234 / 09)$. In: Singh BN, Wellens HJJ. Hiraoka M. ed. Electropharmocological control of cardiac arrhythmias: to delay conduction or to prolong refractoriness. Mnt Kisco, NY, Futura, 1994; 569-75.

35. Wetrwer E. Grundke M. Ravens U. Differential effects of the new class III agents almokalant, E-403! and $\mathrm{d}$-sotalol and of quinidine, on delayed rectifier currents in guinea pig ventricular myocytes. Cardiovase Res 1992; 26: 1145-52.

36. Carmelier E. Electrophysiologic and voltage clamp analysis of the effects of sotalol on isolated cardiac muscle and Purkinje fibers, / Pharmacol Exp Ther 1985; 232: 817-825.

37. Varro A. Nanasi PP, Lathrop DA. Effect of sotalol on transmembrane ionic currents responsible for repolarization in cardiac ventricular myocytes from rabbit and guinea pig. Life Sci 1991: 49; PL7-PL9.

38. Wiesfeld ACP. Crijns HJGM, Tobe TJM, Almgren O, Bergstrand RH, Aberg J, Haaksma J, Lie KI. Electropharmocologic effects and pharmokinetics of almokalant, a new class IIl antiarrhythmic, in parients with healed or healing myocardial infarets and complex ventricular arrhythmias. Am / Cardiol 1992; 70: 990-96.

39. Kuo CS. Munakata K. Reddy P. Surawicz B. Characteristics and possible mechanism of ventricular. arthythmia dependent on the dispersion of action potentials. Circulation 1983: 67: 1356-1367.

49. Davidenko JM, Pertsov AM, Baxter WT. Cabo C. Jalife J. Gradients in action potential duration and conduction velocity underlie polymorphic tachycardia in isolated cardiac tissue. PACE 1994; 17:762 (abstract).

41. Abildskov JA. Lux RL. The mechanism of simulated Torsade de Pointes in a computer model of propagated excitation. / Candionasc Electrophysial 1991: 2: 224-237. 
Chapter 5

\title{
An essential contribution of early afterdepolarizations to dispersion of repolarization in the mechanism of acquired Torsade de Pointes arrhythmias
}

\author{
S. Cora Verduyn \\ Marc A. Vos \\ Jolanda van der Zande \\ Jurren van Opstal \\ Hein J.J. Wellens
}

Article submitred

Abstract presented at NASPE. 1995: Spontaneous termination of acquired Torsade de Pointes arrhythmias in dogs reveals causal relation between early afterdepolarizations with dispersion of repolarization. PACE 1995;18:830 


\section{ABSTRACT}

Spontaneous termination of pacing induced acquired Torsade de Pointes arrhythmias (TdP) and their reinduction was examined in anesthetized dogs with chronic AV block. Therefore early afterdepolarizations (EADs), action potential duration (APD) and interventricular dispersion $(\triangle \mathrm{APD})$, before $(B)$, of the last beat $(\mathrm{L})$ and after $\mathrm{TdP}$, were analyzed in 20 episodes of spontaneous terminating TdP ( $15 \pm 9$ beats, cycle length $(\mathrm{CL}): 240 \pm 20 \mathrm{~ms})$. TdP termination was associated with a shortening of the APD, a decrease in EADs (L: 0/40 vs B: 20/40) and interventricular $\triangle A P D$ (L: $10 \pm 15$ vs B: 80 $\pm 55 \mathrm{~ms}$ ). The first beat after termination again showed EADs and an interventricular $\triangle A P D$ of $60 \mathrm{~ms}$. Thereafter, with no change in CL, EADs diminished significantly from $23 / 40$ (beat 1) to $9 / 40$ (beat 5), while $\triangle A P D$ decreased to control values. TdP could only be reinduced by pacing when EADs and $\triangle \mathrm{APD}$ had completely returned. When measuring interventricular $\triangle \mathrm{APD}$ in the presence and absence of EADs, the contribution of EADs to interventricular $\triangle \mathrm{APD}$ was calculated to be around $35 \%$. Therefore an essential contribution of the EAD to the changes in interventricular $\triangle A P D$ and induction $\mathrm{TdP}$ is indicated.

\section{INTRODUCTION}

Torsade de Pointes arrhythmias (TdP) are an intriguing polymorphic ventricular tachycardia which can either be congenital or acquired following the administration of certain drugs or electrolyte abnormalities (1). In the presence of a prolonged QT(U) interval, TdP is often initiated by a short long short sequence (SLS, 1,2). The occurrence of these premature ectopic beats has been associated with the development of early afterdepolarizations (EADs, 3-7). However the presence of induced EADs leading to ectopic beats does not always result in the initiation of $\mathrm{TdP}(6)$, suggesting that at least one additional parameter is required to initiate TdP. The spontaneously occurring SLS sequence and its consequences can be mimicked by frequency changes induced by pregrammed electrical stimulation (PES) of the heart. In our animal model of acquired $T \mathrm{dP}$, PES is able to reproducibly induce TdP after administration of a therapeutic dose of the class $11 \mathrm{l}$ drug $d$-sotalol (7). We have recently shown, using endocardial monophasic action potential (MAP) recordings, that induction of TdP in this model is associated with bradycardia, prolonged QT duration, EADs, and interventricular dispersion in the duration of ventricular repolarization ( $\triangle A P D, 7,8)$. The presence of EADs, and the length of the action potential duration (APD) are positively correlated to the cycle length (9-14). Interventricular $\triangle A P D$ is also frequency dependent: in the absence of EADs the interventricular dispersion increases when the cycle length prolongs $(8,15)$. It seems plausible that EADs and interventricular $\triangle A P D$ are related, but it is unknown to what extent EADs contribute to interventricular $\triangle A P D$. It is also not clear whether 
EADs and interventricular $\triangle A P D$ play a role in the mechanism of continuation of 'TdP. Because part of the TdP episodes terminate spontaneously $(1,2,7)$, we used these episodes to gain more insight the possible contribution of EADs to interventricular $\triangle \mathrm{APD}$ and their role in the mechanism of TdP.

\section{METHODS}

All experiments were performed according to "Guiding principles in the care and use of animals" of the American Physiological Society and approved by the Committee for Experiments on Animals of the University of Limburg, Maastricht, the Netherlands.

\section{General}

The experiments were performed on 20 anestherized adult dogs with chronic AV block (6 $6 \pm 3.5$, range $2-11$ weeks) of either sex with a body weight berween 20 and $30 \mathrm{~kg}$. Each dog had one epicardial electrode (Bakken Research Center, Medtronic, Maastricht, The Netherlands) implanted at the apex of the left ventricle, after a right sided thoracotomy was performed to produce chronic complete AV block (for details see reference \#16). Pacing was done with a programmable stimulator capable of pacing synchronously to the QRS complexes. Unipolar stimuli were given using a pulse width of $2 \mathrm{~ms}$ and a stimulus strength of twice the diastolic threshold. As indifferent electrode a needle was placed through the skin. Six surface electrocardiographic leads and 2 MAP signals were simultaneously registered, diginized, visualized on a monitor and stored on hard disc. All drugs were administered through a canula in the cephalic vein.

Anaesthesia was induced by 1) premedication i.m. (1 ml/5 kg consisting of $10 \mathrm{mg}$ oxycodon, $1 \mathrm{mg}$ acepromazine and $0.5 \mathrm{mg}$ atropine) and 2) sodium pen robarbital ( 20 $\mathrm{mg} / \mathrm{kg}$ i.v.). The dogs were artificially ventilared through a cuffed endotracheal rube using a mixture of oxygen, nitrous oxide and halothane (vapor concentration $0.5 \%-1 \%$ ) by a respirator. Ventilation was adjusted on the basis of continuous reading of the carbon dioxide concentration in the expired air. A thermal mattress was used to maintain adequate body temperature.

Proper care was taken after the experiments, including antibiotics ( $1000 \mathrm{mg}$ ampicillin) and analgetics $(0.1 \mathrm{mg}$ i.m. buprenorfine). Temporary ventricular pacing (for a maximum of 24 hours) was performed after the AV block operation and after the experiments.

\section{Induction of Torsade de Pointes arrhythmias}

A detailed description of the Torsade de Pointes protocol is given elsewhere (7). In short, anestherized animals received two defibrillation patches that were attached to both sides of the chest and connected with a defibrillator. Half an hour after the onset of 
anaesthesia, pacing was done from the epicardial electrode using two different pacing modes: 1) short long short sequence, with intervals of 400 and $800 \mathrm{~ms}$ followed by an extrastimulus or intervals of 600 , and $1200 \mathrm{~ms}$ followed by an extra stimulus and 2) Eight basic stimuli with an interstimulus interval of $600 \mathrm{~ms}$ followed by an extra stimulus. During both pacing modes the interval of the extrastimulus was shortened from $500 \mathrm{~ms}$ in steps of $50 \mathrm{~ms}$ until $300 \mathrm{~ms}$. After completing the pacing protocol, one of the following class III agents was administered intravenously; $d$-sotalol $(2 \mathrm{mg} / \mathrm{kg} / 5$ $\mathrm{min})$ or almokalant $(0.12 \mathrm{mg} / \mathrm{kg} / 10 \mathrm{~min})$. Pacing was resumed 10 to 15 minutes after the start of the injection of the drug. A Torsade de Pointes arrhythmia was defined as a polymorphic ventricular tachycardia consisting of $\geq 5$ beats, which twisted around the baseline and occurring in the presence of a prolonged QT(U) duration. A second dose of $d$-sotalol ( $2 \mathrm{mg} / \mathrm{kg}$ ) was given when no TdP could be induced after the first dose. This was followed by reperition of the pacing protocol.

\section{Monophasic Action Potentials}

Monophasic action potentials were recorded to observe the occurrence of EADs and to measure the APD in the left and right ventricle before initiation, at the time of and after the termination of the TdP. The method used to record MAPs has been described in detail in an earlier report (8). Briefly, endocardial quadripolar contact electrodes (Franz combination catheter, EPT \# 1650), with pacing and MAP recording capabilities were placed at random in the right and the left ventricle via the external jugular vein and the carotid artery.

MAP phases were defined according to the definitions used for transmembrane action potentials (17). Amplitude was defined as the distance between phase 4 and 2 of the signal. Under control circumstances the MAP was required to have a minimal amplitude of $15 \mathrm{mV}$, an identical configuration in successive beats and a smooth shape.

EADs were defined as an interruption of the smooth contour of phase 2 or 3 of the action potential (5). The presence of EADs was examined in the LV as well as in the RV MAP.

\section{Inclusion criteria of TdP episodes}

We looked at 27 consecutive experiments in which either $d$-sotalol $(n=22)$ or almokalant $(n=5)$ were administered in combination with two simultaneous recorded MAP's in both ventricles. All spontaneously terminating $\mathrm{TdP}$ that were induced by the pacing protocol showing stable MAP recordings were included. Spontaneous initiation of TdP or TdP lasting longer than 10 seconds requiring cardioversion were excluded. 
Both the development of EADs and interventricular $\triangle A P D$ is bradycardia dependent. It is known that $d$-sotalol will increase the development of EADs by increasing APD. Because $d$-sotalol also lengthens CL-IVR, contribution of EADs to interventricular $\triangle A P D$ can only be assessed at the moment EADs appear and/or disappear when $C L$ is kept constant. In 6 additional experiments, we therefore continuously paced the ventricle during administration of $d$-sotalol leading to development of EADs. Paced CL was chosen just beneath IVR at baseline.

Secondly we performed a further subgroup analysis in the TdP group in which the disappearance and reappearance of EADs after termination was related to changes in interventricular $\triangle \mathrm{APD}$.

\section{Data analysis}

All data were analyzed by two independent observers using a custom made computer program with a resolution of $2 \mathrm{~ms}$ and adjustable gain and time scale.

Electrophysiological measurements of cycle length of the idioventricular rhythm (CLIVR) and APD were performed before, at the last beat of the TdP and after the spontaneous termination of the TdP. From each episode of TdP, the number of TdP beats was counted and the mean cycle length of the whole arrhythmia was determined. The first 5 beats after the TdP were individually measured. Thereafter every fifth beat was measured until the pacing train was repeated.

Interventricular dispersion of repolarization $(\triangle A P D)$ was calculated as the difference between the left and right APD using the total repolarization duration $\left(=A P D_{100}\right)$ in each ventricle.

\section{Statistics}

Comparisons were made using a paired or unpaired Student $t$-test when appropriate. $P$ values $\leq 0.05$ were considered significant. All data are presented as mean \pm standard deviation (SD).

\section{RESULTS}

In $15 / 27$ experiments, episodes of TdP could be reproducibly $(\geq 3)$ induced by PES. In the other experiments no TdP could be induced $(n=10)$, or the occurrence of numerous spontaneous TdP episodes prevented the performance of a pacing protocol $(n=2)$, In $10 / 15$ experiments spontaneous terminating TdP occurred. In these 10 experiments $(10$ dogs) a total of 39 (mean $3.9 \pm 1.5$ ) pacing induced episodes were seen: 12 had to be 
CONTROL
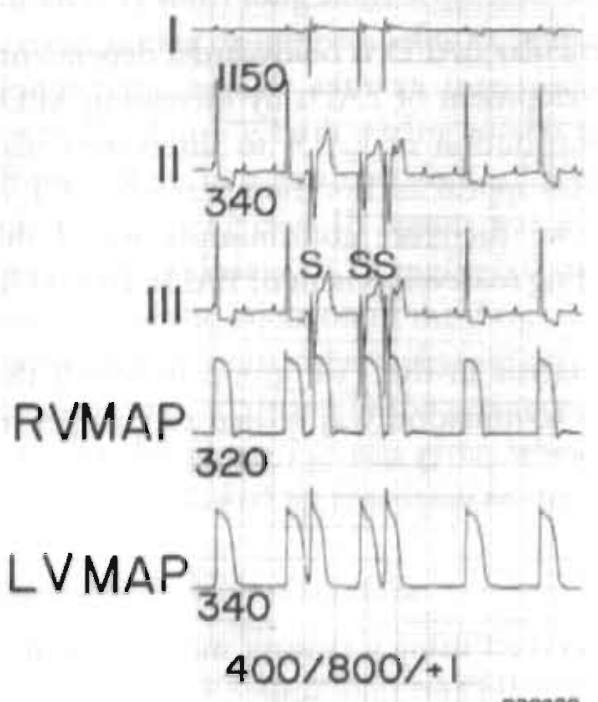
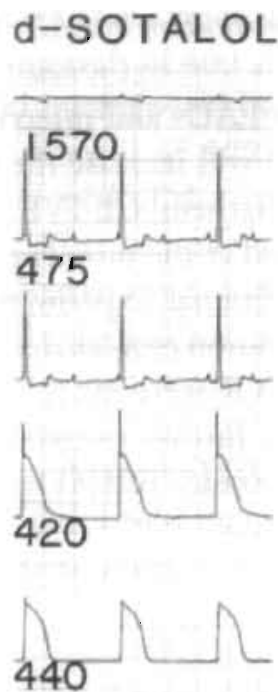

1st dose
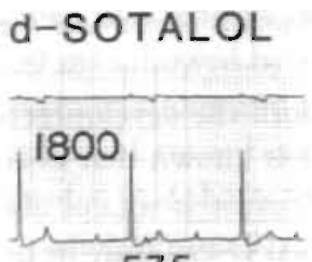

535
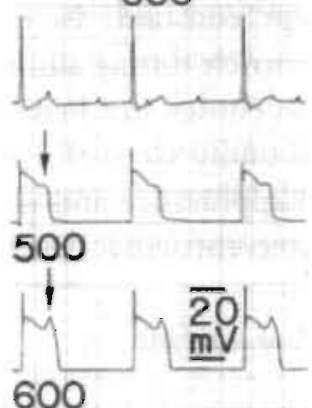

2nd dose

Figure 1. Repolarization parameters during baseline conditions and after administration of two dosages of d-sotalol.

Thiee ECG leads are recorded simultaneously with two monophasic action potential recordings in the right (RV) and in the left ventricle (LV) at a paper speed of $10 \mathrm{~mm} / \mathrm{s}$. Before pacing, a stable idioventricular rhychm (IVR) is seen with a cycle length (CL) of $1150 \mathrm{~ms}$ and a QT time of $340 \mathrm{~ms}$ (panel 1). Both action potentials are smooth with a duration (APD) of $340 \mathrm{~ms}$ for the LV and $320 \mathrm{~ms}$ for the RV. leading to a dispersion in duration of repolarization (AAPD) of 20 ms. The pacing train consisting of two stimuli of 400 and $800 \mathrm{~ms}$ followed by an extra after $400 \mathrm{~ms}$ is not able to induce a TdP under baseline conditions. In the second panel the effect of the firse dose of $d$-sotalol is seen. The CL-IVR and QT time prolong to $1570 \mathrm{~ms}$ and $475 \mathrm{~ms}$, while both APD's increase to 420 and $440 \mathrm{~ms}$ respectively. No TdP could be induced by the pacing protocol. Therefore a second dose of $d$-sotalol (panel 3) was given resulting in a further increase in C.L.IVR to $1800 \mathrm{~ms}$. Also the duration of all repolarization parameters prolonged further. Now the development of carly afterdepolarizations (EADs, arrows) can clearly be seen in both MAPs. The $\triangle A P D$ has increased to $100 \mathrm{~ms}$, due to a more pronounced increase in the LV APD compared to the RV APD.

cardioverted and 27 ended spontaneously. Of the spontaneously terminating TdP, 20 episodes fulfilled the criteria in regard to the MAP signal. These 20 episodes occurred in 6 dogs after the first injection of $d$-sotalol, in 2 dogs after the second dose, and in 2 dogs after almokalant. 
Table 1. Electrophysiological parameters (meantSD) before drug administration, before Torsade de Pointes (TdP), the last beat of TdP and after a spontaneously ending episode of TdP (TdP)

\begin{tabular}{lccccc}
\hline & control & before TdP & last beat of TdP & $1^{\text {st }}$ beat after TdP & $5^{\text {th }}$ beat after TdP \\
\hline CL-IVR (ms) & $1645 \pm 295$ & $1870 \pm 255$ & $250 \pm 30$ & $1920 \pm 420$ & $1935 \pm 315$ \\
LV APD (ms) & $365 \pm 45$ & $460 \pm 80$ & $250 \pm 25^{\circ}$ & $430 \pm 55^{\circ}$ & $390 \pm 55^{*}$ \\
RV APD (ms) & $325 \pm 30$ & $380 \pm 50$ & $235 \pm 15^{\circ}$ & $370 \pm 50^{\circ}$ & $345 \pm 40^{*}$ \\
$\triangle A P D(m s)$ & $40 \pm 25$ & $80 \pm 55$ & $10 \pm 15^{\circ}$ & $60 \pm 50^{\circ}$ & $45 \pm 30$ \\
EAD & 0 & $20 / 40$ & $0 / 40^{\circ}$ & $23 / 40$ & $9 / 40^{*}$ \\
\hline
\end{tabular}

"P<0.05 vs before TdP," P<0.05 vs 1" beat after TdP. CL-IVR: cycle length of the idioventricular rhythm. LV: left ventricle, RV: right ventricle, APD: action potential duration, $\triangle A P D$; difference between LV and RV action potential duration, EAD: early afterdepolarization.

\section{Induction of TdP by PES}

In the control situation, programmed electrical stimulation did not result in TdP, nor were any EADs registered (figure 1, panel 1). Ten minutes after the administration of the class III agents, $d$-sotalol or almokalant, the CL-IVR increased significantly from $1645 \pm 295$ to $1995 \pm 270 \mathrm{~ms}$, the LV APD from $365 \pm 45$ to $500 \pm 110 \mathrm{~ms}$, the RV APD from $325 \pm 30$ to $400 \pm 70 \mathrm{~ms}$ and interventricular $\triangle A P D$ from $40 \pm 25$ to 100 $\pm 75 \mathrm{~ms}$ (all $\mathrm{P}<0.01$ ). In addition, development of EADs after administration of the drugs (figure 1, panel 3 ) was observed in $8 / 10$ experiments prior to TdP induction.

\section{Characteristics of the TdP}

The 20 analyzed periods of TdP lasted $15 \pm 9$ beats (range 5-35), with a mean cycle length of $240 \pm 20 \mathrm{~ms}$ and occurred $22 \pm 9$ minutes after the start of the drug injection. The electrophysiological parameters are summarized in table 1. All parameters were somewhat decreased compared with 10 minutes after the start of the injection. Prior to TdP induction the mean LV APD amounted to $460 \pm 80 \mathrm{~ms}$ and the RV APD $380 \pm$ $50 \mathrm{~ms}$. Therefore the interventricular $\triangle A P D$ prepacing was $80 \pm 55 \mathrm{~ms}$. EADs were present in 20/40 MAP recordings. These EADs were more frequently seen in the LV MAP $(n=14)$ than in the RV MAP $(n=6, P<0.05)$. A representative example of a spontaneously terminating $\mathrm{TdP}$ can be seen in figure 2 .

The high rate of the $\mathrm{TdP}$ resulted in a significantly shorter $\mathrm{APD}$ and almost no dispersion in the last beat of the TdP before spontaneous termination. Furthermore no (subthreshold) EADs were seen in any of the rerminations (table 1, third column and figure 2, panel 2). 

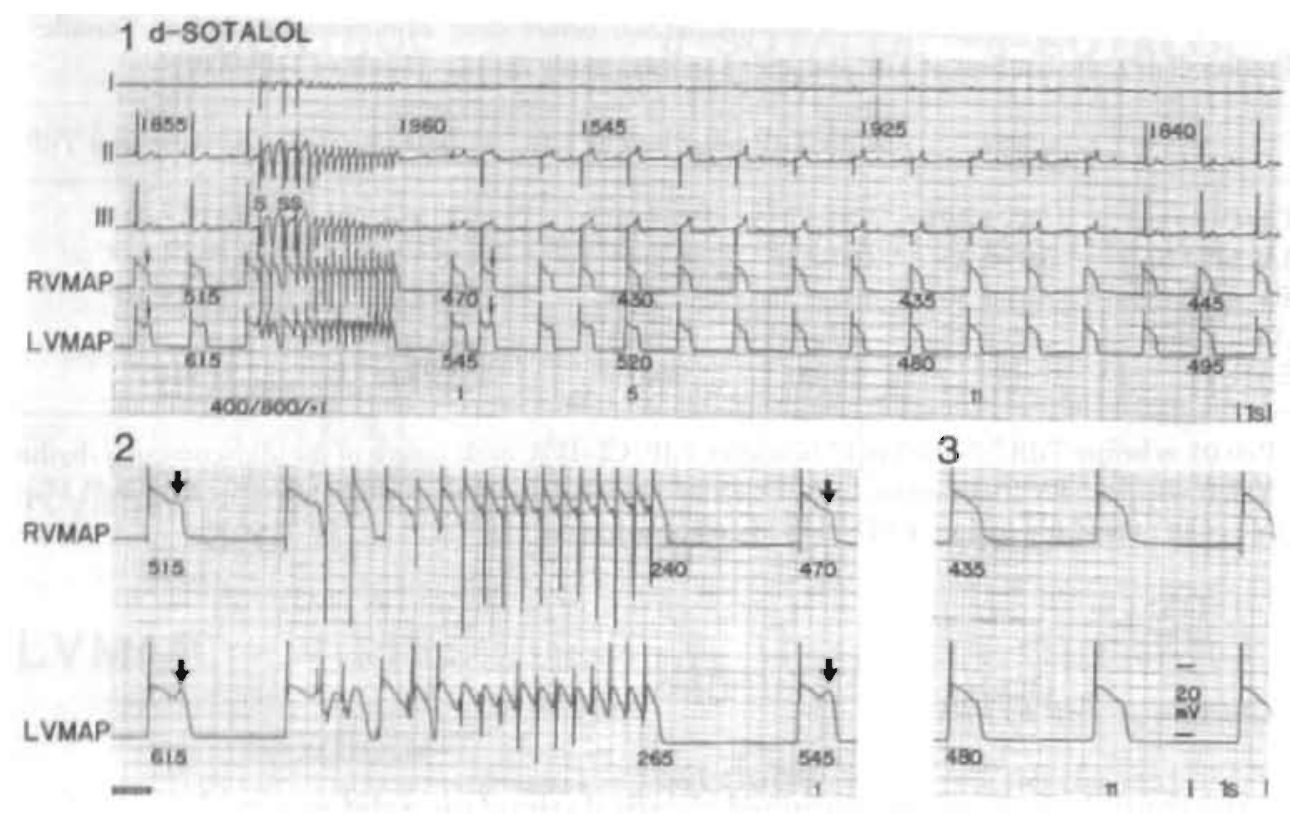

Figure 2. Initiation and spontaneous termination of a Torsade de Pointes arrhythmia (TdP) following d-sotalol administration.

This is the same experiment as in figure 1. Prior to TdP induction by pacing the CL-IVR amounts to 1855 ms with a QT time of $550 \mathrm{~ms}$. The LV APD measures $615 \mathrm{~ms}$ and the RV APD $515 \mathrm{~ms}$ resulting in a $\triangle A P D$ of $100 \mathrm{~ms}$. In both the LV APD and the RV APD a clear EAD (arrow) is seen. The same pacing train $(400 / 800 / 400 \mathrm{~ms}$, indicated by S) is now interrupted by an ectopic beat and after the extrastimulus the TdP starts. In panel 2 the MAP recordings during initiation and spontaneous termination have been enlarged. The last beat of the TdP has a $\triangle A P D$ of $25 \mathrm{~ms}$ and the EADs have disappeared, although a small deviation of the MAP is still present. This was not considered to be an EAD. In the first beat after the TdP the EAD is back in both MAP's (panel 2), In subsequent beats the EAD gradually decreases. In the 5 th beat the EAD from the RV has disappeared and the EAD in the LV has elearly diminished. In the 10th beat post termination the EAD on the LV has also disappeared (shown enlarged in panell 3). In line with the disappearance of the EADs the $\triangle A P D$ decreases $(90 \mathrm{~ms}$ in the 5 th to $45 \mathrm{~ms}$ in the 10 th beat).

\section{Behavior of electrophysiological parameters after spontaneous termination}

The first ventricular beat after the termination of the TdP occurred after $1920 \pm 550$ ms, and had a shorter APD compared with the prepacing beat. However EADs were again present (figure 2, panel 2) and interventricular $\triangle A P D$ was $60 \pm 50 \mathrm{~ms}$. In subsequent beats the APD shortened with a concomitant decrease in interventricular $\triangle A P D$ (figures 2-3). This decrease took place without a change in CL-IVR, and seemed to be related to a decrease in EADs (23/40 at the first beat to $9 / 40$ at the 5 th beat, 


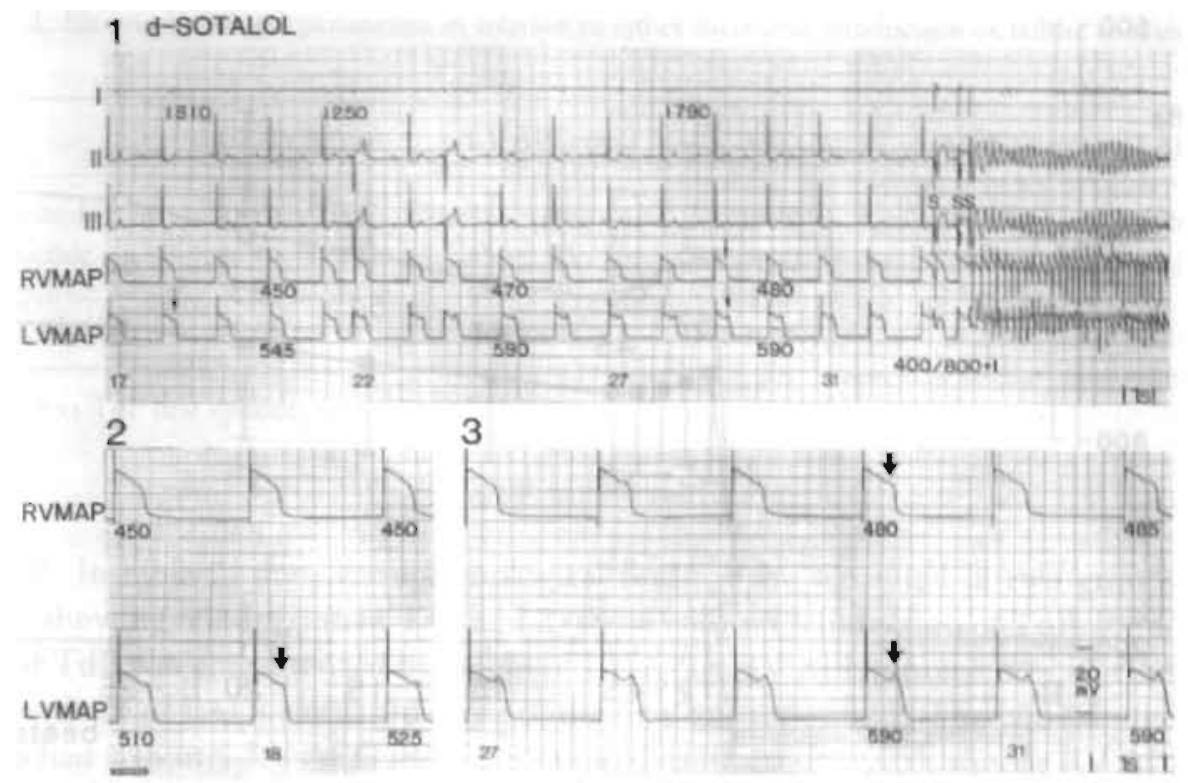

Figure 3. Return of EADs and dispersion leading to reinduction of TdP.

This figure is a continuous registration after figure 2 and has the same composition. It starts 17 beats after spontaneous termination of the TdP. An EAD is only minimally present in the left MAP and becomes more pronounced in the following beats (see the enlargement in panel 2). With the increase in height of the EAD in the LV MAP, the $\triangle A P D$ also gradually starts to increase from 60 (beat 17) to 110 ms (beat 30, see enlargement in panel 3), just before the reperition of the pacing train (panel 1). The EAD in the right MAP returns around the 25 th beat (panel 3). The same pacing train performed after 32 beats again induces a $\mathrm{TdP}$.

$\mathrm{P}<0.05)$. At the fifth beat, interventricular $\triangle A P D(45 \pm 30 \mathrm{~ms})$ is comparable to the control value $(40 \pm 25 \mathrm{~ms})$ for this CL-IVR (table 1).

After a short stable level of the APD between the 5 th and the 10 th beat post termination, the APD of both ventricles started again to increase (figures 2-4). This was accompanied by the reappearance of EADs and augmentation of interventricular $\triangle A P D$ (figure 3). The behavior of the LV and RV APD was not always synchronously, for example in figures 2 and 3, the RV EAD disappears around beat 5 whereas the LV APD only disappears around beat 10 . Also in the reappearance there are differences, the LV EAD is the first to return followed by the RV EAD. This incongruent behavior of the LV and RV EAD influences APD and interventricular $\triangle A P D$. The smallest interventricular $\triangle A P D$ is found when EADs are absent in both ventricles (figure 2, panel 3), and the reappearance of LV EADs increases the interventricular $\triangle A P D$ again to $120 \mathrm{~ms}$ at beat 25 (see further, figure 3). 


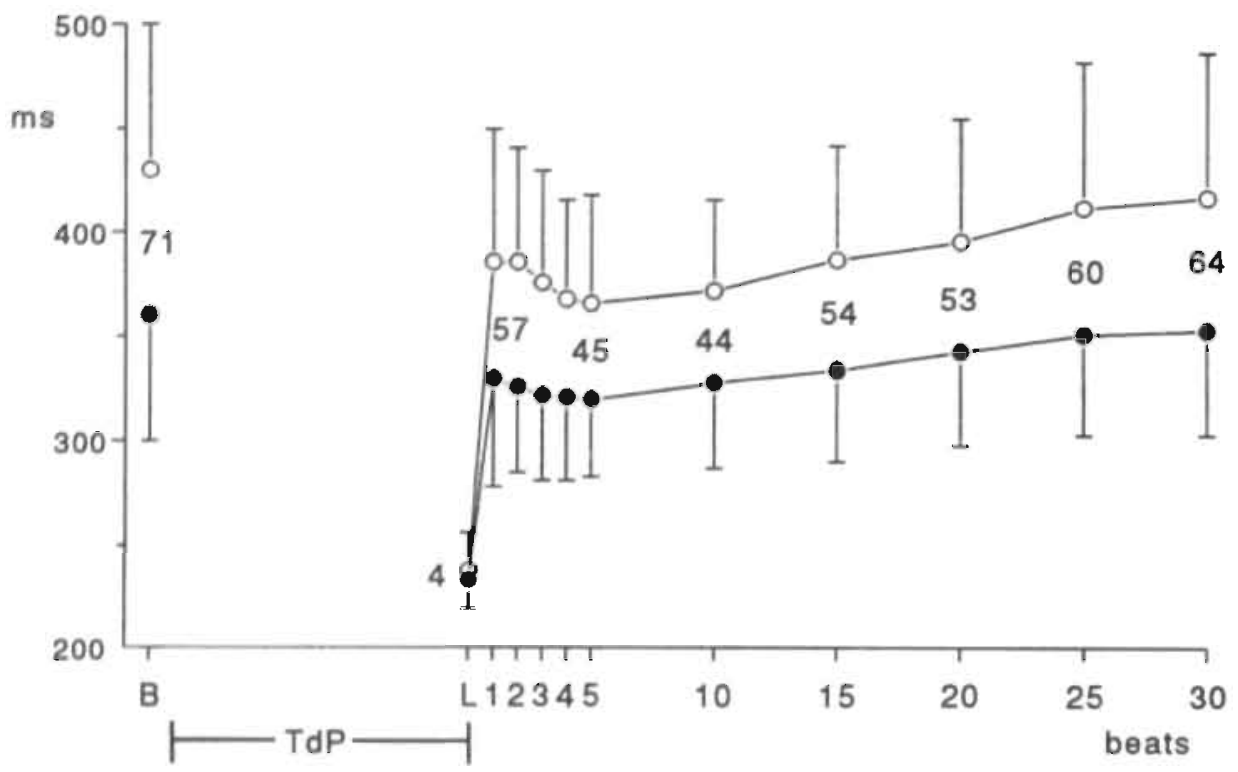

Figure 4. Time course of APD adaptation after spontaneous termination of TdP.

In this figure the time course of the APD of the right (-) and left ventricle $(0)$ is shown as the mean \pm SD before and after 12 episodes of TdP. The length of the APDs are shown on the vertical axis, and the number of beats before and after the TdP on the vertical axis. The first value is the APD of the last beat before (B) the stan of the pacing train leading to induction of TdP. Beat $\mathrm{L}$ is the last beat of the TdP. Due to the fast rate of the $T d I^{k}$ the APD of the last beat is decreased. The first beat (1) after termination of the TdP has an APD significantly shorter than beat B. The APD decreases further rill a minimum value is reached after 5 beats. Thereafter the APD increases slowly. At 30 beats after TdP the APD is still shorter than before the start of the TdP. The AAPD is shown berween the lines of the RV and LV APD. The same pattern of shortening and subsequent increase can be observed.

The course of the APD could be followed in 12 episodes for 30 beats after termination (figure 4). At the end of these 30 beats the APD had not yet completely returned to its prepacing value (see below). Again the difference in APD behavior can be observed, the curve of the LV APD seem to differ from the RV APD. In this subgroup of TdP, the CL-IVR ranged from $1825 \pm 235 \mathrm{~ms}$ at the prepacing beat to $1860 \pm 665,1935 \pm 300$ and $1815 \pm 235 \mathrm{~ms}$ at the first, fifth and 30th beat after termination.

\section{Reinduction of TdP}

Repetition of the pacing train after $32 \pm 9$ beats was performed in $15 / 20 \mathrm{TdP}$. A positive response i.e. reinitiation of TdP was evoked in $8 / 15$ of the attempts (figure 3 ). In 5 other attempts a maximum of 4 ectopic beats were evoked, which did not meet our definition 
Table 2. Electrophysiologic parameters in relation to either successful reinduction or failure to reinduce TdP

\begin{tabular}{llllll}
\hline & CL-IVR (ms) & LV APD (ms) & RV APD (ms) & AAPD (ms) & EADs \\
\hline First episode $\mathrm{n}=8$ & $1810 \pm 295$ & $455 \pm 90$ & $380 \pm 70$ & $70 \pm 30$ & $8 / 16$ \\
Reinducible & $1790 \pm 290$ & $455 \pm 75$ & $385 \pm 60$ & $70 \pm 35$ & $7 / 16$ \\
First episode $\mathrm{n}=7$ & $1965 \pm 220$ & $445 \pm 85$ & $370 \pm 40$ & $75 \pm 65$ & $5 / 14$ \\
Not reinducible & $1995 \pm 150$ & $420 \pm 70^{\circ}$ & $370 \pm 45$ & $50 \pm 40^{\circ}$ & $2 / 14$ \\
\hline
\end{tabular}

P<0,05 vs TdP first episode, same abbreviations as table 1.

of TdP. In table 2, the electrophysiological findings are separated in two groups: 1) Those showing reinduction of $\mathrm{TdP}$ and 2 ) those without reinduction of $\mathrm{TdP}$. Reinduction of TdP was characterized by values of LV APD, RV APD, interventricular $\triangle A P D$ and presence of EADs similar to those of the first episode of TdP. The non reinducible group had a shorter LV APD ( $445 \pm 85$ vs $420 \pm 70 \mathrm{~ms}, \mathrm{P} \leq 0.05)$, similar RV APD, a lower incidence of EADs and a significantly smaller interventricular $\triangle A P D$ than when the TdP could be induced.

\section{Short and long episodes of $T d P$}

The influence of the duration of the TdP was studied with a comparison between short episodes ( $\leq 10$ beats) and long episodes (>10 beats). The CL-IVR, LV APD and interventricular $\triangle A P D$ before $T d P$ were similar. Termination of TdP occurred when the LV APD was $\pm 250 \mathrm{~ms}$ irrespective of duration. Also the reoccurrence of EADs in the first beats after termination and their subsequent disappearance were similar in both groups.

\section{Estimate of the contribution of EADs to interventricular $\triangle A P D$}

Disappearance of EADs: In general after spontaneous termination all EADs disappeared. However the temporal behavior for their disappearance in the dogs was different. Moreover within dogs the response of the LV and RV is different in time (see e.g figure 2-3). The EAD of the left ventricle disappeared after a mean of 5 beats (range 2-9) and that of the right ventricle after 3 beats (range 2-5).

The presence of EADs was diminished from 23/40 (LV:12, RV:11) in beat 1 to $9 / 40$ ( $6 \mathrm{LV}, 3 \mathrm{RV}$ ) in beat 5 . In table 3, four different situations are compared between beat 1 and beat 5: 1) Total absence of EADs in the first and 5th beat $(n=3), 2)$ Total disappearance of the EAD in the left and/or right ventricle $(n=10)$. Irrespective of the 
Table 3. Relation between the presence and or disappearance of EADs with the amount of $\triangle A P D$ in bear I to 5 after spontancous TdP termination

$\triangle A P D$ beat $1 \quad \triangle A P D$ beat 5 difference (ms)

1) Absence of EADs $(n=3)$

2) Total disappearance of all EADs $(n=10)$

$30 \pm 50 \mathrm{~ms}$

$50 \pm 50 \mathrm{~ms}$

$80 \pm 45 \mathrm{~ms}$

3) Disappearance of LV EADs $(n=7)$

4) Continued presence of LV EADs $(n=6)$

$\begin{array}{cc}30 \pm 25 \mathrm{~ms} & 0(0 \%) \\ 35 \pm 15 \mathrm{~ms} & 15(30 \%) \\ 40 \pm 10 \mathrm{~ms} & 40(50 \%) \\ 80 \pm 45 \mathrm{~ms} & 0(0 \%)\end{array}$

$30 \pm 25 \mathrm{~ms}$

$0(0 \%)$

$0(50 \%)$

$0(0 \%)$

For abbreviations see table 1 .

behavior of the EAD in the right ventricle we scored 3) Disappearance of the EAD in the left ventricle $(n=7)$, or 4) Persistence of LV EADs $(n=6)$.

When the EADs disappeared (group 2 and 3) we calculated that EADs contribute 30 to $50 \%$ to the interventricular $\triangle A P D$ (table 3 ). In both other instances no change in interventricular $\triangle A P D$ was observed. In the 15 episodes of table 2, EADs reappeared in 9 MAPs. The reappearance of the LV EAD increased the interventricular $\triangle A P D$ from $75 \pm 55$ to $120 \pm 55 \mathrm{~ms}(45 / 120=35 \%)$.

Oecurrence of EADs: Paced CL was $1750 \pm 390 \mathrm{~ms}$. During the administration of $d$-sotalol the APD of both ventricles significantly increased from $420 \pm 45$ to $495 \pm 65$ ms (LV) and $355 \pm 30$ to $420 \pm 35 \mathrm{~ms}$ (RV). In 4/6 experiments EADs developed (LV EADs: 4 and RV EADs: 1). In the experiments with appearance of EADs, the interventricular $\triangle A P D$ increased significantly with approximately $40 \%$ from $65 \pm 40$ to 90 $\pm 40 \mathrm{~ms}$, whereas in the 2 experiments without appearance of EADs no change in interventricular $\triangle \mathrm{APD}$ occurred.

\section{DISCUSSION}

In this study self terminating TdP was analyzed to 1) obtain further knowledge about the mechanism of termination and thereby also of the mechanism of continuation of TdP, And 2) to address the relationship between EADs and interventricular $\triangle A P D$. Termination of acquired TdP' is associated with a decreased incidence of EADs and. at decreased interventricular $\triangle A P D$, while (re)induction is associated with the presence of EADs and an increased interventricular. $\triangle A P D$. Although. EADs and interventricular $\triangle A P D$ are bradycardia dependent, EADs contribute significantly $(35 \%)$ to interventricular $\triangle \mathrm{APD}$. 
Triggered activity based on EADs is generally considered to be the initiating mechanism of TdP $(4,5,7-10,14,17)$. In our animal model of TdP the occurrence of EADs or triggered ectopic beats after $d$-sotalol administration occur also in non inducible experiments and seems therefore not to be sufficient to initiate TdP (6). We and others suggested that besides EADs, TdP induction requires the presence of a critical amount of interventricular $\triangle \mathrm{APD}(8,18,19)$, caused by regional differences in repolarization, which are possibly accentuated by abrupt frequency changes.

At baseline, EADs are absent, while interventricular $\triangle A P D$ is relatively small. Abrupt frequency changes (by using PES) do not result in TdP. Class III agents induce EADs, increase interventricular $\triangle \mathrm{APD}$ and $\mathrm{TdP}$ can now be induced by sudden frequency changes, which may either occur spontaneously (SLS sequence) or can be induced by the use of PES. Occurrence of (spontaneous) TdP is associated with a large interventricular $\triangle A P D$ and presence of EADs and ectopic beats $(8,20)$.

In this study, confirmation of the involvement of both parameters came in the artempts to reinduce TdP. Reinduction was only possible when EADs and interventricular $\triangle A P D$ had returned to their original values. In addition, suppression of EADs and diminishment of interventricular $\triangle \mathrm{APD}$ by drugs (i.e. $\mathrm{MgSO}_{4}$ or flunarizine) prevents spontaneous and/or pacing induced $\mathrm{TdP}(8.21)$.

\section{Mechanism of termination of the TdP}

By definition a decrease in cycle length (e.g. by a tachycardia), will decrease EADs, APD $(5,7-10,12,13)$ and the interventricular $\triangle A P D(8)$. The disappearance of EADs and the marked shortening of the $(\triangle) A P D$ at spontaneous termination are therefore in line with the effect of the increased rate. In this animal model around $60 \%$ of the total shortening of the APD rakes place in the first 20 beats after an increase in rate (22).

Spontaneous termination indicates the impossibility to continue the arihythmia. The mechanism of termination might give more insight about the electrophysiological changes responsible for continuation. The last beat of the $\mathrm{TdP}$ is devoid of EADs and the interventricular $\triangle A P D$ is small. The time of disappearance is not known because the MAP recording does not allow analysis during the TdP. Because the duration of TdP episodes varies (in clinical circumstances TdP can last over 1 minute $(23,24)$, other factors than EADs and $\triangle A P D$ can be involved in the continuation and eventual termination of TdP. Also the time point at which TdP deteriorated into ventricular fibrillation is different. Because VF is based on a reentrant mechanism (25) there is a strong indication that other mechanisms can be responsible for continuation.

This is also suggested by in vitro and computer models proofing the existence of a reentrant mechanism (e.g. 26,27). However mapping data obtained in vivo demonstrate focal activity $(28,29)$ as possible mechanism of continuation. This point is not yet settled 
and additional experiments should be performed e.g. using multiple transmural MAP electrodes. This would enable to investigate transmural, inter- and intraventricular differences in repolarization and the formation (and triggering) of local EADs.

EADs and $\triangle A P D$ are both present in the first beat post termination. The (re)appearance of EAD might be caused by the sudden deceleration of the rate. As we and other have shown sudden rate changes can lead to pronunciation of (the amplitude of) EADs $(7,30)$. In the following beats the EAD disappears concomitantly with the $\triangle \mathrm{APD}$. The APD (independent of EADs) shortens, which might be a delayed compensation for the fast rate of the TdP. Thereafter APD starts to increase to pre TdP levels. A similar APD behavior has been described in humans after an abrupt deceleration in rate (11).

\section{Presence of EADs and $\triangle \mathrm{APD}$}

Discrimination between EADs and $\triangle A P D$ in the genesis of TdP is difficult because both are bradycardia dependent $(8,13,17,31)$. Already at baseline without EADs, at a CL-IVR of $1650 \mathrm{~ms}$, there is a difference between LV and RV APD of approximately $40 \mathrm{~ms}$. At longer $C L$ this $\triangle A P D$ increases $(8,15)$. This frequency dependence of interventricular dispersion is also observed in vitro: left ventricular cells demonstrate a longer APD than. the right ventricle at slow heart rates. This not only the case for endocardial (and epicardial) cells but also and even more pronounced for the recently described $\mathrm{M}$ cells (32). At $2000 \mathrm{~ms}$ this leads to a $\triangle A P D$ of about $100 \mathrm{~ms}$ (figure 4 of reference 32) withour the presence of acrion potential prolonging drugs. The presence of EADs can further increase $\triangle A P D$. The $M$ cell behaves like a Purkinje fiber in the aspects of rate dependent APD behavior and their sensitivity to develop EADs (14). However Purkinje fibers do not contribute much to the MAP signal due to their small mass (30-33). Because M cells are found throughout the left, right and in the ventricle septum (34), their mass could be sufficient to be registered by the MAPs. In the intact canine heart, EADs arising from the $M$ cells have been also described (35). The combination of EADs and increase in CL contribute both to the observed increase in $\mathrm{APD}$ after class III agents.

In the literature several arguments are in favor of a contribution of the EAD to the $\triangle A P D, 1)$ The longest APD is often the one with the most pronounced EAD (18,19). Site specific EADs could therefore contribute to inter- but also to intraventricular $\triangle A P D, 2)$ Magnesium suppresses the EADs and decreases $\triangle A P D$ despite an increase in CL-IVR (8).

In this study the disappearance of EADs after spontaneous termination is associated with a decrease in $\triangle A P D$ while (re)appearance of EADs corresponds to an increase of $\triangle A P D$ (figures 2,3,4). An estimation of the contribution of EADs to $\triangle A P D$ is only possible without changes in cycle length. We calculated the contribution of the EAD to the $\triangle A P D$ to be berween 25 to $50 \%$.

There are some limitations to this estimate: 1) random placement of the MAPs might fail to detect all EADs, 2) the LV and RV do not seem to behave synchronously (figure 
2-4). This dynamicity alters $\triangle A P D$ from beat to beat, and 3) the role of the RV EAD in $\triangle A P D$ is not clear. Presence of EADs in both ventricles is not associated with a smaller $\triangle A P D$ (see e.g. figure 2-3). A possible explanation for this apparent contradiction could be the difference in baseline values. It is likely that EADs will develop earlier in longer APDs. The RV EAD development will therefore lag behind the LV EAD. If the LV EAD still grows when the RV EAD occurs the value of the $\triangle A P D$ will be maintained, only when the LV EAD has reached its maximum value the contribution of the RV EAD to APD will alter $\triangle \mathrm{APD}$.

A fourth point are the small variations in CL-IVR and QRS complexes after termination. which might have influenced the behavior of EADs and $\triangle A P D$ by different activation times and rate. However the contribution of EADs to $\triangle A P D$ was confirmed in the steady state pacing experiments with $d$-sotalol, where both activation time and rate are constant. Another important fact is that the experiments are performed in dogs with chronic AV block. Chronic AV block leads to biventricular hypertrophy due to volume overload (15) and may play a role in the occurrence of EADs and the magnitude of $\triangle A P D$. It has been described that ventricular hypertrophy facilitates the induction of EADs (9). The effect of hypertrophy on EADs and $\triangle A P D$ requires further investigation.

In conclusion the fast rate of the TdP reduces EADs and interventricular $\triangle A P D$. concomitant with termination of the TdP. Besides their role in the initiation this indicates an important role for as well EADs as $\triangle A P D$ in the mechanism of continuation of TdP. EADs provide an essential contribution (25-50\%) to the changes in interventricular $\triangle A P D$, as evidenced by the behavior of EADs and $\triangle A P D$ after spontaneous termination and after administration of class III agents at paced cycle lengths.

\section{Acknowledgements}

The Bakken Research Center (Medtronic), Maastricht, the Netherlands provided the epicardial electrodes. ASTRA, Gotenburg, Sweden, (dr L. Carlsson) supplied us with almokalant and Bristol Meyers Squibb, Brussels, Belgium with $d$-sotalol.

This study was supported by a grant of the Netherlands Heart Foundation ( $\$ 91.104$ and \#94.010).

\section{REFERENCES}

1. Jackman WM. Friday KJ, Anderson JL, Alior EM, Clark M, Lazzara R. The Long QT syndromes: a critical review, new clinical observations and a unifying hypothesis. Prog Cardiayasc Dis 1988; 31: $115-172$.

2. Leenhardt A, Coumel P, Slama R. Torsade de Pointes. J Cardiovasc Electroptysiol 1992; 3: 281-291.

3. Cranefield PF, Aronson RS. Torsade de Pointes and other pause induced ventricular tachycardias: the short long short sequence and carly afterdepolarizations. PACE 1988; 11:670-678. 
4. Jackman WM, Szabo B, Friday KJ, Margolis PD, Moulton K, Wang X, Patterson E, Lazzara R. Ventricular tachyrhythmias related to early afterdepolarizations and triggered firing: relationship to QT interval prolongation and potential therapeutic role for calcium blocking agents. J Cardiovase Electrophysiol 1990; 1: 170-195.

5. Levine JH, Spear JF, Guarnieri T. Weisfeldt ML, de Langen CDJ. Becker LC, Moore EN. Cesium chloride-induced long QT syndrome: Demonstration of afterdepolarizations and triggered activity in vivo. Circulation 1985; 72: 1092-1103.

6. Verduyn, SC, Vos MA, van der Zande J, Wellens HJJ. Occurrence of early afterdepolarizations induced triggered beats does not guarantee initiation of spontaneous Torsade de Pointes. PACE 1995; 18; 1095 (abstract).

7. Vos MA. Verduyn SC, Gorgels APM, Lipscei GC, Wellens HJJ, Reproducible induction of early afterdepolarizations and torsade de pointes arrhythmias by $d$-sotalol and pacing in the dog with chronic atrioventricular block. Circularion 1995: 91: 864-872.

8. Verduyn SC, Vos MA, Zande van der J. Steld van de BJ, Wellens HJJ. Role of interventricular dispersion of repolarization for the induction of acquired early afterdepolarization dependent Torsade de Pointes arhhythmias:reversal by magnesium. (submitted)

9. Ben-David J, Zipes DP. Ayers GM. Pride HP. Canine left ventricular hypertrophy predisposes to ventricular tachycardia induction by phase 2 early afterdepolarizations after administration of Bay K 8644. I Am Coll Cardiol 1992; 20: 1576-1584.

10. Brachmann J. Scherlag BJ, Rosenshtraukh LV, Lazzara R. Bradycardia dependent triggered activity: Relevance to drug induced multiform, ventricular tachycardia. Circulation 1983: 68: 846-856.

11. Franz MR, Swerdlow CD, Liem LB, Schaefer J. Cycle length dependence of human action potential duration in vivo. Effects of single extrastimuli, sudden sustained rate acceleration and deceleration, and differens steady state frequencies, / Clin Imest 1988: 82: 972-979.

12. Priori SG, Corr PB. Mechanism underlying early and delayed afterdepolarizations induced by cathecholamines. Am / Physiol 1990; 258: H.1796-H1805.

13. Roden DM. Hoffman BF. Action potential prolongation and induction of abnormal automaticity by low quinidine concentrations in canine purkinje fibers. Relationship to potassium and cycle length. Cir Res 1985: 56: 857-867.

14. Wyse KR, Ye V. Campbell TJ. Action potential prolongation exhibits simple dose- dependence for $d$-sotalol, but reverse dose-dependence for quinidine and disopyramide: implications for proarthythmia due to triggered activiry. f Cardiowase Pharmacol 1993: 21: 316-322.

15. Vos AM, de Groot SHM, van der Zande J, Verduyn SC. Wellens HJJ. Electrophysiologic changes observed after creation of AV block in the dog. PACE 1995; 18: 1094 (abstract).

16. Vos MA. Gorgels APM. Lipseci GC, de Groor SHM, Leunissen JDM. Wellens HJJ. Mechanism specific anti-arrhythmic effects of the potassium channel activator leveromakalim against repolarization dependent tachycardias. / Cardiovasc Electrophysio/ 1994: 5: 731-742.

17. Damiano BP, Rosen MR. Effects of pacing on triggered activity induced by early afterdepolarizations. Circulation 1984: 69: 1013-1025.

18. Habbah MA. El-Sherif N. Drug induced Torsade de pointes: Role of early afterdepolarizations and dispersion of repolarization. Am / Medicine 1990; 89: 24:-246.

19. Bonatti V. Rolli A. Botti G. Monophasic action potential studies in human subjects with prolonged ventricular repolarization and long QT syndromes. Eur Heart / 1985; 6: 131-143 (suppl).

20. Verduyn SC, Vos MA. Zande van der J. Wellens HJI. A comparison berween the proarrhythmic effecr of almokalant and d-sotalol in an animal model of Torsade de Pointes arrhythmias. I Am Coll Cardiol 1995: 170A. (abstract).

21. Verduyn SC, Vos MA. Gorgels APM, van der Zande J. Leunissen JDM, Wellens HJJ. The effect of flunarizine and ryanodine on acquired Torsade de Pointes arrhythmias in the intact canine heart. $f$ Candiotase Flectrophysiol 1995; 6: 189-200. 
22. Leerssen, HM, Vos MA, den Dulk K, van der Zande J, Muijijens AM, Begemann MJ, Wellens HJJ. The dynamics of cardiac repolarization after an abrupt decrease in pacing cycle length assessed by simultaneous measurements of the ventricular effective refractory period, the action potential duration and the stimulus T interval. 1995, submitted.

23. Wellens HJJ, Vermeulen A, Durrer D. Ventricular fibrillation occurring from arousal from sleep by auditory stimuli. Circulation 1972; 46: 661-665.

24. Wiesfeld ACP, Crijns HJGM, Tobe TJM, Almgren O, Bergstrand RH. Aberg J, Haaksma J, Lie KI. Electropharmocologic effects and pharmokinetics of almokalant, a new class III antiarrhythmic, in patients with healed or healing myocardial infarets and complex ventricular arrhythmias. Am / Cardiol 1992; 70: 990-996.

25. Hoffman BF Rosen MR. Cellular mechanisms for cardiac arrhythmias. Circ Res 1981; 49: 1-15.

26. Abildskov JA, Lux RL. The mechanism of simulated Torsade de Pointes in a computer model of propagated excitation. J Cardiovase Electrophysiol 1991; 2: 224-237.

27. Davidenko JM, Pertsov AM, Baxter WT, Cabo C, Jalife J. Gradients in action potential duration and conduction velocity underlie polymorphic tachycardia in isolated cardiac tissue. PACE 1994; 17: 762 (abstract).

28. Katsuki T, Usuda K, Sagakami S, Nakamura Y, Takata S, Kobayashi K. Mechanisms of initiation and maintenance of Torsades de Pointes. PACE 1994: 17: 763 (abstract).

29. Sterns LD, Schoels W, Senges JC, Freigang KD, Bauer A, Kuebler W, Brachmann J. Activation parterns of canine cesium chloride induced ventricular arrhythmias determined by three dimensional mapping. PACE 1994; 17: 762 (abstract).

30. Li Z-Y, Maldonado C, Zee-Cheng C. Hiromasa S, Kupersmith J. Purkinje fibre-papillary muscle interaction in the genesis of triggered activity in a guinea pig model. Cardiovase Res 1992:26: 543-548.

31. El-Sherif N, Zeiler RH, Craelius W, Gough WB, Henkin R. QTU prolongation and polymorphic ventricular tachyarrhythmias due to bradycardia dependent afterdepolarizations. Afterdepolarizations and ventricular arrhythmias. Circ Res 1988; 63: 286-305.

32. Antzelevitch C, Sicouri S. Clinical relevance of cardiac arshythmias generated by afterdepolarizations. Role of $\mathrm{M}$ cells in the generation of $\mathrm{U}$ waves, triggered acrivity and Tersade de Pointes. J Am Coll Cardiology 1994: 23: 259-277.

33. Ino T, Karagueuzian HS, Hong K, Meesmann M, Mandel WJ. Peter T. Relation of monophasic action potential recorded with contact electrode to underlying transmembrane action porenrial properries in isolated cardiac rissues: a systemic micro-electrode validation study. Cardiovasc Res 1988; 22: 255-264.

34. Sicouri S. Fish J. Antzelevitch C. Distribution of $\mathrm{M}$ cells in the canine ventricle. / Cardiovase Electrophysiol 1994; 5: 824-837.

35. Hariman RJ, Wang Y, Sharif MA, Louie ES, Hwang MH, Loeb HS, Scanlon PJ. Early afterdepolarizations arising from $\mathrm{M}$ cells in intact dogs. Circulation 1992; 86: I-301 (abstract). 

Chapter 6

\title{
The effect of flunarizine and ryanodine on acquired Torsade de Pointes arrhythmias in the intact canine heart.
}

\author{
S. Cora Verduyn \\ Marc A. Vos \\ Anton P. Gorgels \\ Jolanda van der Zande \\ Jet D.M. Leunissen \\ Hein J.J. Wellens
}

published in J Cardiovasc Electrophysiol 1995;6:189-200. 
Ryanodine, a specific blocker of the $\mathrm{Ca}^{2+}$ release channel of the sarcoplasmic reticulum, and flunarizine, a $\left[\mathrm{Ca}^{2+}\right]_{\mathrm{i}}$ overload blocker, possess antiarrhythmic effects against delayed afterdepolarizations (DADs) and DAD dependent arrhythmias. In vitro controversy exists about their effect against early afterdepolarizations (EADs): no effect was reported against cesium induced EADs, while ryanodine did prevent EADs induced by isoproterenol.

Objectives: To study the possible role of intracellular $\mathrm{Ca}^{2+}$ overload in acquired EAD dependent Torsade de Pointes arrhythmias (TdP), we tested the effects of flunarizine and ryanodine in our animal model of TdP. Methods: Anaesthetized dogs with chronic AV block received $d$-sotalol or almokalant followed by pacing. A subset of dogs with reproducible TdP ( $\geq 3$ times) were selected to receive flunarizine ( $2 \mathrm{mg} / \mathrm{kg} / 2 \mathrm{~min}$ ) or ryanodine $(10 \mu \mathrm{g} / \mathrm{kg} / 10 \mathrm{~min})$. Results: After $d$-sotalol, TdP was induced at a mean cycle length of the idioventricular rhythm (CL-IVR) of $2070 \pm 635 \mathrm{~ms}$ and a QT(U) time of $535 \pm 65 \mathrm{~ms}$. Induction of TdP was prevented by flunarizine in all experiments (8/8), electrophysiologically this was associated with a decrease in CL-IVR, QT(U) and QT time ( $390 \pm 100$ to $320 \pm 45, \mathrm{P}<0.05)$. Ryanodine prevented $\mathrm{TdP}$ induction in $4 / 5$ experiments, and decreased the CL-IVR, QT(U) and the $\mathrm{QT}_{c}$ time from $385 \pm 75$ to $320 \pm 20 \mathrm{~ms}(\mathrm{P}<0.05)$. Both drugs also suppressed the almokalant induced EADs and related ectopic activity. This antiarrhythmic action corresponded with the inability to reinduce TdP by pacing. Conclusions: Blockade of the $\mathrm{Ca}^{2+}$ release channel of the sarcoplasmic reticulum by ryanodine or the reduction of $\left[\mathrm{Ca}^{2+}\right]_{i}$ overload by flunarizine prevents induction of EAD dependent acquired TdP arrhythmias, suggesting a role for $\left[\mathrm{Ca}^{2+}\right]_{\mathrm{i}}$ overload in acquired Torsade de Pointes.

\section{INTRODUCTION}

Over the years, Torsade de Pointes arrhythmias (TdP) have attracted the interest of many investigators. However, several questions are still unresolved or a matter of controversy, including $\mathrm{I}$ ) the mechanism(s) responsible for the initiation and perpetuation of TdP, for which dispersion of repolarization and/or early afterdepolarizations (EADs) have been suggested (1). 2) The transmembrane currents by which TdP can be generated. It has been shown that TdP (or EADs) can be evoked under different circumstances and by several drugs (2-11), all prolonging action potential duration. 3) The involvement of intracellular $\mathrm{Ca}^{2+}$ transients $(9,12,13)$. It was first suggested by Capogrossi and Lakatta (12), that spontaneous $\mathrm{Ca}^{2+}$ oscillations are the common basis of EADs and delayed afterdepolarizations (DADs). Experimentally this has been confirmed in situations of $\left[\mathrm{Ca}^{2+}\right]_{i}$ overload $(9,13,14)$. Pharmaceutical interventions directed 
to reduce the $\left[\mathrm{Ca}^{2+}\right]_{\mathrm{i}}$-overload will suppress $\mathrm{DADs}$ and perhaps EADs and their arrhythmias.

Ryanodine, a blocker of the $\mathrm{Ca}^{2+}$ release channel of the sarcoplasmic reticulum (SR) is known to suppress DAD dependent tachyarrhythmias both in vivo $(15,16,17)$ and in vitro (18). Its effects on EADs is somewhat controversial: in vitro no effect was seen in cesium induced EADs (18) whereas it suppressed isoproterenol induced EADs (9). Similar results have been documented for the $\left[\mathrm{Ca}^{2+}\right]_{i}$ overload blocker flunarizine. Flunarizine prevented the development of DADs caused by ouabain and/or cathecholamines in vitro (19) and stopped and prevented ouabain induced tachycardia in the intact dog heart (17). Flunarizine has been reported not to influence cesium induced EADs in Purkinje fibers (19).

No studies are available on the antiarrhythmic effect of ryanodine and flunarizine on EADs and EAD dependent arrhythmias in the intact heart. Therefore we tested these drugs in our animal model of acquired EAD dependent Torsade de Pointes arrhythmias (20). Secondly, because the exact mechanism of action of flunarizine is still unknown, this study also allowed a comparison between the mode of action of flunarizine and ryanodine.

\section{METHODS}

All experiments were performed according to the principles of the American Physiological Sociery and approved by the Committee for Experiments on Animals of the Universiry of Limburg, Maastricht, the Nerherlands.

The experiments ( $\mathrm{n}=17$ ) were performed on 11 anaestherized adult mongrel dogs with chronic AV block ( $9 \pm 6$ weeks) of either sex with a body weight between 18 and $32 \mathrm{~kg}$. In berween the AV block operation and the experiment, dogs were daily checked whether their idioventricular rate was sufficient to obtain adequate cardiac curpurt.

Each dog had two epicardial electrodes (Bakken Research Center, Medrronic, Maastricht, The Netherlands) implanted at the apex of the lefi ventricle and at the base of the right ventricle, when a right sided thoracotomy was performed to produce a chronic AV block (21).

Pacing was done with a programmable stimulator capabie of pacing synchronously to the QRS complexes. Unipolar stimuli were given using a pulse width of 2 mis and a stimulus strength of twice diastolic threshold. As indifferent electrode a needle was placed through the skin. Six surface electrocardiographic leads were registered and stored on oprical disc. All drugs were administered through a canula in the cephalic vein.

Anaesthesia was induced by 1 ) premedication i.m. (1 ml/5 kg: $10 \mathrm{mg}$ oxycodon, $1 \mathrm{mg}$ acepromazine and $0.5 \mathrm{mg}$ atropine) and 2) sodium pentobarbital $(20 \mathrm{mg} / \mathrm{kg}$ i.v. $)$ The dogs were artificially ventilated through a cuffed endotracheal tube using a mixture of oxygen, nitrous oxide and halothane (vapor concentration $0.5 \%$ ) by a respirator. 
Ventilation was controlled by continuous reading of the carbon dioxide concentration. in the expired air. A thermal mattress was used to maintain adequate body temperature. Proper care was taken before and after the experiments, including antibiotics ( $1000 \mathrm{mg}$ ampicillin) and analgesics (0.1 mg i.m. buprenorfine). A temporary ventricular pacemaker (maximum of 24 hours) was given after the AV block operation and after the experiments.

\section{Induction of Torsade de Pointes arrhythmias}

A detailed description of the Torsade de Pointes protocol is given elsewhere (20). In short, anesthetized animals with chronic AV block received two defibrillation patches that were attached to both sides of the chest and connected with a defibrillator. Half an hour after onset of anaesthesia, pacing was done from the epicardial electrode and consisted of three different pacing modes: 1) short long short sequences and 2) 8 basic stimuli followed by an extrastimulus and 3) 3 basic stimuli. The interstimulus interval was 400,600 or $1200 \mathrm{~ms}$, the extrastimulus interval shortened from $500 \mathrm{~ms}$ in steps of $40 \mathrm{~ms}$ until the ventricular effective refractory period was reached. After completing the pacing protocol, $d$-sotalol $(2 \mathrm{mg} / \mathrm{kg} / 5 \mathrm{~min})$ or almokalant $(0.12 \mathrm{mg} / \mathrm{kg} / 10 \mathrm{~min})$ was administered. Pacing was resumed 10 minutes after the start of the injection. A Torsade de Pointes arrhythmia was defined as a polymorphic ventricular tachycardia consisting of $\geq 5$ beats, which twisted around its baseline in the presence of a prolonged QT(U) duration. When TdP did not stop spontaneously within 10 seconds or deteriorated into ventricular fibrillation, cardioversion (60-70 J) was performed.

Inducibility was defined as the initiation of TdP 3 or more times using the same pacing mode. Earlier experiments have proven that the electrophysiological and pro-arrhythmic effects of a single intravenous bolus of $d$-sotalol and almokalant last for at least 60 minutes $(20,22)$. In 3 experiments (flunarizine $\mathrm{n}=2$, ryanodine $\mathrm{n}=1$ ) a second bolus of $d$-soralol or $d l$-sotalol was needed to provide reproducible inducible TdP. In subsequent experiments, in two of these three dogs induction was repeated consistently after the second bolus to also test this reproducibility in time.

\section{Flunarizine and ryanodine administration}

Reproducible inducible TdP experiments were selected to test the preventive effect of flunarizine $(2 \mathrm{mg} / \mathrm{kg} / 2 \mathrm{~min})$ and ryanodine $(10 \mu \mathrm{g} / \mathrm{kg} / 10 \mathrm{~min})$. Both drugs were administered within 45 minutes after the last bolus of $d$-sotalol, and within 20 minutes after almokalant. Five minutes (flunarizine) and 10 minutes (ryanodine) after the start of the injection the pacing train(s) which initiated the TdP was (were) repeated.

Both flunarizine and ryanodine are known to decrease blood pressure $(16,23,24)$, due to their vasodilatory effects and/or negative inotropic effects. This blood pressure drop may lead to a reflex tachycardia. Because an increased ventricular rate may protect against 
TdP induction (20), we performed for both drugs experiments in which the basic heart rate was kept constant by pacing. In case of ryanodine, TdP induction was attempted with the use of a basic ventricular paced rhythm of $2000 \mathrm{~ms}$ during two entire experiments ( $d$-sotalol and almokalant), because the CL-IVR of the dogs was very slow ( $\pm 2200 \mathrm{~ms}$ ). With flunarizine, TdP induction was attempted for $d$-sotalol both at IVR $(1320 \mathrm{~ms})$ and at the "expected" CL after flunarizine (1100 ms), and at a basic ventricular rhythm of $2000 \mathrm{~ms}$ for almokalant. In one experiment TdP was induced by administration of $d l$-sotalol instead of $d$-sotalol, so that the acceleration of ventricular rate by flunarizine would be prevented by $\beta$ blockade.

\section{Electrolytes}

In 8 of these animals electrolyte levels were measured after complete anesthesia was installed. To exclude changes in electrolytes by drugs, or due to cardioversion, we measured electrolytes in 2/8 dogs at two other time points: namely after induction of $\mathrm{TdP}$ (with and without the necessity to cardiovert) and after administration of flunarizine or ryanodine.

\section{Electrophysiology}

Electrophysiological measurements of cycle length of the idioventricular rhythm (CLIVR) and QT(U) time were performed before and after the administration of $d$-sotalol, almokalant and the two drugs. The $\mathrm{QT}_{\mathrm{c}}$ time was calculated using the formula of Bazett (25).

\section{Early afterdepolarizations}

To review the direct effects of ryanodine and flunarizine on the presence of EADs, a monophasic action porential catherer (MAP) was placed in the right ventricle to visualize action potential duration (APD) and EADs in 5 experiments after $d$-sotalol. The MAP (Franz combination carheter, EPT \# 1650) was placed under fluoroscopy through the jugular vein. The MAP was amplified by a DC-coupled differential amplifier, which is provided with a $20 \mathrm{mV}$ calibration pulse. The MAP signals were sampled at a rate of 1 $\mathrm{KHz}$. The recording sites were chosen based on stability, quality of the signal and an amplitude which had to exceed $15 \mathrm{mV}(20)$.

In the first experiments $(n=3)$, we had difficulties to maintain a stable MAP rhroughout the duration of the experiment ( \pm 120 minutes). Although this problem is now resolved, it is often difficult to visualize clearly distinguishable EADs afrer $d$-sotalol in the right ventricle (see also ref \#20). Therefore we used a second class III drug: almokalant of which the prevalence of endocardial EADs is higher than afrer $d$-sotalol (22). 


\section{Statistics}

Statistical significant differences ( $\mathrm{P} \leq 0.05$ ), were calculated with the use of a paired student $t$-test. All values are given as mean $\pm \mathrm{SD}$.

\section{RESULTS}

\section{Induction TdP}

In our animal model of TdP, the combination of bradycardia, $d$-sotalol and pacing results in reproducible TdP in about $50 \%$ of the experiments (20). A second bolus of $d$-sotalol increases this figure to almost $90 \%$. Administration of almokalant results in \pm $80 \%$ of the animals in reproducible TdP (22).

Fifteen inducible experiments $(\mathrm{n}=13$ with $d$-sotalol $)$ in 11 dogs were selected to test the preventive antiarrhythmic activity of ryanodine $(n=6)$ and flunarizine $(n=9)$. Animals tested twice had 1) different pacing modes tested in the subsequent experiments ( $n=2)$, or 2 ) $\mathrm{dl}$-sotalol instead of $d$-sotalol to provide $\beta$ blockade $(n=1)$. Identical responses to $d$-sotalol were observed in these dogs indicating a high reproducibility of this animal model.

$d$-Sotalol prolonged the CL-IVR from $1830 \pm 510$ to $2070 \pm 635 \mathrm{~ms}(\mathrm{P}<0.01)$ and the QT(U) time from $445 \pm 60$ to $535 \pm 65 \mathrm{~ms}$ ( $\mathrm{P}<0.01$ ). $d$-Sotalol administration was often accompanied by a change in the TU wave configuration. In one experiment next to pacing induced TdP, some episodes of spontaneous TdP were seen. In figure 1, a representarive example of pacing induced TdP is presented.

Administration of almokalant $(\mathrm{n}=2)$ resulted in the presence of stable EADs (figure 2, panel 2). Moreover, spontaneous and pacing induced TdP were seen. TdP induction by almokalant is alike $d$-sotalol characterized by an increased CL-IVR, QT time and change in QT morphology (22).

Reproduction of TdP in time after second bolus of d-sotalol

Application of cardioversion in order to terminate the TdP did not influence the reproducible induction of the TdP. Also after a second bolus of $d$-sotalol, TdP induction remained reproducible until 60 minutes after administration.

\section{Flunarizine}

Administration of flunarizine did not alter $\mathrm{CO}_{2}$ values of the capnograph indicative that no major hemodynamic changes occurred by flunarizine. In table 1 , the time dependent effects of $d$-sotalol and flunarizine $(n=7)$ are summarized. Following the bolus of 


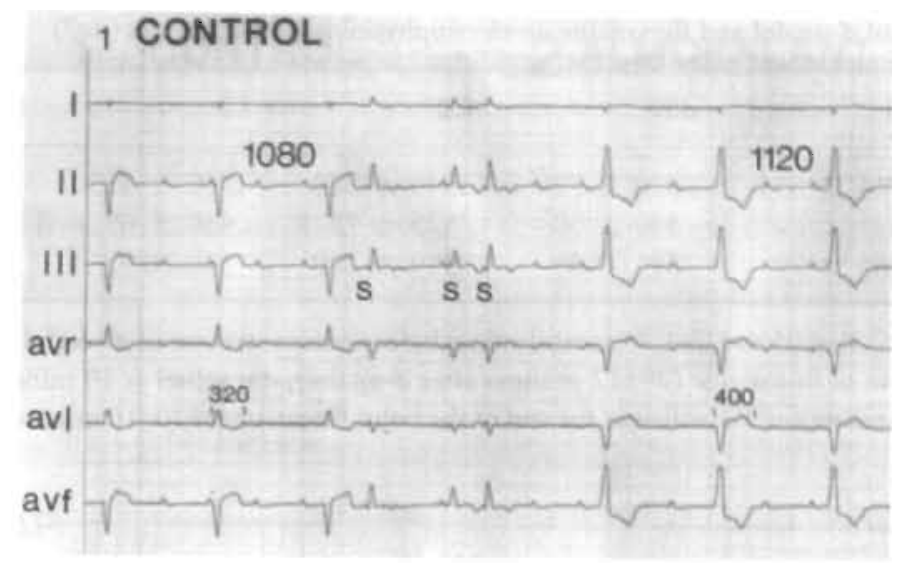

\section{2 d-SOTALOL}

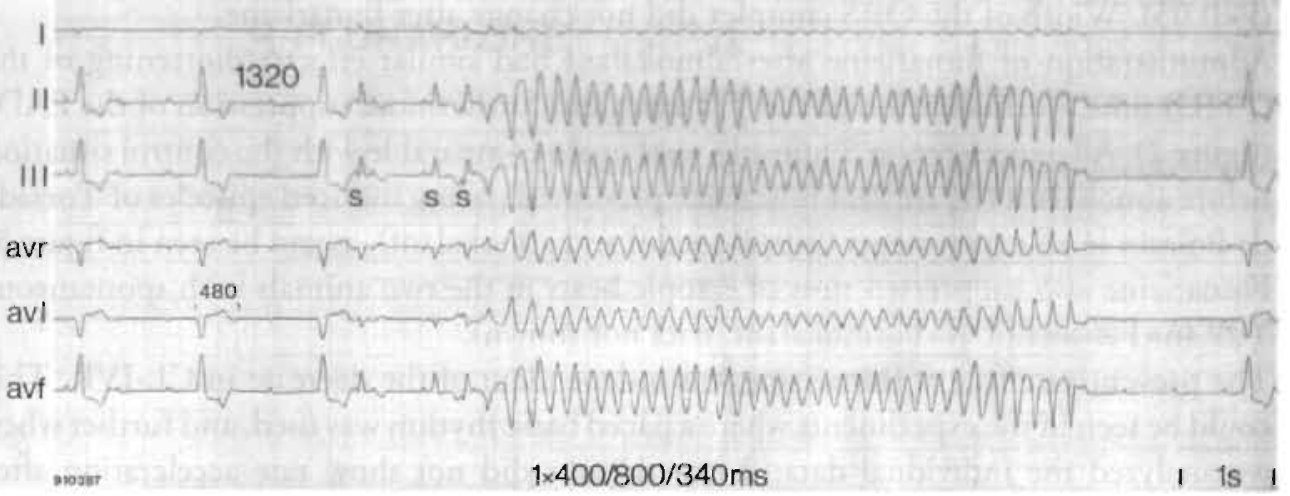

Figure 1. Induction of a Torsade de Pointes arthythma by d-sotalol and pacing.

A six lead ECG at a paper speed of $25 \mathrm{~mm} / \mathrm{s}$ is shown. In the upper panel two QRS morphologies can to seeri, one before and one complex after pacing. In control conditions (panel 1) pacing (400/800 and an extra of 340) ms does not result in ectopic activity (stimulated beats are indicated by an 5). In this animal the stimuli were given via a bipolar endocardially located catheter in the right ventricle and not by the epicardial electrode as done in all other experiments. $d$-Sotalol (panel 2) increases the CL-IVR and the QT time. The same pacing train results in a self terminating TdP.

$d$-sotalol, its electrophysiologic effects diminished over time. Therefore we added a second 'control' measurement (C2), just before the start of flunarizine $(29 \pm 12 \mathrm{~min}$ after $d$-sotalol). There were no differences in the electrophysiological values at 10 minutes after $d$-sotalol compared to C2. Flunarizine decreased the CL-IVR (18\%) and 
Table 1. Effects of $d$-sotalol and flunarizine on electrophysiological parameters ( $n=7$ )

\begin{tabular}{lcrrrr}
\hline & C1 & dS & C2 & F2 & \multicolumn{1}{c}{ F10 } \\
\hline CL-IVR & $1715 \pm 595$ & $2030 \pm 780^{\circ}$ & $1940 \pm 580$ & $1760 \pm 485$ & $1595 \pm 380^{* *}$ \\
QT & $435 \pm 60$ & $540 \pm 50^{\circ}$ & $525 \pm 75$ & $440 \pm 65$ & $395 \pm 55^{* *}$ \\
QT $_{c}$ & $345 \pm 70$ & $395 \pm 55^{\circ}$ & $390 \pm 100$ & $340 \pm 55$ & $320 \pm 45^{* *}$ \\
\hline
\end{tabular}

P<0.05 vs C1, " $\mathrm{P}<0.05$ vs $\mathrm{C} 2$; $\mathrm{C} 1$ : control values before administration of $d$-sotalol, $\mathrm{C} 2$ : value before the administration of flunarizine (29 12 minutes after $d$-sotalol), dS: values at 10 minutes after the start of $d$-sotalol administration, F2: values at the end of the bolus flunarizine, F10: 10 minutes after flunarizine administration.

QT $(U)$ time (25\%). The latter was more pronounced than could be expected from the decrease in CL-IVR, as expressed by the decrease in $\mathrm{QT}_{\mathrm{c}}$ from $390 \pm 100$ to $320 \pm 45$ $(\mathrm{P}<0.05)$. Width of the QRS complex did not change after flunarizine.

Administration of flunarizine after almokalant had similar effects: shortening of the QT $(U)$ time, normalization of the TU wave and furthermore suppression of the EADs (figure 2). All parameters at 5 minutes were again comparable with the control situation before almokalant (figure 2). Flunarizine prevented pacing induced episodes of Torsade de Pointes in all experiments $(9 / 9, d$-sotalol and almokalant), as can be seen in figure 3 . Flunarizine also suppressed runs of ectopic beats in the two animals with spontaneous $\mathrm{TdP}$ ( $\mathrm{n}=1 d$-sotalol, $\mathrm{n}=1$ almokalant, data not shown).

The preventive effect of flunarizine was independent of the decrease in CL-IVR. This could be seen in the experiments where a paced basic rhythm was used, and further when we analyzed the individual data: 2 experiments did not show rate acceleration after flunarizine. In one of these two experiments this was due to $\beta$ blockade by $\mathrm{dl}$-sotalol. The antiarrhythmic effect of flunarizine lasted at least 30 minutes. Thereafter TdP could be reinduced in 2 experiments. Besides these electrophysiological effects, flunarizine had also distinct effects on the configuration of the TU wave in all experiments; after flunarizine administration the $\mathrm{U}$ wave disappeared or the $\mathrm{T}$ wave became more peaked suggesting a more homogeneous repolarization of the ventricles. This was also present in a dog that showed repolarization disturbances already during and directly after pacing under control conditions (figures 4-5).

\section{Ryanodine}

Ryanodine had no effect on the $\mathrm{CO}_{2}$ values of the capnograph. Ryanodine was administered at $36 \pm 19$ minutes after $d$-sotalol (C2). Again there was no difference in electrophysiologic parameters between $\mathrm{C} 2$ and 10 minutes after $d$-sotalol. Ryanodine decreased the QT(U) time and did not significantly affect the CL-IVR at the end of the 
1 CONTROL

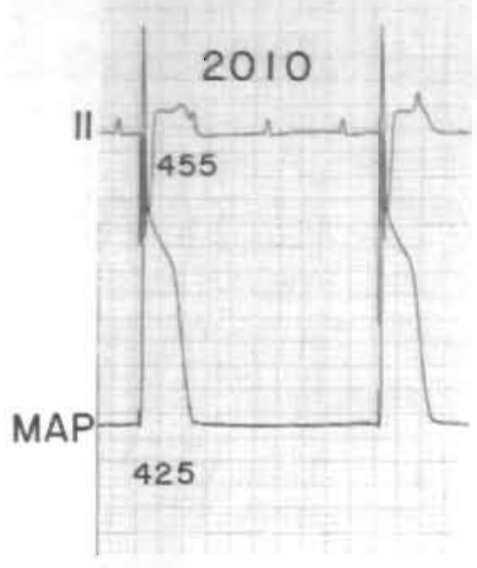

3 FLUNARIZINE

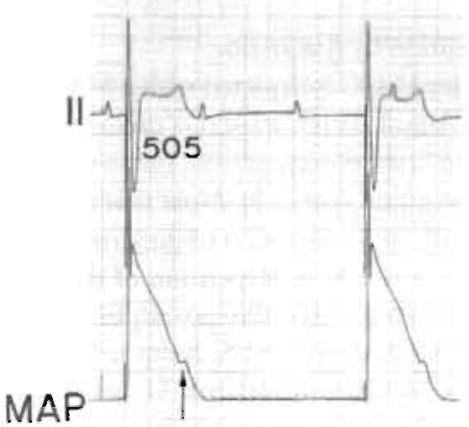

540
2 ALMOKALANT

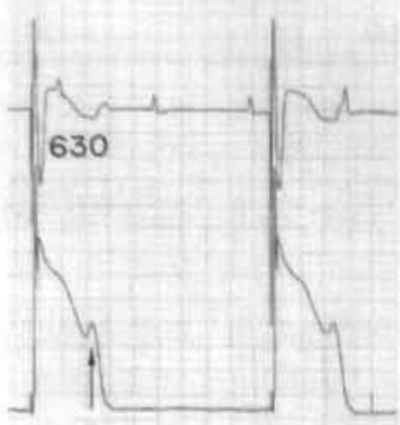

615

4

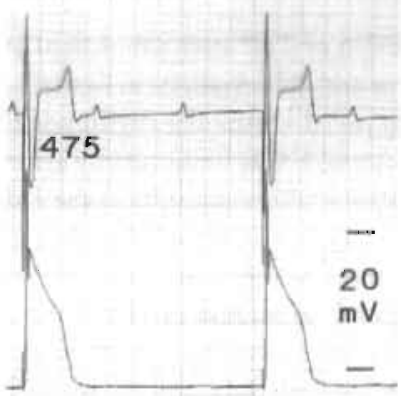

420

$\mathrm{t}=5$

I is I

Figure 2. Development of EADs after almokalant and suppression of EAD, by flunarizine.

Lead II of the normal surface ECG and a monophasic action potential recording (MAP) at a paper speed of $25 \mathrm{~mm} / \mathrm{s}$ are shown. In panel 1, the control situation is depicted: a ventricular paced rhythm of $2010 \mathrm{~ms}$ and a QT rime of $455 \mathrm{~ms}$ can be seen. Just before the administration of flunarizine ( $\left.2 \mathrm{mg} / \mathrm{kg} / 2^{\prime}\right)$, almokalant $(0.12$ $\mathrm{mg} / \mathrm{kg}$ ) has increased the QT time and APD, has changed the QT morphology and has led to EADs (arrows, panel 2). At the end of the bolus flunarizine (panel 3), the QT and the APD has been shortened to $505 \mathrm{~ms}$ and $540 \mathrm{~ms}$ but an EAD is still present. At 5 minutes after flunarizine the EAD has completely disappeared and the QT and the APD have been further reduced (panel 4). 


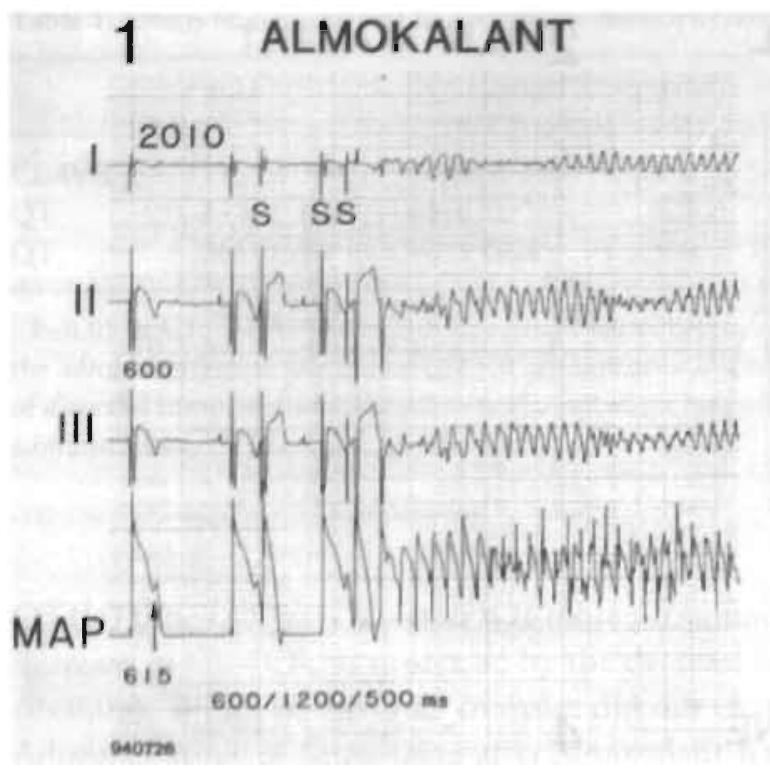

\section{FLUNARIZINE}
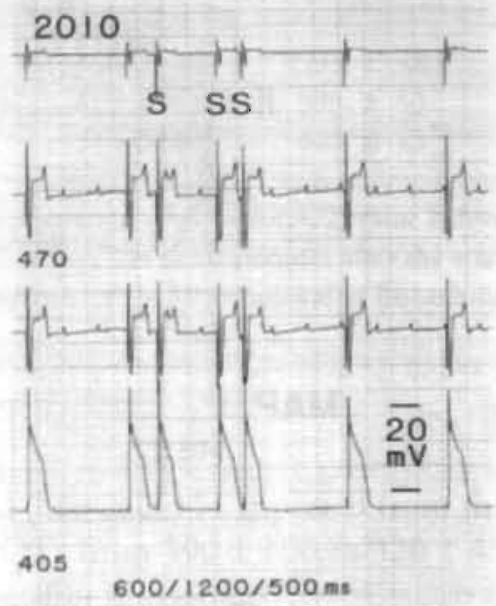

$|1 \mathrm{~s}|$

Figure 3. Induction of TdP after almokalant and prevention by flunarizine.

Same experiment and abbreviations as figure 2. A three lead ECG is depicted with a MAP recording. There

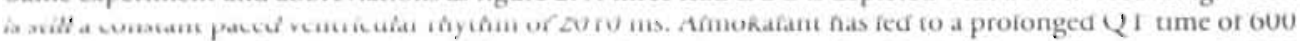
ms and appearance of EADs (indicated by arrow). Pacing (a short cycle of 600 , followed by a pause of 1200 and an extrastimulus $500 \mathrm{~ms}$ ) results in the induction of a TdP (panel 1). Note that the last extrastimulus does not capture and that an ectopic beat initiates the TdP. Administration of flunarizine shortens the QT. normalizes TU morphology and causes disappearance of the EADs. Repetition of the same pacing train now does not lead to induction of 'TdP'.

infusion (10 minutes). At 15 minutes both QT(U) time (23\%) and CL-IVR (20\%) were however significantly reduced (table 2).

Ryanodine prevented pacing dependent TdP successfully in $4 / 5$ dogs after $d$-sotalol. In the one experiment with almokalant ryanodine prevented spontaneous TdP by a decrease in APD and a suppression of EADs, starting from the 8 th. minute after start of the infusion.

The effect of ryanodine cannot only be attributed to the acceleration in rhythm, as seen from the $\mathrm{QT}_{c}$ and in the experiments with a constant paced rhythm in which it was also effective. The effect of both ryanodine and flunarizine seems therefore to be dependent. on the (more pronounced) decrease in QT ${ }_{(c)}$ time. No reoccurrences of the TdP were observed after the preventive effect of ryanodine.

In one dog ryanodine administration after $d$-sotalol did not prevent TdP. In that experiment even a spontaneous TdP occurred during administration of ryanodine 


\section{QT morphology}

CONTROL
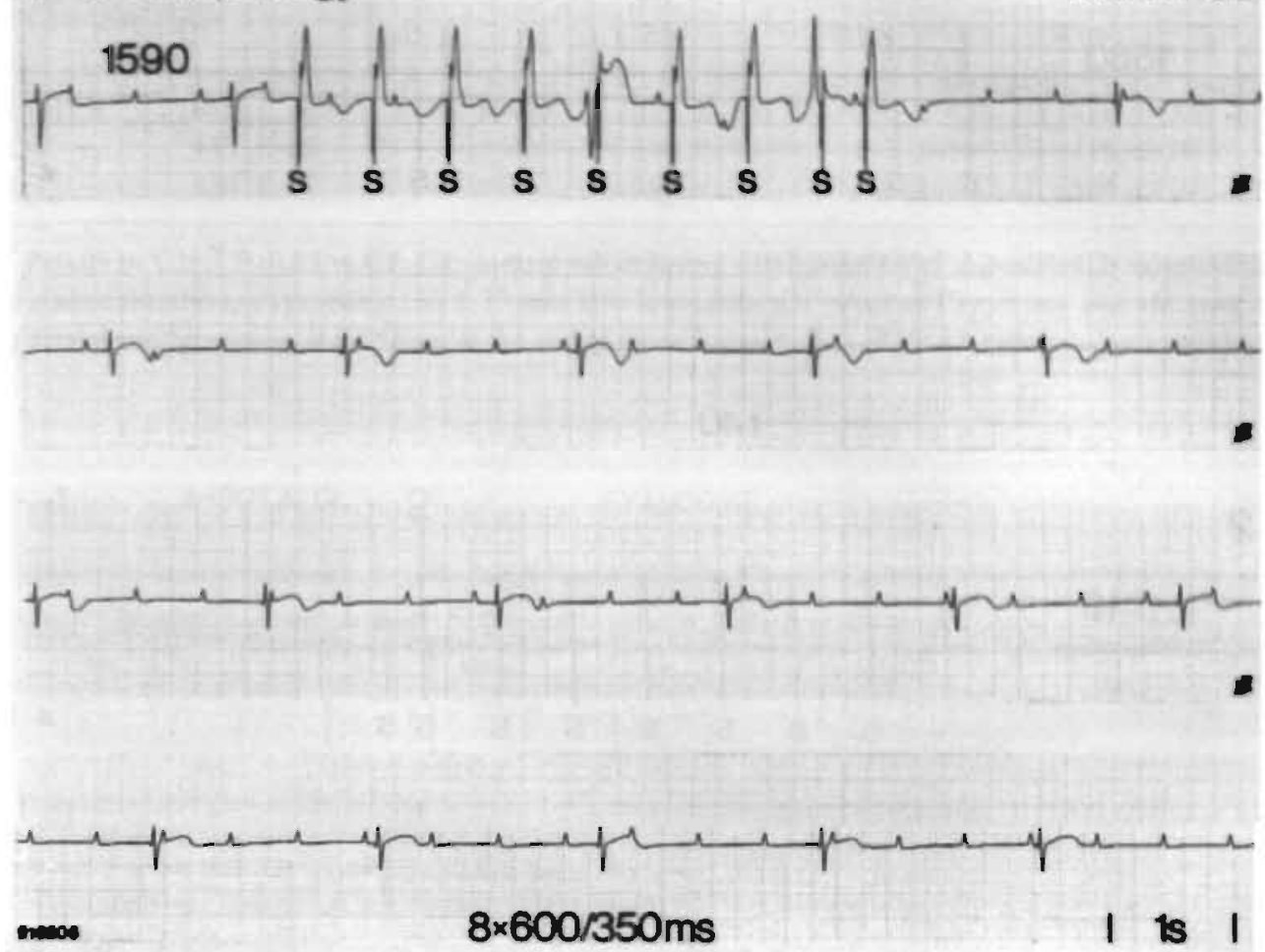

Figure 4. Occurrence of pacing induced negative T waves under baseline conditions.

One ECG lead at a paper speed of $25 \mathrm{~mm} / \mathrm{s}$ is shown. Pacing under control conditions reveals repolarization disturbances as seen by: 1) the development of a deep TU wave during and after pacing; and 2) the occurrence of two spontaneous ectopic beats in the pacing train. The altered TU wave morphology postpacing is disappearing in time (continuous racing).

(figure 6). During $d$-sotalol the use of a pacing train was always necessary to initiate the TdP. The spontaneous TdP at 7 minutes afrer the start of the bolus points to a possible agonistic effect of ryanodine at low concentrations. Repecition of the pacing protocol after 10,30 and 40 minutes however still resulted in the induction of TdP. With the exception of a longer Cl-IVR, there were no electrophysiological differences found in this animal in comparison with the other animals. 

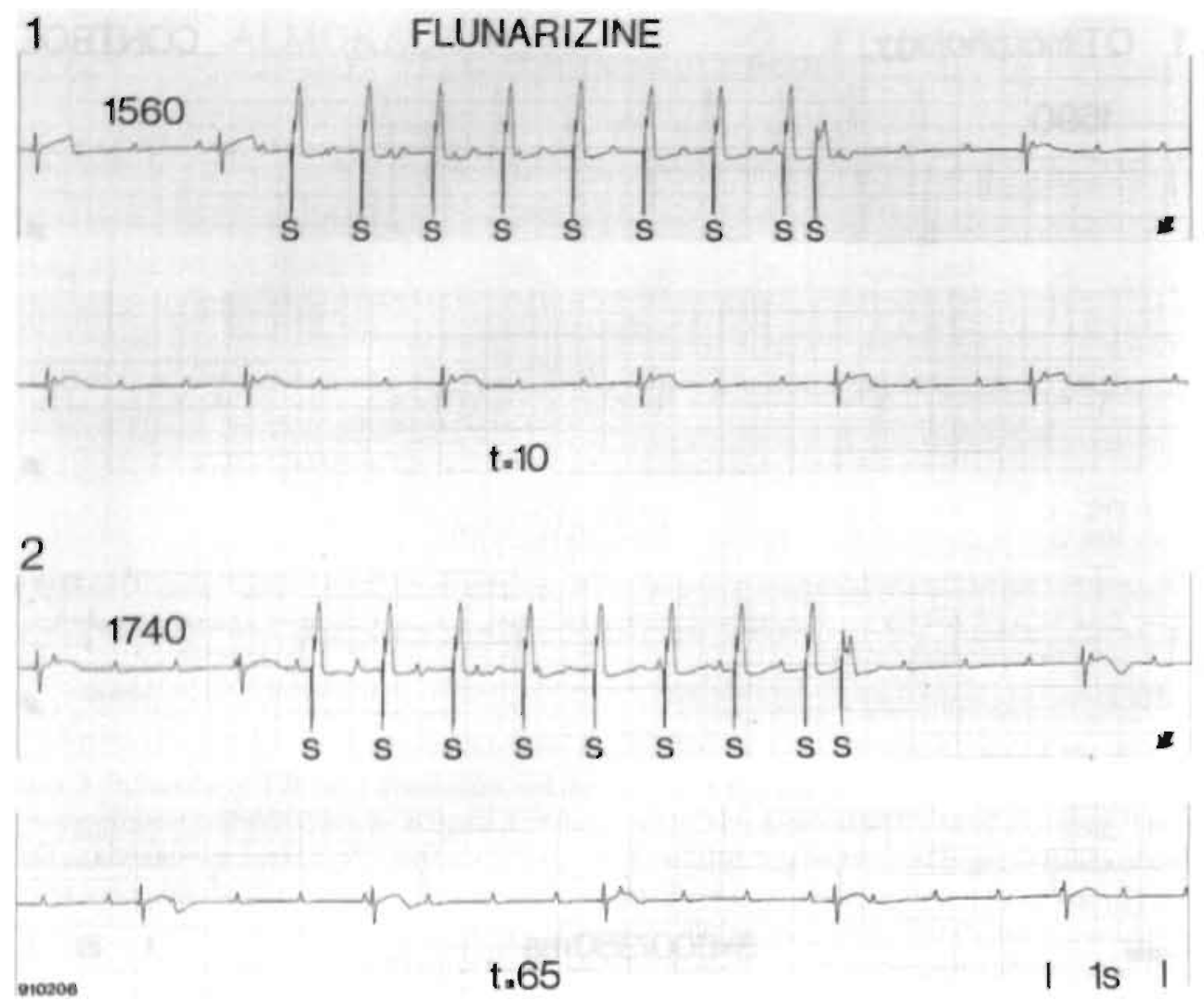

Figure 5. Homogenization of repolarization under baseline conditions by flunarizine.

Administration of flunarizine (panel 1) in the experiment of figure 4 prevents the development of the deep TU wave during and after pacing. Furthermore no spontaneous activity arises during the pacing train. At 65 minutes after flunarizine (panel 2) the effecr of flunarizine is diminished. The pacing train again leads to the development of negative TU waves post pacing, although they are present for a shorter time post pacing as at control (see figure 4). No ectopic activity is seen.

\section{Electrolytes}

All tested animals had normal electrolyte levels, mean potassium and magnesium leveli were $4.2 \pm 0.54 \mathrm{mmol} / \mathrm{L}$ and $0.81 \pm 0.05 \mathrm{mmol} / \mathrm{L}$ respectively. Administration of $d$-sotalol/ almokalant, flunarizine/ryanodine or cardioversion did not change the level of any of the electrolytes. 
Table 2. Effects of $d$-sotalol and ryanodine on electrophysiological parameters $(n=5)$

\begin{tabular}{lccccc}
\hline & C1 & dS & C2 & R10 & R15 \\
\hline CL-IVR & $1965 \pm 400$ & $2175 \pm 485^{\circ}$ & $2015 \pm 345$ & $1930 \pm 430$ & $1620 \pm 220^{* *}$ \\
QT & $455 \pm 65$ & $530 \pm 80^{\circ}$ & $540 \pm 90$ & $490 \pm 55$ & $415 \pm 20^{\circ *}$ \\
QT $_{C}$ & $320 \pm 30$ & $365 \pm 50^{\circ}$ & $385 \pm 75$ & $360 \pm 60$ & $320 \pm 20^{\circ *}$ \\
\hline
\end{tabular}

- P<0.05 vs C1, " $\mathrm{P}<0.05$ vs C2; C1: control values before administration of d-sotalol. C2: value before the administration of ryanodine ( $36 \pm 19 \mathrm{~min}$ after $d$-sotalol), dS: values at 10 minutes after the start of d-sotalol administration. R10: values at the end of the bolus ryanodine, R15: 15 minutes after ryanodine.
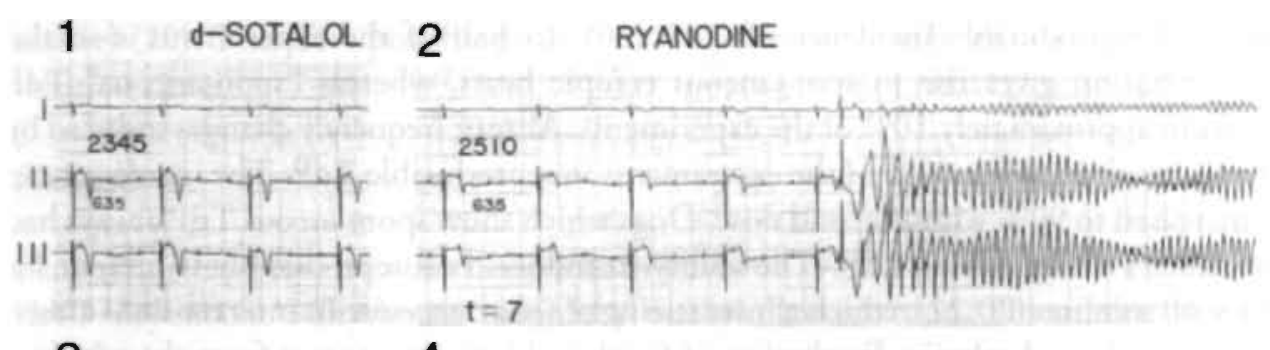

\section{3}

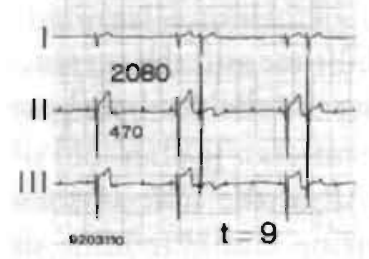

4

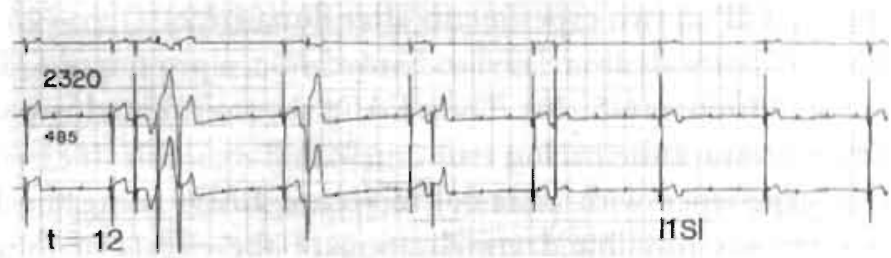

Figure 6. Development of a spontaneous TdP after ryanodine.

Three ECG leads at a paper speed of $10 \mathrm{~mm} / \mathrm{s}$ are shown. Just before administration of ryanodine a slow thythm (CL-IVR: $2345 \mathrm{~ms}$ ) with a prolonged QT interval of $635 \mathrm{~ms}$ and very deep T waves during $d$-sotalol (panel 1).

Ryanodine $(10 \mu \mathrm{g} / \mathrm{kg})$ is administered in 10 minutes. At 7 minures after the start of ryanodine infusion (panel 2) the CL-IVR increases to $2510 \mathrm{~ms}$, the T wave becomes less negative although the QT time is not altered. Intertuption of the IVR by a spontaneous beat initiates a TdP. This episode of TdP requires cardioversion because it did not stop spontaneously within 10 seconds. After this episode of TdP spontaneous ectopic activity remains present in the form of single ectopic beats or short runs (panels 3 and 4). Note that the $T$ wave changes after ryanodine and is completely positive at 9 minutes. 


\section{DISCUSSION}

Induction of EAD dependent acquired Torsade de Pointes arrhythmias was prevented by administration of ryanodine and flunarizine. The prevention of TdP was associated with a normalization of repolarization as evidenced by a decrease in $\mathrm{QT}(\mathrm{U})_{(\mathrm{c})}$ time following both drugs. Because both drugs decrease intracellular $\mathrm{Ca}^{2+}$, their inhibition of EADs and preventive action against TdP points to the involvement of $\left[\mathrm{Ca}^{2+}\right]_{i}$ overload and/or intracellular $\mathrm{Ca}^{2+}$ dyshandling in the initiating mechanism of TdP.

\section{Animal model}

Our animal model of acquired pacing dependent Torsade de Pointes arrhythmias has a high and reproducible incidence of TdP (20). In half of the experiments $d$-sotalol administration gives rise to spontaneous ectopic beats, whereas "spontaneous" TdP occurs in approximately $10 \%$ of the experiments. Abrupt frequency changes induced by pacing, result in about $50 \%$ of the experiments in reproducible TdP. The incidence can be increased to $90 \%$ with a second dose. Dogs which show spontaneous TdP always had inducible TdP by pacing (20). The ability to induce TdP reproducibly is present for about 60 minutes $(20,22)$, which allows testing of (pharmaceutical) interventions aimed to prevent the arrhythmia. Further proof for this observation comes from the reinduction of TdP in two experiments after flunarizine.

The TdP periods are related to bradycardia, a prolonged QT(U) time and the presence of EADs (figures 4-5, 20). These EADs are accentuated by pacing and their ectopic beats ofien interrupt the pacing train.

Our experience with $d$-sotalol to record EADs using the MAP at the time of these experiments prohibited visualization of the effects of flunarizine and ryanodine on EADs. Because we know that almokalant, also a $I_{\mathrm{Kr}}$ blocker, leads to more pro arrhythmogenic responses and shows (at random placement of the MAP) more (pronounced) EADs than $d$-sotalol (22), we added this drug. Unfortunately we could not establish in these experiments a direct link berween the EAD and the start of the TdP (figure 3) as we have done before. The ability to record triggering EADs depends on the good fortune to place the MAP catheter (already during control) close to the site of origin of the (later developing) EADs (as e.g. in the observations during the development of this model, figure 4 of ref $\# 20$ ). Replacing the catheter is time consuming and was not judged to fall within the scope of this investigation. New experiments are currently performed in which we study the site specificity of EADs in the right and also in the left ventricle.

None of the interventions performed during the study led to a change in electrolyte levels. Also there were no major hemodynamic changes during the experiment place as evidenced by the stable $\mathrm{CO}_{2}$ values registered by the capnograph. Although we are aware 
that this is a crude measurement. Therefore we do not consider it likely that electrolyte or hemodynamic changes contribute to the prevention of TdP.

\section{Ryanodine}

Ryanodine inhibits the $\mathrm{Ca}^{2+}$ release channel of the sarcoplasmic reticulum $(26,27)$. A dose of $10 \mu \mathrm{g} / \mathrm{kg}$ was effective to suppress ouabain induced tachycardias without reaching toxic levels $(15,16)$. Toxicity of ryanodine is dependent on the dose and the infusion rate, that has to be slow enough to prevent death of the animals (15). During a slow rate of infusion their will be a relatively long time with a low plasma concentration, that may exert an agonistic effect on the $\mathrm{Ca}^{2+}$ release (28) instead of an antagonistic effect. A low dose of ryanodine have been reported to enhance cesium induced ectopic activity (29). Therefore possible proarrhythmic responses can be anticipated during the infusion time.

\section{Flunarizine}

Flunarizine has proven to be effective both in vitro $(19,30,31)$ and in vivo (17) against DAD dependent arrhythmias caused by ouabain intoxication. Flunarizine is a very specific drug to suppress triggered arrhythmias. without affecting arrhythmias based on abnormal automaticity or reentry $(19,23,32)$.

The mechanism of flunarizine is not clear. A broad scala of mechanisms have been proposed, which all involve regulation of intracellular $\mathrm{Ca}^{2+}$. A possible mechanism could be blockade of sodium entry (30), although flunarizine does not interfere with the TTX sensirive $\mathrm{Na}^{+}$channels. The effect on sarcolemmal Ca ${ }^{2+}$ channels is low (33), and only detected at high concentrations. Under physiologic conditions, ECG parameters representing different electrophysiological parameters did nor show any changes afrer flunarizine (23). Another possible mechanism of action is a direct effect on the SR, e.g. the ryanodine sensitive $\mathrm{Ca}^{2+}$ release channel or $\mathrm{SR} \mathrm{Ca}^{2+}$ ATPase.

\section{Mechanisms of EADs and $\left(\mathrm{Ca}^{2+}\right]_{i}$ overload}

EADs can be caused by several interventions that prolong the action potential duration. These include clinical drugs such as class Ia and class III drugs $(2-5,11,20)$ and experimental drugs such as cesium $(6,7,19,34)$, anchopleurine (8), and Bay K 8644 (10). More recently isoprenaline has been found to induce EADs (9). The exact mechanism of the EAD is unclear and can be different for the different substances.

EADs can be differentiared in early (phase 2) EADs and late (phase 3) EADs (6). Early EADs are probably based on the $\mathrm{Ca}^{2+}$ entry trough the L-type $\mathrm{Ca}^{2+}$ channel $(10,18)$, because they are suppressed by the $\mathrm{Ca}^{2+}$ antagonist nitrendipine and potentiated by the $\mathrm{Ca}^{2+}$ agonist Bay K 8644 (18). On the orher hand late EADs, seem to depend on an 
increased intracellular $\mathrm{Ca}^{2+}$ overload $(9,13,14)$. That can be suppressed by ryanodine, benzamil and low extra cellular $\mathrm{Na}^{+}(9,34)$.

$\left[\mathrm{Ca}^{2+}\right]_{i}$ overload is an established cause of triggered arrhythmias based on DADs. It has been suggested that spontaneous $\mathrm{Ca}^{2+}$ oscillations are the common basis of both DADs and specific (phase 3) EADs $(9,12-14)$. The $\mathrm{Ca}^{2+}$-overload related afterdepolarizations could be induced by an inward $\mathrm{Na}^{+}$current e.g. via the $\mathrm{Na}^{+} / \mathrm{Ca}^{2+}$ exchange $(9,34)$, and/or non inactivated $\mathrm{Na}^{+}$channels $(3,7,35)$. Recent computer simulation confirmed the possible role of both $\mathrm{Na}^{+}$current and $\mathrm{Na}^{+} / \mathrm{Ca}^{2+}$ exchange (36) in the formation of EADs. Therefore we used two drugs known to suppress DADs, to evaluate an effect of diminished $\mathrm{Ca}^{2+}$ overload in TdP.

\section{Prevention of TdP by flunarizine and ryanodine}

The normalization of the repolarization, and the preventive effect of flunarizine and ryanodine was independent of the increase in heart rate. The latter can be associated with a reflex mechanism due to the negative hemodynamic or inotropic effect of these drugs $(16,23,24)$. When we corrected the increase by the use of a paced rhythm $(n=4)$, or by $\beta$ blockade using $\mathrm{dl}$-sotalol $(\mathrm{n}=1)$, we saw similar preventive effects. Therefore it seems that these drugs exert their antiarrhythmic effect by a direct effect on EADs and APD. This is in contrast with the observation of others who describe that ryanodine (18) and flunarizine (19) had no effect against cesium induced EADs in vitro. From these findings Marban et al. draw the conclusion that involvement of $\left[\mathrm{Ca}^{2+}\right]_{i}$ overload was less likely, and he emphasized the involvement of the $\mathrm{Ca}^{2+} \mathrm{L}$ type channel in the genesis of EADs (18). However recent data with isoprenaline induced EADs and DADs showed that they are caused by complex $\mathrm{Ca}^{2+}$ transients which can be abolished by the use of ryanodine (13). Therefore, it seems logic that the different ways to initiate EADs also require different treatments. The EADs observed in our animal model (figures 2-3, 20) occur most frequently during phase 3 of the action potential similar to isoproterenol induced EADs. These EADs were diminished and/or suppressed by flunarizine and ryanodine, explaining the preventive action of flunarizine and ryanodine on pacing induced $\mathrm{TdP}$.

The occurrence of a spontaneous TdP during the bolus of ryanodine may point to the enhancement of the SR Ca ${ }^{2+}$ channel by a low concentration of ryanodine (29). This is an extra argument for a role of $\left[\mathrm{Ca}^{2+}\right]_{i}$ overload and or $\mathrm{Ca}^{2+}$ dyshandling in the mechanism of TdP.

\section{Comparison flunarizine and ryanodine}

A way to assess the mechanism of a drug is to compare it with drugs of known action. Prevention of Torsade de Pointes arrhythmias, either induced by d-sotalol or almokalant, was achieved by both drugs. Electrophysiologically the effects were similar, 
although flunarizine decreased the $\mathrm{QT}_{\mathrm{c}}$ time more than ryanodine. The fact that flunarizine was effective in all dogs within 2 minutes, whereas ryanodine took longer to be effective and was ineffective in one experiment might point to an important difference. This difference can be related to the possible agonistic effect of ryanodine at low concentrations (28) as seen in these experiments and by others (29). Another confirmative observation was made recently in dogs, ryanodine caused an acceleration of ouabain ventricular tachycardia before termination occurred (17). Although the data of the present study gave a similar result of ryanodine and flunarizine in suppressing EADs and prevention of TdP, this does not imply that flunarizine blocks the ryanodine sensitive $\mathrm{Ca}^{2+}$ release of the $\mathrm{SR}$.

\section{Limitations of the study}

In this study we report that $\left[\mathrm{Ca}^{2+}\right]_{i}$ overload could play an important role in the mechanism of acquired EAD dependent TdP. We come to this conclusion based on the indirect effects of ryanodine and flunarizine. And although these drugs are very specific to prevent $\left[\mathrm{Ca}^{2+}\right]_{\mathrm{i}}$ overload and restore a normal $\mathrm{Ca}^{2+}$ condition in the cell $(19,26,27)$, we did not measure $\mathrm{Ca}^{2+}$ transients to prove $\left[\mathrm{Ca}^{2+}\right]_{i}$ overload in the generation of $\mathrm{TdP}$.

\section{General conclusions}

The results of these animal experimenrs point to $\left[\mathrm{Ca}^{2+}\right]_{\mathrm{i}}$ overload as playing a role in the development of acquired TdP. This is suggested by the preventive effecr of ryanodine and flunarizine as well as by the occurrence of a spontaneous TdP after ryanodine.

\section{Acknowledgements}

We thank Prof. dr M. Borgers of Janssen Pharmaceutics, Beerse, Belgium for supplying flunarizine, Mr H. Wiering and Mr C. Ketelaars, ASTRA. Rijswijk, the Netherlands for providing almokalant and Mr J Verschuuren, Bristol Meyers Squibb, Brussels, Belgium for providing $d$-sotalol, and Bakken Research Center (Medironic), Maastricht, the Netherlands in providing the epicardial electrodes. This study was supported by a grant from the Nerherlands Hearr Foundarion (\#91.104).

\section{REFERENCES}

1. Surawicz B. Electrophysiological substrate of Torsade de Pointes: Dispersion of repolarization or early afterdepolarizations. J Am Coll Cardiol 1989; 14: 172-182.

2. Dangman $\mathrm{KH}$, Hoffman BF. In vivo and in vitro antiarthyhtmic effects of N-acetyl Procainamide. J Pharmacol Exp Ther 1981:217:851-862. 
3. Roden DM, KA Thompson, BF Hoffman, RL Woosley. Clinical features and basic mechanisms of quinidine induced arrhythmias. J Am Coll Cardiol 1986; 8; 73A-78A.

4. Strauss HC, Bigger JT. Hoffman BF. Electrophysiological and beta-receptor blocking effects of MJ1999 on dog and rabbit cardiac tissue. Circ Res 1970; 26: 661-678.

5. Gough WB, El-Sherif N. The differential response of normal and ischaemic Purkinje fibres to clofilium, d-sotalol and bretylium. Cardiovase Res 1989; 26: 554-559.

6. Damiano BP, Rosen MR. Effects of pacing on triggered activity induced by early afterdepolarizations. Circulation 1984; 69: 1013-1025.

7. Brachmann J, Scherlag BJ, Rosenshtraukh LV, Lazzara R. Bradycardia dependent triggered activity: Relevance to drug induced multiform, ventricular tachycardia. Circulation 1983; 68: 846-856.

8. El-Sherif N, Zeiler RH, Craclius W. Gough WB. Henkin R. QTU prolongation and polymorphic ventricular tachyarrhythmias due to bradycardia dependent afterdepolarizations. Afterdepolarizations and ventricular arrhythmias. Cire Res 1988; 63: 286-305.

9. Priori SG, Corr PB. Mechanism underlying early and delayed after-depolarizations induced by cathecholamines. Am / Physiol 1990; 258; H1796-H1805.

10. January CT, Riddle JM, Salata JJ. A model for early afterdepolarizations with the $\mathrm{Ca}^{2 *}$ channel agonist Bay K 8644. Circ Res 1988; 62:563-571.

11. Carlsson L, Abrahamsson C. Andersson B, Düker G, Schiller-Linhardr G. Proarrhythmic effects of the class III agent almokalant: importance of infusion rate, QT dispersion, and early afterdepolarizations. Cardiovase Res 1993: 27: 2186-2193.

12. Capogrossi MC, Lakatta EG. Frequency modulation and synchronization of spontaneous oscillations in cardiac cells. Am / Physiol 1985; 248: H412-H418.

13. Yamada KA, Corr PB. Effects of $\beta$-adrenergic receptor activation on intracellular calcium and. membrane potential in adult cardiac myocytes. / Cardiovasc Electrophysial 1992; 3: 209-224.

14. Szabo B, Sweidan R, Patterson A, Scherlag Bj, Lazarra R. Increased intracellular Ca ${ }^{2 *}$ may be important also for early afterdepolarizations. (abstract) / Am Coll Cardiol 1987; 9:210A.

15. Hadju S, Lconard E. Action of ryanodine on mammalian cardiac muscle. Effects on contractility, and. reversal of digitalis induced ventricular arrhythmias. Circ Res 1961; 9: 1291-1298.

16. Kahn M. Shiffman 1. Kuhn A, Jacobson TE. Effects of ryanodine in normal dogs and in those with. digitalis-induced arrhythmias. Hemodynamic and Electrocardiographic studies. Am / Cardiol 1964; 14: 658-668.

17. Vos M, Gorgels A, Verduyn C, Leunissen H, Zande van der J, Wellens H. The effects of ryanodine and flunarizine on triggered arrhythmias in the intact canine heart. Cardiovase Drugs and Ther 1993; 7: 44 (abstract).

18. Marban E, Robinson SW, Wier GW. Mechanism of arrhythmogenic delayed and early afterdepolarizations in ferret ventricular muscle. / Clin Invest 1978; 78: 1185-1192.

19. Park JK, Danilo P. Rosen MR. Effects of flunarizine on impulse formation in canine Purkinje fibers. I Cardiovasc Electrophysiol 1992: 3: 306-314.

20. Vos MA. Verduyn SC, Gorgels APM, Lipscei GC, Wellens HJJ. Reproducible induction of early afterdepolarizations and torsade de pointes arrhythmias by $\mathrm{d}$-sotalol and pacing in the dog with chronic atrioventricular block. Circulation 1995: 91: 864-872.

21. Sherlag BJ. Kosowsky BD, Damato AN. A technique for ventricular pacing from the His Bundle of the intact heart. J Applied Physiol 1967; 22: 584-587.

22. Venduyn SC, Vos MA. Zande van der J. Wellens HJJ. A comparison between the proarrhythmic effect of almokalant and d-sotalol in an animal model of Torsade de Pointes arrhythmias. J Am Coll Cardiol 1995; 170A (abstract).

23. Vos MA, Gorgels APM, Leunissen. JDM, Nagel van der T, Halbertsma FJJ. Wellens HJJ. Further. observations to confirm the arrhythmia mechanism specific effects of flunarizine. / Cardionase Pharmacol 1992: 19: 682-690. 
24, Kubo K, Van de Water A, Wouters L, Xhonneux R, Reneman RS. Cardiac and hemodynamic effects of intravenous administrations of flunarizine in closed chest anaesthetized mongrel dogs. Drug Res 1984; 34(I): 434-439.

25. Bazett HC. An analysis of the time relations of electrocardiograms. Heart 1920; 7:353-368.

26. Sutko JL, Willerson JT, Templeton GH, Jones LR, Besch HR, Ryanodine: its alterations of cat papillary muscle contractile state and responsiveness to inotropic interventions and a suggested mechanism of action. J Pharmacol Exp Ther 1979; 209: 37-47.

27. Sutko JL, Kenyon JL. Ryanodine modification of cardiac muscle responses to potassium free solutions. Evidence for inhibition of the sarcoplasmic reticulum calcium release. J Gen Plysiol 1983; 82:385-404.

28. Meissner G, Henderson JS. Rapid calcium release from cardiac sarcoplasmic reticulum vesicles is dependent on $\mathrm{Ca}^{2+}$ and is modulated by $\mathrm{Mg}^{2 *}$, adenine nucleotide, and calmodulin. J Biol Chem 1987; 262: 3065-3073.

29. D'Alonzo AJ, Hess TA, Darbenzio RB, Sewter JC. Effects of intracoronary glyburide on cesium induced arrhythmias in anesthetized dogs. J Cardiovase Pharmacol 1994; 23: 446-452.

30. Patmore L, Duncan GP. Spedding M. The effects of calcium antagonist on calcium overload contractures in embryonic shock myocytes induced by ouabain and veratrine. Br J Pharmacol 1989; 97: 83-94.

31. VerDonck L. $\mathrm{Ca}^{2+}$-overload phenomena and cytoprotection in isolated cardiomyocytes. Thesis. Katholieke universiteit Leuven. 1991:59-72.

32. Vos MA, Gorgels APM, Leunissen JDM, Wellens HJJ. Flunarizine allows differentiation between mechanism of arrhythmias in the intact heart. Circulation 81: 343-349,1990.

33. Tytgat J, Vereecke J, Carmeliet E. Differential effects of verapamil and flunarizine on cardiac L-type and T-type channels. Anch Pharmacol 1988; 337: 690-692.

34. Szabo B, Sweidan R, Rajagopalan CV, Lazzara R. Role of $\mathrm{Na}^{*}: \mathrm{Ca}^{2+}$ exchange in $\mathrm{Cs}^{+}$-induced early afterdepolarizations in Purkinje fibers. J Cardiovase Electrophysiol 1994; 5: 933-944.

35. Jackman WM, Szabo B, Friday KJ, Margolis PD, Moulton K, Wang X, Patterson E, Lazzara R. Ventricular tachyrhythmias related to early afterdepolarizations and triggered firing: relationship to QT interval prolongation and potential therapeutic role for calcium blocking agents. J Cardiovasc Electrophysiol 1990; 1: 170-195.

36. Luo CH, Rudy Y. A dynamic model of the cardiac ventricular action potential. II. Afterdepolarizations, triggered activity, and potentiation. Circ Res 1994; 74: 1097-1113. 



\title{
Chapter 7
}

Electrophysiologic adaptations induced by chronic complete atrioventricular block predispose the canine heart for the induction of acquired Torsade de Pointes arrhythmias

\author{
S. Cora Verduyn \\ Marc A. Vos \\ Jolanda van der Zande \\ S. H. Maricke de Groot \\ Jet D.M. Leunissen \\ Maurits A. Allessie \\ Hein J.J. Wellens
}

Article in preparation

Abstract presented at the American Heart Association congress, 1995

Circulation 1995;92:1-504. 


\section{ABSTRACT}

We have reported that the combination of $2 \mathrm{mg} / \mathrm{kg} d$-sotalol (dS) and pacing results in the reproducible induction of early afterdepolarization (EAD) dependent Torsade de Pointes arrhythmias in $50 \%$ of anesthetized dogs with chronic complete AV block. The AV block induced bradycardia accompanied by a volume overload causes biventricular hypertrophy: left ventricle/body weight (LV/BW) increases from $4.3 \pm 0.9$ to $5.8 \pm 0.9$ $\mathrm{g} / \mathrm{kg}$ and the RV/BW from $1.4 \pm 0.4$ to $2.6 \pm 0.9 \mathrm{~g} / \mathrm{kg}(\mathrm{P}<0.05)$. Ventricular hypertrophy is associated with prolongation of the action potential duration (APD) and sudden death. What the contribution of the changes due to AV block are for the occurrence of acquired TdP is not known. In this model the effect of pacing and $\mathrm{dS}$ was therefore tested twice: at the moment of AV block $(n=9)$ and after 5 weeks of complete AV block $(n=10)$. Five dogs were tested at both time points. Cycle length $(C L)$ was kept constant in both experiments. Monophasic actionpotential catheters were placed in the right (RV) and the left ventricle (LV) to record EADs, to measure actionpotential duration (APD), dispersion of repolarization ( $\triangle A P D$ : LV APD-RV APD), and the incidence of TdP. Results: At baseline: CL ( $1600 \pm 280 \mathrm{~ms})$, both the LV APD $(295 \pm 20$ vs $390 \pm 60 \mathrm{~ms})$ and RV APD ( $260 \pm 20$ vs $315 \pm 10$ ms) significantly increased after 5 weeks of AV block $(\mathrm{P}<0.05)$. EADs were not seen and $T d P$ was not inducible at baseline. $d S$ administration increased APD significantly in both groups, but to a different degree. There was a more pronounced increase in $\triangle A P D(40 \pm 35$ to $45 \pm 30$ vs $70 \pm 30$ to 125 $\pm 65 \mathrm{~ms}$ ) and more EADs at 5 weeks. No TdP could be induced after $\mathrm{dS}$ at 0 weeks, whereas $\mathrm{TdP}$ occurred in $6 / 10$ dogs at 5 weeks $\mathrm{AV}$ block.

Conclusions: The changes occurring after chronic complete AV block increase the arrbythmogenic effects of $\mathrm{dS}$ resulting in a higher incidence of TdP. This study also emphasizes again the role of $\triangle A P D$ and EADs in the genesis of TdP.

\section{INTRODUCTION}

Left ventricular hypertrophy is a well known risk factor for sudden (arrhythmic) deach $(1-4)$. This higher incidence of yentricular arrhythmias is independent of other factors like coexisting coronary disease and/or heart failure $(4,5)$. Cardiac hypertrophy can have different etiologies, !ike pressure or volume overload $(6,7)$ and may involve the left, the right or both ventricles. Many studies have described the mechanical, structural and biochemical alterations occurring in ventricular hypertrophy (e.g. 6-10). Much less attention has been given, to the electrophysiological changes that occur in the hypertrophied myocardium (11). Independent of its cause, ventricular hypertrophy is associated with a lengthening of the transmembrane action potential duration (8). It has been suggested that due to this lengthening of repolarization, early afterdepolarizations (EADs) and triggered activity may occur in hypertrophy $(2,11)$, and one may assume 
that EAD related Torsade de Pointes arrhythmias with the possibility of deterioration into ventricular fibrillation could be a possible cause for sudden death (12). Other pathological conditions such as fibrosis or ischemia, could also lead to arrhythmogenic death based on other mechanisms like reentry or abnormal impulse formation.

In our animal model of acquired Torsade de Pointes arrhythmias (TdP), we have reported the reproducible development of pacing induced TdP in 50\% of the dogs after administering a class III agent, $\mathrm{d}$-sotalol $(2 \mathrm{mg} / \mathrm{kg}, 13)$. These dogs were tested minimally 2 weeks after creation of complete atrioventricular (AV) block. Other investigators using a similar or higher dosage of $(d)$-sotalol $(14,15)$ did not report the occurrence of spontaneous TdP in dogs, when the experiments were carried out in the acute phase of AV block.

Similar to clinical TdP (16), induction of TdP in our canine model depends on bradycardia, prolonged APD and the development of EADs (13). Furthermore, we have described that interventricular dispersion plays an essential role in the induction of TdP (17).

Our first goal was to assess the structural and electrophysiologic processes, which take place after the creation of complete AV block. Comparing dogs with normally conducted sinus rhythm (SR) with chronic AV block (see results), we noticed that the AV block dogs had 1) biventricular hypertrophy, and 2) prolonged repolarization parameters. The role of these in the development of acquired $\mathrm{TdP}$ in our animal model is unknown and was the subject of this study.

\section{METHODS}

The study protocol was approved by the Commitree for Experiments on Animals of the Universicy of Limburg, Maastricht, the Netherlands and conducted in accordance with the guidelines of the American Physiological Society.

\section{General}

The experiments were performed on 15 anestherized adult mongrel dogs of either sex with a mean body weight of $25 \pm 4 \mathrm{~kg}$ (range $20-41 \mathrm{~kg}$ ). Anesthesia was induced by 1) premedication i.m. (1 ml/5 kg: $10 \mathrm{mg}$ oxycodon, $1 \mathrm{mg}$ acepromazine and $0.5 \mathrm{mg}$ atropine) and 2) sodium pentobarbital (20 $\mathrm{mg} / \mathrm{kg} \mathrm{i.v.).} \mathrm{The} \mathrm{dogs} \mathrm{were} \mathrm{artificially}$ ventilated through a cuffed endotracheal tube using a mixture of oxygen, nitrous oxide and halothane (vapor concentration $0.5 \%-1 \%$ ) by a respirator. Ventilation was controlled by continuous reading of the carbon dioxide concentration in the expired air. A thermal mattress was used to maintain adequate body temperature.

A right sided thoracotomy was performed 1) to implant an epicardial electrode (Bakken Research Center, Medtronic, Maastricht, The Netherlands) at the apex of the left 
ventricle, and 2) to create complete AV block by injection of formaldehyde (37\%) in the AV node (18). Proper care was taken after the experiments, including antibiotics (1000 mg ampicillin, pre and post operatively) and analgesics $(0.1 \mathrm{cc} / 7 \mathrm{~kg} \mathrm{i} . \mathrm{m}$. buprenorfine).

\section{Pacing}

All electrical stimulation was done from the left epicardial electrode with a custom build programmable stimulator (University of Limburg), that delivers unipolar stimuli synchronous to the QRS complexes, with a pulse of $2 \mathrm{~ms}$ and a stimulus strength of twice the diastolic threshold. As indifferent electrode a needle was placed through the skin.

\section{Measurement of electrophysiological parameters}

Retrospective analysis consisted of a comparison between electrophysiological studies obtained in dogs with normal conducted SR $(n=18,18-20)$ and in dogs with chronic AV block $(n=9,13)$. In these experiments the ventricular effective refractory period (VERP) was determined using the extrastimulus technique, after a basic train of 8 paced stimuli with an interstimulus interval ranging between 250 and $600 \mathrm{~ms}$. The coupling interval of the extrastimulus was shortened with $10 \mathrm{~ms}$ steps till refractoriness was reached. The VERP was defined as the longest interval that did not capture. QT time was measured in lead II of the ECG from the last five ventricular paced beats after 30 seconds of continuous pacing at a cycle length of 300 and $400 \mathrm{~ms}$.

\section{Heart weight}

To assess the amount of hypertrophy due to the volume overload, the heart weight was determined in rwenty of the dogs used for the above described electrophysiologic studies (SR: $n=11$, AV block: $n=9$ ). After a final experiment the hearts were excised, rinsed with water and stored in a formaldehyde solution for at least 2 weeks. The weight of the total heart, right and left ventricle (including septum) was assessed and related to the body weight. In addition, the heart weight was assessed in five dogs used in the prospective limb of this study,

\section{Evaluation of the electrophysiologic and proarrhythmic effects of d-sotalol}

Animals were instrumented to investigate the response to $d$-sotalol during spontaneous idioventricular rhythm (IVR) at both time points: acure AV block and at 5 weeks of chronic complete AV block. Directly after closure of the chest following creation of AV block, MAP catheters were placed in both ventricles of 7 dogs. Thereafter the TdP 
induction protocol was performed (see further). To avoid possible influences of the preceding thoracotomy, four dogs received a ventricular (VVI) pacemaker immediately after AV block. The pacemaker was programmed at a rate comparable to the former SR and the dogs were scheduled to be tested three days later. Each day an electrocardiogram was registered to check pacemaker function. These dogs were again anestherized, three days after creation of AV block and the endocardial MAP cartheters were placed and the VVI pacemaker was switched off. In the presence of a stable IVR ( $\geq 5$ minutes), the TdP protocol (see further) was performed. Unfortunately one of these four dogs died before the experiment could be carried out, and in another dog the AV node conduction partially returned (2:1 AV block). These dogs were excluded, so that 9 dogs were evaluated for TdP induction in the acute phase of AV block.

In these experiments 7 dogs met the standards in respect to the quality of both MAPs to ensure appropriate data sampling $(7 \times 2=14 \mathrm{MAPs})$. These dogs were planned to be retested 4-6 weeks later. Unfortunately one of them died, and in one dog we could not record adequate MAP signals during the second experiment, i.e. five dogs could be analyzed at both time points (table 3 ). To increase the number of dogs with chronic AV block, we added 4 consecurive dogs that were only tested at 5 weeks of AV block. So during chronic AV block 10 dogs were given $d$-sotalol, of which 9 had adequate MAPs for electrophysiological analysis $(9 \times 2=18 \mathrm{MAPs})$.

\section{Torsade de Pointes induction protocol}

A detailed description of the $\mathrm{TdP}$ inducrion protocol is described elsewhere (13). In short, anesthetized animals received two defibrillation patches that were antached wo both sides of the chest and connected with a defibrillator. Two different pacing modes were used 1) short long short sequence, A) an interstimulus interval of $400 \mathrm{~ms}$ followed by one of $800 \mathrm{~ms}$ and by an extrastimulus or B) four intervals of 600 , followed by one of $1200 \mathrm{~ms}$ and an extra stimulus and 2) An $8+1$ protocol with an interstimulus interval of $600 \mathrm{~ms}$ followed by one extra stimulus (13). During both pacing modes the coupling interval of the extrastimulus was shortened from 500 to $300 \mathrm{~ms}$ in $50 \mathrm{~ms}$ steps. After completing the pacing protocol, $\mathrm{d}$-sotalol $(2 \mathrm{mg} / \mathrm{kg} / 5 \mathrm{~min} \mathrm{i} . v$.) was administered. The pacing protocol was resumed 10 minutes after the start of the drug injecrion. A Torsade de Pointes arrhythmia was defined as a polymorphic ventricular tachycardia consisting of $\geq 5$ bears, which rwisted around the baseline and occurring in the presence of a prolonged QT (U) duration. A dog was called inducible when TdP could be induced $\geq$ 3 times with the same pacing mode. When TdP did not terminate spontaneously within 10 seconds or when it deteriorated into ventricular fibrillation, cardioversion (60-70 j) was performed.

Because pacing is necessary to induce TdP, we also paid careful attention in those dogs tested twice to the development of EADs and ectopic beats within the pacing mode. 
Variables of ventricular repolarization are heart rate dependent and it was previously reported that inducible dogs have a longer cycle length of the IVR than the non inducible ones (13). Therefore, in those dogs studied both during acute and chronic AV block, we performed when necessary the TdP induction protocol after $d$-sotalol during AV block at two basic cycle lengths: during spontaneous IVR and at a paced cycle length identical to the cycle length of the first experiment. Continuous pacing was started 20 minutes after $d$-sotalol.

\section{Monophasic Action Potentials}

MAPs were recorded to observe the occurrence of EADs and to measure the duration of the action potential (APD) of the left and right ventricular endocardium at $100 \%$ of repolarization. Quadripolar contact electrodes (Franz combination catheter, EPT \# 1650), that provide both pacing and MAP recording capabilities were randomly placed endocardially in the left and the right ventricle via the carotid artery and the external jugular vein. MAP phases were defined according to the definitions used for transmembrane potentials (21). Amplitude was defined as the voltage difference berween phase 4 and 2 of the signal. Besides a minimal MAP amplitude of $15 \mathrm{mV}$, a stable configuration and a smooth shape had to be present under control circumstances. EADs were defined as an interruption of the smooth contour of phase 2 and/or 3 of the acrion potential (22), and were examined in both MAPs.

\section{Data acquisition and analysis}

Six surface electrocardiographic leads and 2 MAP signals were simultaneously registered and stored on hard disc during the experiment. Both MAPs and ECG leads were sampled with at rate of $1 \mathrm{kHz}$. Applying a custom made computer program (ECG View; University of Limburg, Maastriche, the Netherlands) with a resolution of $2 \mathrm{~ms}$ and adjustable gain and time scale, the following parameters were measured: CL-IVR, QT time (lead 11) and LV and RV A.PD 100 at baseline and at 10 minutes after $d$-sotalol. In the 5 dogs tested twice we also measured these parameters at 20 minutes after $d$-sotalol when the cycle length was corrected. All electrophysiological data reported are the mean of 5 consecutive beats. Interventricular dispersion ( $\triangle A P D$ ) was defined as the difference between the left and right ventricular APD at a certain time point.

\section{Statistics}

Paired and unpaired Student's $t$-test, were applied to compare data obtained in pre drug condition and after $\mathrm{d}$-sotalol and between 0 and 5 weeks of AV block. The $\chi^{2}$ test was used when the data were presented as a proportion. P values $\leq 0.05$ were considered significant. All data are presented as mean \pm standard deviation (SD). 


\section{RESULTS}

Effects of chronic AV block: heart weight and electrophysiologic findings

Assessment of the heart weight in dogs with chronic AV block ( $20 \pm 11$ weeks) revealed a significant increase in mass when compared to the hearts of dogs in SR with comparable body weight (table 1). This increase is present in the left and right ventricle (table 1), leading to biventricular hypertrophy.

Anesthetized dogs with chronic AV block (CL-IVR: $\pm 1670 \mathrm{~ms}$ ) had significantly longer repolarization parameters than dogs in SR (SR-CL: $\pm 520 \mathrm{~ms}$ ). This remained present after 30 seconds of continuous ventricular pacing at $300 \mathrm{~ms}$ : the QT time amounted $205 \pm 15 \mathrm{~ms}$ in dogs with SR, vs $275 \pm 20 \mathrm{~ms}$ in the chronic AV block dogs $(\mathrm{P}<0.05)$. A similar pattern was found with $400 \mathrm{~ms}$ pacing ( $225 \pm 15 \mathrm{vs} 300 \pm 20 \mathrm{~ms}$ ). At these cycle lengths the VERP was also significantly increased when chronic AV block dogs were compared with dogs in sinus rhythm (figure 1).

\section{Prospective study}

\section{Heart weight}

The amount of biventricular hypertrophy in the subgroup of 5 dogs studied prospectively was: $\mathrm{LV} / \mathrm{BW}$ of $5.9 \pm 0.8$ and a RV/BW of $2.6 \pm 0.3 \mathrm{~g} / \mathrm{kg}$. The dogs had chronic

Table 1. Heart weights of dogs in sinus rhyrhm (SR) compared with dogs with chronic complete AV block (20 weeks, range 10-34)

\begin{tabular}{lll}
\hline & SR $(\mathrm{n}=11)$ & AV $(\mathrm{n}=9)$ \\
\hline Heart weight $(\mathrm{g})$ & $225 \pm 34$ & $280 \pm 64^{\circ}$ \\
$\mathrm{H} / \mathrm{BW}(\mathrm{g} / \mathrm{kg})$ & $7.7 \pm 1.2$ & $11.2 \pm 1.9^{\circ}$ \\
$\mathrm{LV}(\mathrm{g})$ & $125 \pm 26$ & $145 \pm 32^{\circ}$ \\
$\mathrm{RV}(\mathrm{g})$ & $40 \pm 8$ & $65 \pm 22^{\circ}$ \\
$\mathrm{LV} / \mathrm{BW}(\mathrm{g} / \mathrm{kg})$ & $4.3 \pm 0.9$ & $5.8 \pm 0.9^{\circ}$ \\
$\mathrm{RV} / \mathrm{BW}(\mathrm{g} / \mathrm{kg})$ & $1.4 \pm 0.4$ & $2.6 \pm 0.9^{\circ}$ \\
$\mathrm{BW}(\mathrm{kg})$ & $29.6 \pm 5.6$ & $25.1 \pm 5.6$ \\
\hline
\end{tabular}

H/BW: Heart/bodyweight $(\mathrm{g} / \mathrm{kg})$, LV: left ventricle weight $(\mathrm{g}), \mathrm{RV}$ : right ventricle weight $(\mathrm{g})$, LV/BW: left ventricle/body weight (g/kg). RV/BW: right ventricle/bodyweight; $P<0.05$ vs SR 


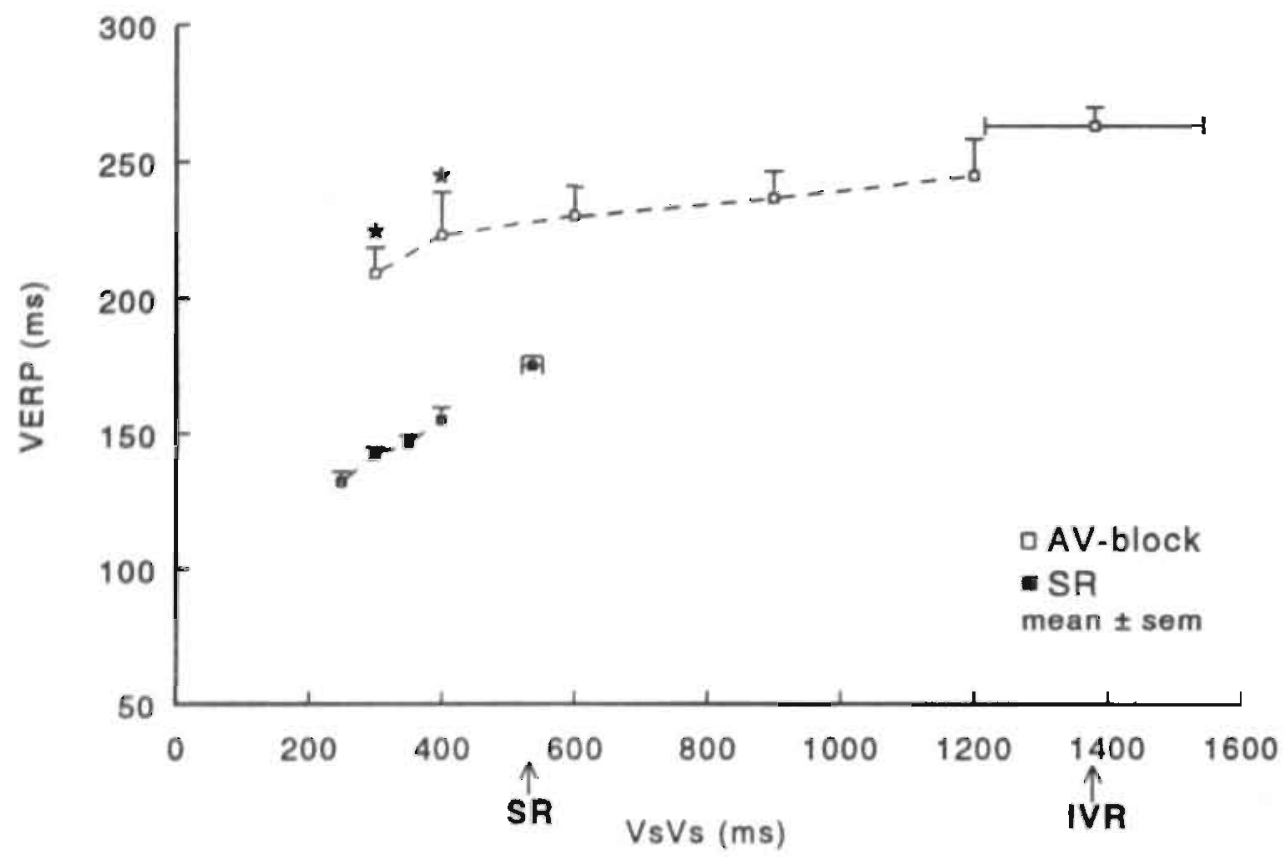

Figure 1. Increase in ventricular effective refractory period after chronic AV block.

Graph showing the results of a retrospective study performed in anesthetized dogs in which we compare the ventricular effective refractory period (VERP) in sinus rhythm $(\mathbf{n}, \mathrm{n}=18)$ with dogs in chronic AV block ( \pm 9 weeks, $\square \mathrm{n}=9$ ). The VERP was determined by one single extrastimulus following 8 basic stimuli at different basic cycle lengths. The ventricular cycle length during sinus rhythm (SR) and the mean cycle length of the idioventricular rhythm (CL-IVR) are indicated on the horizontal axis. The AV blocked dogs show a significantly longer VERP than the dogs in SR at those cycle lengths that can be compared (400 $-300 \mathrm{~ms}$ ).

AV block for 9 weeks and the data were comparable with the retrospective data shown in table 1.

\section{Behavior of APD and interventricular $\triangle A P D$ at IVR during baseline}

After creation of complete block or after switching off the pacemaker a stable idioventricular rhythm evolved with a cycle length of $\pm 1600 \mathrm{~ms}$. No differences were found in the electrophysiological parameters of the dogs in which the experiment was performed right after closure of the chest or with a delay of three days. Therefore we combined the results of the two groups (table 2). At baseline all dogs had smooth MAP signals: no EADs were present. At this time point TdP could not be induced by pacing $(\mathrm{n}=9)$. 


\section{ACUTE AV BLOCK}

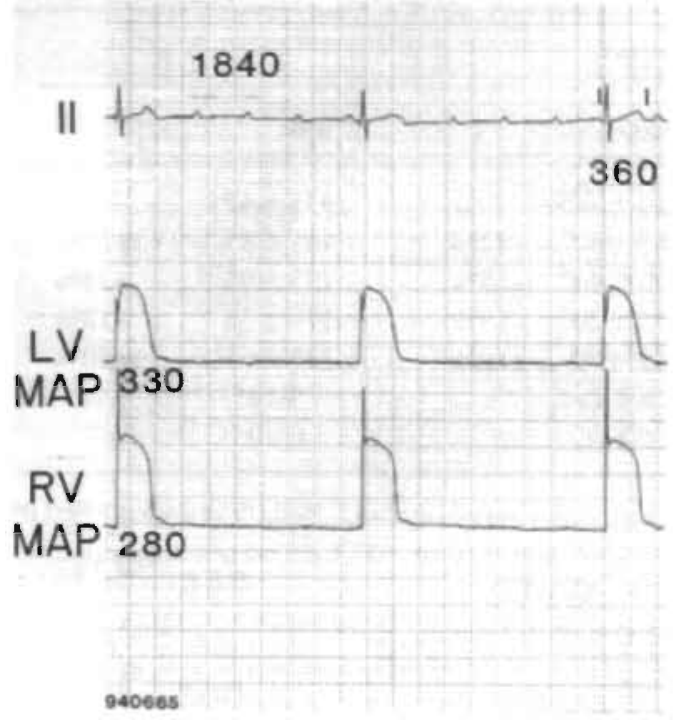

\section{CHRONIC AV BLOCK}

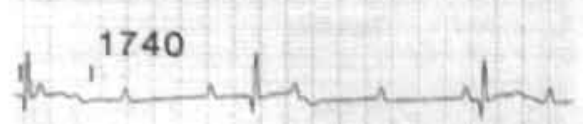

520

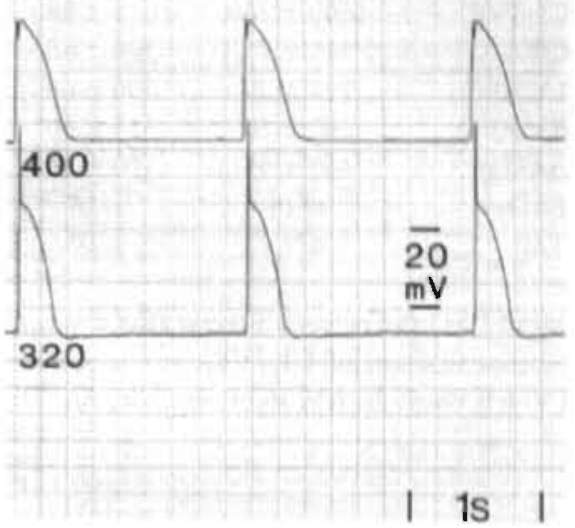

Figure 2. Differences in baseline repolarization values in acute and chronic AV block.

Two panels with a lead II ECG and a recording of the left and right ventricular (LV and RV) monophasic acrion potential (MAP) are shown at a paper speed of $25 \mathrm{~ms}$. Panel 1 shows the baseline situation, directly after creation of AV block. The cycle length of the idioventricular thythm (CL-IVR) is $1840 \mathrm{~ms}$ with a QT time of $360 \mathrm{~ms}$. The action potential duration (APD) of the LV is 330 ms whereas the RV APD is $280 \mathrm{~ms}$ resulting in an interventricular dispersion of repolarization ( $\triangle A P D)$ of $50 \mathrm{~ms}$. In this dog, 6 wecks of chronic complere AV block led to a prolonged QT cime (panel 2) while the CL-IVR and QRS duration are similar. The LV APD and RV APD are also prolonged. Because this prolongation is more pronounced for the LV, the $\triangle A P D$ has increased to $80 \mathrm{~ms}$.

Five weeks of chronic AV block led to a significant increase in all repolarization parameters (table 2) while the cycle length of IVR was similar. The number of EADs was not increased, but the interventricular $\triangle A P D$ augmented from $40 \pm 35$ to $70 \pm 30$ $m$ due to the absolute and relative larger increase of the LV APD compared with the RV APD. A representative example of the differences in QT, LV and RV APD measured in the acute and chronic phase of complete AV block is shown in figure 2. In one dog very ourspoken repolarization disorders were present in the form of EADs in the left ventricle, resulting in a larger $\triangle \mathrm{APD}$ (130 ms). $\mathrm{TdP}$ could be induced by pacing.

\section{Effect of d-sotalol}

In the acute phase of complete AV block (after \pm 30 minutes), $d$-sotalol increased the CL-IVR, the QT time and APD in both ventricles (rable, 2), to an extent that was less 
Table 2. Electrophysiologic effects of chronic complete AV block and effect of $d$-sotalol

\begin{tabular}{|c|c|c|c|c|c|c|}
\hline & \multicolumn{2}{|l|}{ bascline } & \multicolumn{4}{|l|}{$d$-sotalol } \\
\hline & 0 wks & 5 wks & 0 wks" & & $5 \mathrm{wks}$ & \\
\hline CL-IVR & $1600 \pm 280$ & $1615 \pm 280$ & $1720 \pm 465$ & & $1935 \pm 425$ & \\
\hline QT & $315 \pm 25$ & $390 \pm 65^{\circ}$ & $385 \pm 40^{2}$ & $+22 \%$ & $485 \pm 85^{\circ}$ & $+25 \%$ \\
\hline LV APD & $295 \pm 20$ & $390 \pm 60^{\circ}$ & $340 \pm 40^{x}$ & $+15 \%$ & $495 \pm 95^{\circ}$. & $+28 \%$ \\
\hline RV APD & $260 \pm 20$ & $315 \pm 40^{\circ}$ & $295 \pm 20^{4}$ & $+15 \%$ & $370 \pm 55^{\circ}$ & $+18 \%$ \\
\hline$\triangle \mathrm{APD}$ & $40 \pm 35$ & $70 \pm 30$ & $45 \pm 30$ & $+12 \%$ & $125 \pm 65^{\circ}$ & $+80 \%$ \\
\hline EADs & $0 / 14$ & $1 / 18$ & $4 / 14$ & & $9 / 18^{\circ}$ & \\
\hline $\mathrm{TdP}$ & $0 / 9$ & $1 / 10$ & $0 / 9$ & & $6 / 10^{*}$ & \\
\hline
\end{tabular}

Mean \pm SD and percent increase after $d$-sotalol: ": 5 dogs with a paced rhythm, "P<0.05 vs 0 wks, " $P<0.05$ baseline vs d-sotalol, CL-IVR: cycle length of the idioventricular rhythm. APD: action potential duration. LV: Ieft ventricle, RV: right ventricle, $\triangle A P D: I V$ APD - RV APD.

Table 3. Incidence of early afterdepolarizations (EAD), amount of interventricular dispersion of repolarization ( $\triangle A P D)$ and incidence of Torsade de Pointes arrhythmias (TdP) at 0 and 5 weeks after d-sotalol. (dS) in the same dog

\begin{tabular}{|c|c|c|c|c|c|c|c|}
\hline dog & LV/RV & EAD 0 & $\triangle A P D$ & TdP 0 & EAD 5 & $\triangle A P D$ & TdP 5 \\
\hline 1 & $\begin{array}{l}\text { LV } \\
\text { RV }\end{array}$ & + & 75 & - & + & 180 & + \\
\hline 2 & $\begin{array}{l}\text { IV } \\
\text { RV }\end{array}$ & - & 35 & - & - & 70 & - \\
\hline 3 & $\begin{array}{l}\text { IV } \\
\text { RV }\end{array}$ & - & 80 & - & + & 150 & + \\
\hline 4 & $\begin{array}{l}\text { IV } \\
\text { RV }\end{array}$ & - & 25 & - & + & 80 & + \\
\hline 5 & $\begin{array}{l}\text { IV } \\
\text { RV }\end{array}$ & + & 40 & - & + & 125 & + \\
\hline Total & & $4 / 10$ & $50 \pm 25$ & $0 / 5$ & $8 / 10$ & $120 \pm 45^{\circ}$ & $4 / 5$ \\
\hline
\end{tabular}

: P 0.010 (1) 5 weeks, IV: left ventricle, RV: right ventricle. 


\section{D-SOTALOL}

\section{1}

\section{ACUTE AV BLOCK}

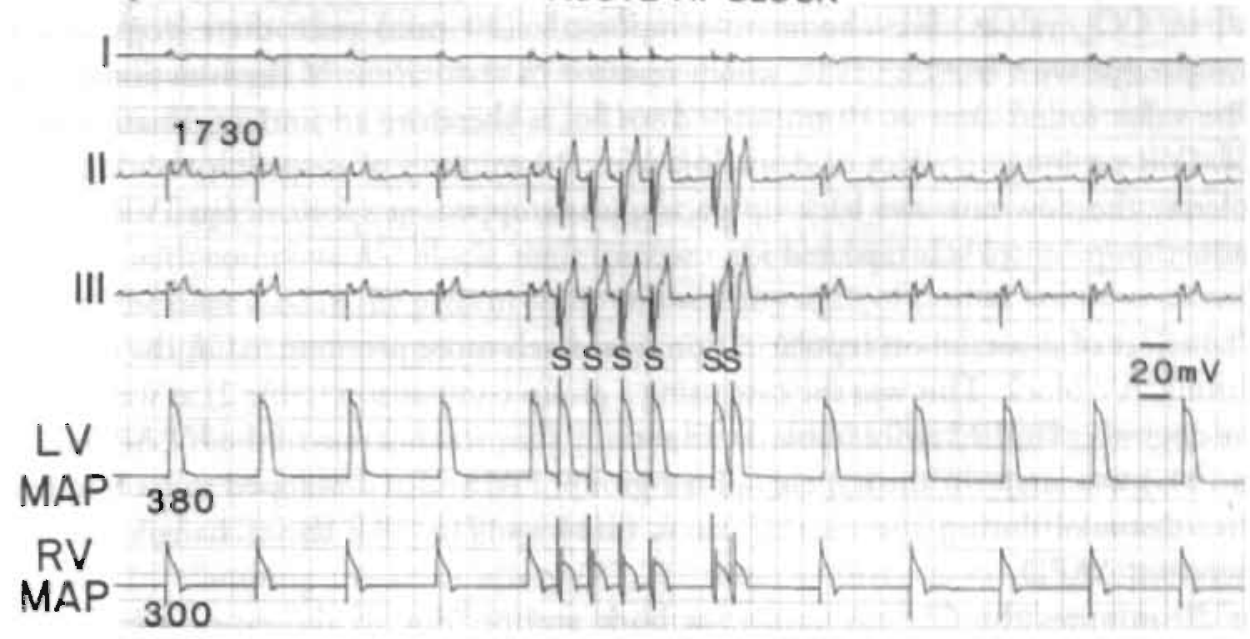

2

CHRONIC AV BLOCK
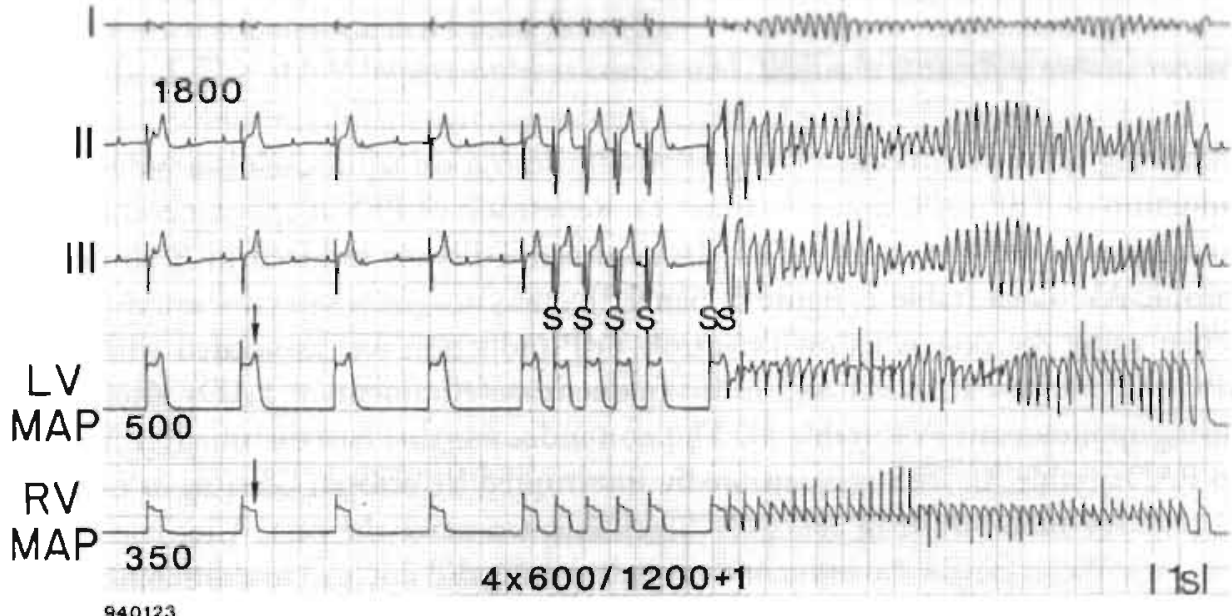

Figure 3. Difference in arrhychmogenie response after d-sotalol.

This figure (for abbreviations see figure 2) consists of three ECG leads and rwo MAP recordings, one in the RV and one in the LV at a paper speed of $10 \mathrm{~mm} / \mathrm{s}$, After d-sotalol, during a paced rhythm of 1730 $m s$ the LV APD is 380 and the RV APD $300 \mathrm{~ms}$ resulting in a $\triangle A P D$ of $80 \mathrm{~ms}$. Both MAP's are smooth: no early afterdepolarizations (EADs) are present. Performance of a pacing protocol consisting of 4 beats with a cycle length of 600 followed by beat after $1200 \mathrm{~ms}$ and an extra stimulus after $350 \mathrm{~ms}$ does not result in an arrhychmia. Six weeks later (panel 2), administration of $2 \mathrm{mg} / \mathrm{kg} \mathrm{d}$-sotalol results in a LV APD of 500 and a RV APD of $350 \mathrm{~ms}$ causing a $\triangle A P D$ of $150 \mathrm{~ms}$. Note that both MAPs now show EADs (arrows). Performance of the same pacing mode results in a self terminating TdP. 
in comparison to the effect of the chronic adaptations present after AV block. The latter occurred uniformly so that no effect on interventricular $\triangle A P D$ was seen. In five dogs, the prolongation of the CL-IVR by $\mathrm{d}$-sotalol, led to hyperventilation as evidenced by a fall in $\mathrm{CO}_{2}$ values. We choose to temporarily $(20 \mathrm{~min})$ pace these dogs at a $\mathrm{CL}$ comparable with baseline IVR, which resulted in restoration of the functional status. The value found after at 10 minutes $\mathrm{d}$-sotalol is therefore an underestimation of the CL-IVR prolonging effect of $d$-sotalol. After 20 minutes of $d$-sotalol, the dogs could tolerate the slow rate and back up pacing was stopped, at spontaneous IVR the TdP induction protocol was repeated for a second time.

The effect of d-sotalol on repolarization was much more pronounced in the dogs with chronic AV block. This was the case using a group comparison (table 2) as well as when the dogs were studied twice (table 3$)$. Especially the prolongation of the LV APD $(+28 \%$ vs $15 \%$ ) was larger in the hypertrophied group. EADs also developed more frequently after d-sotalol during chronic AV block (4/14 vs 9/18). All these changes led to an increased $\triangle \mathrm{APD}$.

At 20 minutes the CL was similar at both groups (due to the rate correction) the difference in QT, LV APD, RV APD and $\triangle A P D$ remained significantly higher after chronic AV block.

\section{Proarrhythmic response to d-sotalol}

Following acute AV block, pacing after administration of $d$-sotalol never resulted in induction of TdP (0/9), figure 3, panel 1). Repetition of PES at spontaneous IVR after $d$-sotalol also did not induce TdP. In contrast, TdP was induced in $6 / 10 \mathrm{dogs}$ with chronic AV block (table 2, figure 3, panel 2).

When using the dog as its own control, TdP induction was associated with a longer $A P D$, an increased $\triangle A P D$ and more frequent development of EADs after $d$-sotalol during spontaneous IVR (table 3). The non inducible dog had the smallest $\triangle A P D$ and no EADs (table 3). PES was repeatedly interrupted by ectopic beats in 3/5 dogs after chronic AV block while in acute AV block this was never the case. After correcting for the slower heart rate in the inducible animals, pacing did not lead to a different response. They remained inducible.

\section{DISCUSSION}

Amount of hypertrophy

Chronic complete AV block is not a frequently used method to induce cardiac hypertrophy, although such a model was already described in the beginning of the century 
(23). The increase in heart weight is due to the adaptations that take place to compensate for the volume overload that occurs when the heart rate slows (24). Hypertrophy has been described to appear in both the right as well as in the left ventricle $(24,25)$. These authors also describe the occurrence of cardiac failure in a number of dogs (7/11) when the animals are regularly exercised (25). Later reports in a larger series of dogs, showed compensated hypertrophy on as evidenced by the findings of normal LV hemodynamics (26). It is also our experience that compensated biventricular hypertrophy occurs when the dogs are kept in their cages without regular exercise. In our series of approximately 150 dogs with complete AV block, the incidence of overt heart failure is low ( $\pm 10 \%)$. None of the dogs used in the present study showed any signs of cardiac failure as assessed by body weight measurements, overall impression (ascites), and auscultation of the lungs.

In our model the LV mass to body weight ratio has increased from $4.3 \mathrm{~g} / \mathrm{kg}$ during sinus rhythm to $5.8 \mathrm{~g} / \mathrm{kg}$ during chronic AV block. Other canine studies using volume overload due to mitral valve regurgitation or arteriovenous fistula $(6,7)$ or pressure overload by clamping the renal artery $(27,28)$ show similar values of left ventricular hypertrophy. In contrast, aortic banding of puppies results in higher values: from 6.9 to $8.8 \mathrm{~g} / \mathrm{kg}$ (7.9). In this model, the authors have suggested to differentiate in two subgroups of hypertrophy: mild or severe depending on percent increase of the LV mass and diminished subendocardial blood flow (9).

As far as the degree of RV hypertrophy is concerned, the increase in RV to body weight ratio is more pronounced than that of the left ventricle. In dogs wirh arteriovenous shunt (6) and pulmonary banding (10) a similar amount of RV hypertrophy $( \pm 2.6 \mathrm{~g} / \mathrm{kg})$ has been found.

\section{Hypertrophy and electrophysiological changes}

Ventricular hypertrophy results in lengthening of the repolarization paramerers, like QT time and APD. It has been suggested that this prolongation predisposes the heart for EADs and triggered arrhythmias (11).

Mild hypertrophy caused by pressure overload in dogs has been shown to prolong LV APD by $14 \%$ both in situ (28), and in vitro (29). The present study shows that chronic AV block leads to a prolongation of LV APD with $32 \%$. This different increase in LV APD, despite a similar amount of LV hypertrophy, could be due to differences in cycle length between the two groups: $800 \mathrm{~ms}$ in the pressure vs $1600 \mathrm{~ms}$ in our dogs (28). $\mathrm{APD}$ is frequency dependent and when our dogs are paced at comparable rates the prolongation is less pronounced (30).

Surprisingly, the increase in RV APD is less severe $(+21 \%)$ than that of the LV APD, despire a similar absolute increase in heart weight and an even higher percentual increase of the right ventricular mass. This could indicare thar the changes in the electrophysiological paramerers are not only related to hypertrophy and/or bradycardia. 
A comparison with other models is not possible because to our knowledge no report has been published describing the electrophysiologic effects in dogs with RV hypertrophy. An explanation for this difference could be the different hemodynamics in the right and left ventricle. Functionally the left ventricle is completely adapted to the volume overload. as measured by pressure volume loops (SHM de Groot, personal communication) and also other studies indicate compensation $(24,26)$. The functional status of the right ventricle has not been determined yet, but it is conceivable that a similar volume overload leads to different wall strains in the right compared with the left ventricle. Stretch has the capability to shorten APD (31), and this opposing effect may infiuence the amount of prolongation.

Also for the comparison of the APD at the two time points, this stretch induced shortening may be a confounding parameter. The measured APD at control could be shorter as expected on the basis of the bradycardia alone.

A second but less likely reason for the difference between the LV and RV APD response, could be a different rate response in M cells of the right and left ventricle. At longer cycle lengths the prolongation of the LV is much longer than the RV (32). Studies in dogs and humans have shown the presence of $\mathrm{M}$ cells $(32,33)$.

\section{Consequences of interventricular dispersion}

The consequence of the relative smaller increase in the RV APD compared with the LV $\mathrm{APD}$ is an increase in the interventricular dispersion under baseline conditions in the chronic AV block phase. Interventricular dispersion is bradycardia dependent, the slower the hear rate the longer the difference between the LV and RV APD (17). In this study, we have controlled for the cycle length, so that the observed increase in dispersion is not based on the frequency. This increased amount of dispersion could have important pro arrhythmic consequences as we have recently described (17), because it is one of the components necessary to induce $\mathrm{TdP}$ in our animal model. The occurrence of $\mathrm{TdP}$ after administration of class III agents (13) is associated with bradycardia, QT/APD prolongation and the development of EADs (17). Suppression of EADs and a diminished interventricular $\triangle A P D$ by magnesium prevents TdP (17), whereas the class III agent almokalant, which results in more EADs and a larger $\triangle \mathrm{APD}$ as $d$-sotalol, has a higher incidence of (spontaneous) TdP occurrence (34).

Similar findings were obtained in this study , both in the serial testing as in the group comparison. TdP induction was related to the presence of EADs and an impressive amount of interventricular dispersion. Following acute AV block no EADs were present under baseline situation and interventricular $\triangle A P D$ amounted to $40 \mathrm{~ms}$. Administration of $d$-sotalol led to a lengthening of the repolarization parameters, appearance of EADs, but not to an increase in $\triangle A P D$, and no TdP could be induced. After 5 weeks of AV block, interventricular $\triangle A P D$ was increased under baseline situation, while EADs were still not present, with one exception. In that dog TdP could be induced during baseline. 
d-Sotalol increased interventricular $\triangle \mathrm{APD}$ further because of to its more pronounced effect on the LV APD and led to a higher incidence of EADs, and to TdP induction in $60 \%$ of the dogs. This means that not only the baseline values are higher in hypertrophy but that also the increase in APD and $\triangle A P D$ after $d$-sotalol is larger. The dogs with a low interventricular $\triangle \mathrm{APD}$ after $d$-sotalol did not develop TdP (see e.g. table 3 ).

\section{Role of hypertrophy for the induction of TdP}

Hypertrophy and its concomitant increase in the dispersion of intra- and/or interventricular repolarization is also associated with a higher vulnerability to other ventricular arrhythmias in other studies $(2,11,27,28,35,36)$. Moreover, regression of hypertrophy concomitant with a decrease of the electrophysiological parameters results in a marked reduced incidence of arrhythmias to baseline (36).

It would also be interesting to see whether the changes in electrophysiologic parameters in our dogs can be influenced by the prevention or regression of hypertrophy. In this context it is important to mention the study of Kreher et al. (37) suggesting that the adaptations leading to hypertrophy and electrophysiologic changes could be two different processes which can operate independently (37).

Occurrence of TdP in dogs in the acure phase of AV block is not impossible. Two studies have shown the occurrence of spontaneous $\mathrm{TdP}$ and polymorphic ventricular arrhythmias after administration of class III agents $(38,39)$. However addition of an $\alpha$-agonist (39) or a three times higher dose of almokalant was required $(34,38)$. This could imply that the processes which takes places in the weeks following creation of complete AV block are more a facilitating than an absolute requirement for the induction of TdP, especially in regard to the increased APD and dispersion. In this regard it is of interest that in the human heart with complete $\mathrm{AV}$ block, $\mathrm{TdP}$ is rarely seen during acute ischemic AV block in myocardial infarcrion, bur much more in chronic fibrotic AV block. It is likely that in the latrer parient group ventricular hypertrophy is present.

\section{Sensitivity to d-sotalol}

Prolonged repolarization facilitates the development of EADs (11). The ionic mechanism of these EADs and of the increase in APD are nor completely understood. Several reports show diminishment in outward $\mathrm{K}^{+}$currents $(2,40)$. $d$-Sotalol, like most class III agents, blocks the outward $\mathrm{K}^{+}$current. Blockade of an already diminished current may explain the higher sensitivity to $d$-sotalol of the hypertrophied muscle in AV block dogs. 


\section{Limitations}

In this study, we did not assess the time dependent behavior of the anatomical and electrophysiological changes. Because we measured only at two time points, it is possible that the adaptations were not fully completed. Earlier studies, however, showed that there is no relation with duration of AV block and total heart weight when assessed after two weeks $(24,25)$. We had similar findings comparing the obtained heart weights at 20 weeks with 9 weeks AV block. In relation to the electrophysiological effects, the response to $d$-sotalol does not change in time, when we compare the experiments that have been started after 2 weeks AV block (13). This suggests that the alteration responsible for the facilitated TdP induction is already present at two weeks. The time period between 0 and 2 weeks will be the subject of further investigations.

A second limitation could be the random placement of the endocardial MAPs during these experiments. This method ignores possible intraventricular differences in APD. However we have shown that the intraventricular difference is always much smaller (only $20 \%$ ) than the interventricular dispersion (17).

Finally, we have the difficulty that we are not yet able to measure the changes that occur during the pacing train leading to induction of TdP. We know that changes in frequency lead to augmentation of EADs, and to occurrence of triggered ectopic beats. The dynamicity of the changes in interventricular $\triangle A P D$ can however not been assessed at this time.

\section{Possible clinical implications}

Exirapolation from data derived from experimental animals to the human setting should always be done with great caution. It is known that many different arrhythmic mechanisms may be generated in the hypertrophied myocardium resulted in symptomatic arrhythmias and death $(2,3)$. We can hypothesize that patients with ventricular hypertrophy are more prone to the proarrhythmic effects of the TdP type during treatment with repolarization prolonging agents than patients without hypertrophy. A first step to be better informed about that possibility could be to stratify patients with TdP not only to QT interval, QT dispersion and heart rate but also to their degree amount and/or kind of ventricular hypertrophy.

\section{General conclusions}

Chronic complete AV block causes volume overload induced biventricular hypertrophy. Changes after creation of complete AV block do not only results in an increase in APD, they also lead to an increase in EADs and $\triangle \mathrm{APD}$ after $d$-sotalol. This change is accompanied by the occurrence of $\mathrm{TdP}$ arrhythmias, once again confirming the imporrance of both EADs and $\triangle A P D$ in the genesis of TdP. 
The staff of the Animal Care Facility under supervision of T van den Boogaard DVM is gratefully acknowledged for taking care of the dogs. $d$-Sotalol was provided by $\mathrm{Mr} \mathrm{J}$ Verschuuren, Bristol Meyers Squibb, Brussels Belgium. The Bakken Research Institute (Medtronic) Maastricht, the Netherlands supplied the epicardial electrodes. This study was financed by a grant from the Netherlands Heart Foundation $\# 94.010$.

\section{REFERENCES}

1. Kannel WB, Gordion T, Offutt D. Left ventricular hypertrophy by electrocardiogram. Prevalence incidence and mortality in the Framingham study, Ann Intern Med 1969; 71: 89-101.

2. Tomaselli GF, Beuckelmann DJ. Calkins HG, Berger RD, Kesssler PD, Lawrence JH, Kass D, Feldman AM. Marban E. Sudden cardiac dearh in heart failure. The role of abnormal repolarization. Cinculation 1994: 90: 2534-2539.

3. Pye MP. Cobbe SM. Mechanisms of ventricular arrhythmias in cardiac failure and hypertrophy. Cardionate Res 1992; 26: 740-750.

4. Messerli FH. Grodzicki T. Hypertension, left ventricular hypertrophy, ventricular and sudden death. Eur Heart J 1992; 13: 66-69 (supplement D).

5. Klein RC. Ventricular arrhythmias in aortic valve disease: analysis of 102 parients. Am / Cardiol 1984; 53: 1079-1083.

6. Omens JH, Covell JW. Transmural distribution of myocardial tissuc growth induced by volume overload hypertrophy in the dog. Circulation 1991; 84: 1235-1245.

7. Carabello BA, Zile MR, Tanaka R, Cooper G IV. Lefi ventricular hyperirophy due to volume overload versus pressure overload. Am J Physiol 1992; 263: H1137-H1 144.

8. Hart G. Cellular electrophysiology in cardiac hypertrophy and failure. Cardiovase Res 1994; 28: 933-946.

9. Hirringer L, Patrick T, Ihara T, Hasebe N, Shen YT, Kalthof B, Shannon RP, Vatner SF. Exercise induced cardiac dysfunstion in both moderate, compensated and severe hypertrophy. Circulation, 1994: 89: 2219-2231.

10. Bonnin CM, Sparrow MP. Taylor RR. Collagen synthesis and content in right ventricular hypertrophy in the dog. Am J Physiol 1981; 241: H708-H713.

11. Aronson RS, Ming Z. Cellular mechanisms of arrhythmias in hypertrophied and failing myocardium. Circulation 1993; 87: VII76-VII83.

12. Bayes De Luna A, Coumel P. Leclercẹ JF. Ambulatory sudden cardiac death: mechanisms of production of fatal arrhychmia on the basis of data from 157 cases. Am Heart / 1989; 117: 151-159.

13. Vos MA, Verduyn SC, Gorgels APM, Lipscei GC, Wellens HJJ. Reproducible induction of early afterdepolarizations and torsade de pointes arrhythmias by $\mathrm{d}$-sotalol and pacing in the dog with chronic atrioventricular block. Circulation 1995; 91: 864-872.

14. Strauss HC, Bigger JT. Hoffman BF. Electrophysiological and beta-receptor blocking effects of MJ1999 on dog and rabbit cardiac rissue. Circ Res 1970; 26: 661-678.

15. Taggart P, Sutton P, Donaldson R. d-Sotalol: a new potent class III anti-arrhythmic agent. Clinical Science 1985; 68: 631-636. 
16. Jackman WM, Szabo B, Friday KJ, Margolis PD, Moulton K, Wang X. Patterson E, Lazzara R. Ventricular tachyrhythmias related to carly afterdepolarizations and triggered firing: relationship to QT interval prolongation and potential therapeutic role for calcium blocking agents. / Cardiovase Electrophysiol 1990; 1: 170-195.

17. Verduyn SC, Vos MA. Zande van der J. Steld van de BJ. Wellens HJJ. Role of interventricular dispersion of repolarization in the mechanism of acquired early afterdepolarization dependent Torsade de Pointes arrhythmias: reversal by magnesium. (submitted)

18. Vos MA, Gorgels APM, Lipscei GC, de Groot SHM, Leunissen JDM. Wellens HJJ. Mechanism specific anti-arrhychmic effects of the potassium channel activator levcromakalim against repolarization dependent tachycardias. / Cardiovasc Electrophysiol 1994: 5: 731-742.

19. Vos MA, Gorgels APM, Leunissen JDM, Nagel van der T, Halbertsma FJJ. Wellens HJJ. Further observations to confirm the arrhythmia mechanism specific effects of flunarizine. / Cardiovase Pharmacol 1992: 19: 682-690.

20. Vos MA, Van Deursen RTAM, Gorgels APM, Leunissen JDM, Wellens HJJ. R56865, an antiarrhythmic drug with class III effects that terminates ouabain induced ventricular tachycardia in an inverse rate dependent manner. Cardiovase Res 1993; 27: 1491-1497.

21. Damiano BP, Rosen MR. Effects of pacing on triggered activicy induced by early afterdepolarizations. Circulation 1984: 69: 1013-1025.

22. Levine JH. Spear JF, Guarnieri T. Weisfeldr ML. de Langen CDJ., Becker LC. Moore EN. Cesium chloride-induced long QT syndrome: Demonstration of after-depolarizations and triggered activity in vivo. Circulation 1985: 72: 1092-1103.

23. Erlanger J. Blackman JR. Further studies in the physiology of heart block in mammals. Chronic auriculo-ventricular heart block in the dog. Heart 1910; I: 177-229.

24. Brockman SK. Cardiodynamics of complete heart block. Am / Cardiol 1965; 16: 72-83.

25. Starzl TE. Gaertnet RA. Chronic heart block in dogs. A method for producing experimental heart failure. Circulation 1955; 12:259-270.

26. Wusten B, Flameng W. Schaper W. Cardiac function in the chronically volume-overloaded canine heart. Basic Res Cardiol 1977: 72: 172-177.

27. Martins JB, Kim W, Marcus ML. Chronic hypertension and left ventricular hypertrophy facilitate induction of sustained ventricular tacycardia in dogs 3 hours after lefi circumflex coronary artery occlusion. / Am Coll Cardiol 1989; 14: 1365-1373.

28. Ben-David J, Zipes DP. Ayers GM. Pride HP. Canine left ventricular hypertrophy predisposes to ventricular tachycardia induction by phase 2 early afterdepolarizations after administration of Bay K 8644. J Am Coll Cardiol 1992; 20: 1576-1584.

29. Cameron JS, Myerburg RJ, Wong SS, Gaide MS, Epstein K, Alvarez TR, Gelband H, Guse PA, Bassett AL. Electrophysiologic consequences of chronic experimentally induced left ventricular pressure overload. / Am Coll Cardiol 1983; 2: 481-487.

30. Vos AM, de Groot SHM, van der Zande J, Verduyn SC. Wellens HJJ. Electrophysiologic changes observed after creation of AV block in the dog. PACE: 18: 1995: 1094 (Part II, abstract).

31. Franz MR, Burkhoff D. Yue DT. Sagawa K. Mechanically induced action potential changes and arrhythmia in isolated and in situ canine hearts. Cardiovase Res 1989: 23: 21-223.

32. Antzelevitch C. Sicouri S. Clinical relevance of cardiac arrhythmias generated by afterdepolarizations. Role of $\mathrm{M}$ cells in the generation of $\mathrm{U}$ waves, triggered activity and Torsade de Pointes. I Am Coll Cardiol 1994: 23: 259-277.

33. Drouin E, Charpentier F, Gauthier C, laurent K. Le Marec H. Electrophysiological characteristics of cells spanning the left ventricular wall of human heart evidence for the presence of $\mathrm{M}$ cells. / Am Coll Candiol 1995: 26: 185-192. 
34. Verduyn SC, Vos MA, Zande van der J. Wellens HJJ. A comparison between the proarrhyrhmic effect of almokalant and d-sotalol in an animal model of Torsade de Pointes arrhythmias. $/ \mathrm{Am}$ Coll Candiol 1995; 170A (abstract).

35. Kowey PR. Frichling TD, Sewter J. WU Y, Sokil A, Paul J. Nocella J. Electrophysiological effects of left ventricular hypertrophy. Effect of calcium and potassium channel blockade. Circulation 1991; 83: 2067-2075.

36. Rials SJ, WU Y, Ford N, Paulerto FJ. Abramson SV, Rubin AM, Marinchak RA, Kowey PR. Effecr of left ventricular hypertrophy and its regression on ventricular electrophysiology and vulnerability to inducible arrhythmia in the feline heart. Cinculation 1995; 91:426-430.

37. Kreher P, Ristori MT, Verdetri J. Effects of chronic angiotensin l-converting enzyme inhibition on the relations between ventricular action potential changes and myocardial hypertrophy in aging hearts. / Candiovase Pharmacol 1995: 25: 75-80.

38. Duker GD, Linhardt GS, Rahmberg M. An animal model for studying class III induced proarrhythmias in the halothane-anesthetized dog. I Am Coll Cardiol 1994: 326A (abstract).

39. Buchanan L.V. Gibson K. Characterization of monomorphic and polymorphic tachycardia in a canine model of proarrhythmia. Circulation 1994: 90: 248 (abstract).

40. Furukawa T, Myerburg RJ. Furukawa N. Kimura S, Bassett AL. Metabolic inhibition of $\mathrm{I}_{\mathrm{Ca}} \mathrm{L}$ and $\mathrm{I}_{\mathrm{K}}$ differs in feline left ventricular hypertrophy. Am / Physol 1994; 266: 1121-1131.

41. Nuss HB, Houser SR. Effect of duration of depolarisation on contraction of normal and hypertrophied feline ventricular myocytes. Cardiorvase Res 1994; 28: 1482-1489.

42. Carre F, Rannou F, Saintre Beuve C, Chevalier B, Moalic JM. Swijnghedauw B, Charlemagne C. Arrhythmogenicity of the hypertrophied and senescent heart and relation to membrane proteins involved in the altered calcium handling. Cardionass Res 1993; 27: 1784-1789. 



\section{Chapter 8}

\section{General discussion}

Since the beginning of this decade, there has been an increase in the use of class III agents instead of class I antiarrhythmic drugs. Class I drugs primarily delay conduction, while class III drugs act by lengthening of repolarization. This change is the result of multi center trials pointing to a higher complication rate when class I drugs are used. 1) The CAST trials $(1,2)$, in which administration of class I drugs (flecainide, encainide, and morizicine) after myocardial infarction led to increased mortality. This adverse effect is observed in patients who had shown a decrease in ventricular arrhythmias on Holter recordings while using these drugs. 2) The ESVEM trial (3), in which various class I agents were found to be less effective than sotalol in treating parients with symptomatic ventricular tachycardia (VT) or those surviving cardiac arrest. In these patients antiarrhythmic treatment was guided by either Programmed Electrical Stimulation (PES) or Holter. 3) The CASCADE trial (4), in which empiric amiodarone therapy was proven to be more effective than class I agents. Again in this study, treatment was guided by PES or Holter.

These findings provided the major motive for the development of new class JII agents (5,6). Also, because the existing class III agents (sotalol and amiodarone) 1) bad orther effects next to their prolongation of the action potential duration, and 2) lacked specific $\mathrm{K}^{+}$channel blocking properties, new "pure" class III agents were the targets to develop. Class III agents in general do have the potential to induce proarrhythmic reacrions. The best known is the occurrence of Torsade de Pointes arrhythmias (TdP). An increasing clinical use of class III drugs makes it likely that there will be a proporrionate increase in TdP. Fear of this problem has already resulted in the discontinuation of the development of a number of pure class III agents (7), as is the case with $d$-sotalol where an increased morcality rate with this drug was reported in the SWORD trial (8), but also in case of almokalant (9) and sematilide.

To develop a safe class III antiarrhythmic drug, it is necessary to define exactly the precise electrophysiologic mechanisms of $\mathrm{TdP}$, the clinical circumstances favoring its occurrence and how these are effected by the antiarrhythmic drug. For that purpose, it becomes mandatory to have an animal model of TdP in which TdP can be reproducibly induced under "clinical" circumstances. Moreover, such a model would allow systematic 
investigation of the different parameters involved and would enable comparison of different proarrhythmic and antiarrhythmic effects of drugs.

In our opinion, our recently developed TdP model, which is described in this thesis, meets those requirements. We performed a total of 115 experiments ( $88 d$-sotalol, 27 almokalant) to study the different aspects of TdP. We were not only able to reproducibly induce $\mathrm{TdP}$ during a single experiment but this $\mathrm{TdP}$ induction was maintained over weeks (figure 1).

Like clinical acquired $T d P^{\prime}(10)$, the initiation of $T d P$ in our animal model is related to the following parameters 1 ) heart rate (bradycardia), 2) prolonged QT time, 3) presence of early afterdepolarizations (EADs), and 4) abrupt frequency changes (short long short sequence). In addition, we have confirmed the presumed relevance of another parameter: $5)$ interventricular dispersion of repolarization $(\triangle A P D)$ in the genesis of TdP. In the following paragraphs each of these parameters will be discussed in relation to the results presented in this thesis and compared to data from the literature.

\section{Heart rate}

The importance of a slow heart rate or long cycle length of the idioventricular rhythm (CL-IVR) is based on the following observations: 1) In the clinical situation TdP often occurs during bradycardia because of sinoatrial or atrioventricular block. In patients with atrial fibrillation TdP typically develops after conversion to (a slower) sinus rhythm; 2) In our own model, non inducible dogs have a faster rhythm; 3) However when the CL-IVR of these non inducible dogs is prolonged with a second bolus of $d$-sotalol, half of them become inducible (chapter 2); 4) Both in the clinical siruation and in our dog model, acceleration of the CL-IVR by isoproterenol or ventricular pacing prevents/suppresses TdP induction (chapter 2); 5) CL-IVR is a major determinant of all repolarization parameters: QT time, EADs and interventricular $\triangle A P D$.

Although we consider bradycardia to be an important requisite, it has also beeñ shown that other factors need to be concomitantly present like an additional prolonged repolarization time. For example, we demonstrated in inducible dogs that a similar increase in CL-IVR after the $\beta$ blocker atenolol did not lead. to TdP induction (chapter 2). Secondly, a further prolongation of the CL-IVR after magnesium administration was not accompanied by persistence of TdP because the reduction in repolarization prevented occurrence of TdP (chapters 2 and 3 ).

\section{QT rime}

In the literature QT values have been mentioned which could possibly predict the risk for the development of TdP $(11,12)$. Therefore we plotted the QT and CL-IVR at baseline, 10 minutes after $d$-sotalol and after prevention by $\mathrm{MgSO}_{4}$, verapamil. flunarizine, ryanodine or leveromakalim (13) to relate these parameters to the induction 


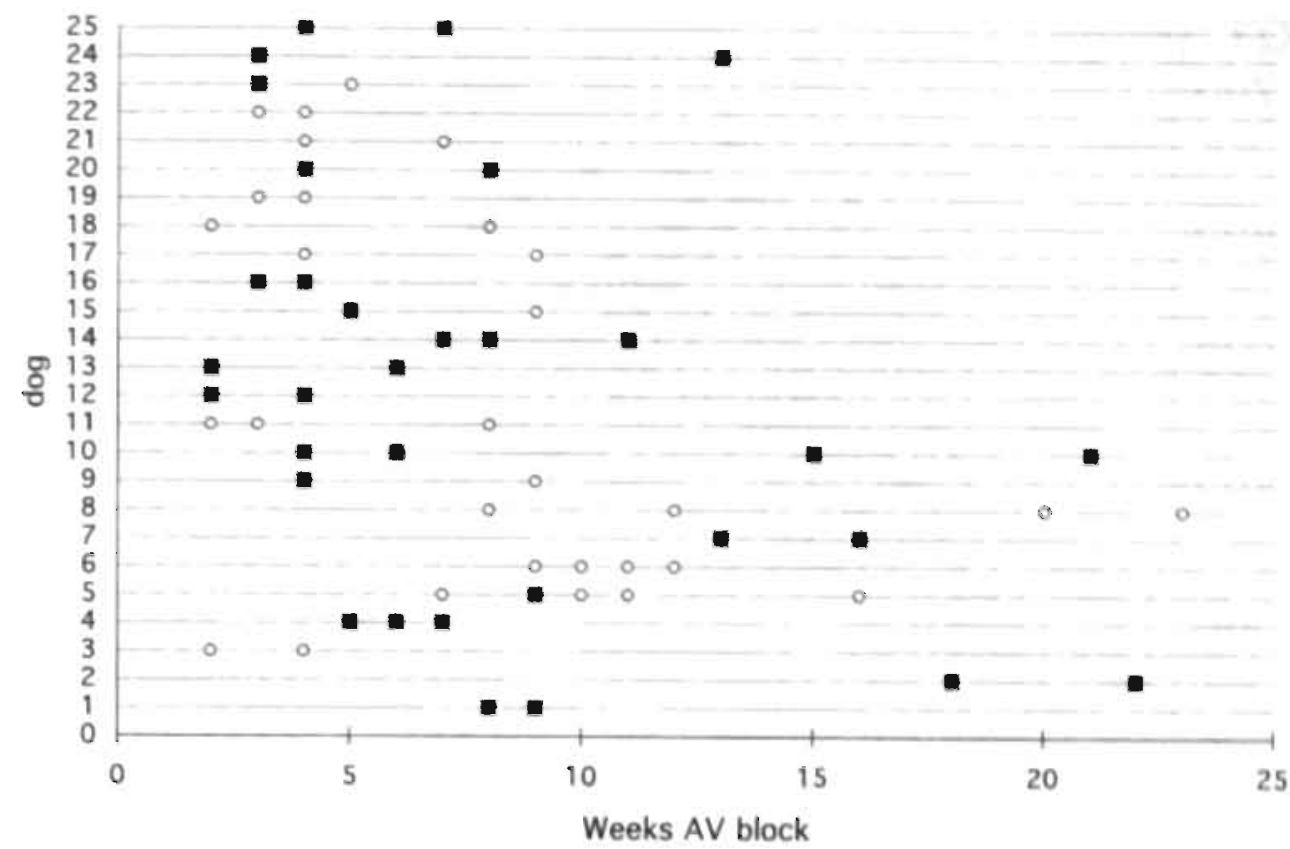

Figure 1. Reproducibility of the (in)ability to induce Torsade de Pointes arrhychmias (TdP) after d-sotalol over weeks.

The response of the dogs which were tested more than once for the TdP experiments after $2 \mathrm{mg} / \mathrm{kg} d$-sotalol is shown: induction of TdP $(\square)$ or no induction of $T d P(O)$. On the horizontal axis the number of weeks after the crearion of chronic complete atrioventricular block is depicted. Only $4 / 62$ cases showed a different response, leading to a reproducibility of $94 \%$ over weeks. Two of these changes could be explained by the use of a diuretic.

of TdP. From figure 2 it is clear that most inducible points fall in the north east quarter of this graph, but no discriminatory line can be established with a sufficient sensitivity and/or specificity to predict TdP occurrence. However, the transition to inducible ( $d$-sotalol) or non inducible events (after preventive medication) is always associated with a change in QT. These data confirm clinical findings that the absolute value of QT prolongation is not of great value. In this regard it is of interest to mention that amiodarone while causing a similar or even longer QT time as other class III or class Ia agents, does not result in TdP $(14,15)$.

Lately, articles have appeared that indicate that QT dispersion, that is the difference between the longest and the shortest QT time on the ECG, may be used as a possible predictor for $\mathrm{TdP}$ in acquired (16-18) and congenital TdP (19). This work has many limitations, like reproducibility, variation in the number of leads which are measured, differences in merhodology of QT time measurements, how to account for $T$ wave 


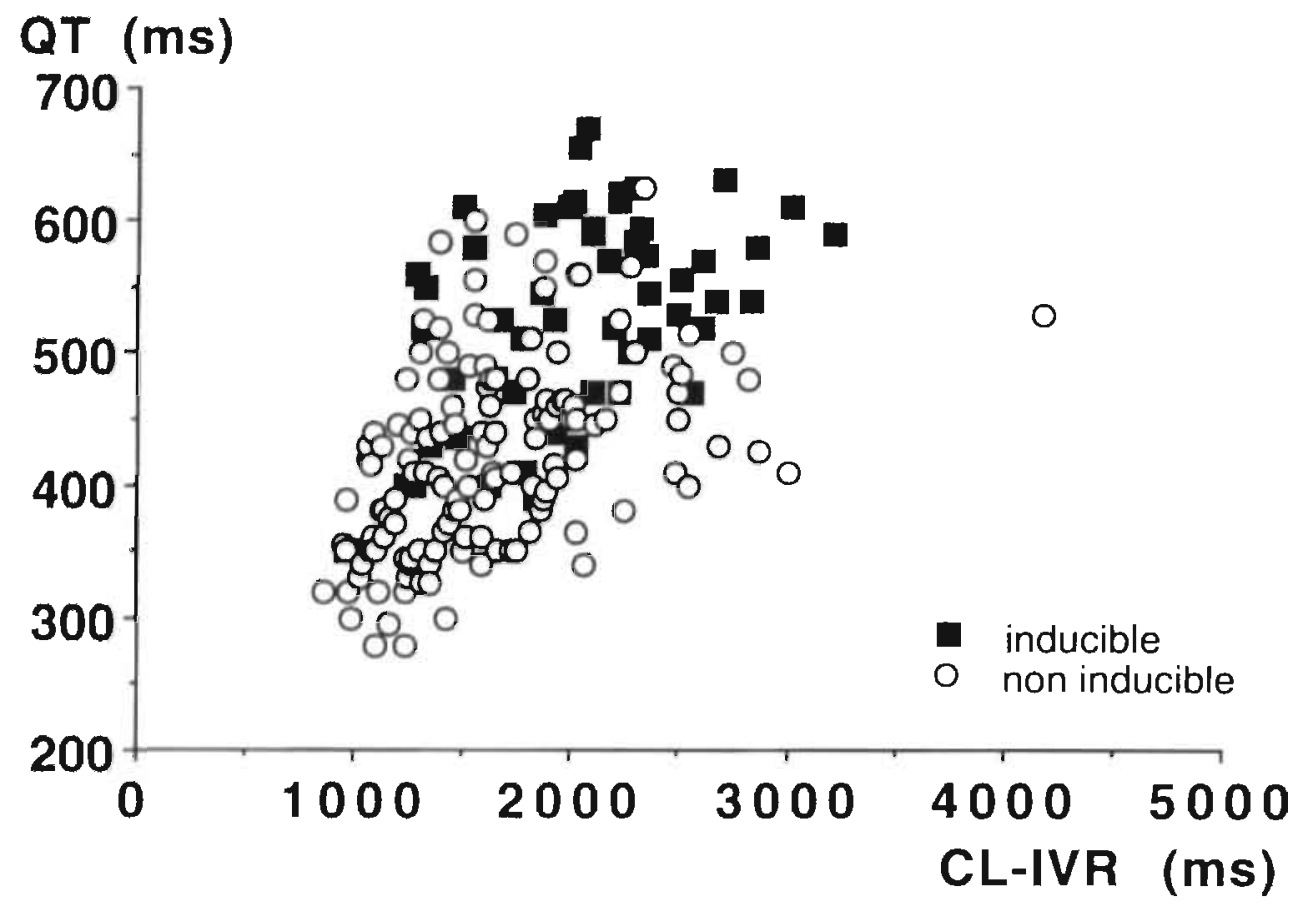

Figure 2. Importance of the QT time and the cycle length of the idioventricular rhythm for the (in)ability to induce $\mathrm{TdP}$.

In this figure, data from 80 experiments with $d$-sotalol are combined. Open circles $(O)$ indicate time points in the experiment in which no TdI could be indueed: !) during baseline, 2) first bolus d-sotalol not leading to TdP (non inducible animals) and 3) after anti arrhythmic treatment using MgSO4 (100 mg/kg), ryanodinc $(10 \mu \mathrm{g} / \mathrm{kg})$, verapamil $(0.04 \mathrm{mg} / \mathrm{kg})$, flunarizine $(2 \mathrm{mg} / \mathrm{kg})$ or leveromakalim $(0.01 \mathrm{mg} / \mathrm{kg})$. The closed squares (-) are the time points at which TdP could reproducibly be induced after PES (first and second bolus of $d$-soialol). The specificity and/or sensitivity are low. For example a QT time of $500 \mathrm{~ms}$ has a specificity of 0.88 , but only a sensitivity of 0.66 . When the QT time is lowered to $450 \mathrm{~ms}$, the specificity decreases to 0.61 , while the sensirivity increases to 0.8 . Therefore no discriminating line can be found using either CL-IVR or QT to predict occurrence of TdP.

morphology, the inportance of normal and abnormal spread of ventricular activation, and what to do with the U wave (20). Also these series are small, and follow up time often to short to get an idea about the true value of this approach.

\section{Dispersion of repolarization}

Regional differences in the length of repolarization can be subdivided in inter-, intraventricular or transmural dispersion, including dispersion between Purkinje and myocardial tissues. Since the introduction of the MAP catheter, many studies have been 
performed that measured APD at different sites. Most of them are limited to intraventricular $\triangle \mathrm{APD}$. In the normal human heart (see table 5 in chapter 1), the intraventricular difference in MAP duration ranges from 0 to 73 milliseconds (21-23). In patients with congenital long QT values around $125 \mathrm{~ms}$ (23) have been described, while there has been found an interventricular $\triangle A P D$ of over $250 \mathrm{~ms}$ (24) in a patient with acquired TdP. Transmural and interventricular dispersion have also been the subject of investigation in vitro. In figure 3 , the reaction of 3 different canine ventricular cell types to changes in cycle length of both ventricles are depicted. At longer CL, the APD of the epicardial and endocardial cells are shorter than that of the midmyocardial (M) cell. In addition the APDs of LV endocardial and LV epicardial cells, but especially the M cells are significantly longer than that of the right ventricular cells (25) (compare right and left panels of figure 3 ).

In the dog heart with chronic complete AV block, baseline values of about $60 \mathrm{~ms}$ for interventricular $\triangle \mathrm{APD}$ are encountered. Interventricular dispersion was shown to be bradycardia dependent (chapter 3), even without the presence of EADs. At a short cycle length $(500 \mathrm{~ms})$, there is already an interventricular difference in the APD of around 10-30 ms (chapter 3 and figure 4). The increase in interventricular $\triangle A P D$ with an increase in CL can be explained by the difference in response of the right versus left ventricular cells.

Administration of $d$-sotalol or almokalant results in a more pronounced interventricular $\triangle A P D$. In our dogs the intraventricular difference is only 20 to $30 \%$ compared with the interventricular $\triangle A P D$ (table l of chapter 3) after class III drugs. This can not only be explained by the different sensitivity of the LV compared to the RV in regard to changes in frequency or class III drugs, but is in part also related to the development of EADs (see below).

Dispersion of repolarization is not only related to differences in APD but can also be attributed to differences in local activation time (AT) with the beginning of the QRS complex as a reference. It will change when the normal sequence of activation as occurring during conducted sinus rhythm changes to a paced or idioventricular rhythm. In the normal heart there exists an inverse relationship berween AT and APD resulting in a relatively homogeneous (endpoint) of repolarization (26). A long repolarization time can therefore to a certain extent be compensated by differences in AT. Although we did not determine AT yet (due to the different activation patterns during the CL-IVR) we do not believe that this is a major contributor to interventricular $\triangle A P D$ in our experiments.

\section{EADs and ectopic beats}

Early afterdepolarizations are defined as an interruption or retardation of the repolarization (27) that prolong the APD. In vitro, not all cells are equally sensitive to develop EADs $(28,29)$. Also in situ, there are findings which suggest a preferential site of EAD 

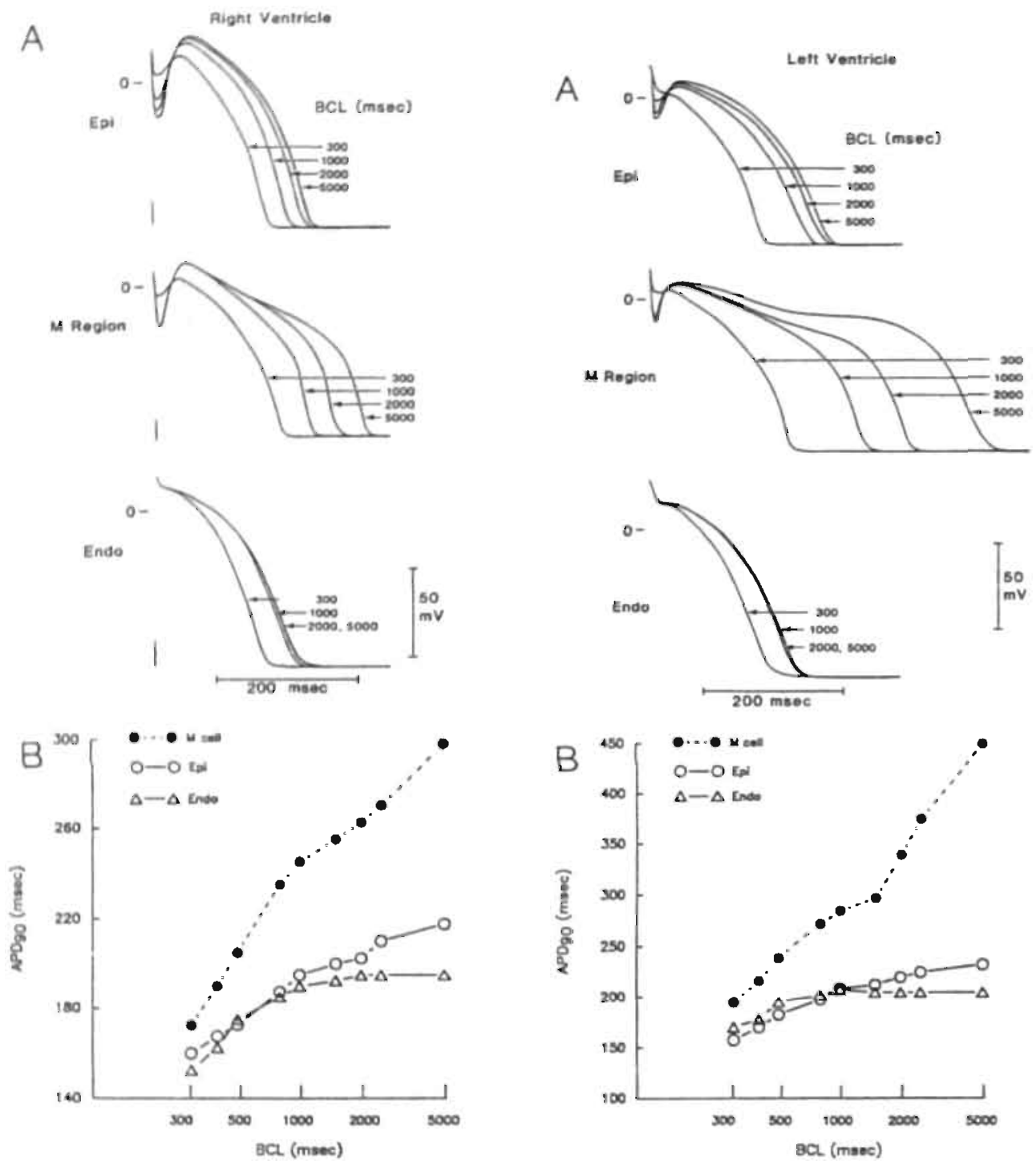

Figure 3. Interventricular and transmural diffẹenceses in canine ventricular action potential duration (APD) in vitro.

The action potential of the left and right ventricle is shown at different cycle lengths for the individual ventricular cell types: endocardial ( $\Delta)$, epicardial (o) and $\mathrm{M}$ cells $(\bullet)$. Besides larger transmural differences in APD at the longer cycle lengths there is also an appreciable difference in the APD when the left (right part) and right ventricle (left part) are compared. This results in a large interventricular $\triangle A P D$ of approximately $100 \mathrm{~ms}$ at a CL of $2000 \mathrm{~ms}$. Figure adapted from reference 25, published with permission of the American Heart Association and the authors. 
development: 1) Endocardial MAP recordings in humans do not show EADs on every site $(23,24)$. 2) Experimental studies in dogs have indicated that a) EADs are more prone to develop on the endocardial than on the epicardial site (29) and b) there exists a differential response of the left and right ventricular EAD amplitude after cesium and left stellate ganglion stimulation (30). We have shown (chapters 2,3 and 5) that after $d$-sotalol the EADs occur more frequently in the left ventricle, whereas with almokalant EADs developed in both ventricles (chapter 4).

The manifestation of EAD dependent triggered activity needs some prerequisites: 1) critical prolongation of the APD by reducing outward current (as after class III agents), or increasing inward current, 2) a net depolarizing current to create the EAD, and 3) propagation of the EAD to other regions of the heart resulting in an extrasystole. The net depolarizing current, causing the EAD, may be secondary to a disbalance in the intracellular calcium, because both ryanodine and flunarizine prevented the EAD and related triggered beats (chapter 6). In our experiments we have found that the coupling interval of such an extrasystole or ectopic beat (EB) is not always within the APD or QT time. This can be explained by the fact that 1) the EB was originating from a cell with a very long APD (e.g. Purkinje or M cell), that is not represented on the MAP or the ECG due to the small mass, or 2) a long conduction time between the triggering cells and the ventricular muscle (29) or both. An alternative explanation that is more controversial, could be the simultaneous presence of EADs and delayed afterdepolarizations (31). When the latter are responsible for the EBs the coupling interval will be beyond the APD.

\section{Frequency changes}

In parients a short long short sequence of the rhythm is observed at the start of most episodes of $\mathrm{TdP}(12,32,33)$. A recent analysis of Holter recordings in patients with TdP showed that before the development of $\mathrm{TdP}$ there was a significant increase in heart rate with the occurrence of short long shorr sequences in the last minutes preceding the $T d P$ (34).

Frequency changes, either spontaneously occurring (almokalant) or induced by PES (our $d$-sotalol experiments) form the basis for the initiation of the TdP. Withour a first ectopic beat no TdP will start. Wirh PES induced $T d P$, one frequency change can already be sufficient to start EBs and TdP (chapter 2). In the other 50\%, more frequency changes are necessary. On the orher hand, the occurrence of spontaneous EBs is nor always sufficient to start a spontaneous $\mathrm{TdP}(35)$ and has no meaning for the inducibility of $\mathrm{TdP}$ with PES. The difference could be that 1 ) the coupling interval of the EB is not appropriately timed, and/or 2) the number of beats is insufficient. The observation that class III agents (chapters 2 and 3) favor the occurrence of (or pronunciation of) the EADs after a rate acceleration was recently confirmed in in vitro studies (36). Rate acceleration 
can also affect the interventricular $\triangle A P D$ due to different dynamic responses of the right and left ventricle to adaptation of the APD.

\section{$E A D$ s and interventricular $\triangle A P D$}

The relation berween EADs and $\triangle A P D$ is not entirely clear. Often the EAD is observed in the MAP with the longest APD $(23,24)$, thereby contributing to the $\triangle A P D$. On the other hand, presence of EADs in both ventricles, as with almokalant, is not associated with a smaller interventricular $\triangle \mathrm{APD}$ (chapter 4 , see below). From the behavior after spontaneous termination of TdP and the increase in $\triangle \mathrm{APD}$ after the development of EADs at a stable paced rhythm we concluded that EADs do contribute to interventricular $\triangle A P D$ (chapter 5). While it is difficult to quantify their exact contribution, we have hypothesized it to be around 25 to $30 \%$. Furthermore the electrophysiological adaptations that occur after chronic complete AV block seem to facilitate the occurrence of both EADs and interventricular $\triangle A P D$ (chapter 7).

That both parameters in combination are necessary for TdP induction can be derived from observations like: $\mathrm{Al}$ ) the significant difference in incidence/magnitude of EADs and interventricular $\triangle A P D$ between inducible and non inducible dogs. There existed however a significant difference in CL between the two groups (chapter 3); A2) When corrected for this parameter (similar CL), it was noticed that almokalant is associated wech mor EADs and a larger inervenericular $A A D D$ and a highes incidence of (spontancous) TdP compared to $d$-sotalol (chapter 4); A3) the significant difference in interventricular $\triangle A P D$ between acute and chronic AV block experiments with $d$-sotalol and their relevance to the induction of $\mathrm{TdP}$ (chapter 7). BI) Independent of the effect on the CL-IVR, suppression/prevention of TdP by magnesium (chapter 3), flunarizine, ryanodine (chapter 6), levcromakalim (13), isoprenaline or ventricular pacing, diminishes both the EADs and interventricular $\triangle A P D$, at the last beat of the TdP' no EADs are present and interventricular $\triangle A P D$ is small and $C$ ) Reinduction of TdP is only possible when EADs and interventricular $\triangle A P D$ have returned to their original prepacing values, which changed directly after termination of TdP (chapter 5).

In figure 4, we have hypothesized how EADs occurring in both ventricles can lead to a (remporarily present) arrhythmogenic window. Either the EADs occur at different, time points in the fwo ventricles or they have different contribution to the APD or both. When the $L V$ is considered the most sensitive for the development of EADs, both possibilities will lead to a maximum interventricular dispersion. Over time this dispersion will be maintained or reduced, as the RV APD increases.

A limitation of our data is that all measurements concerning interventricular $\triangle A P D$ where performed during a relative steady state (CL-IVR or paced rhythm) without dynamic changes in CL. However, the alterations during. PES in EADs and interventricular $\triangle A P D$ suggest that a non homogeneous response of the ventricles to an acceleration, may be very important in the continuation of the $\operatorname{TdP}(37,38)$. 


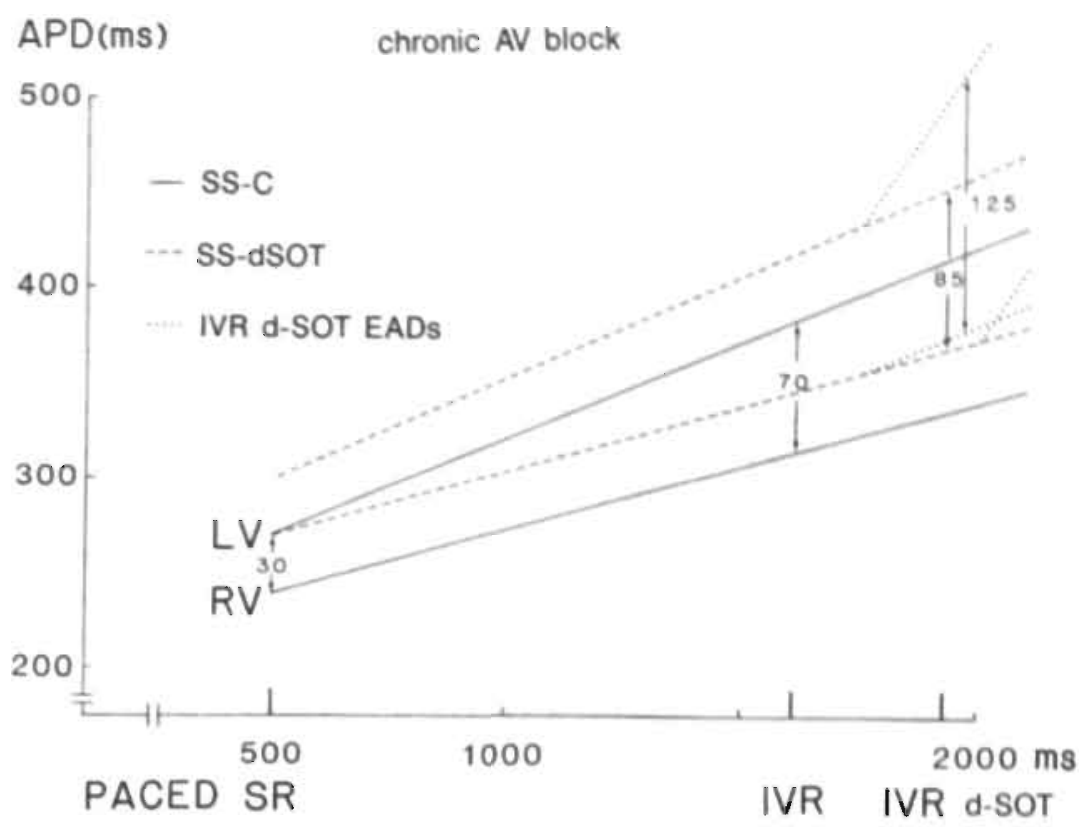

Figure 4. The relevance of the cycle length and presence of EADs to interventricular dispersion (AAPD) affer d-sotalol

Graph illustrating the possible way in which administration of $d$-sotalol leads to a larger interventricular $\triangle A P D$. The solid lines indicate the frequency behavior of the APD and interventricular $\triangle A P D$ during baseline at paced frequencies. Interventricular $\triangle A P D$ is bradycardia dependent: from $30 \mathrm{~ms}$ at $500 \mathrm{~ms}$ (comparable with SR) to $70 \mathrm{~ms}$ at idioventricular rhythm (IVR). Administration of $d$-sotalol (interrupted line) prolongs APD homogeneously. Therefore there is no increase in interventricular $\triangle A P D$. The second effect of $d$-sotalol, namely the lengthening of the cycle length of the idioventricular rhythm (IVR-CL d-sot) does lead to an increased interventricular $\triangle A P D$. Finally, administration of $d$-sotalol may lead to EADs. This may further contribute to interventricular $\triangle A P D$. As shown by the dotted line [) the increase in the RV APD lags behind the LV APD due to a slower development of the EAD and/or 2) the RV EADs develop later in time. Both changes will increase the interventricular $\triangle \mathrm{APD}$, to arrhythmogenic levels:

In table 1, the individual role of interventricular $\triangle A P D, E B$ and EADs in the genesis of TdP is summarized as evidenced from the results obrained in our animal model. Without EADs and interventricular $\triangle \mathrm{APD}$ (baseline or after preventive measures) no TdP can be generated, not even by PES. This suggests that the presence of (rriggered) EADs is no guarantee for $T d P$. PES in the setting of a sufficienr interventricular $\triangle A P D$ may start TdP because PES may mimic and reinforce the occurrence of EADs. Only the combination of EADs, EBs and interventricular $\triangle A P D$ lead to the spontaneous occurrence of TdP. The occurrence of each of these parameters is favored by bradycardia, administration class III agents and chronic complete AV block (biventricular hypertrophy). 
Table 1. Factors related to induction of Torsade de pointes arrhythmias (TdP)

\begin{tabular}{llllll}
\hline EADs & EBs & $\triangle \mathrm{APD}$ & $\Rightarrow$ & spont TdP & PES TdP \\
\hline- & - & - & $\Rightarrow$ & - & - \\
+ & - & - & $\Rightarrow$ & - & - \\
+ & + & - & $\Rightarrow$ & - & - \\
- & - & + & $\Rightarrow$ & - & + \\
+ & - & + & $\Rightarrow$ & - & + \\
+ & + & + & $\Rightarrow$ & + & + \\
\hline
\end{tabular}

Abbreviations: EADs: early afterdepolarizations, EBs: Ectopic beats, $\triangle \mathrm{APD}$ : interventricular dispersion; spont TdP: spontaneous TdP, PES TdP: programmed electrical stimulation induced TdP, +: presence of the parameter, - : absence of the parameter.

\section{Consequences of EADs and interventricular $\triangle A P D$ for the continuation of acquired TdP}

It has been suggested that the electrophysiologic mechanism responsible for the initiating beat is triggered activity due to EADs (possibly arising from Purkinje fibers or M cells): In addition the data in this thesis support the hypothesis that a sufficiently long interventricular $\triangle A P D$ should be present for the initiation of TdP. The electrophysiologic mechanism of the subsequent beats leading to the actual polymorphic oscillatory pattern of TdP is less certain. Preliminary results show that continuation could be due to triggered activity arising from several endocardial sites (39-41), or local reentry $(41,42)$. A reentrant tachycardia requires adjacent zones in which large differences in APD exist. The large difference in APD seems to be the case in our dogs. However, the distance between the left and right ventricle could cause some problems to picture a reentrant circuit between these two ventricles. On the other hand, a possible transmural difference could form the base of the reentrant tachycardia. Another argument against a reentrant circuit is the finding that the first beat of subsequent spontaneous $T d P$ episodes often arises from different places, suggesting different sites of occurrence in the maintenance of TdP.

So far, the mechanism of TdP continuation, being triggered activity, reentrant tachycardia and/or a combination has not been unraveled and will need further study.

\section{REFERENCES}

1. CAST investigators, Mortality and morbidity in patients receiving encainide, flecainide and placebo. The Cardiac Arrhythmia Suppression Trial. New Engl J Med 1991; 324: 781-788.

2. CAST investigators. Effect of the antiarthythmic agent morizine on survivals after myocardial infarction. The Cardiac arrhythmia Suppression trial II Investigators. New Engl J Med 1992; 327: 227-233. 
3. ESVEM investigators. The ESVEM trial: electrophysiological sudy versus electrocardiographei monitoring for slection of antiarrhythmic therapy of ventricular tachyarrhythmias. Cimwlarion 1989; 79: $1354-1360$.

4. Cascade investigators. Randomized antiarrhythmic drug therapy in survivors of cardiac arrest (the CASCADE study) Am / Candiol 1993; 72: 280-287.

5. Hondeghem LM, Snyders DJ. Class III antiarthythmic agents have a lot of potential but a long way to go. Reduced effectiveness and dangers of reverse use dependence. Circulation 1990; 81: 687-690.

6. Colatsky TJ, Follmer CH, Starmer CF. Channel specificity in antiarthythmic drug action. Mechanism of potassium channel block and its role in suppressing and aggravating cardiac arrhythmias. Circularion 1990; 82: 2235-2242.

7. Hohnloser SH, Singh BN. Proarrhythmia with class III antiarrhythmic drugs: definition, electrophysiologic mechanisms, incidence, predisposing factors, and clinical implications. / Cardionese Electrophysiol 1995: 6: 920-936.

8. Waldo AL, Camm AJ, de Ruyter de H. Friedman DJ. MacNeill BP, Pratt CM. Schwartz PJ, Veleri EP. SWORD investigators. Preliminary mortality results from the survival with oral $d$-sotalol (SWORD) trial. J Am Coll Cardiol 1995; 15A.

9. Wiesfeld ACP, Crijns HJGM. Tobe TJM, Almgren O, Bergstrand RH, Aberg J, Haaksma J, Lie KI. Electropharmocologic effects and pharmokinetics of almokalant, a new dass III antiarrhythmic, in patients with healed or healing myocardial infarcts and complex ventricular arrhythmias. Am / Cardiol 1992; 70: 990-996.

10. Jackman WM, Friday KJ. Anderson JL. Aliot EM, Clark M, Lazzara R. The Long QT syndromes: a critical review, new clinical observations and a unifying hypothesis. Prog Candiovasc Dis 1988; 31: $115-172$.

11. Keren A, Tzivoni D, Gavish D, Levi J, Gottlieb S, Benhrin J. Stern S. Etiology, warning signs and therapy of corsade de Pointes. A study of 10 patients. Circulation 1981; 64: 1167-1174.

12. Bauman JL, Bauernfeind RA, Hoff JV, Strasberg B, Swiryn S, Rosen KM. Torsade de Pointes due to quinidine: Observations in 31 parients. Am Heart / 1984; 107: 425-430.

13. Vos MA, Gorgels APM, Lipseci GC, de Groot SHM, Leunissen JDM, Wellens HJJ. Mechanism specific anti-arrhythmic effects of the potassium channel activaror levcromakalim against repolarizarion dependent achycardias. / Cardiovasc Electrophysiol 1994; 5: 731-742.

14. Nguyen TP. Scheinman. MM Seger J. Polymorphous ventricular tachycardia: clinical characterization, therapy and QT interval. Circulation 1986; 74:340-349.

15. Matrioni TA, Zherrin TA, Sermiento J], Sermiento J], Parker M. Lesch M, Kehou RF. Amiodarone in patients with previous drug mediated torsade de pointes. Long tem efficacy. Ann Inimal Med 1989; 111: 574-580.

16. Hii JTY, Wyse DG, Gillis AM, Duff HJ, Solylo MA, Mitchell LB. Precordial QT time interval dispersion as a marker of torsade de pointes: disparate effects of class $1 \mathrm{~A}$ anriarrhychmic drugs and amiodarone. Circulation 1992; 86; 1376-1382.

17. Hohnloser SH, Loo van de A, Kalusche D. Arendis W, Quart B. Does Sotalol induced alterarion of QT dispersion predicr drug effectiveness or proarrhythmic hazard. Circulation 1993; 88: 1-2130 (absract).

18. Carlsson L, Abrahamsson C. Andersson B, Düker G, Schiller-Linhardt G. Pioarrhythmic effects of the class III agent almokalant: importance of infusion rate, QT dispersion, and early afterdepolarizations. Cardiovase Res 1993; 27: 2186-2193.

19. Priori SG, Napolitano C. Diehl L, Schwartz P. Dispersion of QT interval. A marker of therapeutic efficacy in the idiopathic long QT syndrome. Circulation 1994; 89: 1681-1689.

20. Statters DJ, Malik M, Ward DE, Camm A]. QT dispersion: problems of methodology and clinical significance. / Cardiovasc Electrophysiol 1994; 5: 672-685. 
21. Olsson SB. Right ventricular monophasic action potentials during regular rhythm. A heart catheterization study in man. Acta Med Scand 1972; 191: 145-157.

22. Bonatti V. Rolli A, Botri G. Monophasic action potential studies in human subjects with prolonged ventricular repolarization and long QT syndromes. Eur Heart / 1985; 6: 131-143 (suppl).

23. Shimizu W, Ohe T, Kurita T, Takaki H, Aihara N, Kmakurka S, Marsuhisa M. Shimomura K. Early afterdepolarizations induced by isoproterenol in patients with congenital long QT syndrome. Circulation 1991; 84: 1915-1923.

24. Habbab MA, El-Sherif N. Drug induced Torsade de pointes: Role of early afterdepolarizations and dispersion of repolarization. Am / Medicine 1990; 89: 241-246.

25. Sicouri S. Antzelevitch C. A subpopulation of cells with unique electrophysiological properties in the deep subepicardium of the canine ventricle. The M cell. Circ Res 1991: 68: 1729-1741.

26. Franz MR. Bargheer K, Rafflenbeul W. Haverich A. Lichtlen PR. Monophasic action potential mapping in human subjects with normal electrocardiograms: direct evidence for the genesis of the T wave. Circulation 1987; 75: 379-386.

27. Cranefield PF, Aronson RS, Cardiac arrhythmias: the role of triggered activity. Futura, Mnt Kisco, NY 1988.

28. Sicouri S, Antzelevitch C. Drug induced afterdepolarizations and triggered activity occur in a discrete subpopulation of ventricular muscle cells ( $\mathrm{M}$ cells) in canine the canine heart: Quinidine and digitalis. / Cardiovase Electrophysiol 1993: 4: 48-58.

29. El-Sherif N, Zeiler RH, Craclius W, Gough WB. Henkin R. QTU prolongarion and polymorphic ventricular tachyarrhythmias due to bradycardia dependent afterdepolarizations. Afterdepolarizations and ventricular arrhythmias. Cire Res 1988: 63: 286-305.

30. Ben-David J. Zipes DP. Differential response to right and left ansae subclavia stimulation of early afterdepolarizations and ventricular tachycardia induced by cesium in dogs. Circulation 1988: 78: 1241.1250

31. Patterson E, Szabo B. Scherlag BJ. Lazzara R. Early and delayed afterdepolarizations associated with cesium chloride-induced arrhythmias in the dog. Cardsovass Res 1990; 15; 323-331.

32. Roden DM. Thompson. KA. Hoffman BF, Woosley RL. Clinical features and basic mechanisms of quinidine induced arrhythmias. J Am Coll Cardiol 1986: 8: 73A-78 A.

33. Kay GN, Plumb VJ. Arciniegas JG. Henthorn RW. Waldo AL. Torsade de Pointes: the long short initiating sequence and other clinical features: observations in 32 patients. / Am Coll Cardiol 1983; 2 . 806.817.

34. Locati EH. Maison-Blanche P, Dejode P. Cauchemez B, Coumel P. Spontaneous sequences of onser of Torsade de Pointes in patients with acquired prolonged repolarization: quantitative analysis of holter recordings. / Am Coll Card 1995: 25: 1564-1575.

35. Verduyn SC, Vos MA, van der Zande J. Wellens HJJ. Occurrence of early afterdepolarizations induced triggered beats does not quarantec initiation of spontaneous Torsade de Pointes. PACE 1995; 18: 1095 (Part II, abstract).

36. Burashinikov A. Antzelevitch C. Acceleration induced early after depolarization and triggered activity. Circulation 1995: 92: 1-434.

37. Linker NJ. Camm AJ. Ward DE. Dynamics of ventricular repolarisation in the congenital long QT. syndromes. Br Heart / 1991: 66:230-237.

38. Krikler DM, Curry PVL. Torsade de Pointes, an atypical ventricular tachycardia. Br Heart/1976: 38: $117 \cdot 120$.

39. Sterns L.D. Schoels W. Senges JC. Freigang KD. Bauer A, Kuebler W, Brachmann J. Activation patterns of canine cesium chloride induced ventricular arrhythmias determined by three dimensional mapping. PACE 1994: 17: 762 (abstract).

40. Katsuki T. Usuda K. Sagakami S. Nakamura Y. Takata S, Kobayashi K. Mechanisms of initiation and maintenance of Torsades de Pointes. PACE 1994: 17: 763 (abstract). 
41. El-Sherif N, Restivo M, Caref EB, Piracha M. Electrophysiologic mechanism(s) of Torsade de Pointes ventricular tachyrrhythmias (TdP). Tridimensional mapping of ventricular activation. Circulation 1995: 92: 1-641 (abstract).

42. Derackchan K. Klug D. Bouchard C. Helie F. Pharand C. Sasyniuk B. Kus T. Cardinal R. Torsade de Pointes induced by $d$-sotalol in canine atrioventricular block: initiation in the conduction system followed by spatially unstable reentry. Circulation 1995; 92: 1-640 (abstract). 



\section{Summary}

Disturbances in cardiac rhythm are a common phenomena in humans. These may vary from a single innocent ectopic beat to life threatening arrhythmias. Medical treatment of these arrhythmias is sometimes associated with a worsening of the exisiting arrhythmia and/or development of a new arrhythmia (proarrhythmic event). In this thesis the mechanism and possible treatments of one of these proarrhythmic events, Torsade de Pointes (TdP) arrhythmias, is studied. TdP is a polymorphic tachycardia, occurring in the setting of an (abnormally) prolonged repolarization in which the QRS complexes twist around the isoelectric axis. TdP can be caused by several antiarrhythmic drugs, but also by other medicamention which prolong the repolarization.

Chapter 1 is a literature review of the different causes of TdP, with a central role for acquired TdP by antiarrhythmic drugs. Examples are the class la drugs: quinidine, procainamide and drugs with a class III effect like $(d)$-sotalol, amiodarone and almokalant. In addition the different experimental models dealing with TdP that were published before 1992 are reviewed. The majority of these models used substances that (in the used dose) are not (or cannot be) used in patients.

In dogs with chronic complete atrioventricular (AV) block, TdP' can be reproducibly induced by administration of antiarrhythmic drugs in a clinical relevant dose (chapter 2). In this model the conduction becween atria and ventricles is interrupted permanently. This offers the possibility to study ventricular arrhythmias, without interference by normal activation and impulse formation of the atria through the AV node. In addition there is a slow heart rate (a substantial part of acquired TdP).

During the AV block operation an electrode is placed on the heart. Combined with a pacemaker this electrode can be used to change (accelerate) the heart rare. After at least two weeks of AV block, dogs are anestherized again and monophasic acrion porential (MAP) carheters are advanced in both heart chambers. The MAP can decermine regionally the action potential duration and morphology. The action potential exists of an activation (depolarization) and a deactivation (repolarization) phase.

After this, the TdP induction prococol is performed: a specific pacing protocol after administration of $2 \mathrm{mg} / \mathrm{kg} d$-sotalol. With this treatment $T d P$ develops reproducibly in half of the dogs. Acceleration of the basal rhythm with continuous pacing or with isoprenaline prevents $\mathrm{Td} P$, alike the patient situation.

Chapter 3 describes a group comparison in arimals with and without TdP. TdP depends on 1) a prolonged repolarization (QT rime, APD), 2) presence of early afterdepolarizations (EADs) and 3) a sufficient difference between the APD of the left and right ventricle; the so called interventricular dispersion ( $\triangle A P D)$. EADs are depolarizing 
currents that occur before the repolarization is finished. EADs may result in triggered ectopic beats. Both EADs and interventricular $\triangle A P D$ are increased at a slow heart rate. Magnesium prevents and suppresses TdP, because both the EADs and the $\triangle A P D$ are diminished.

The response to $d$-sotalol remains similar in the same animal at different experiments. Therefore a comparison can be made to the effect of several interventions, with the animal as its own control like described in chapter 4 . In 14 animals $d$-sotalol and almokalant $(0.12 \mathrm{mg} / \mathrm{kg})$ were given in consecutive experiments. A higher incidence in the same animal of EADs and $\triangle A P D$ after almokalant resulted in a higher incidence of (spontaneous) TdP (5/14 vs 12/14). Which confirmed the importance of EADs and $\triangle \mathrm{APD}$ in the initiation of TdP.

Most episodes of TdP end spontaneously. This fact combined with possibility of reproducible induction of the TdP, allowed study of the behavior of the EADs and interventricular $\triangle \mathrm{APD}$. This provides insight in the mechanism of termination and so by thus in the mechanisms of continuation (chapter 5). In the last beat of the TdP, EADs are absent and the difference in APD between the ventricles is minimal. Reoccurrence of EADs coincided with an increase in interventricular $\triangle A P D$. Reinduction of $\mathrm{TdP}$ is only possible when both the EADs and the interventricular $\triangle \mathrm{APD}$ are back to their previous level.

Alshough interventricular $\triangle A P D$ is an independent parameter, showing a clear frequency dependence, EADs contribute to the interventricular $\triangle A P D$. This is supported by the fact that EADs and interventricular $\triangle A P D$ simultaneously disappear and reappear after spontaneous termination of TdP episodes, and appearance of EADs at a constantly paced CL. after sotalol increases the $\triangle \mathrm{APD}$ (chapter 5).

$d$-Sotalol and almokalant prolong the APD, induce EADs and lead to TdP. This is prevented by administration of flunarizine and ryanodine (chapter 6). These two drugs affect the $[\mathrm{Ca}]_{i}$. A shortening of the repolarization and a suppression of the EADs. Their prevention points to a disturbed intracellular $\mathrm{Ca}^{2+}$ in the genesis of EADs and thereby TdP.

The role of AV block for the TdP model is studied in chapter 7. Dogs $(n=9)$ were studied at the moment of the creation of AV block and 4 to 6 weeks after AV block $(n=10)$ had. evolved. In five of these dogs both time points could be studied. The APD of both ventricles was significantly longer when measured at chronic AV block. In addition the dogs with chronic AV block showed a more pronounced response to $d$-sotalol, this was especially the case for the left ventricle resulting in a significantly larger $\triangle A P D$. TdP could never be induced direcrly after creation of AV block whereas at chronic AV block. $6 / 10$ dogs showed reproducible induction of TdP after $d$-sotalol and PES. This was not only the case for the group comparison but also when individual animals were compared. The thesis is concluded by a general discussion which summarizes the results obtained in this model and points to their consequences for the mechanism of TdP. 
In short, this animal model of acquired TdP allows 1) reproducible induction of TdP (spontaneous and PES induced), 2) investigation into preventive and suppressive interventions and 3) comparisons between the proarrhythmic effect of different medicaments. The initiating mechanisms of TdP in this animal model depend on the presence of EADs in combination with interventricular $\triangle A P D$. Both parameters are bradycardia dependent. Furthermore, EADs contribute to interventricular. $\triangle A P D$. The mechanism responsible for the continuation of $\mathrm{TdP}$ is not completely clear. Further investigation should be performed to clarify this continuation. 



\section{Samenvatting}

Verstoringen van het hartritme zijn een normaal verschijnsel in elk mensenleven. Deze kunnen variëren van een onschuldige extra slag tot levensbedreigende ritmestoornissen. Behandeling van deze aritmieën met medicijnen gaat soms (3-5\%) gepaard met een verslechtering van een bestaande en/of het ontstaan van een nieuwe ritmestoornis (een proaritmogene reactie). In dit proefschrift wordt het mechanisme en de mogelijke behandeling van een van de proaritmogene responsen de zogenaamde Torsade de Pointes ritmestoornissen (TdP) bestudeerd. TdP is gedefinieerd als een polymorfe kamerritmestoornis waarbij de QRS complexen een rotatie om de iso-elektrische as vertonen op het ECG (vandaar de franse naam Torsade de Pointes). TdP komt voor bij een (abnormaal) verlengde repolarisatie dat onder meer het gevolg kan zijn van het gebruik van bepaalde anti-aritmica, maar ook kan worden veroorzaakt door andere medicamenten die in de geneeskunde worden toegepast.

In hoofdstuk 1 is een overzicht gegeven van de literatuur met betrekking tot de verschillende oorzaken van TdP, waarbij de door anti-aritmica veroorzaakte TdP (“acquired" TdP) centraal staat. Voorbeelden van deze medicijnen zijn klasse I anti-aritmica als: quinidine, procainamide en disopyramide en stoffen met klasse III effecten als $d$-sotalol, amiodarone, en almokalant. Tevens zijn de verschillende (dier)experimentele modellen besproken die zijn gepubliceerd voor 1992. Her merendeel van deze modellen werkte met stoffen die (in die dosering) nier bij patiënten gebruikt (kunnen) worden. In honden mer een chronisch compleet atrioventriculair (AV) blok kan TdP op cen reproduceerbare wijze worden geïnduceerd door toediening van anti-aritmica in klinisch relevante doseringen (hoofdstuk 2). Bij dit AV blok model, waarbij een onderbreking in de geleiding tussen de boezem en de kamer wordt geïnduceerd, is her mogelijk kamerritmestoornissen te bestuderen zonder de invloed van de normale kameractivatie door impuls geleiding van de boezem over de AV knoop. Tevens onistaar er een traag kamerritme (een essentieel onderdeel van "acquired" TdP). Tijdens de AV biok operatic wordt er een elektrode op het hart aangebracht. Die in samenspraak met cen pacemaker kan worden gebruikt om her harr een andere (snellere) frequentie op te leggen. Nadat dit complete AV blok minstens 2 weken heeft bestaan worden de honden opnieuw onder narcose gebracht en worden er tijdelijk monofasische actiepotentiaal carherers (MAP's) ingebrache in beide hartkamers. Met deze MAPs kan lokaal de vorm en de duur van de actiepotentiaal van het hart worden bepaald. Deze actiepotentiaal is opgebouwd uit een activatie- (depolarisatie) en een herstel fase (repolarisatie).

Het TdP inductie protocol dat hierna wordt uitgevoerd bestaat uit een specifiek paceprotocol na toediening van $2 \mathrm{mg} / \mathrm{kg} d$-sotalol. In de helft van de honden $\mathrm{kan}$ op deze manier reproduceerbaar $T d P$ worden geinduceerd. De TdP episoden zijn net als 
bij de humane patiënt te voorkomen door een versnelling van het basale hartritme, met behulp van isoprenaline ( $\beta$ i agonist) of elektrisch pacen.

Een groepsvergelijking tussen dieren met en zonder TdP laat zien dat TdP initiatie afhankelijk is van I) een verlengde repolarisatie (QT tijd en/of actie potentiaal duur (APD) 2) vroege nadepolarisaties (EADs) en 3) een voldoende groot verschil in actiepotentiaal duur tussen de linker en de rechterkamer: de zogenaamde interventriculaire dispersie ( $\triangle A P D$, hoofdstuk 3). EADs zijn elektrische ontladingen die optreden voordat de repolarisatie fase beëindigd is. EADs kunnen resulteren in het optreden van extra slagen. Zowel het optreden van EADs als interventriculaire $\triangle A P D$ wordt versterkt door een trager hartritme. Magnesium voorkomt TdP, doordat het zowel de vroege nadepolarisaties onderdrukt als de interventriculaire $\triangle A P D$ vermindert.

De reactic op $d$-sotalol (dat wil zeggen het wel of niet optreden van TdP) is reproduceerbaar bij hetzelfde dier tijdens verschillende experimenten. Daarom kunnen vergelijkingen gemaakt worden naar het effect van verschillende interventies met het dier als zijn eigen controle zoals beschreven in hoofdstuk 4 . In totaal 14 honden kregen zowel $d$-sotalol als almokalant. Almokalant geeft meer EADs en een groter verschil in repolarisatie duur tussen de linker en rechter kamer dan $d$-sotalol. Dit gaat gepaard met een significante toename in incidentie van (spontane) TdP. Dit bevestigt de noodzaak van EADs en interventriculaire dispersie voor het initiëren van TdP.

Omdat $\mathrm{TdP}$ in de meeste gevallen spontaan eindigt en reproduceerbaar is op te wekken, kan het gedrag van de actiepoientiaal duur en de EADs na afloop van een TdP worden bestudeerd. Dit is gebruikt om meer inzicht kunnen krijgen in de terminatie en dus de mechanismen verantwoordelijk voor de continuatie van de aritmie (hoofdstuk 5). De laatste slag van de TdP heeft geen EADs en het verschil in APD van de linker en. rechterkamer is miniem. Her opnieuw optreden van de EAD na afloop van de TdP' ging samen met een toename van de interventriculaire dispersie. Het opnieuw induceren van TdP is alleen mogelijk als zowel de EAD als de interventriculaire $\triangle A P D$ weer terug zijn op hun oude niveau. Interventriculaire dispersie is een zelfstandig fenomeen dat onafhankelijk van de aanwezigheid van de EADs roeneeme bij een afname van de hart frequentic. De ontwikkeling van EADs na $d$-sotalol bij een gepacede gelijkblijvende. hartfrequentie leidẽ ook tố een toename vañ de interventriculaire $\triangle A P D$. Dit betekent dat de EAD een wezenlijke bijdrage levert aan de interventriculaire dispersie.

Verlenging van de APD door $d$-sotalol en almokalant leidt tot EADs en TdP. Dit kan voorkomen worden door toedienen van ryanodine en flunarizine. Deze twee stoffen. beïnvloeden de calcium huishouding in de cel. Flunarizine corrigeert ook repolarisatie stoornissen aanwezig in controle omstandigheden. De preventie van TdP door deze twee stoffen duidt op een belangrijke rol van (intracellulair) calcium in het ontstaan van de ritmestoornis (hoofdstuk 6).

Her chronische complete AV blok vertraagt de kamerfrequentie, waardoor er een volume overbelasting optreedt (hoofdstuk 7). Het hart moet een zelfde hoeveelheid bloed in minder slagen uitpompen. Het hart past zich hieraan aan met een toename van de 
spiermassa in beide kamers (biventriculaire hypertrofie). Gecorrigeerd naar het lichaamsgewicht van de hond neemt de rechterkamer meer toe (toename 80\%) dan de linkerkamer (toename 40\%). Honden met een chronisch compleet AV blok hebben dus niet alleen bradycardie maar ook biventriculaire hypertrofie. De electrofysiologische gevolgen van chronisch compleet AV blok is bestudeerd in 15 honden. Daartoe werden op twee tijdstippen metingen verricht: 1) direct na en 2) 4-6 weken na het maken van AV blok. $\mathrm{Na}$ 4-6 weken AV blok is de kamerrepolarisatieduur verlengd en ook het interventriculaire verschil in repolarisatie is toegenomen ten opzichte van metingen direct na het maken van AV blok. Bovendien is bij een zelfde hartfrequentic het effect van $d$-sotalol op de repolarisatieduur en dispersie veel meer uitgesproken. Er ontstaan dan ook meer vroege nadepolarisaties en een grotere interventriculaire $\triangle A P D$. In dieren met een chronisch AV blok was TdP aanwezig in $60 \%$ van de dieren na $2 \mathrm{mg} / \mathrm{kg} d$-sotalol terwijl na acuut AV blok in geen enkel dier TdP kon worden opgewekt met deze dosering $d$-sotalol. Dit maakt duidelijk dat de aanpassingen als gevolg van het chronische compleet AV blok het ontstaan van TdP ritmestoornissen na $d$-sotalol vergemakkelijken of de omstandigheden tijdens acuut AV blok TdP voorkomen.

Samenvattend kan worden gesteld dat in dit diermodel van "acquired" TdP het mogelijk is om 1) reproduceerbaar TdP op te wekken (spontaan en PES-induced), 2) diverse preventieve en suppressieve interventies te onderzoeken en 3) vergelijkingen te maken tussen het proaritmogene effect van verschillende medicamenten. Het initiërend mechanisme van TdP in dit diermodel is afhankelijk van de aanwezigheid van EADs in combinatie met een voldoende grote interventriculaire $\triangle \mathrm{APD}$. Beide factoren nemen toe mer een vertraging van her hart ritme. Los daarvan dragen de EADs bij aan de interventriculaire $\triangle A P D$. Het mechanisme dat verantwoordelijk is voor continuatic van de $\mathrm{TdP}$ is nog niet geheel duidelijk. Verder onderzoek zal dit moeten aantonen. 



\section{Nawoord}

Het "onderzoeksvirus", met als primaire uiting promotic onderzock, was de afgelopen jaren een zeer besmettelijk fenomeen. terug te vinden in groot deel van mijn studievrienden. Hoewel het "onderzoeksvirus" bij mijzelf gelukkig nog lang niet is genezen, wordt met dit promotieboekje toch een periode afgesloten. Aan het einde van dit proefschrift is dan de gelegenheid om iedereen te bedanken voor zijn of haar bijdragen.

Prof dr. Hein Wellens, wil ik bedanken voor het kritisch doornemen van de manuscripten. Het aandragen van klinische relevante voorbeelden was en is een extra inspiratic bij her doen van onderzoek.

Dr. Marc Vos, beste Marc, zonder jou ideeën, geen onderzoek naar Torsade de Pointes ritmestoornissen (TdP). Je altijd aanwezige enthousiasme voor onderzoek en dagelijkse begeleiding werken aanstekelijk. Zonder jou steun in "deadline" momenten, had de realisatie van dit boekje veel langer in beslag genomen, bedankt. Ik hoop ook de komende tijd nog veel van je te leren.

Jet Leunissen en Jolanda van der Zande, zonder jullie hujp zou geen enkel experiment tot een goed einde zijn gebracht. Mede door jullie zorgvuldigheid bij de lay out van ECG plaarjes en grafieken ziet dit proefschrift er zo mooi uit. Jolanda, ik ben blij, dar je ondanks je verhuizing naar Utrechr, mijn paranimf wilt zijn om zo samen het "TdP avontuur" af te sluiten.

Dierexperimenteel onderzoek, kan alleen plaats vinden dankzij de goede verzorging van de honden door de medewerkers van het C.P.V. met name Ton van de Boogaard, Huuh Simons, Frans Slangen, bedankt. Voor de uitvoering en verwerking van experimenten wordt veel apparatuur gebruikt, goed onderhoud door de instrumentele dienst is hierbij essentieel. Het telefoonnummer van Leon Dohmen ken ik inmiddels uit mijn hoofd, bedankt voor al je hulp bij het "redden" van mijn data.

Cardiologie zelf is een prima afdeling om kennis te maken met een zeer uitgebreide selectie Limburgse vlaaien, die bijna continu aanwezig zijn, behalve het suikergehalte wordt zo ook op een leuke manier de kennis met de rest van de vakgroep op peil gebracht. De directe collega's van een experimentele cardiologie: Marieke de Groot, Henny Leerssen, Paul Volders, Attila Kulscár, Erik van der Veen en Jo Habets. Marieke, Henny, Paul en Arrilla wil ik ook bedanken voor de vele discussies over onderzoek, het meedenken over protocollen, correcties etcetera die behalve het werk sterk veraan- 
genamen ook verantwoordelijk zijn voor het ontstaan van nieuwe ideeën en experimenten.

Jurren van Opstal vanaf 1994 ben je bijna continu bezig geweest met het helpen analyseren van Torsade de Pointes, bedankt. Tijdens moeizame schrijfuren werd ik opgefleurd door de mensen van kantoortuin 3: Jacqueline, Lidwien, Willie, bedankt voor de vele kopjes thee.

De leden van de beoordelingscommissie: Prof dr. M.A. Allessie (voorzitter), Dr H.J.G.M. Crijns, Prof dr R.S. Reneman, Prof dr J.F.M. Smits wil ik bedanken voor de beoordeling van dit proefschrift. I also like to thank Dr C. Antzelevitch for his willingness to be a member of the review committee, and to be present at my defense.

Writing in english, also a word of thanks to the foreign guests who were involved in this project, Katja and Dr. Tamas Fazekas. Tamas, you make analyzing TdP a wonderful imaginary world. Thanks for reviewing the hypertrophy manuscript.

Experimentele cardiologie zit verscholen aan het einde van de gang van fysiologie. Dat veroorzaakt lange loop afstanden, maar ook een aantal "gedag zeggende" Fysiologie collega's op die daardoor de wandeltocht veraangenamen. Naast de OK's ligt een koffickamer, waar als je er niet voor de koffie komt (heren, waar blijft de thee ?) voor een altijd vriendelijk "goedemorgen" terecht kunt, Ruud, Theo, Ferenc en Bas bedankt. En Ferenc, welkom bij Cardiologie en veel succes bij jouw TdP onderzoek.

Ook een woord van dank aan de mensen in de diverse laboratoria voor het lenen van stikstofemmertjes, weegschalen, etcetera, en de goede raad bij het oplossen van medicamenten.

Ilse, bedankt voor het realiseren van het Cardiac Ballet aan de voorkant van dit proefschrift.

Hans en Peter, het is fijn om zulke broers te hebben, die je op vreemde momenten altijd kunt lastig vallen. Hans, ik ben blij dat je mijn paranimf wilt zijn.

Als laatste wil ik mijn ouders bedanken, voor hun altijd openstaan voor dat vreemde universitaire wereldje. 


\section{Publications}

\section{Articles}

Berentsen PBM, Giesen GWJ, Verduyn SC. Manure legislation effects on income and. on N, P and K losses in dairy farming. Livest Prod Sci 1992; 31: 43-56.

Vos MA, Verduyn SC, Gorgels APM, Lipscei GC, Wellens HJJ. Reproducible induction of early afterdepolarizations and Torsade de Pointes arrhythmias by d-sotalol and pacing in the dog with chronic atrioventricular block. Circulation 1995; 91: 864-872.

Verduyn SC, Vos MA, Gorgels APM, van der Zande J, Leunissen JDM, Wellens HJJ. The effect of flunarizine and ryanodine on acquired Torsade de Pointes arrhythmias in the intact canine heart. / Cardiovasc Electrophysiol 1995; 6: 189-200.

Verduyn SC, Vos MA, Zande van der J, Steld van de BJ, Wellens HJJ. Induction of early afterdepolarizations dependent acquired Torsade de Pointes arrhythmias is also related to dispersion of repolarization reversal by magnesium. Accepted for publication in Circulation.

Verduyn SC, Vos MA, Zande van der I, Smeers JLRM, Wellens HJJ. Furrher observations to confirm the importance of dispersion of repolarization and early afrer depolariza-tions in the genesis of acquired Torsade de Pointes arrhythmias.

A comparison between almokalant and $d$-sotalol using the dog as its own control. 1995 Accepted for publication in I Cardiol Am Coll.

\section{Abstracts}

Vos MA, Verduyn SC, Lipscei GE, van der Zande J, Leunissen HDM APM Gorgels. Induction of acquired bradycardia dependent Torsade de Pointes arrhythmias is. prevented by flunarizine a comparison with $\mathrm{MgSO}_{4}$. Circulation 1992; 86: I-560.

Vos MA, Verduyn SC, APM Gorgeis, van der Zande J, Leunissen HDM, Wellens HJJ. Animal model of acquired bradycardia dependent Torsade de Pointes arrhythmias. Neth. I Cardiol. 1992: 5: 300. 
Verduyn SC, Vos MA, Gorgels APM, van der Zande J, Leunissen HDM, Wellens HJJ. Relevance of the number of cycle length changes in pacing induced Torsade de Pointes arrhythmias. Pflizgers Arch 1993; 424: R9.

Vos MA, Gorgels APM, Verduyn SC, Leunissen HDM, van der Zande J, Wellens HJJ. The effect of ryanodine and flunarizine on triggered arrhythmias in the intact canine heart. Cardiovascular Drugs and therapy 1993; 7: 444.

Vos MA, Gorgels APM, Verduyn SC, Leunissen JD, van der Zande J, Wellens HJJ. Ryanodine prevents early afterdepolarizations dependent Torsade de Pointes arrhythmias in the intact heart. J Am Coll Cardiol 1994; 282a.

Verduyn SC, Vos MA, Gorgels APM, Leunissen JDM, van der Zande J, Wellens HJJ QT time: predictor of the occurence of acquired Torsade de Pointes arrhythmias. PACE 1994; 17: 826.

Verduyn SC, Vos MA, Zande van de J, Steld van de BJ, Wellens $\mathrm{H}_{.} \mathrm{MgSO}_{4}$ prevents induction of acquired Torsade de pointes arrhythmias by reducing dispersion and suppression of early afterdepolarizations. Circulation 1994; 90: I-412.

Verduyn SC, Vos MA, Zande vd J, Steld vd BJ, Wellens HJ. Torsade de Pointes arrhythmias: role of dispersion and early after depolarizations. Cardiologie 1994; 1: 438.

Verduyn SC, Vos MA, Zande van der J. Wellens HJJ. A comparison between the proarrhythmic effect of almokalant and $\mathrm{d}$-sotalol in an animal model of Torsade de Pointes arrhythmias. J Am Coll Cardiol 1995: 170A.

Verduyn SC, Vos MA, Zande van der J, van Opstal JM, Wellens HJJ. Torsade de Pointes arrhythmias: study of spontaneous termination reveals causal realation afterdepolarizations and dispersion of repolarization in the mechanims of this arrhythmia. Pflügers Archiv 1995; 430: R176.

Verduyn SC, Vos MA, van Opstal J, van der Zande J, Wellens HJJ. Spontaneous termination of acquired Torsade de Pointes arrhythmias in dogs reveals causal relation between early afterdepolarizations with dispersion of repolarization. PACE 1995: 18:830

Verduyn SC. Vos MA, van der Zande J, Wellens HJJ. Occurrence of early afterdepolarizations induced triggered beats does not quarantee initiation of spontaneous Torsade de Pointes. PACE 1995: 18: 1095 
Vos AM, de Groot SHM, van der Zande J, Verduyn SC, Wellens HJJ. Electrophysiologic changes observed after creation of AV block in the dog. PACE; 1995: 1094

Verduyn SC, Vos MA, J van der Zande, SHMA de Groot. HJJ Wellens, Biventricular hypertrophy increases the arrhythmogenic effects of d-sotalol. FEPS, Pfliegers Anchiv 1995; 430: R163.

Verduyn SC, Vos MA, J van der Zande, SHMA de Groot, MA Allessie, HJJ Wellens. Biventricular Hypertrophy Facilitates Occurrence of Acquired Torsade de Pointes Arrhythmias in Dogs. Circulation 1995; 92: I-504

Verduyn SC, Vos MA, J van der Zande, SHMA de Groot, MA Allessie, HJJ Wellens. Biventricular Hypertrophy induced prolongation Facilitates Acquired Torsade de Pointes Arrhythmias in Dogs. Cardiologie 1995; 2: 444.

\section{Letters to the editor}

Vos MA, Verduyn SC, Wellens HJJ. Circulation 1995; 92; 1666-1667. 



\section{Curriculum Vitae}

Sara Cornelia Verduyn

1967 Geboren op 5 januari te Zevenhuizen

1967-1979 Opgegroeid en basisschool te Oud Verlaat gemeente Zevenhuizen

1979-1985 Ongedeeld VWO aan de chr. s.g Comenius te Capelle aan de IJssel

1985-1991 Studie Zoötechnick, Landbouw Universiteit Wageningen, afstudecrvakken: Fysiologie, Veevoeding en Agrarische Bedrijfseconomie

1991-1992 Onderzoek ruwvoeropname bij melkvee

Medewerker praktijkbedrijf Frankrijk

Practicum assistent Vakgroep Fysiologie Wageningen

1992-1996 A.I.O. vakgroep Cardiologic Rijksuniversiteit Limburg

1996- Postdoc vakgroep Cardiologie Rijksuniversireit Limburg 


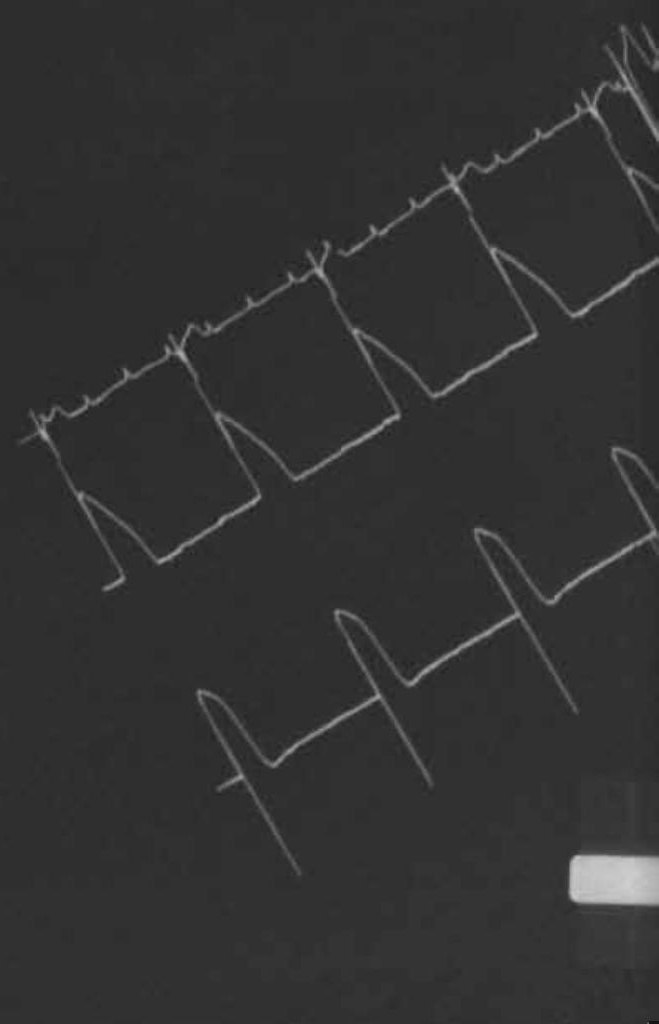

